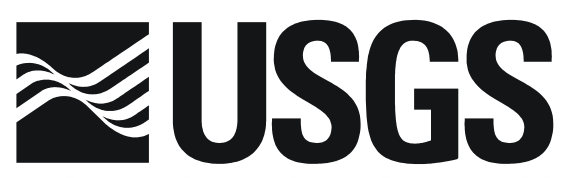

science for a changing world

\title{
Magnetotelluric Data in the Delta River Mining District, near the Tangle Lakes area of south- central Alaska
}

By

Louise Pellerin

Consultanting Geophysicist

Berkeley, California

Jay Sampson

U.S. Geological Survey

Denver, Colorado

This report is preliminary and has not been reviewed for conformity with U. S. Geological Survey editorial standards or with the North American Stratigraphic Code.

Any use of trade, firm, or product names is for descriptive purposes only and does not imply endorsement by the U. S. Government.

Open-File Report 03-238

Online Release

U. S. Department of the Interior

U. S. Geological Survey 


\section{TABLE OF CONTENTS}

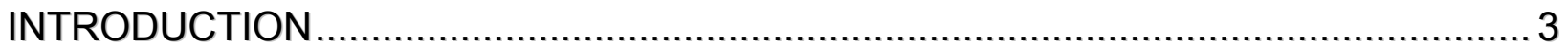

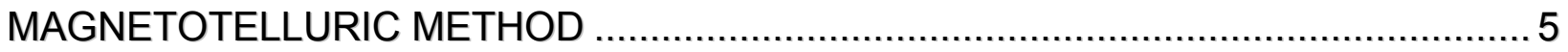

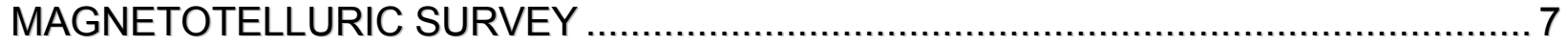

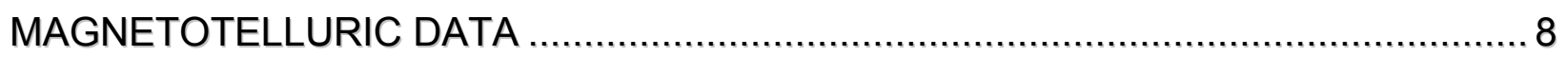

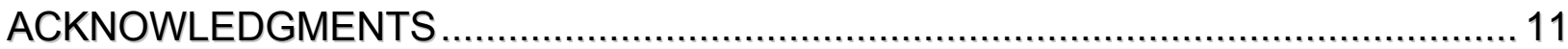

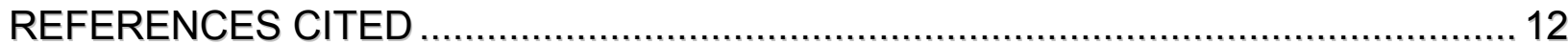

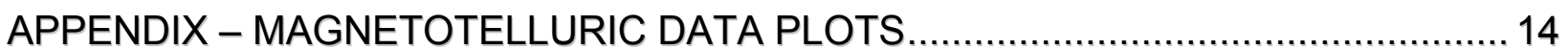

\section{TABLE OF FIGURES}

Figure 1. Index map of MT stations, Tangle Lakes area, south-central Alaska............. 4

\section{TABLE OF TABLES}

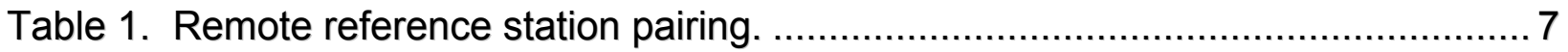

Table 2. Coordinates and elevation of stations along Line M................................... 8

Table 3. Coordinates and elevation of stations along Line G ................................... 8 


\section{INTRODUCTION}

During the summer of 2002, magnetotelluric (MT) data were acquired at seventeen stations in the Bureau of Land Management (BLM) Delta River mining district in south-central Alaska as shown in Figure 1. Eight stations along profile Line M (M0 M7) form a $37 \mathrm{~km}$ northeast trending transect. The nine stations of profile Line $\mathrm{G}$ (G2 G10) form a nearly parallel $37 \mathrm{~km}$ transect offset $18 \mathrm{~km}$ to the west of Line M. The northernmost station of Line $M$ is located in the rugged Delta Mountains east of Rainbow Ridge while the northernmost station of Line $G$ is located just south of the Denali Fault on the west side of Isabela Pass. Both lines are centered along strike of the Amphitheater Mountains with Line M extending south of the Denali Highway.

The MT survey permits interpretation of structures and lithologic packages at depth. Various rock assemblages and structural features are crossed by these transects. MT data obtained in this study in conjunction with magnetic and gravity data were acquired to provide the following information:

1. An estimate of the thickness of the Nikolai basalts in the Amphitheater Syncline.

2. Whether or not the Fish Lake and Tangle ultramafic complexes join at depth or are at different stratigraphic horizons beneath the Amphitheater Mountains Syncline.

3. A determination if there is a deep rooted magmatic feeder or a sequence of sedimentary material beneath the Amphitheater Syncline.

4. The dip and orientation of the Rainy and Broxson Gulch thrust systems.

5. Identification of other structures along the profile.

The purpose of this report is to release the MT sounding data. No interpretation of the data is included. 


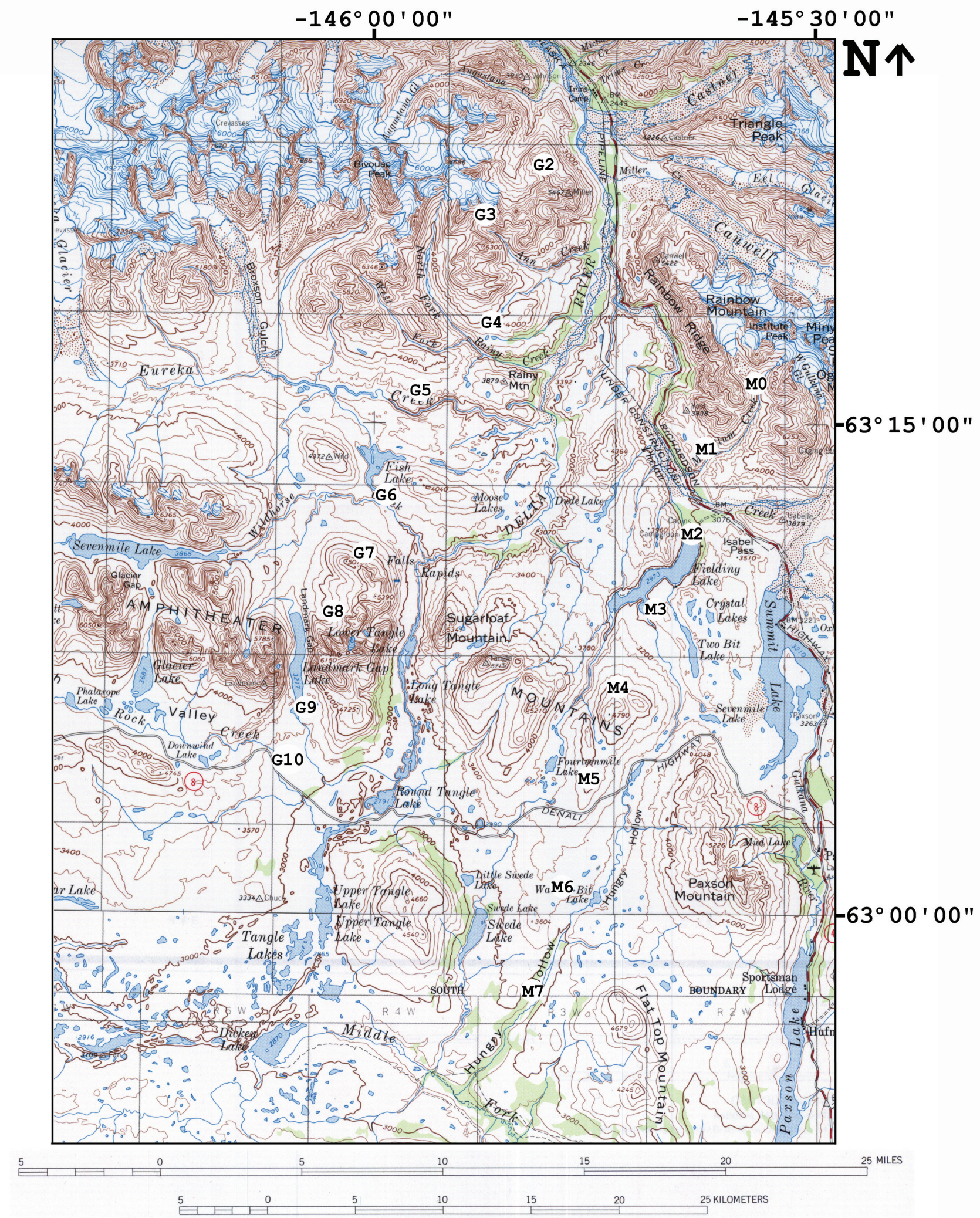

Figure 1. Index map showing the locations of seventeen magnetotelluric (MT) stations acquired during the summer of 2002 in the Tangle Lakes area of southcentral Alaska. Base maps used for this figure are the Mt. Hayes and Gulkana, Alaska 1:250000 U.S. Geological Survey topographic maps. 
MAGNETOTELLURIC METHOD

The magnetotelluric (MT) method is a passive geophysical technique that uses the earth's natural electromagnetic (EM) field as a source to investigate the electrical resistivity structure of the subsurface. The resistivity of geologic units is largely dependent upon their fluid content, porosity, degree of fracturing, temperature, and conductive mineral content (Keller, 1989). Saline fluids within the pore spaces and fracture openings can reduce resistivities in a resistive rock matrix. Resistivity can be lowered by the presence of conductive clay minerals, carbon, and metallic mineralization. Increased temperatures cause higher ionic mobility and mineral activation energy, reducing rock resistivities significantly. Unaltered, unfractured igneous rocks are normally very resistive (typically thousands of ohm-meters (ohm-m)). Fault zones can appear as low resistivity units of less than $100 \mathrm{ohm}-\mathrm{m}$ when they are comprised of rocks fractured enough to have hosted fluid transport and consequent mineralogical alteration (Eberhart-Phillips and others, 1995). Carbonate rocks are moderately to highly resistive with values of hundreds to thousands of ohm-m depending upon their fluid content, porosity, fracturing, and impurities. Marine shales, mudstones, and clay-rich alluvium are normally very conductive - a few ohm-m to tens of ohm-m. Unaltered, metamorphic, non-graphitic rocks are moderately to highly resistive (hundreds to thousands of ohm-m). Tables of electrical resistivity for a variety of rocks, minerals and geological environments may be found in Keller (1987) and Palacky (1987).

The MT method can be used to probe the crust from depths of tens of meters to tens of kilometers (Vozoff, 1991). Natural variations of the Earth's magnetic and electric field are measured and recorded at each MT station. The MT signal in the frequency range of $10,000 \mathrm{~Hz}$ to $1 \mathrm{~Hz}$ is due to worldwide lightning activity while that at $1 \mathrm{~Hz}$ to $0.0001 \mathrm{~Hz}$ are from geomagnetic micro-pulsations. The natural electric and magnetic fields propagate vertically in the earth because the very large resistivity contrast between the air and the earth causes a vertical refraction of both fields transmitted into the earth (Vozoff, 1972).

The natural electric and magnetic fields are recorded in two orthogonal, horizontal directions. If the vertical magnetic field is recorded, a transfer function between the horizontal and vertical components can be constructed, commonly referred 
to as the tipper. The tensor impedance, parameterized as apparent resistivity and phase, are obtained from the time-series signals. Traditionally, signals from a single site are converted to complex cross-spectra using a Fourier-transform technique. A least-squares, cross-spectral analysis (Bendat and Piersol, 1971) then is used to solve for a transfer function (impedance) that relates the observed electric fields to the magnetic fields under the assumption that the Earth consists of a two-input, two-output, linear system with the magnetic fields as input and the electric fields as output.

Remote reference (RR) processing is commonly used now to reduce noise and bias errors, due to instrumental or environmental noise, in the impedance determinations (Gamble and others, 1979a; Clarke and others, 1983). Horizontal magnetic fields are recorded simulateously at a separate, remote site and crosscorrelated with the EM fields at the local site. The RR method is one of the simplest, yet most useful, ways in which simulateous MT measurments from two sites can be used to improve the quality of the local impedance estimates. In many cases, neither the natural signal or the noise source can be adequately modeled as Gaussian, and thus, least-square techniques can fail even with remote referencing. Hence, robust processing techniques in which a weighting term is included in the RR impedance estimator are becoming popular (Egbert and Booker, 1986; Chave and Thompson, 1989).

The apparent resisitivity parameter can be distorted by near-surface resistivity inhomogeneities, called "static shifts", as described by Pellerin and Hohamnn (1990). Data are often corrected with an independent dataset. Approximately $10 \%$ of any given dataset may have significant static shift distortions. A helicopter electromagnetic data set over both profile lines is available through the State of Alaska Geological and Geophysical Surveys

For a two-dimensional (2-D) Earth, the diagonal terms of the impedance tensor are zero. The off-diagonal terms are decoupled into transverse electric (TE) and transverse magnetic (TM) modes. When the geology satisfies the 2-D assumption, the MT data for the TE mode is for the electric field parallel to geologic strike, and the data for the TM mode is for the electric field across strike. Data were processed with a fixed rotation parallel and perpendicular to regional strike, as acquired in the field. The MT method is well suited for studying complicated geological environments because the electric and magnetic relations are sensitive to vertical and horizontal variations in 
resistivity. The method is capable of establishing whether the EM fields are responding to subsurface terranes of effectively 1-, 2-, or 3-dimensions. An introduction to the MT method is given in Telford and others (1991) and a more advanced treatment is contained in Vozoff (1991).

\section{MAGNETOTELLURIC SURVEY}

Seventeen MT soundings were acquired during the summer of 2002 in the BLM Delta River mining district of south-central Alaska, shown in Figure 1. Access to all but two sites required helicopter support. All stations were collected with an EMI MT-24 system (EMI, 1999), a five channel 24-bit system. Horizontal electric fields were measured using lead-lead chloride electrodes in an L-shaped array with dipole lengths of nominally $100 \mathrm{~m}$. The three, orthogonal components of the magnetic field, with horizontals in the same direction as the electric-field array, were measured with permalloy-cored induction coils. Data were acquired in two bands with sampling frequencies of $200 \mathrm{~Hz}$ and $50 \mathrm{~Hz}$. The recording period for the $50 \mathrm{~Hz}$ band was typically one recording period of 12-15 hours. Several recordings of the $200 \mathrm{~Hz}$ band were made for 15-30 minutes. Remote-referencing was used for all stations with the pairing shown in Table 1. Horizontal magnetic field measurements were acquired at the Tangle River Inn (TRI), 21 mile Denali Highway, as the remote for three sites when a full site was not possible.

Remote Reference Station Pairs

\begin{tabular}{|c|c|c|c|c|c|c|c|c|c|}
\hline G2 & G4 & G6 & G7 & G8 & G9 & M0 & M1 & M2 & M4 \\
\hline G3 & G5 & M6 & TRI & TRI & G10 & M3 & TRI & M7 & M5 \\
\hline
\end{tabular}

Table 1. Remote reference station pairing. Horizontal magnetic measurements were made at the Tangle River Inn (TRI) for three sites.

Table 2 and Table 3 show the eight MT station coordinates and elevation for line $M$ and the nine for Line $G$, respectively. Locations were recorded using a Garmin global positioning system during field acquisition. Coordinates are referenced to the 1866 Clarke spheroid and North American 1927 Western United States datum. Longitude and latitude format is in decimal degrees. Universal Transverse Mercator units are in meters. Station elevation is given in meters and feet. 
Profile Line M Coordinates

\begin{tabular}{|c|c|c|c|c|c|c|}
\hline Site & Latitude & Longitude & UTM-E & UTM-N & Elev $-\mathrm{m}$ & Elev $-\mathrm{ft}$ \\
\hline M0 & 63.2648500 & -145.569416 & 571767.62 & 7016311.44 & 1268 & 4159 \\
\hline M1 & 63.2351666 & -145.629933 & 568801.21 & 7012938.28 & 1098 & 3602 \\
\hline M2 & 63.1988833 & -145.648616 & 567947.74 & 7008876.25 & 915 & 3001 \\
\hline M3 & 63.1566500 & -145.685916 & 566167.84 & 7004132.30 & 994 & 3261 \\
\hline M4 & 63.1155500 & -145.718766 & 564604.40 & 6999520.11 & 1280 & 4197 \\
\hline M5 & 63.0684667 & -145.753433 & 562957.39 & 6994240.37 & 1281 & 4201 \\
\hline M6 & 63.0083000 & -145.787016 & 561386.99 & 6987505.01 & 1004 & 3294 \\
\hline M7 & 62.9602000 & -145.817250 & 559954.76 & 6982117.90 & 922 & 3025 \\
\hline
\end{tabular}

Table 2. Coordinates and elevation of stations along Line $M$, in latitude, longitude and UTM coordinates. Elevation is given in meters and feet above sea level.

Profile Line G Coordinates

\begin{tabular}{|c|c|c|c|c|c|c|}
\multicolumn{1}{c}{ Site } & Latitude & Longitude & UTM-E & UTM-N & Elev $-\mathrm{m}$ & Elev $-\mathrm{ft}$ \\
\hline G2 & 63.3815833 & -145.800033 & 559950.42 & 7029079.35 & 1377 & 4516 \\
\hline G3 & 63.3488333 & -145.880950 & 555969.50 & 7025357.40 & 1353 & 4438 \\
\hline G4 & 63.3015667 & -145.865700 & 556825.82 & 7020104.77 & 1225 & 4018 \\
\hline G5 & 63.2601167 & -145.949533 & 552699.32 & 7015415.14 & 1072 & 3515 \\
\hline G6 & 63.2271000 & -145.983567 & 551049.21 & 7011709.14 & 1029 & 3374 \\
\hline G7 & 63.1850167 & -146.011850 & 549700.02 & 7006998.32 & 1246 & 4087 \\
\hline G8 & 63.1518333 & -146.045883 & 548042.12 & 7003275.35 & 1289 & 4227 \\
\hline G9 & 63.1071333 & -146.078450 & 546472.66 & 6998271.23 & 1060 & 3478 \\
\hline G10 & 63.0720500 & -146.108850 & 544992.77 & 6994340.86 & 970 & 3183 \\
\hline
\end{tabular}

Table 3. Coordinates and elevation of stations along Line $G$, in latitude, longitude and UTM coordinates. Elevation is given in meters and feet above sea level.

\section{MAGNETOTELLURIC DATA}

After transforming the recorded time-series data to the frequency domain, standard RR processing (EMI, 1999) was employed to determine apparent resistivity and phase tensor at each site. Data were edited to remove outliers and to reduce the number of frequencies for use in inverse modeling software. Data are not rotated, but fixed at $x=25^{\circ}$, as acquired in the field. The $x y$ mode is the nominal TM and the $y x$ the TE mode. Error bars on the Apparent Resistivity, Impedance Phase, Skew, Tipper Magnitude, and Tipper Strike plots represent probable errors within one standard 
deviation of the sample variance (Gamble and others, 1979b). Data are available in two formats: avg and res. For each station, ten separate plots are given in the Appendix:

1. Apparent Resistivity for the TM and TE modes at a fixed axis direction of $25^{\circ}$.

2. Impedance Phase for the TM and TE modes at a fixed axis direction of $25^{\circ}$.

3. Skew and Log Anisotropy for the impedance tensor.

4. Multiple E-Predicted Coherency for the maximum (Ex-HxHy) and minimum (Ey$\mathrm{HxHy}$ ) modes of the electric field.

5. Multiple Coherency for Hx-Ey and Hx-Ex.

6. Multiple Coherency for Hy-Ex and Hy-Ey.

7. Multiple Coherency for $\mathrm{Hz}-\mathrm{Hx}$ and $\mathrm{Hz}-\mathrm{Hy}$.

8. Impedance Polar Plots.

9. Tipper Magnitude of the vertical magnetic field.

10. Tipper Strike of the vertical magnetic field.

Apparent resistivity is the ratio of one component of the electric field magnitude over the orthogonal component of the magnetic field magnitude, normalized by frequency and the magnetic susceptabilty for free space. The impedance phase is the arctangent of the unnormalized ratio. The apparent resistivity and phase are related through a Hilbert Transform; the phase is proportional to the slope of the apparent resistivity curve on a log-log plot, but from a baseline at -45 degrees (Vozoff, 1991). A measure of the dimensionality for MT data is provided by the impedance skew of the impedance tensor. If the effective measured resistivity response to the geology beneath a MT station is truly 1-D or 2-D, then the skew will be zero. Both instrument and environmental sources of noise contribute to non-zero skew values, but are typically small (about 0.1) for relatively low noise level recordings. Higher skews (above 0.2) are an indication of either the resistivity response to 3-D geology or higher levels of noise (Vozoff, 1972).

Anthropomorphic noise, such as power lines, power generators, moving vehicles and trains, can produce an incoherent noise mainly affecting frequencies above $1 \mathrm{~Hz}$. Other electrical noise, such as direct current electric trains and active cathodic protection of pipelines produce coherent EM signals mainly affecting frequencies below $1 \mathrm{~Hz}$. However this survey was located in a remote area and only one site (M1) was in the vicinity of the radio repeater station, and data quality was good. The trans-Alaska 
oil pipeline was between stations M1 and M2, but no distortion due to the pipeline was detected. Wind noise was minimized by burying the magnetic induction coils and keeping the electric dipole wires flat on the ground surface.

Predicted values of the electric field can be computed from the measured values of the magnetic field (Vozoff, 1991). The coherence of the predicted electric field with the measured electric field is a measure of the signal-to-noise ratio provided in the multiple E-predicted coherency plot. Values are normalized between 0 and 1, where values at 0.5 signify signal levels equal to noise levels. For this data set, coherencies were generally at an acceptable level, except in the "dead band" of 0.1 to $5 \mathrm{~Hz}$ (10 to 0.2 seconds), from 0.05 to $1 \mathrm{~Hz}$ (20 to 1 seconds) for site $\mathrm{G} 7$, and from $0.03 \mathrm{to} 3 \mathrm{~Hz}$ (32 to 0.3 seconds) for site $\mathrm{G} 10$.

The impedance polar plots provide a measure of the MT data dimensionality (Reddy and others, 1977). The impedance is a scalar value for a 1-D Earth, the diagonal elements are zero for a 2-D Earth, and a full 2 by 2 for a 3-D Earth. Hence for 1-D resistivity structures, the principal impedance polar diagram (red line) is a circle. For 2-D or 3-D resistivity structures, the principal impedance polar diagram, determined from the off-diagonal elements, elongates either parallel or perpendicular to strike direction. Over resistors, the principal impedance polar diagram elongates perpendicular to strike direction and over conductors, the principal impedance polar diagram elongates parallel to strike direction. For nearly 2-D resistivity structures, the polar diagram, determined from the diagonal elements, (black line) attains the shape of a small symmetric clover leaf. For 3-D resistivity structures, the two polar plots are of comparable ampitude. The polar diagrams of site G6, G7, G8, M5, and to a lesser extent in G5, G9, M3, M4, M6, and M7 indicate strong 3-D effects, however this can also be a symptom of noisy data in the diagonal terms. Comparison of both modes of the apparent resisitivity curves at sites M4 and M5 confirm the presence of 3-D structures.

The tipper is the transfer function between the vertical and horizontal components of the magnetic field. The tipper magnitude is a measure of the tipping of the magnetic field out of the horizontal plane (Vozoff, 1991). The magnitude is zero for the 1-D case and typically increases between 0.1 to 0.5 , and rarely as great as 1 , as it responds to vertical and sub-vertical structures. The tipper strike is typically used to help resolve the 90-degree ambiguity in the impedance rotation angle $\mathrm{The} \mathrm{HzHx}$ and $\mathrm{HzHy}$ 
coherency is a measure of the signal-to-noise ratio of the vertical magnetic field with respect to each of the orthogonal horizontal magnetic field directions. Values are normalized between 0 and 1 , where values at 0.5 signify signal levels equal to noise levels. These three-component magnetic field coherencies provide a check on the signal-to-noise ratio of the measured values in the tipper magnitude and tipper strike plots. The vertical magnetic field is typically small and difficult to measure with induction coils in mountainous terrain.

No independent electromagnetic data were acquired specifically to correct static shifts effects, which are present in G5, G6, G7, G8 and M5. However a helicopter EM (HEM) survey was acquired over MT stations G3 - G10 and M0 - M5 by the State of Alaska, Department of Natural Resources, Division of Geological \& Geophysical Surveys, and is available through them. The HEM data are higher frequencies than the MT data, recorded at $900 \mathrm{~Hz}, 7200 \mathrm{~Hz}$ and $56 \mathrm{kHz}$, but may be helpful is accessing and correcting static shift distortions.

\section{ACKNOWLEDGMENTS}

We thank the Consortium for Electromagnetic Studies of the Continents for the use of the EMI MT24 instrumentation. Peter Bittenbender, US Bureau of Land Management, for field support. 


\section{REFERENCES CITED}

Bendat, J.S., and Piersol, A.G., 1971, Random Data: Analysis and Measurement Procedures: New York, Wiley Interscience, 407p.

Chave, A.D., and Thompsen, D.J., 1989, Some comments on magnetotelluric response function estimation, J. Geophys. Res., 94, 14, 215-14.

Clarke, J., Gamble, T.D., Goubau, W.M., Koch, R.H., and Miracky, R.F., 1983, Remotereference magnetotellurics: Equipment and procedures: Geophysical Prospecting, vol. 31, p. 149-170.

Eberhart-Phillips, D., Stanley, W.D., Rodriguez, B.D. and Lutter, W.J., 1995, Surface seismic and electrical methods to detect fluids related to faulting: Journal of Geophysical Research, vol. 100, no. B7, p. 12,919-12,936.

EMI, 1999, ACQ24 Version 6.2, EMI MT-24 Networked System Acquisition Program, USERS MANUAL: ElectroMagnetic Instruments, Inc., Richmond, California.

Egbert, G.D., and Booker, J.R., 1986, Robust estimation of geomagnetic transfer functions, Geophys. J. R. Astron. Soc., 87, 173-194.

Gamble, T.D., Goubau, W.M. and Clarke, J., 1979a, Magnetotellurics with a remote magnetic reference: Geophysics, v. 44, no. 1, p. 53-68.

Gamble, T.D., Goubau, W.M. and Clarke, J., 1979b, Error analysis for remote reference magnetotellurics: Geophysics, v. 44, no. 5, p. 959-968.

Keller, G.V., 1987, Rock and mineral properties, in Electromagnetic Methods in Applied Geophysics Theory: M.N. Nabighian, Ed., Society of Exploration Geophysicists, Tulsa, Oklahoma, v. 1, p. 1351.

Keller, G.V., 1989, Electrical properties, in Carmichael, R.S., Ed., Practical handbook of physical properties of rocks and minerals: CRC Press, Boca Raton, Florida, p. 359-427. 
Palacky, G.J., 1987, Resistivity characteristics of geologic targets, in Electromagnetic Methods in Applied Geophysics Theory: M.N. Nabighian, Ed., Society of Exploration Geophysicists, Tulsa, Oklahoma, vol. 1, p. 53129.

Pellerin, L., and Hohmann, G.W., 1990, Transient Electromagnetic Inversion: A Remedy for Magnetotelluric Static Shifts: Geophysics, 55, 9, p. 1242-1250.

Reddy, I.K., Rankin, D., and Phillips, R.J., 1977, Three-dimensional modelling in magnetotelluric and magnetic variational sounding: Geophysics Journal of the Royal Astronomical Society, vol. 51, p. 313-325.

Telford, W. M., Sheriff, R. E., and Sheriff, R. E., 1991, Applied Geophysics (2 ${ }^{\text {nd }}$ Edition) Cambridge University Press, 790 pages

Vozoff, K., 1972, The magnetotelluric method in the exploration of sedimentary basins: Geophysics, vol. 37, p. 98-141.

Vozoff, K., 1991, The magnetotelluric method, in Electromagnetic methods in applied geophysics: M.N. Nabighian, Ed., Society of Exploration Geophysicists, Tulsa, Oklahoma, vol. 2, part B, p. 641-711. 


\section{APPENDIX - MAGNETOTELLURIC DATA PLOTS}

The "Magnetotelluric Data" section in this report contains an explanation for ten separate plots for each station:

1. Apparent Resistivity for axis direction of $25^{\circ}$. Nominal TM mode is $x y$ (blue square) and TE is yx (red triangle).

2. Impedance Phase for axis direction of $25^{\circ}$. Nominal TM mode is xy (blue square) and TE is yx (red triangle).

3. Skew (blue square) and Log Anisotropy (red triangle) for the impedance tensor.

4. Multiple E-Predicted Coherency for the maximum Ex-HxHy (blue square) and minimum Ey-HxHy (red triangle) modes of the electric field.

5. Multiple Coherency for Hx-Ey (red triangle) and Hx-Ex (blue square).

6. Multiple Coherency for Hy-Ex (blue square) and Hy-Ey (red triangle).

7. Multiple Coherency for $\mathrm{Hz}-\mathrm{Hx}$ (blue square) and $\mathrm{Hz}-\mathrm{Hy}$ (red triangle).

8. Impedance Polar Plots.

9. Tipper Magnitude of the vertical magnetic field.

10. Tipper Strike of the vertical magnetic field. 


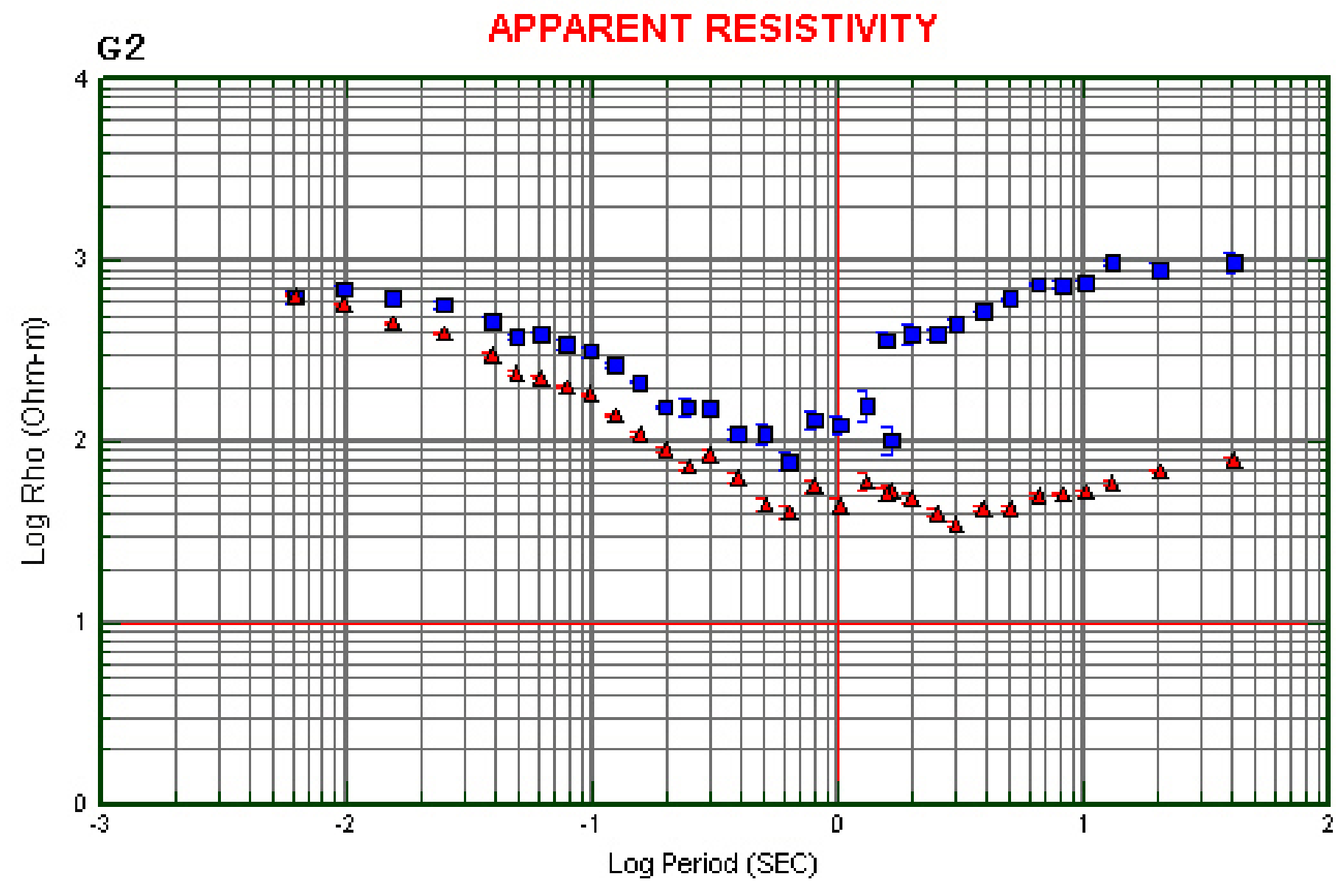

- Rho $X Y$

$\Delta$ Rho $Y x$ 


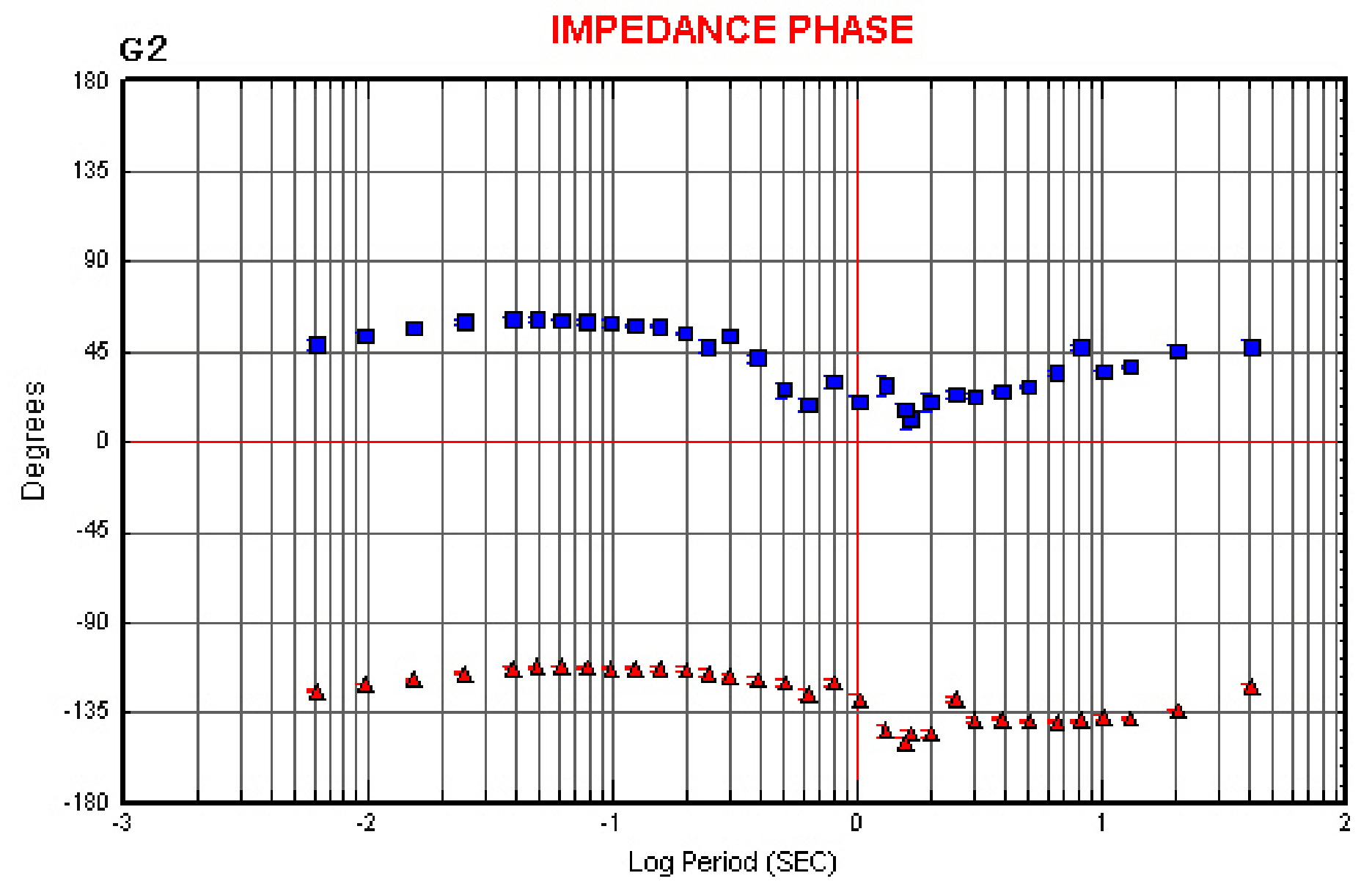

- Phase $X Y$

i Phase $Y x$ 
$\Xi$

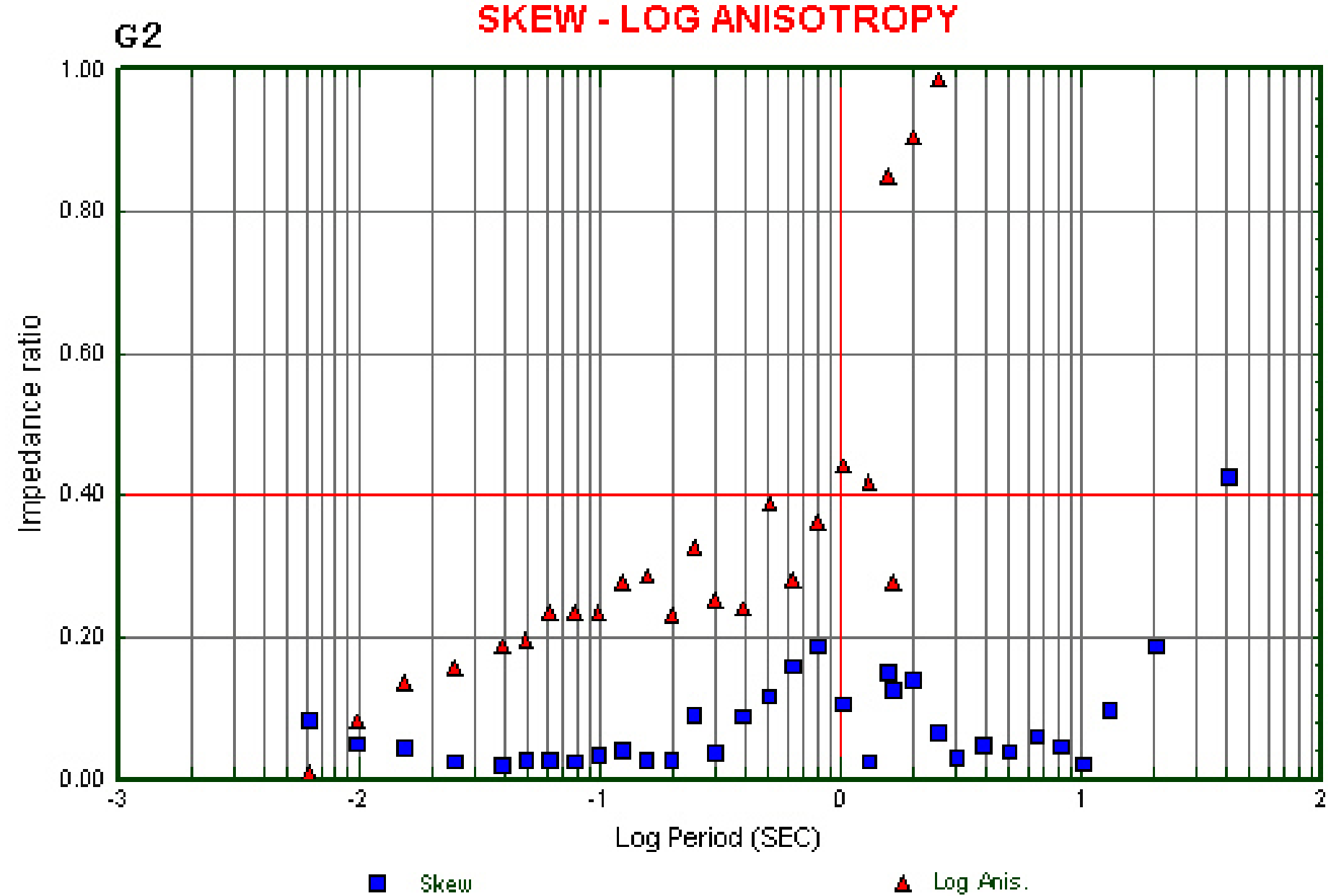




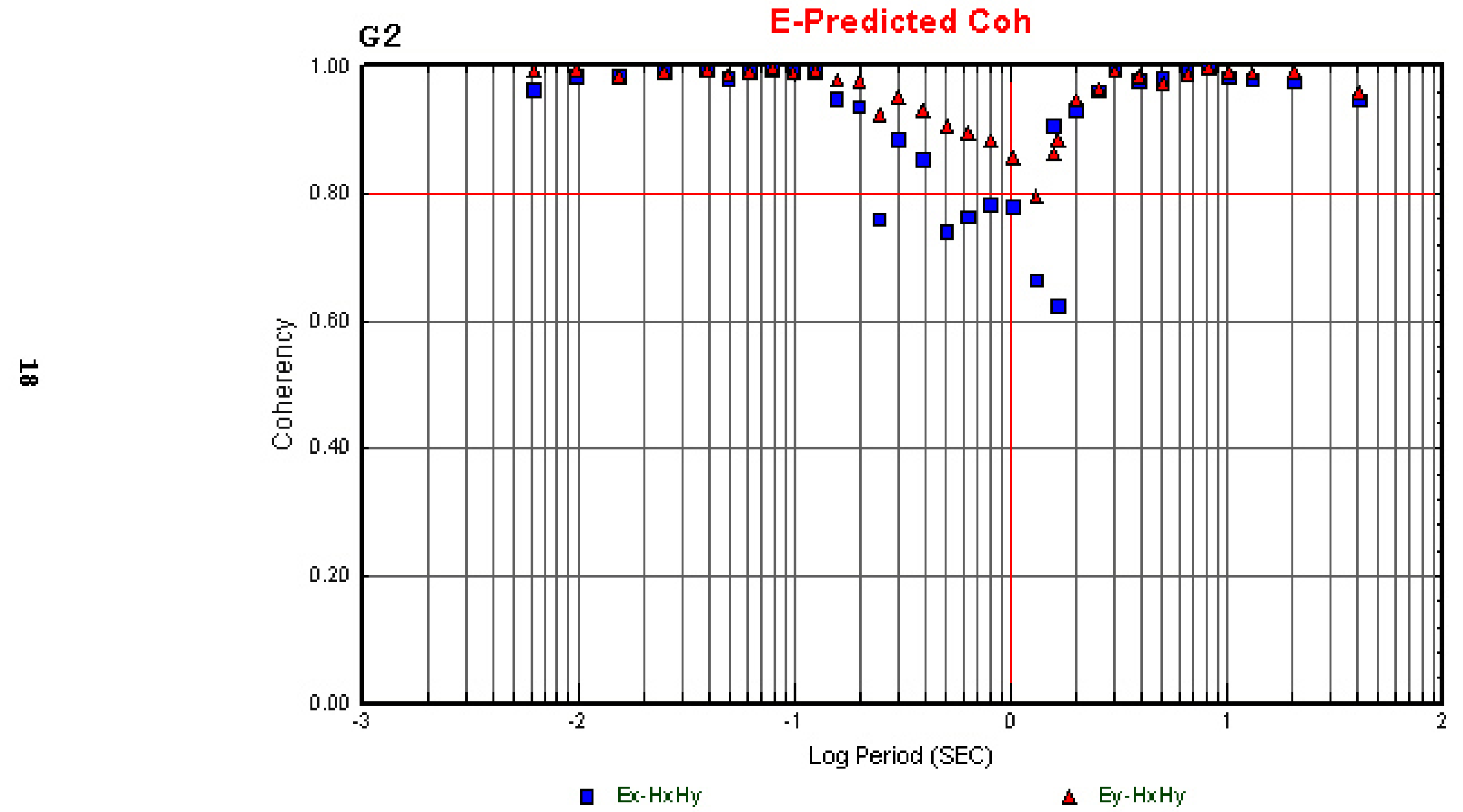


5

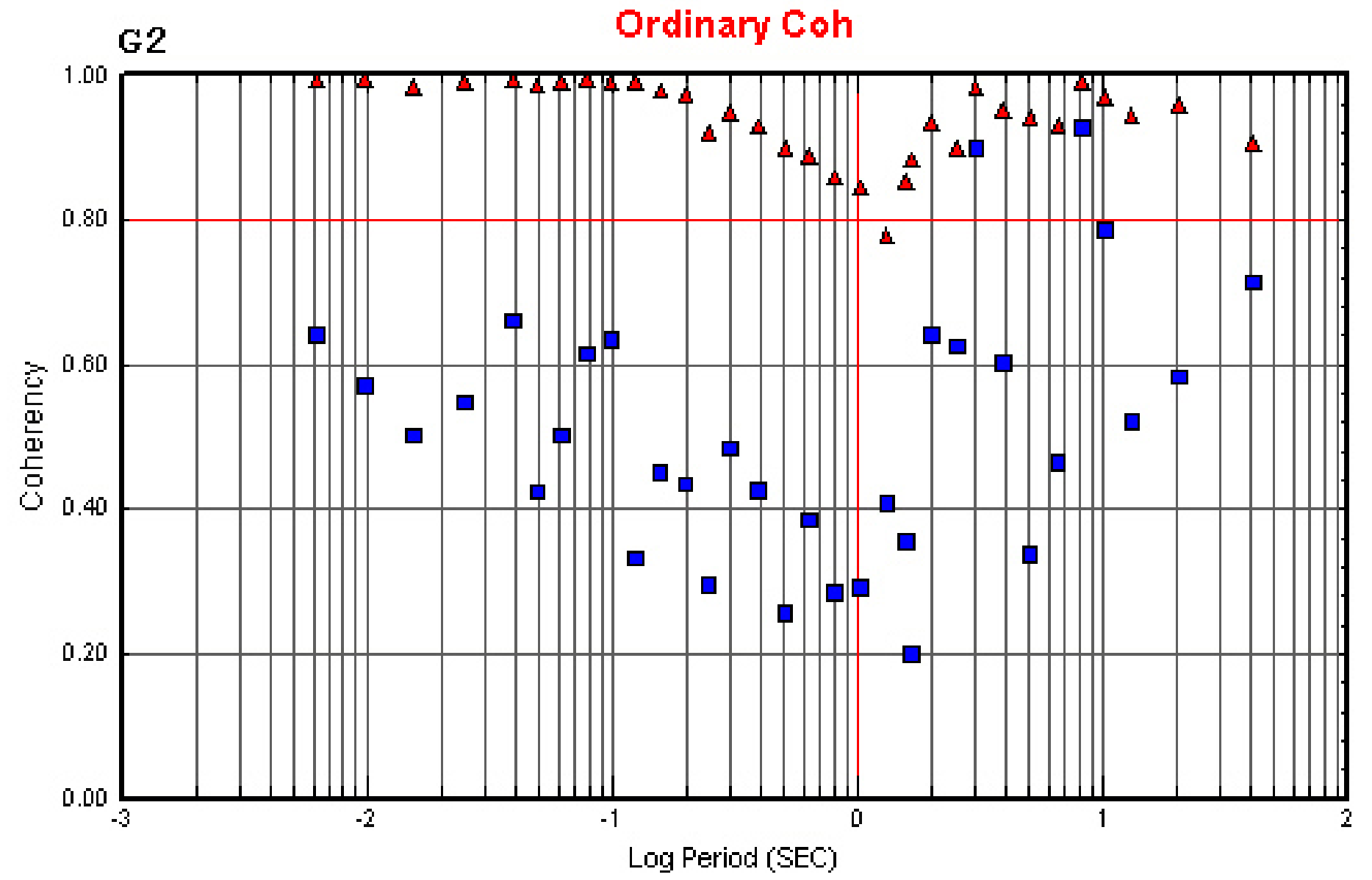

- $\mathrm{Hx}-\mathrm{Ex}$

$\Delta \mathrm{Hx}-\mathrm{Ey}$ 
$\cong$

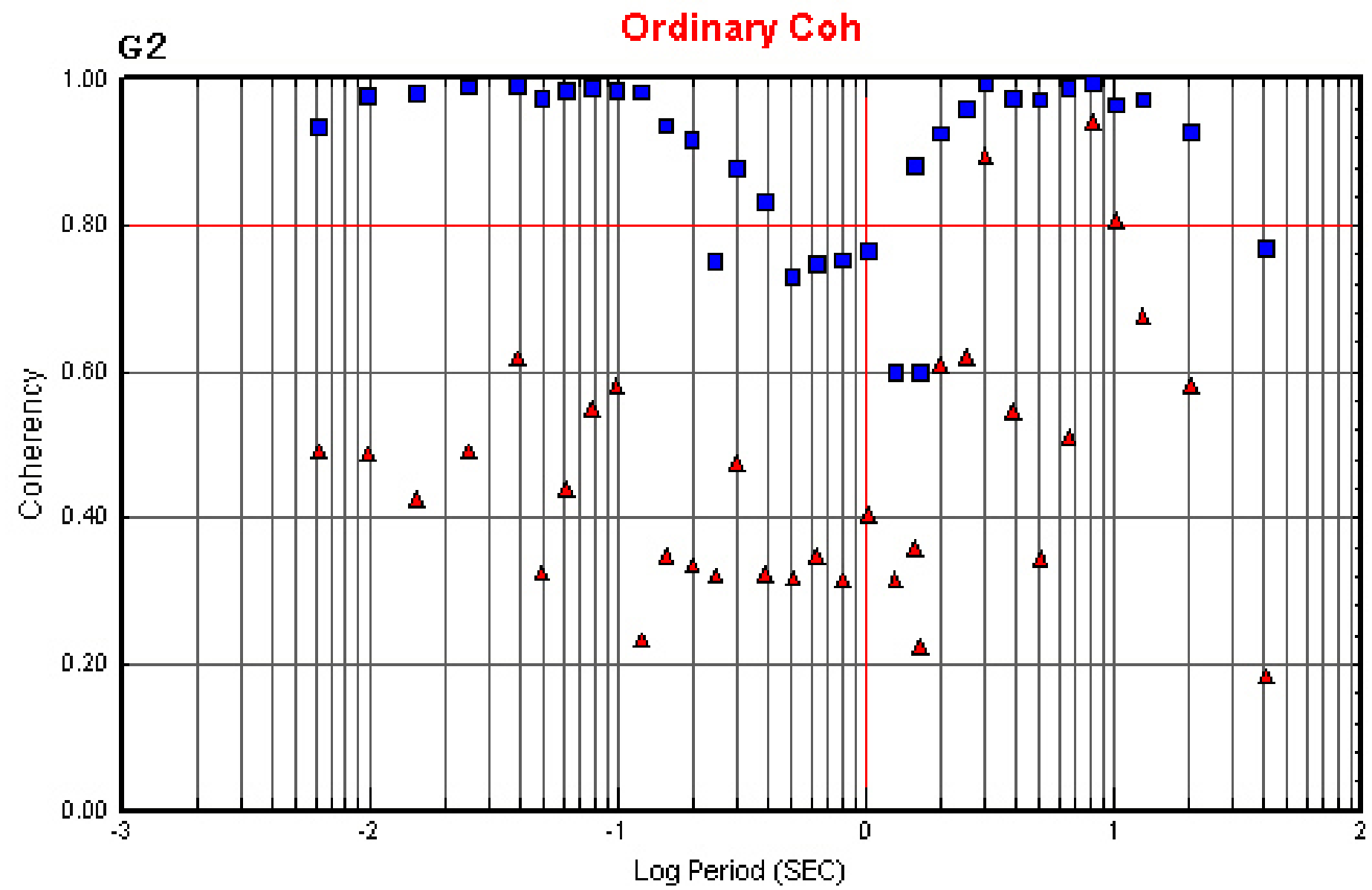

a $H y-E x$

A Hy-Ey 


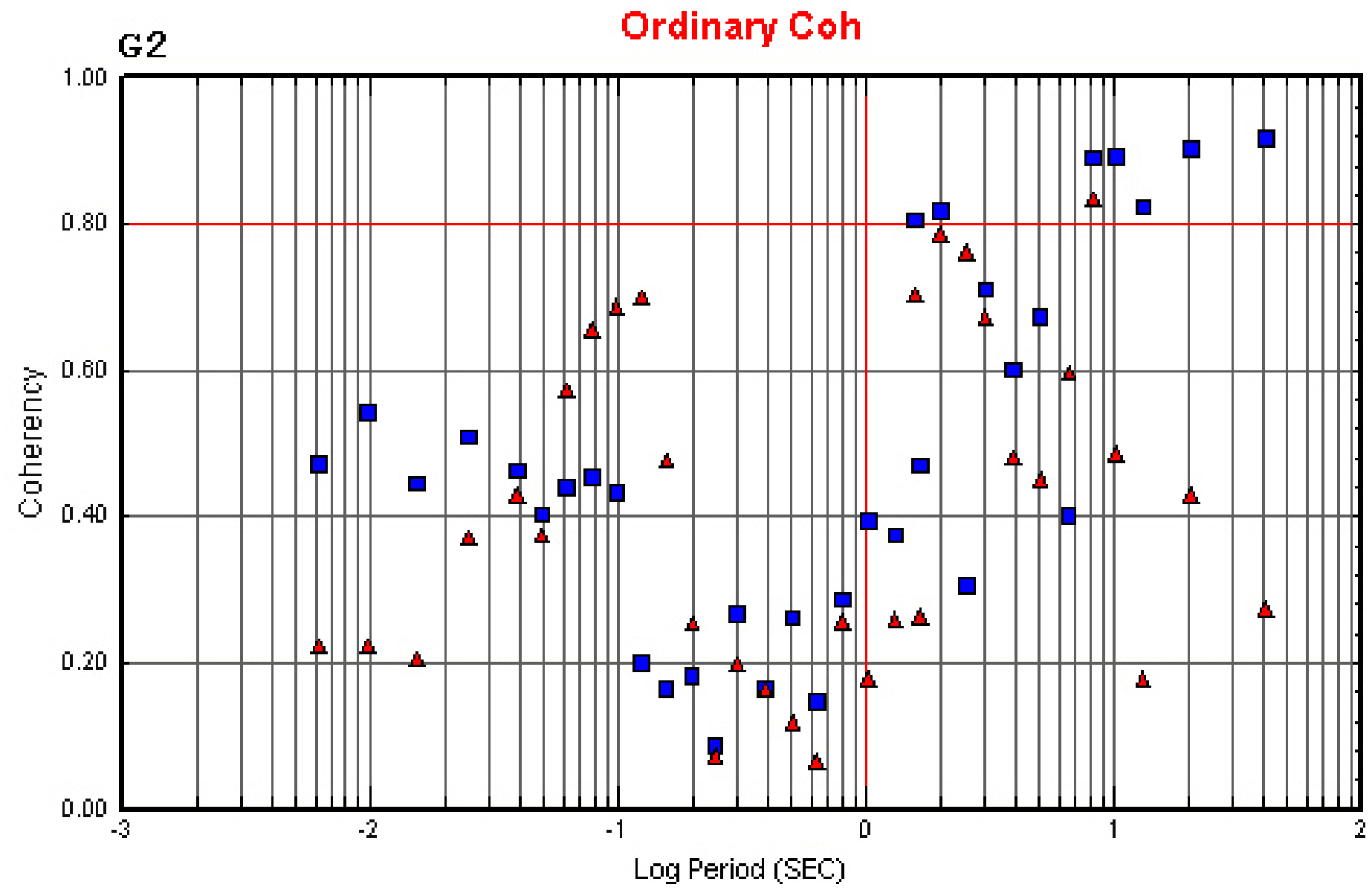




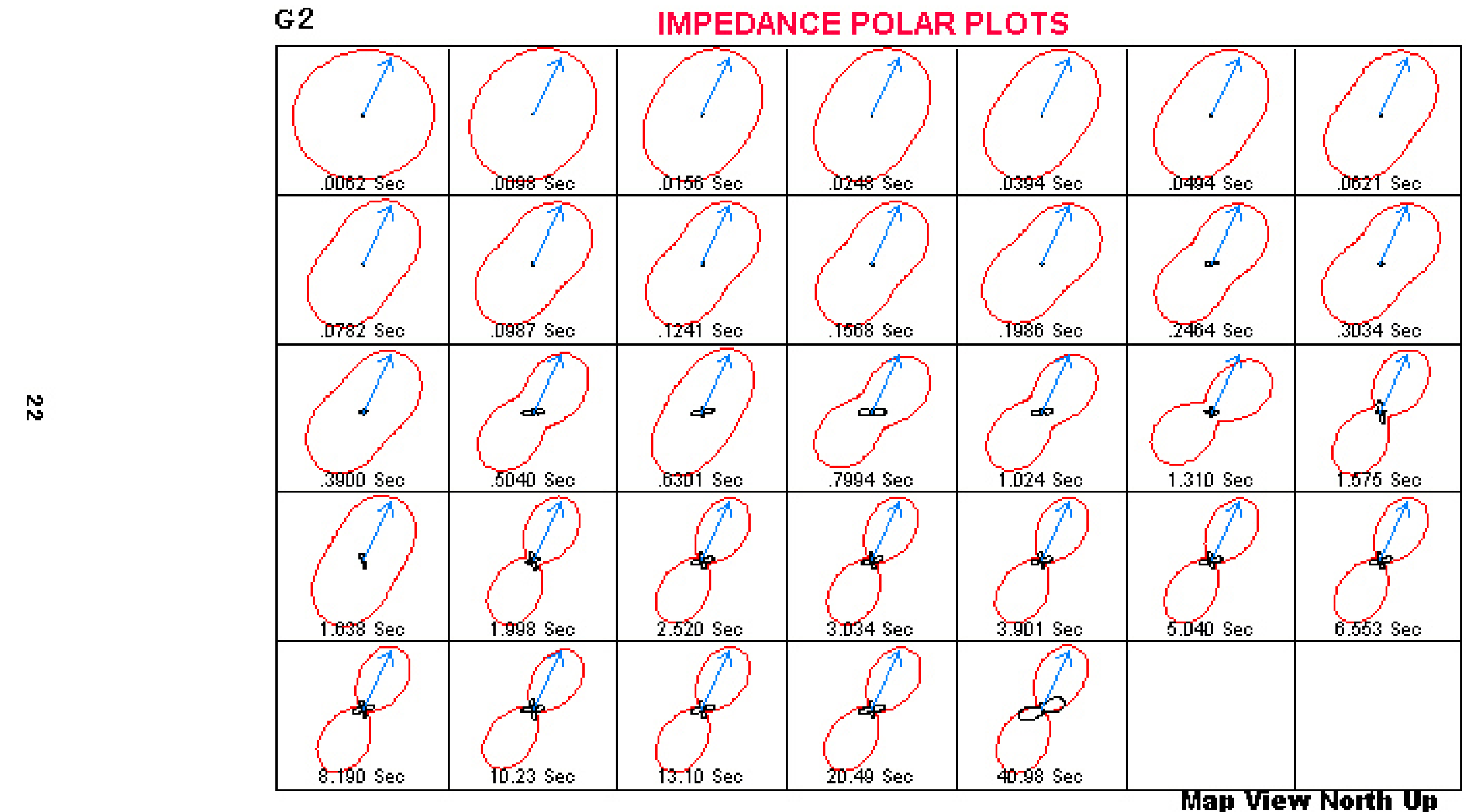

Map Vew North Up 


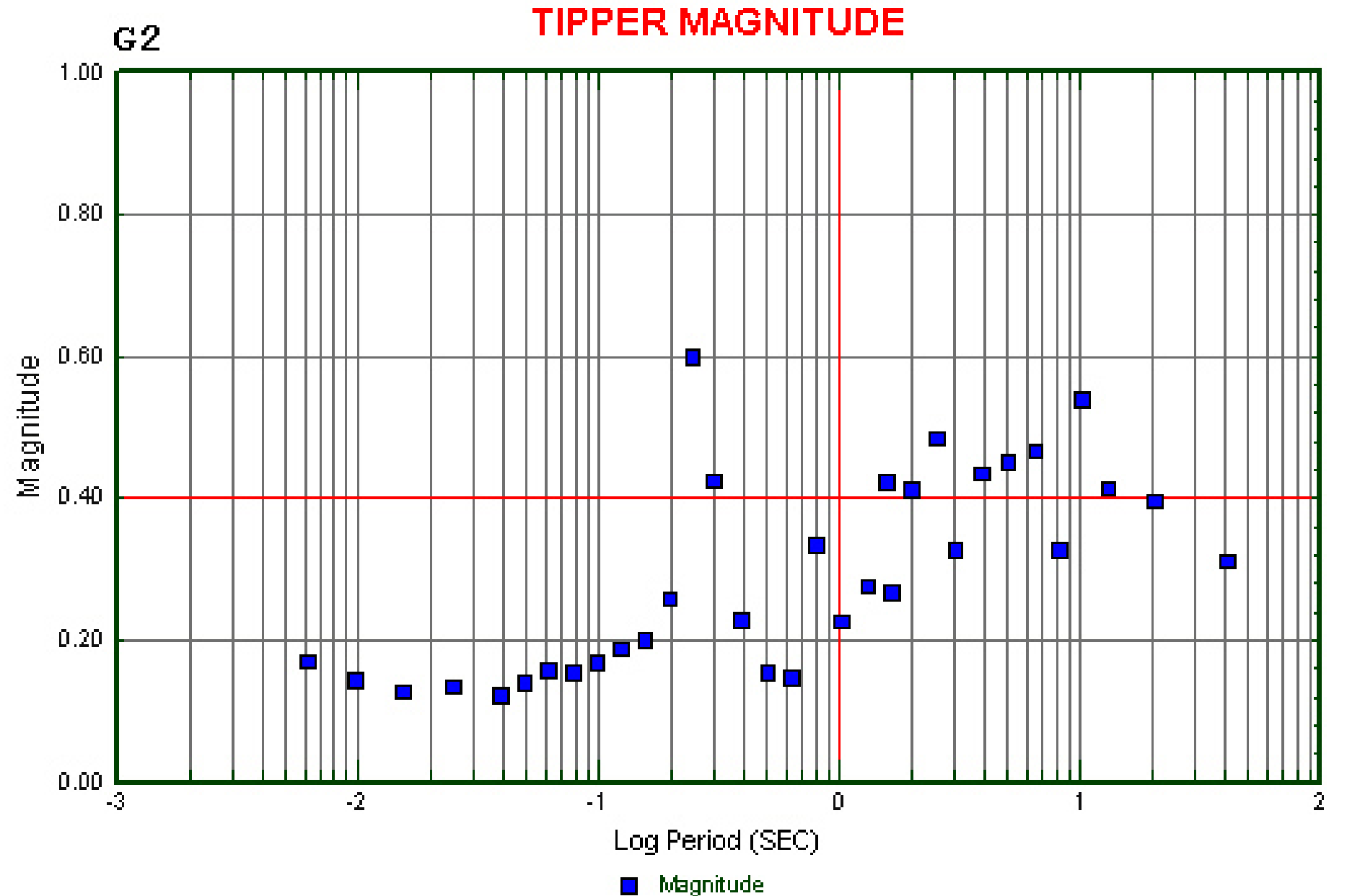




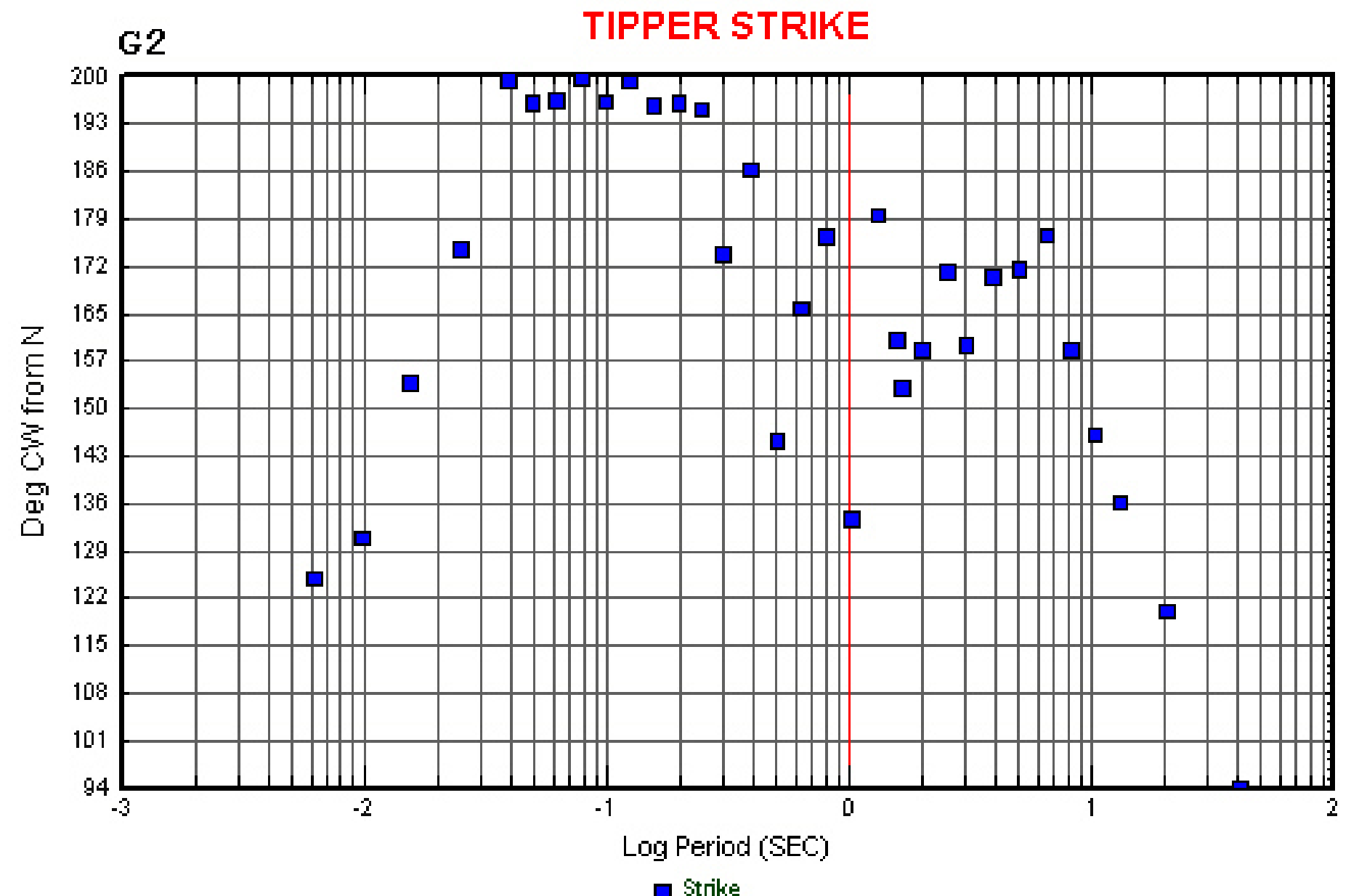

口 Strike 


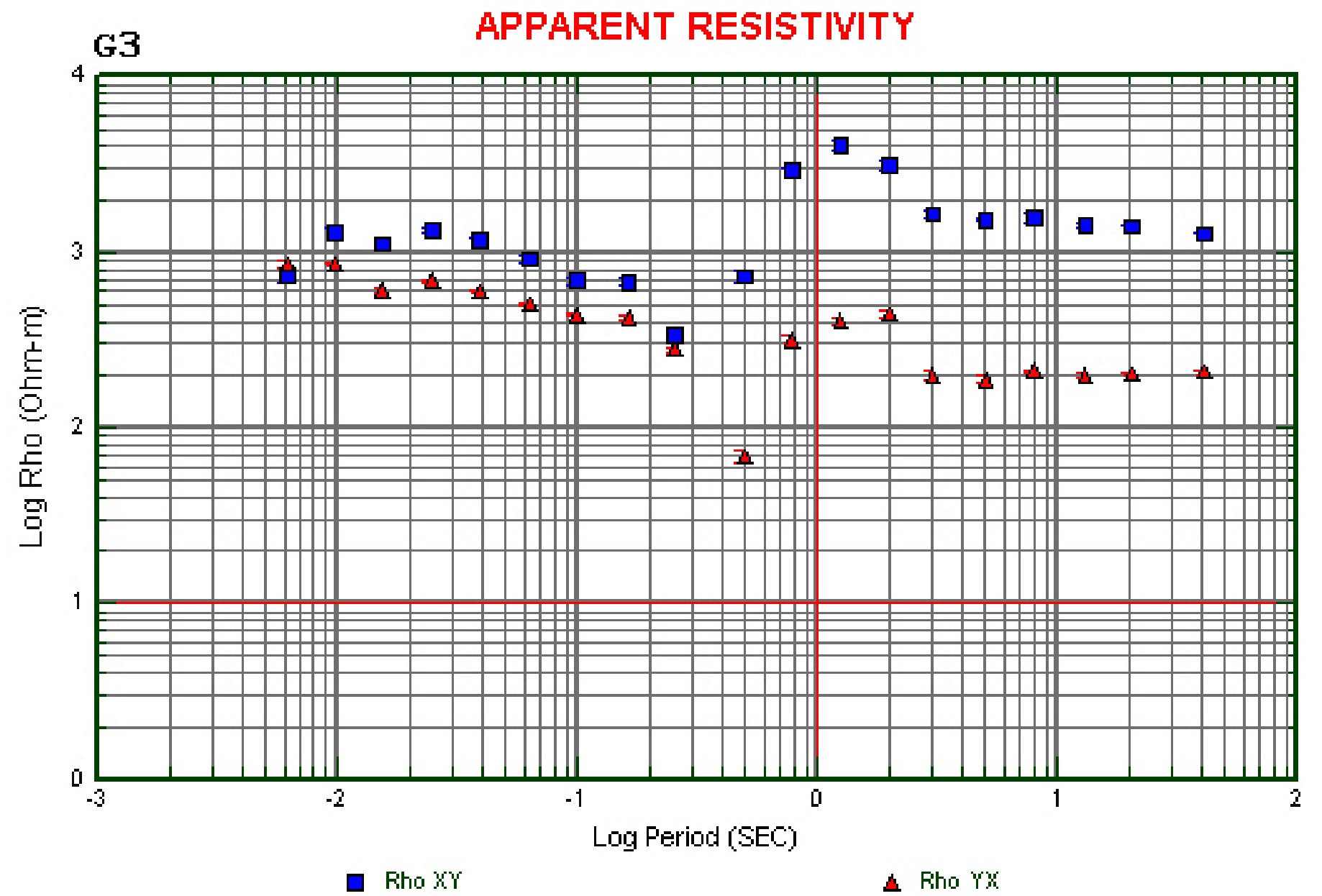


ล

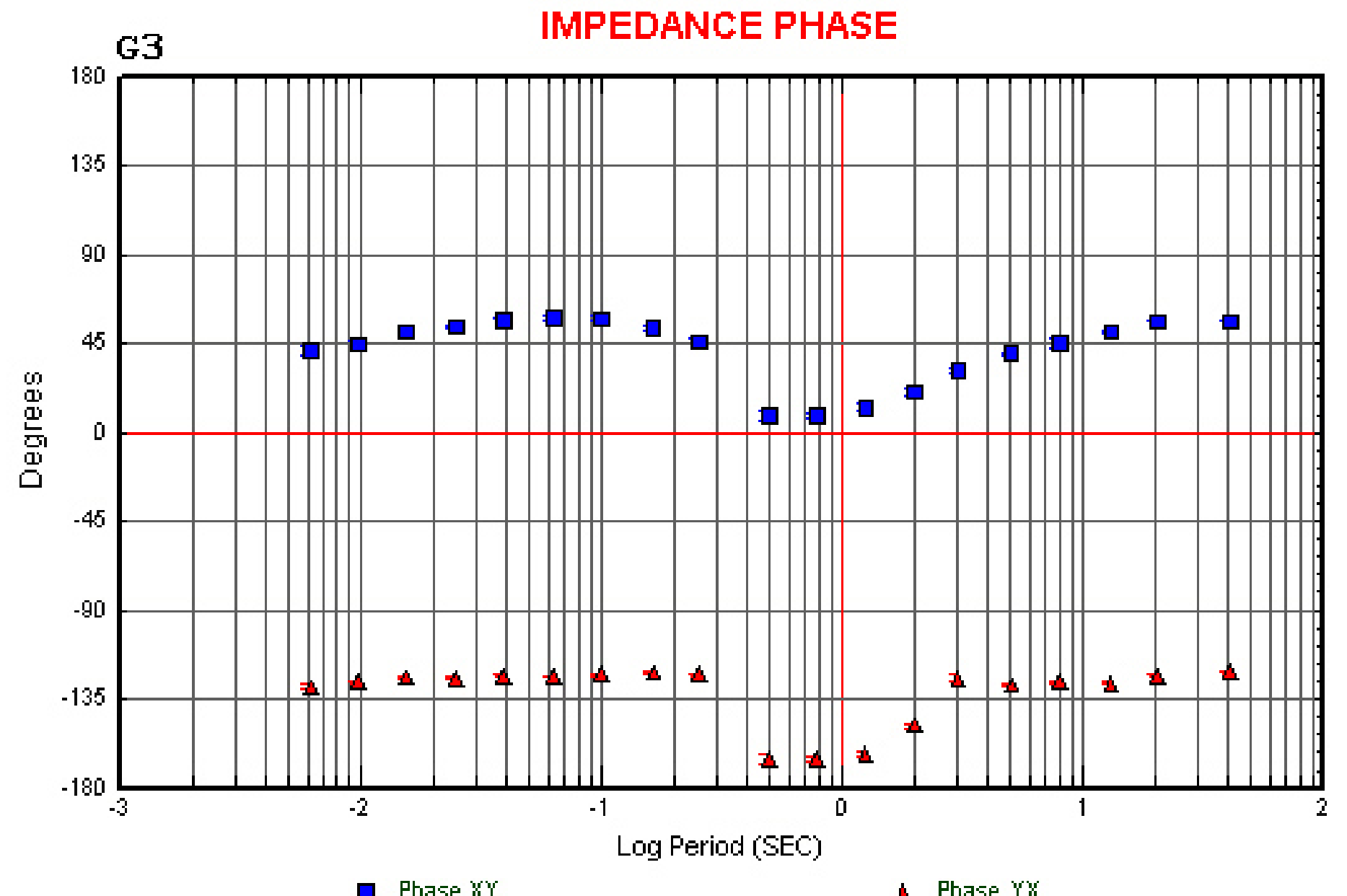




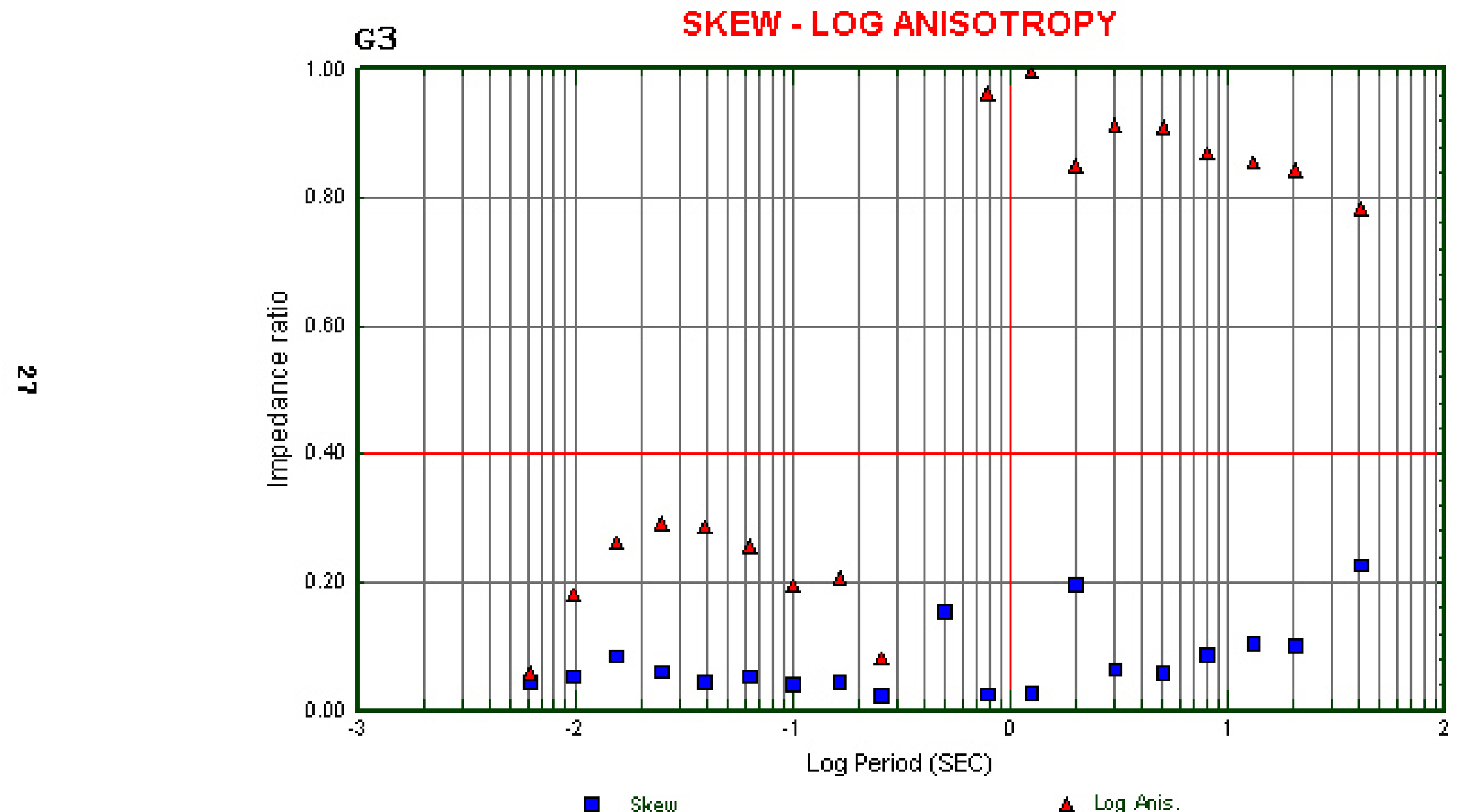


N

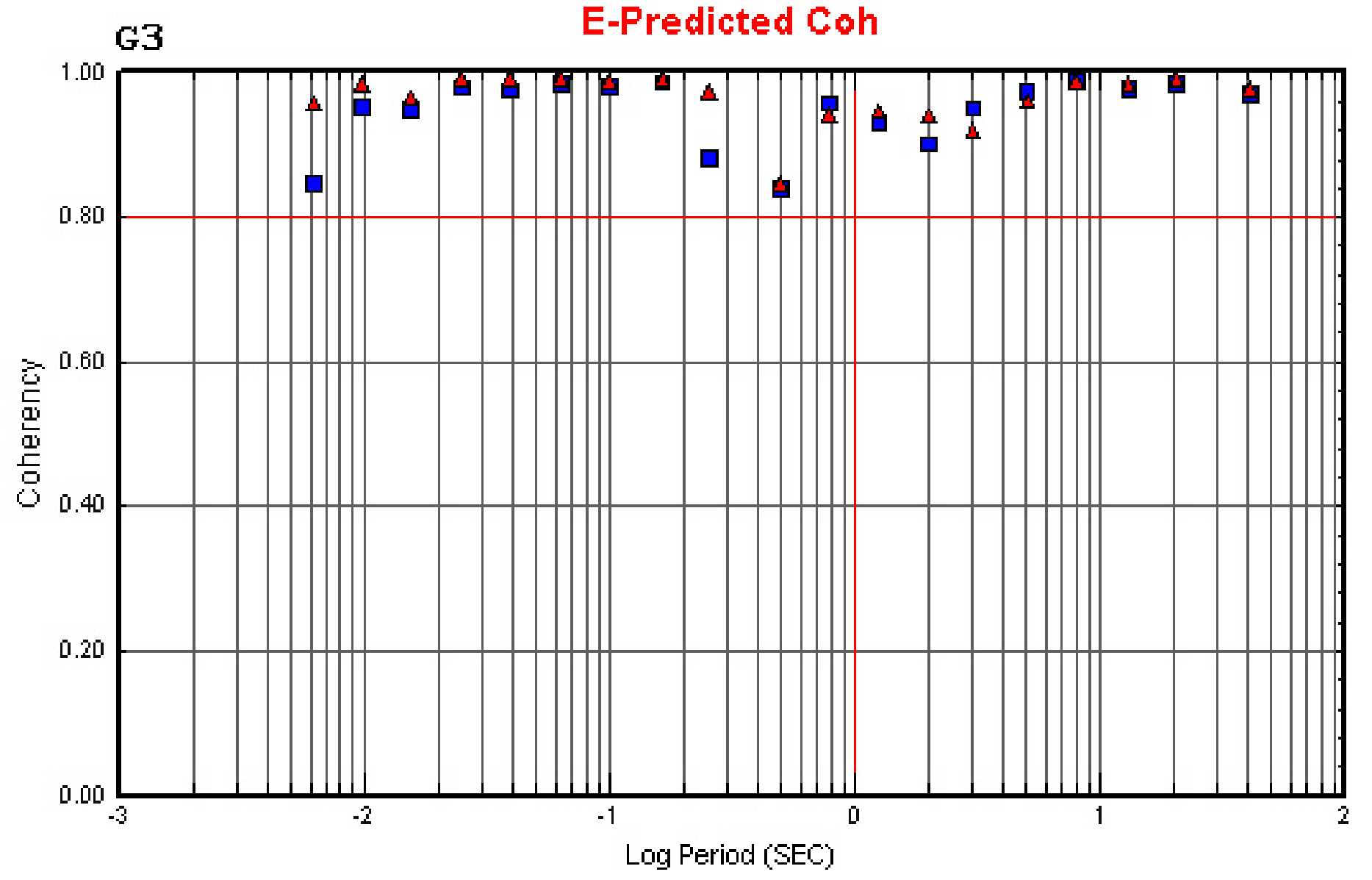

a $\mathrm{Ex}-\mathrm{H} x \mathrm{Hy}$

A Ey- $\mathrm{HxHy}$ 


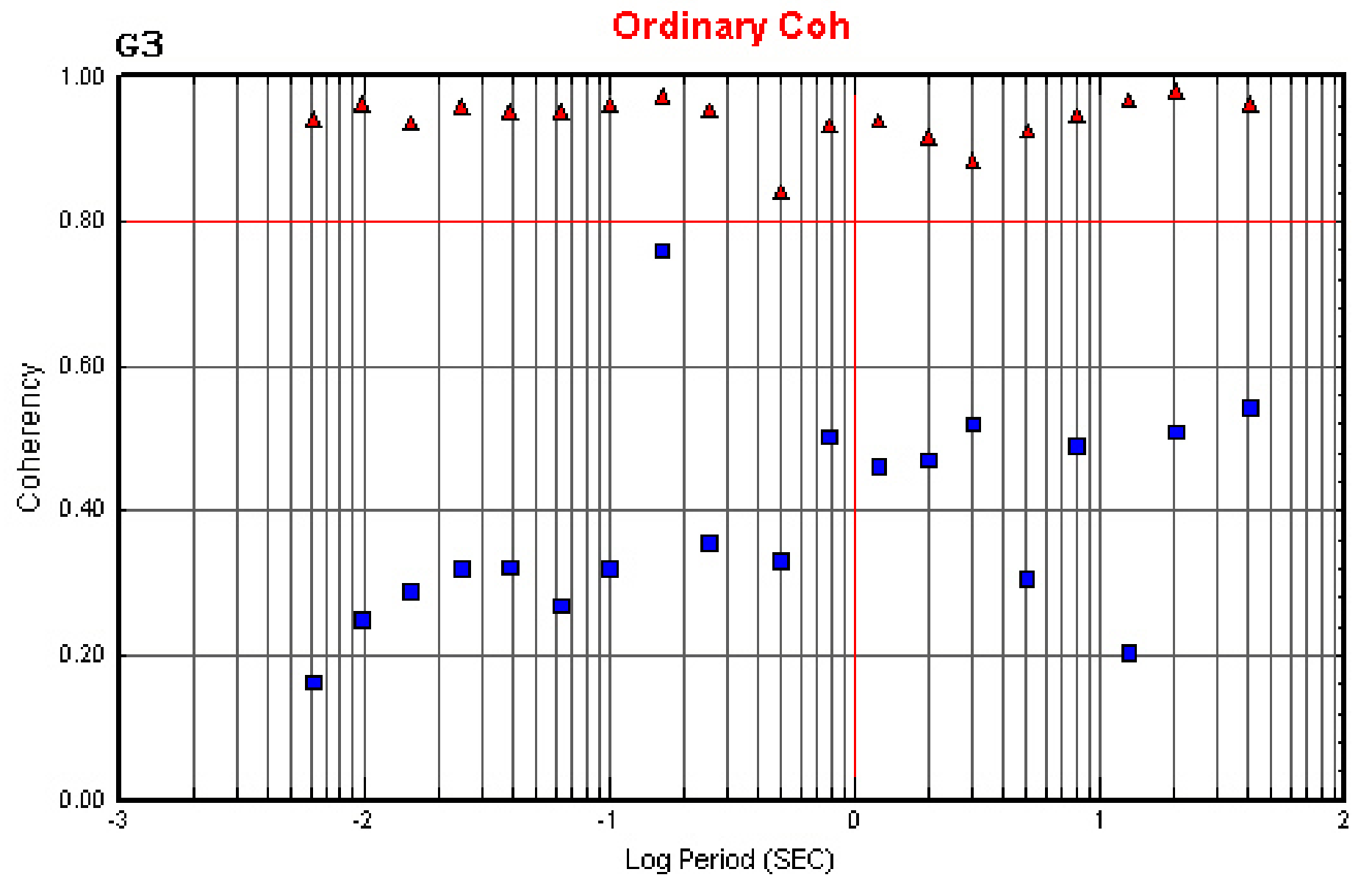

A $\mathrm{H} x-\mathrm{E} y$ 


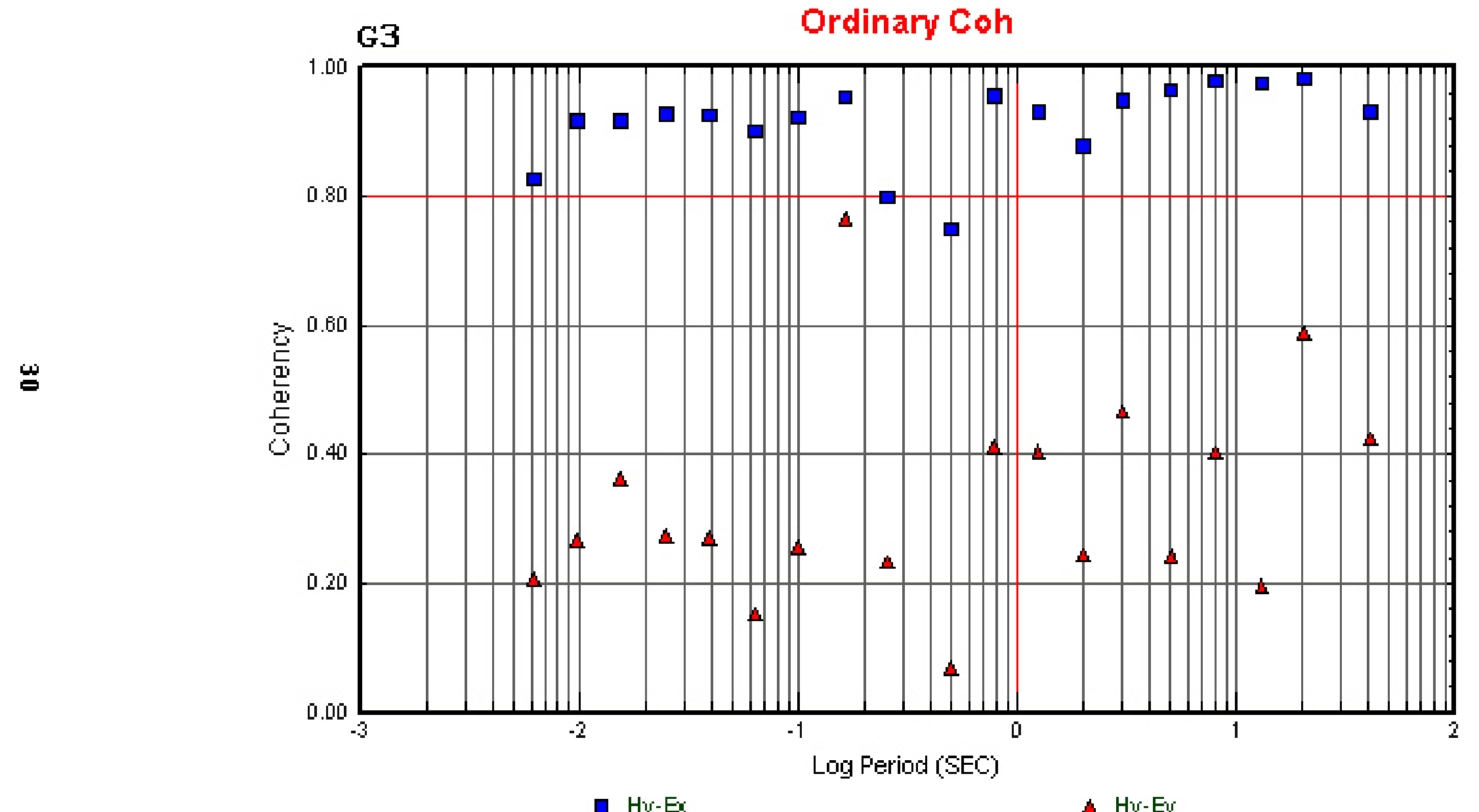




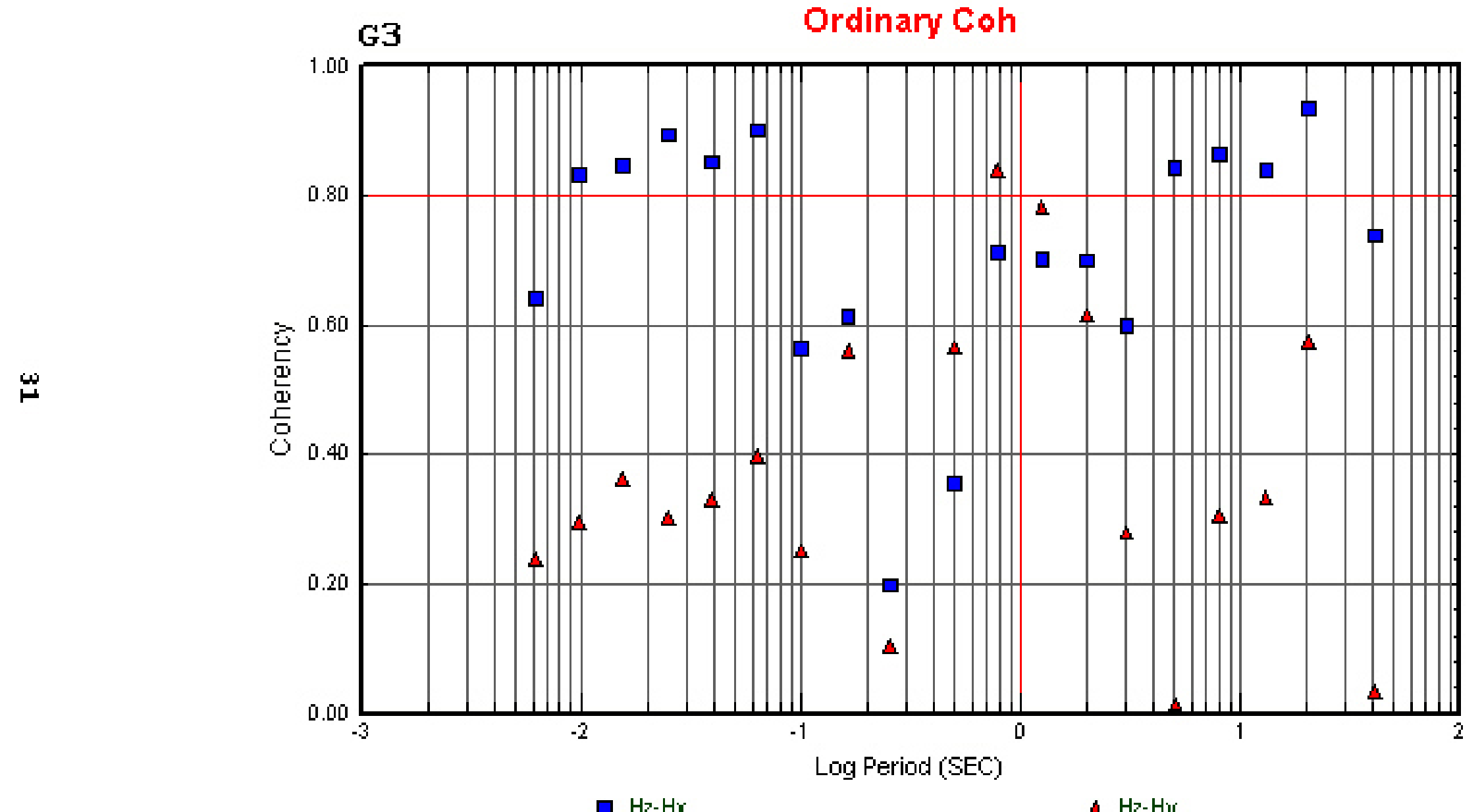


IMPEDANCE POLAR PLOTS

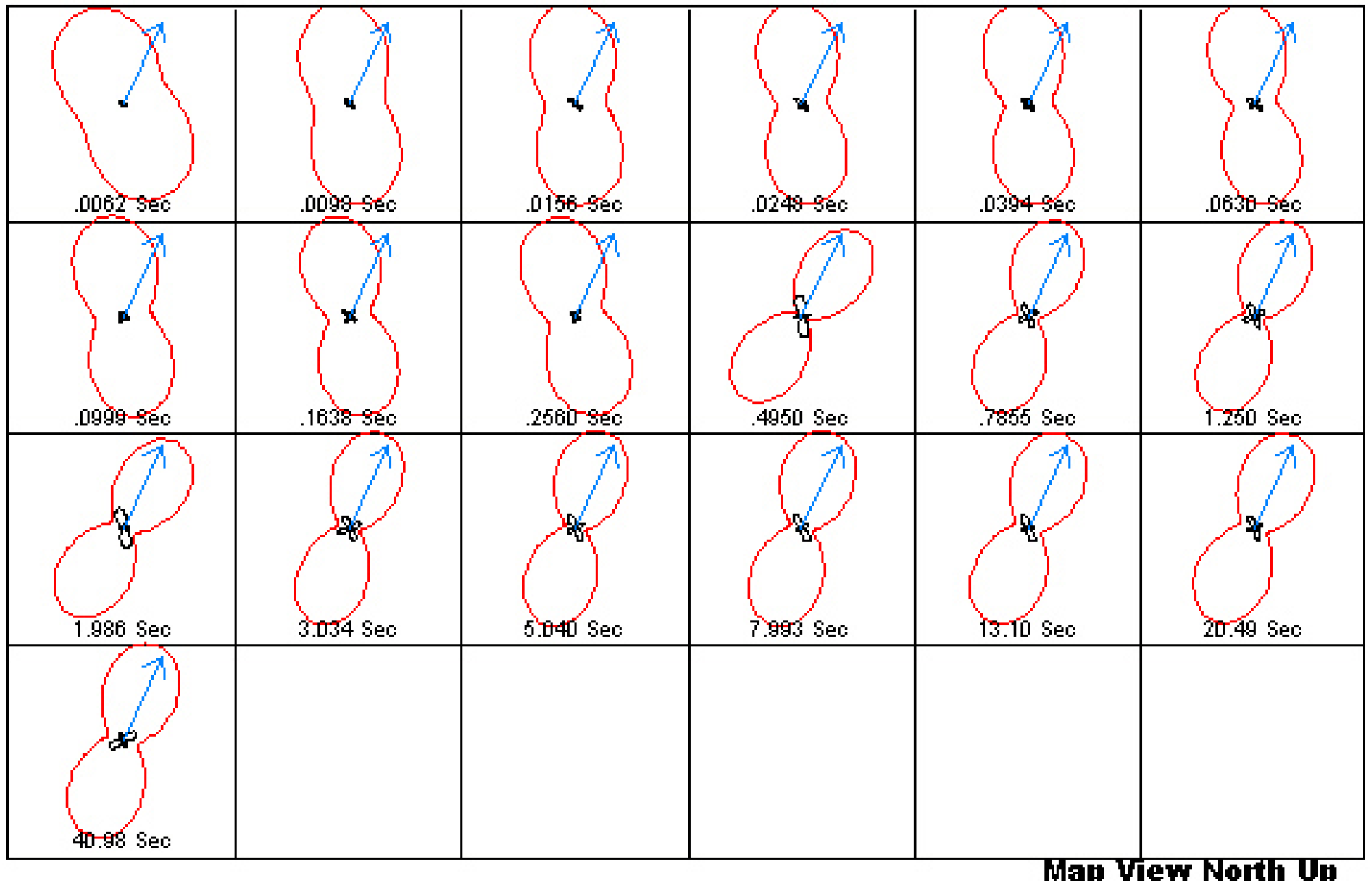




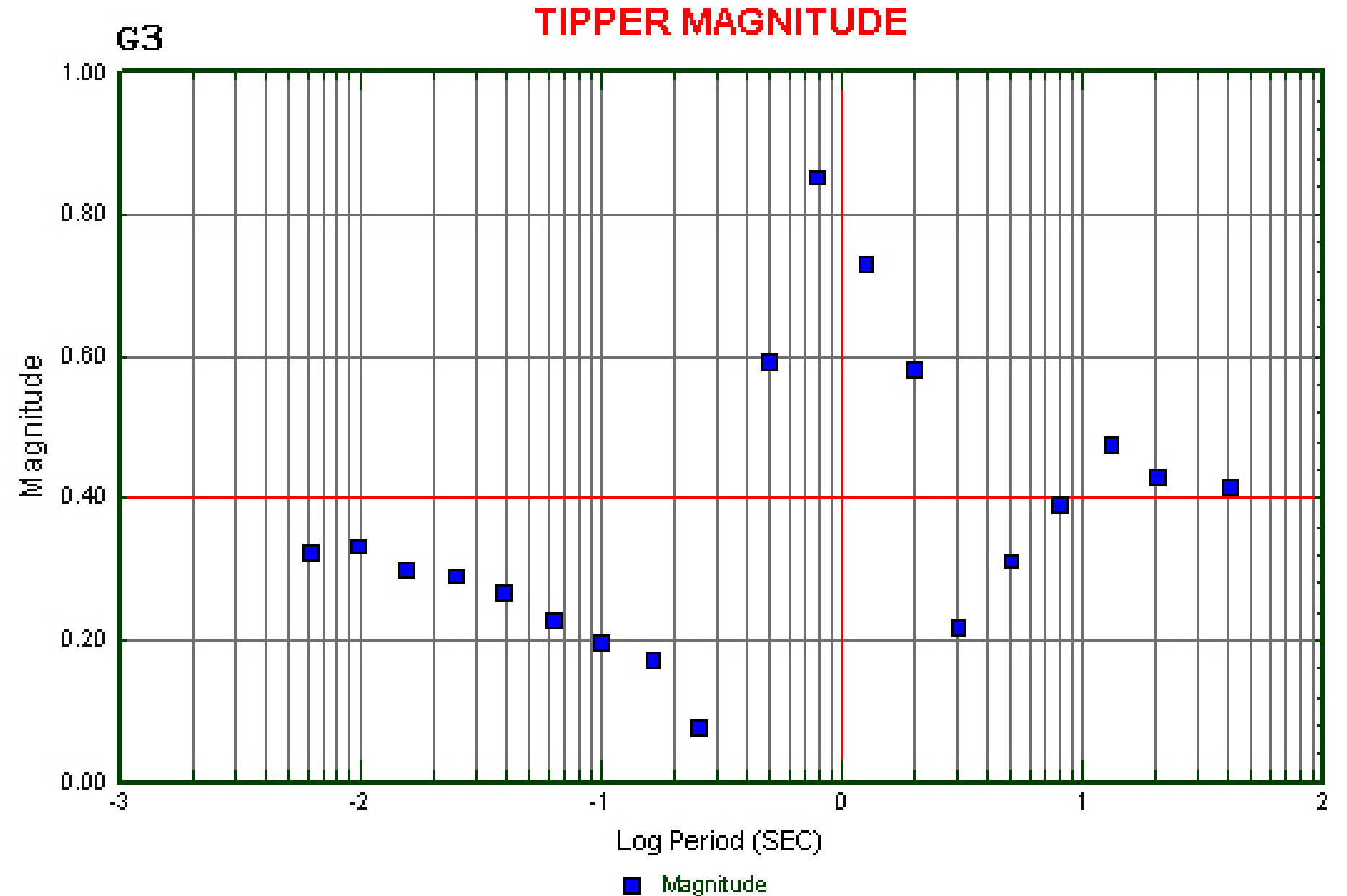




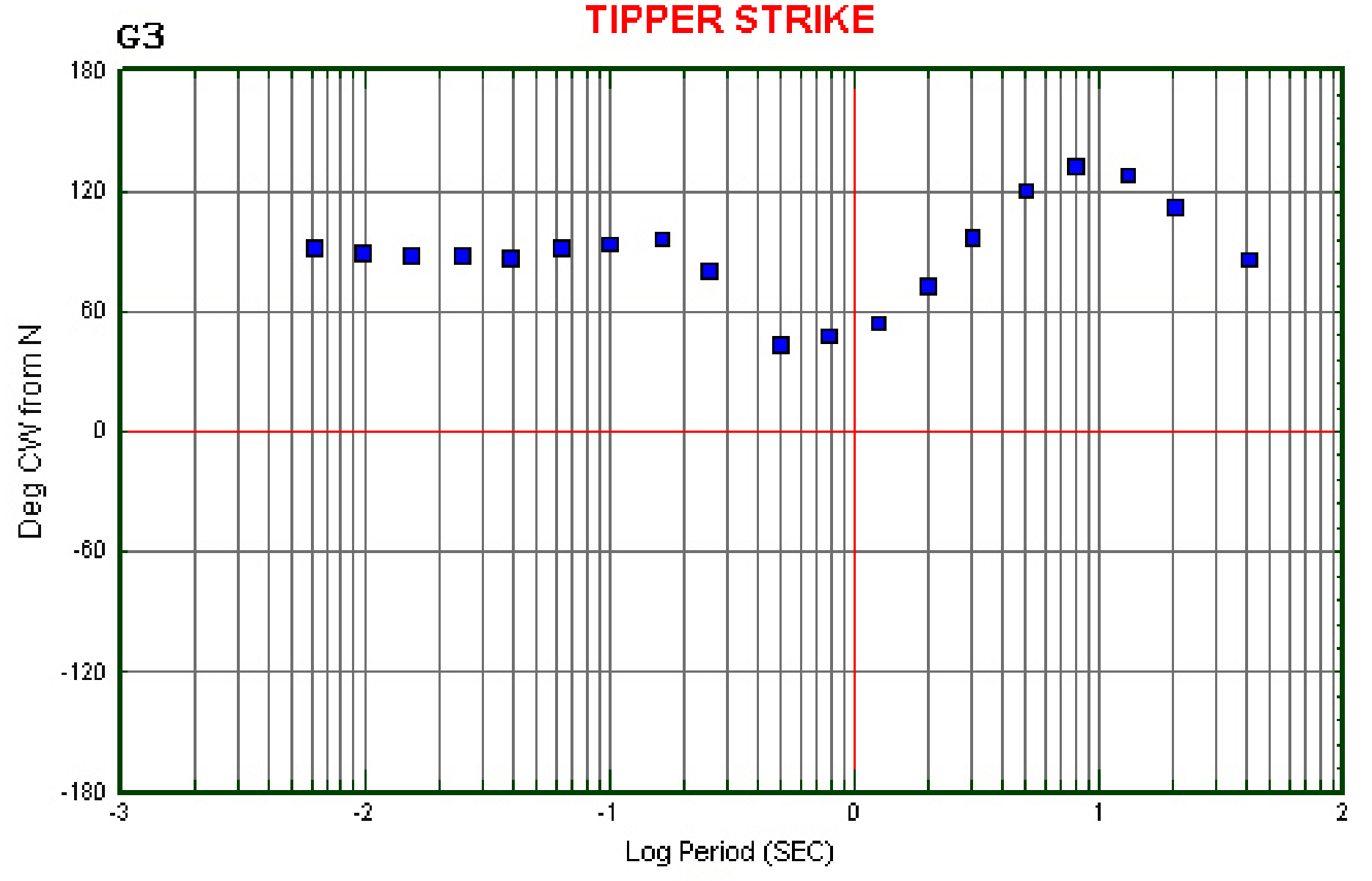




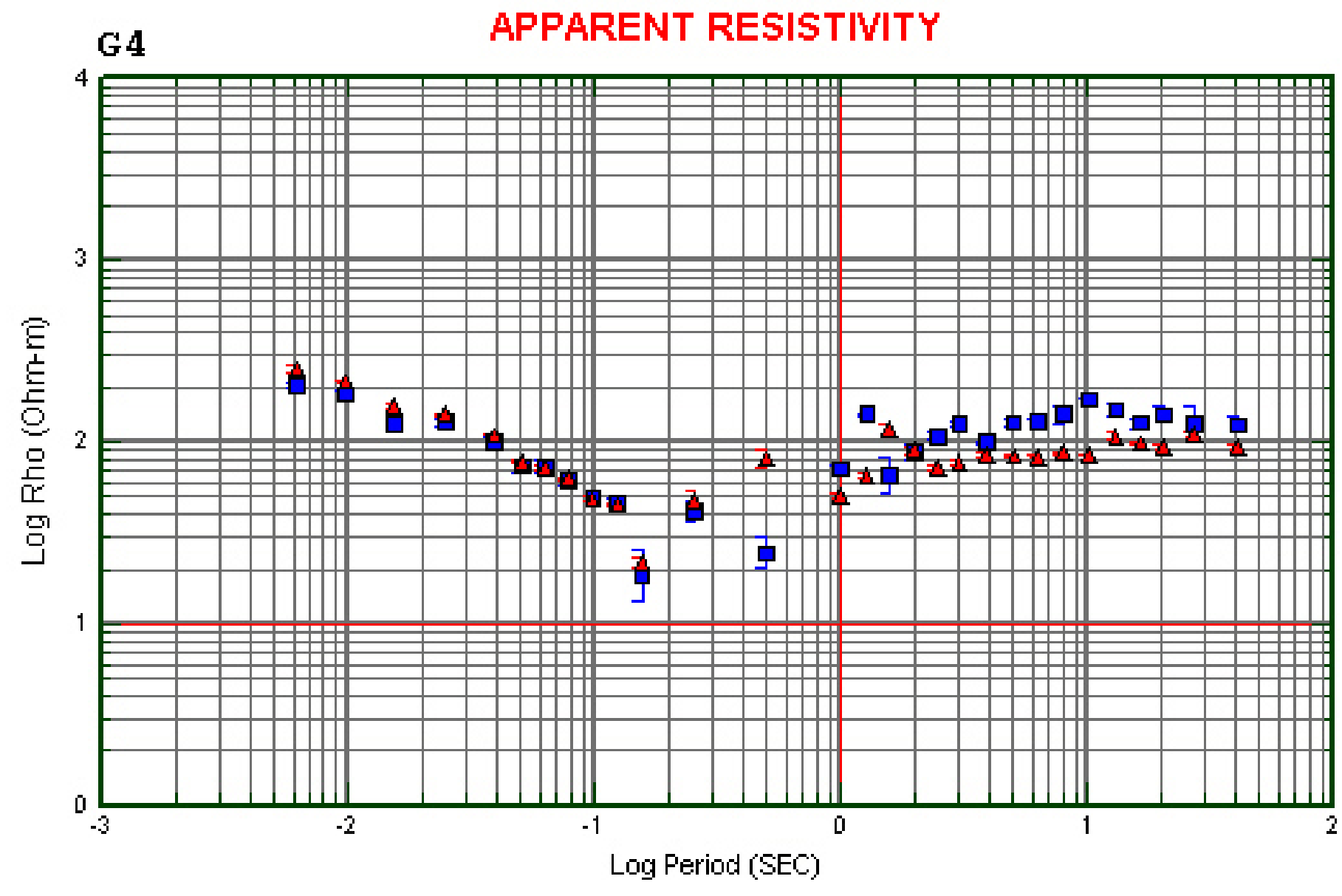

- Rho $X Y$

$\Delta$ Rho $Y x$ 


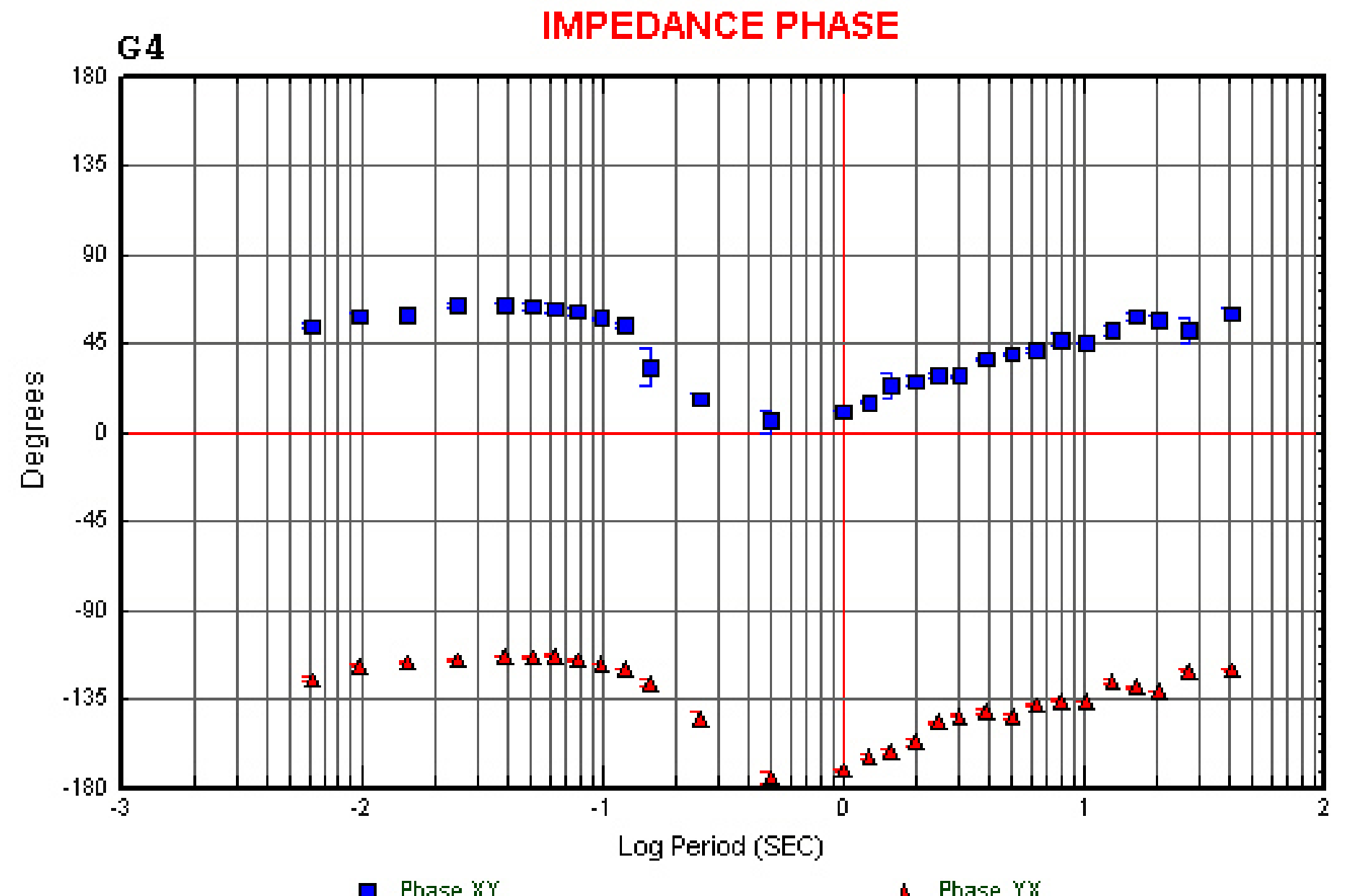




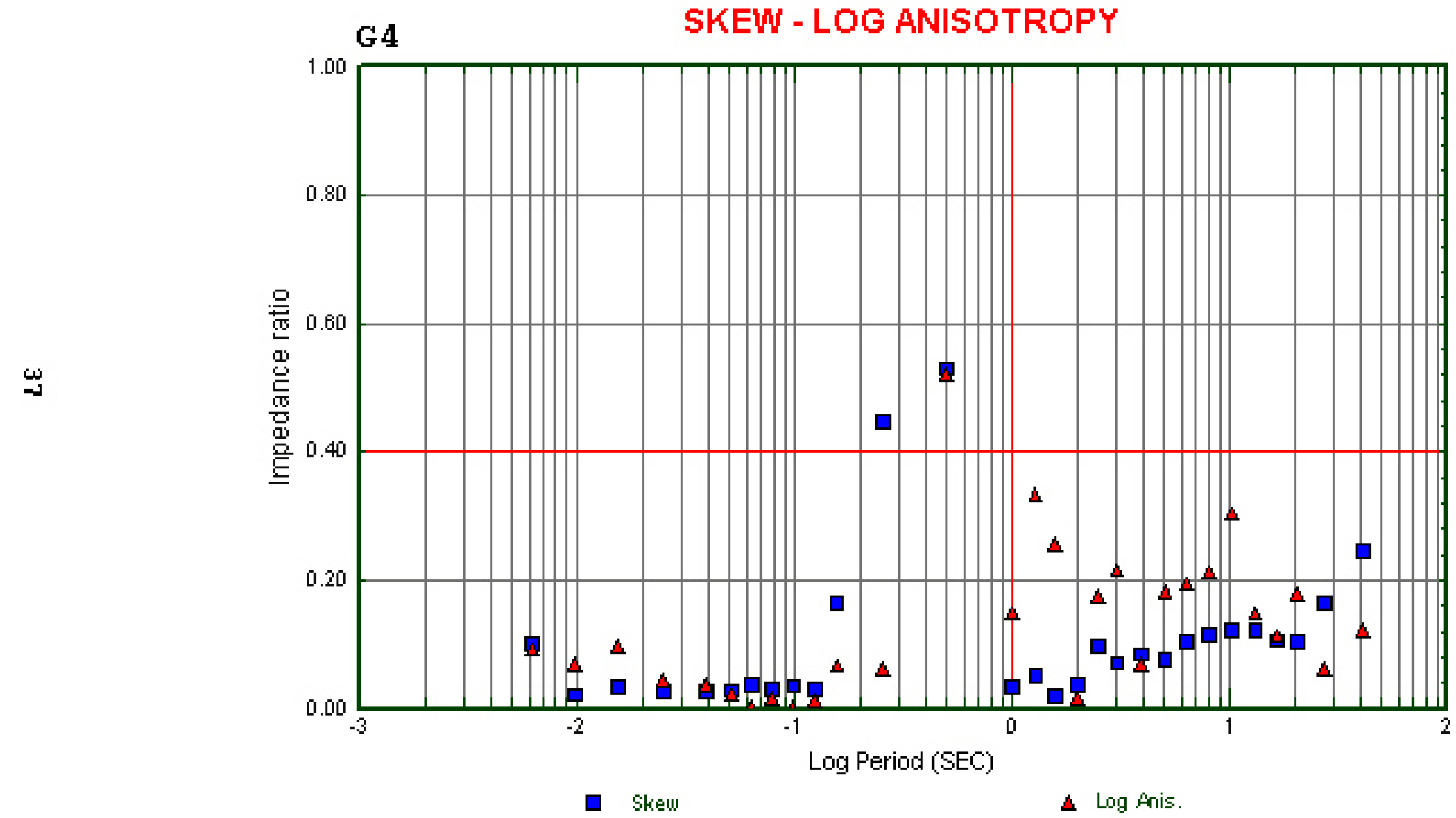


$\stackrel{\uplus}{\infty}$

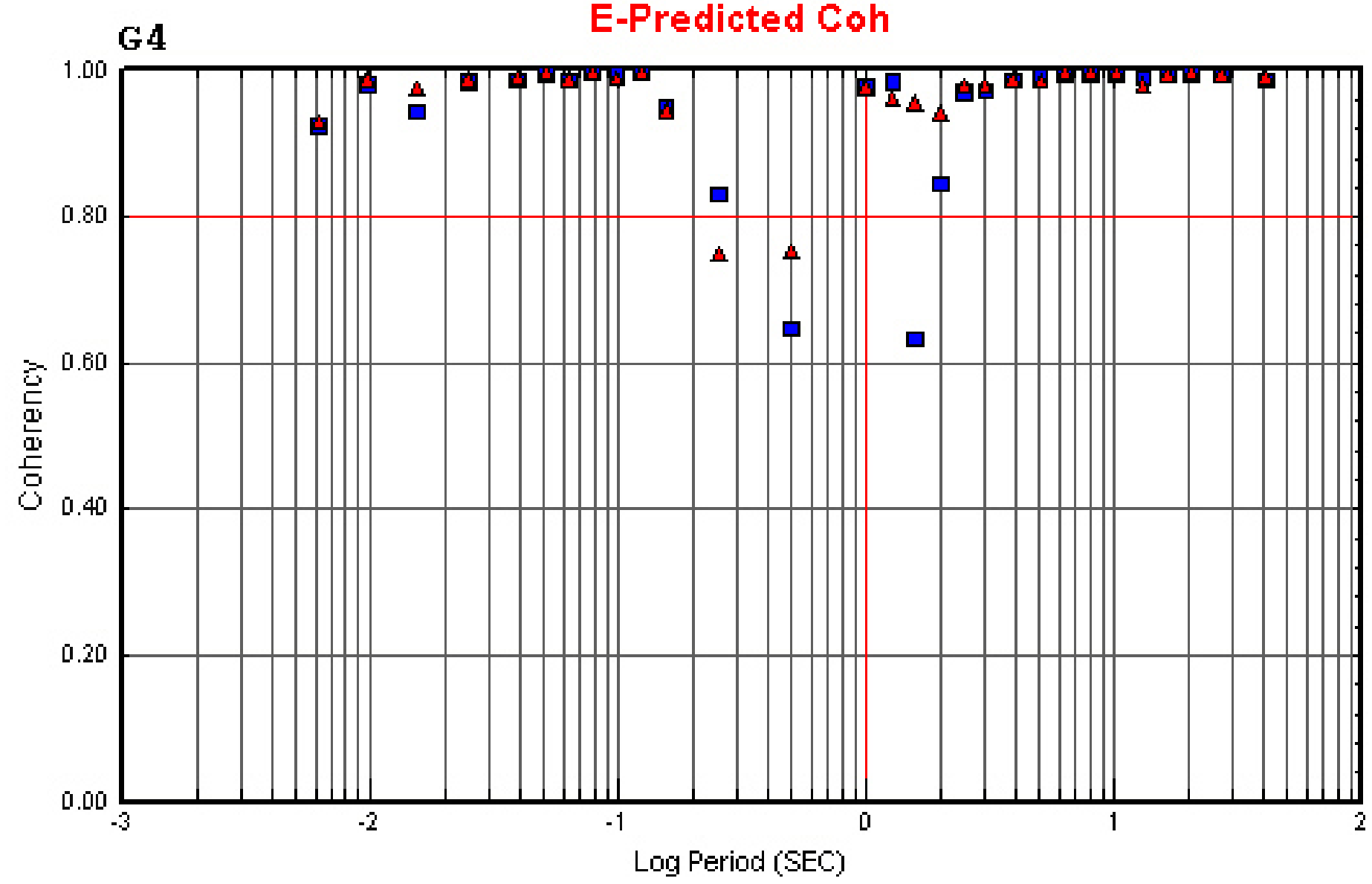

- Ex-HxHy

A Ey- $\mathrm{HxHy}$ 


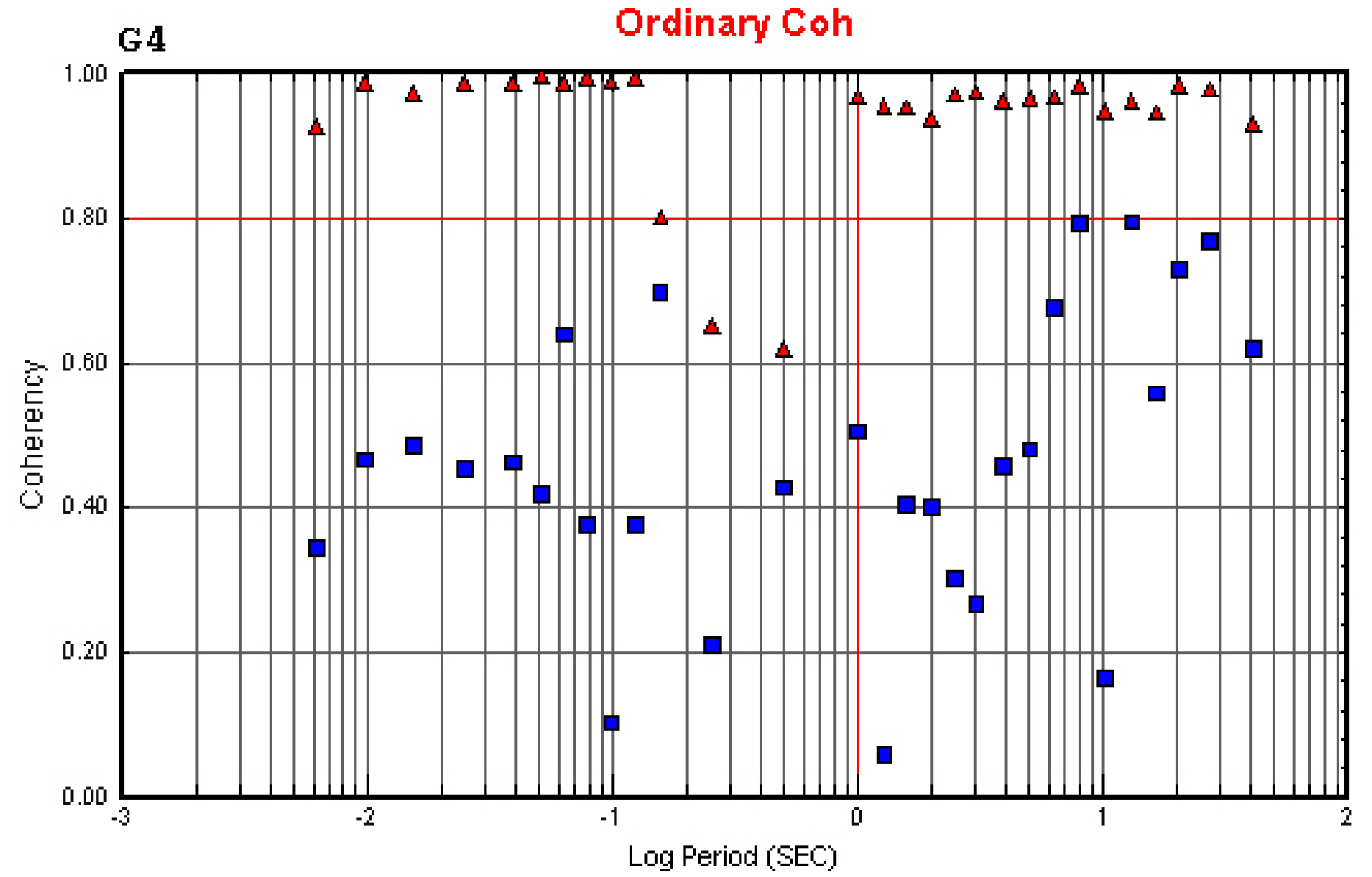

a $\mathrm{H} x-\mathrm{Ex}$

A $\mathrm{H} x-\mathrm{E} y$ 


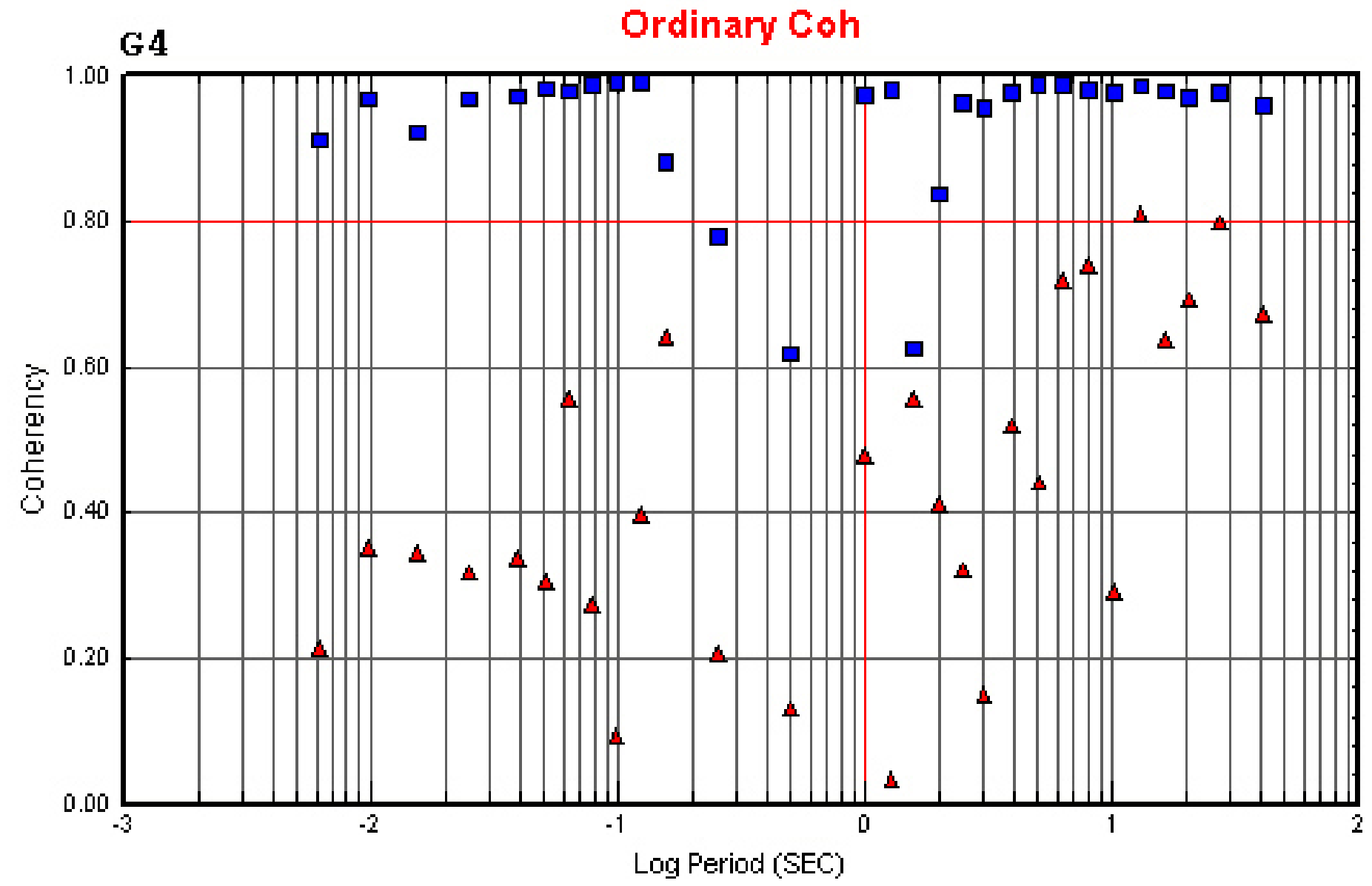

- $\mathrm{Hy}$-Ex

A Hy-Ey 


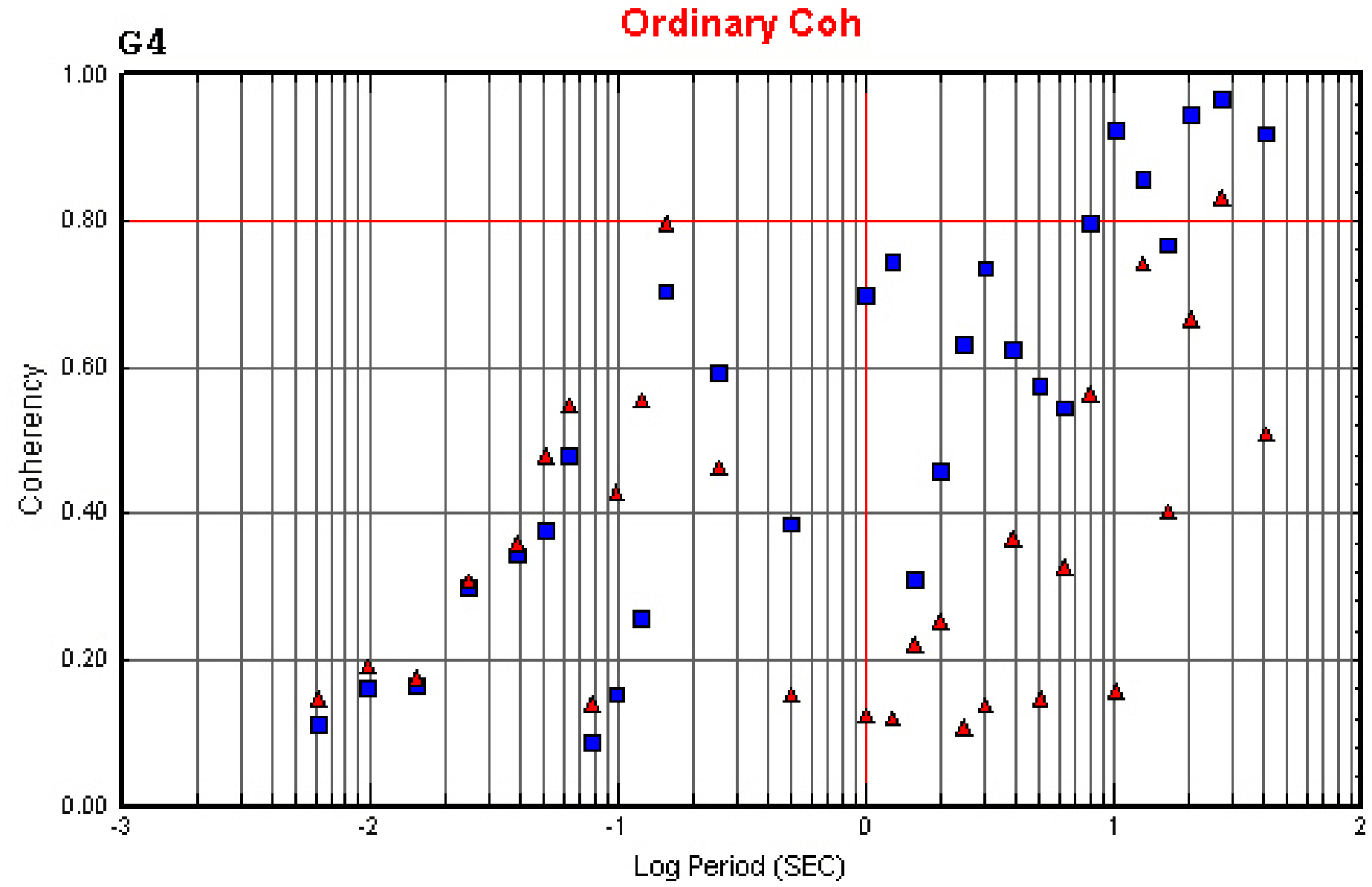




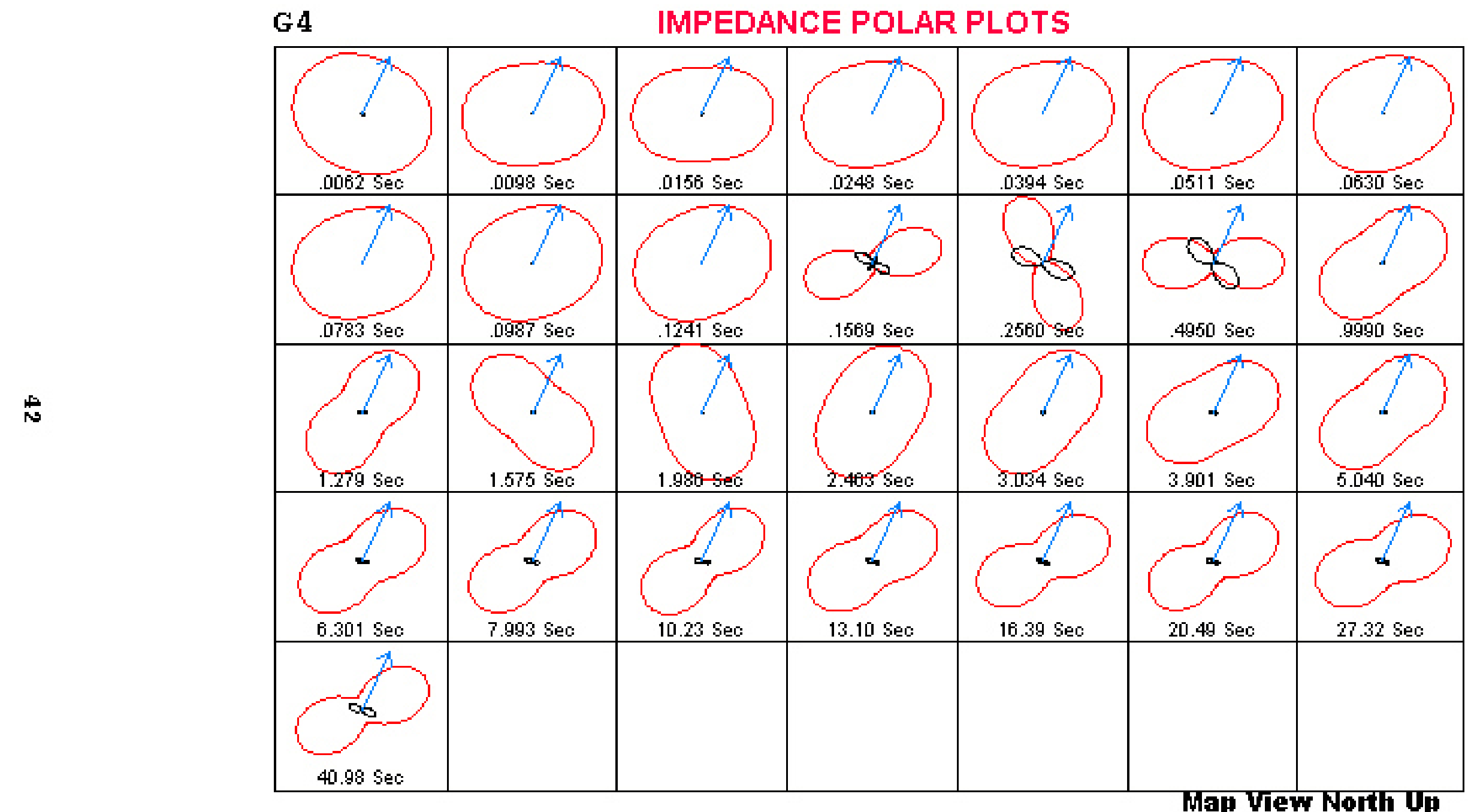




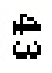

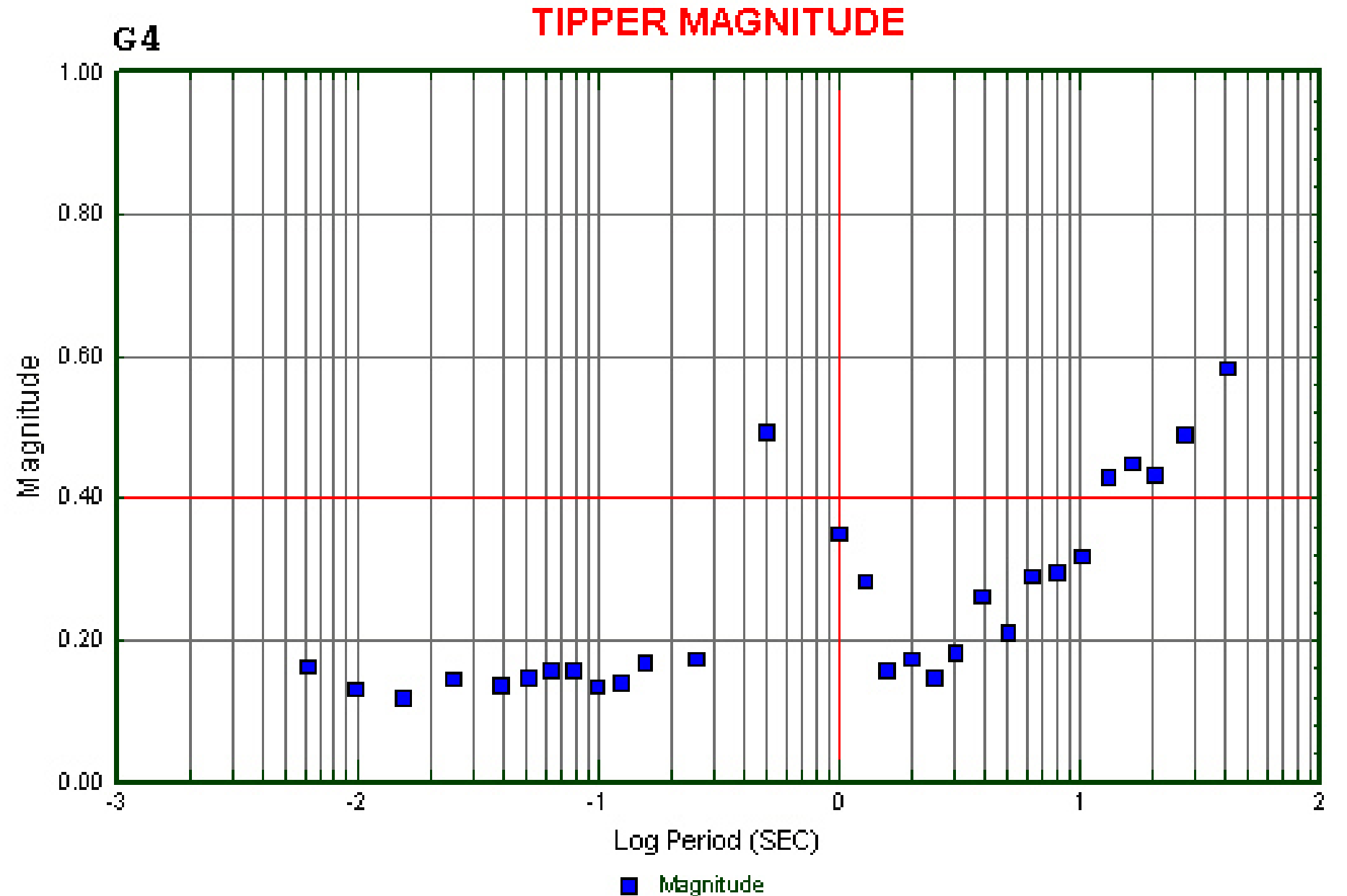




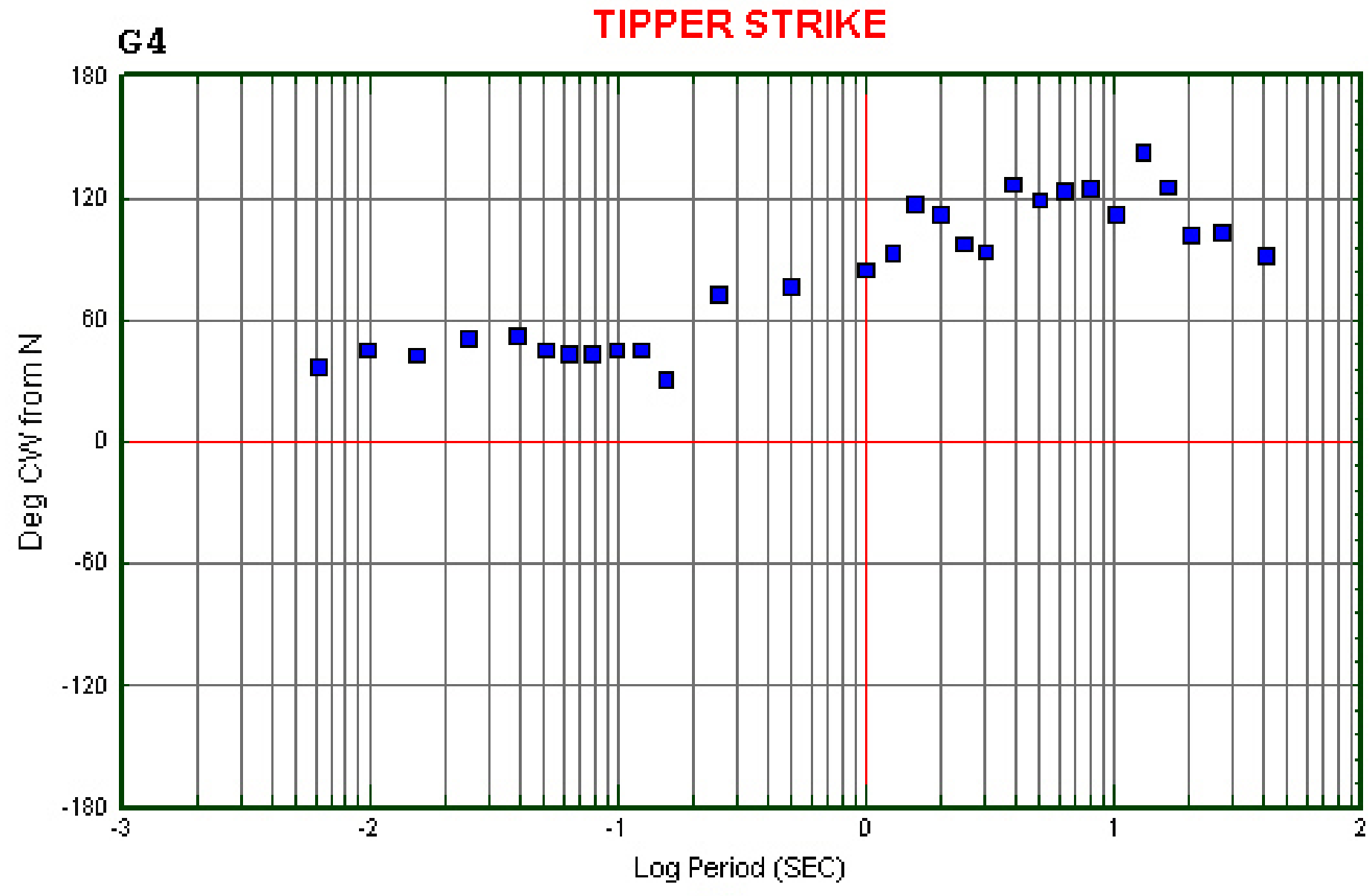




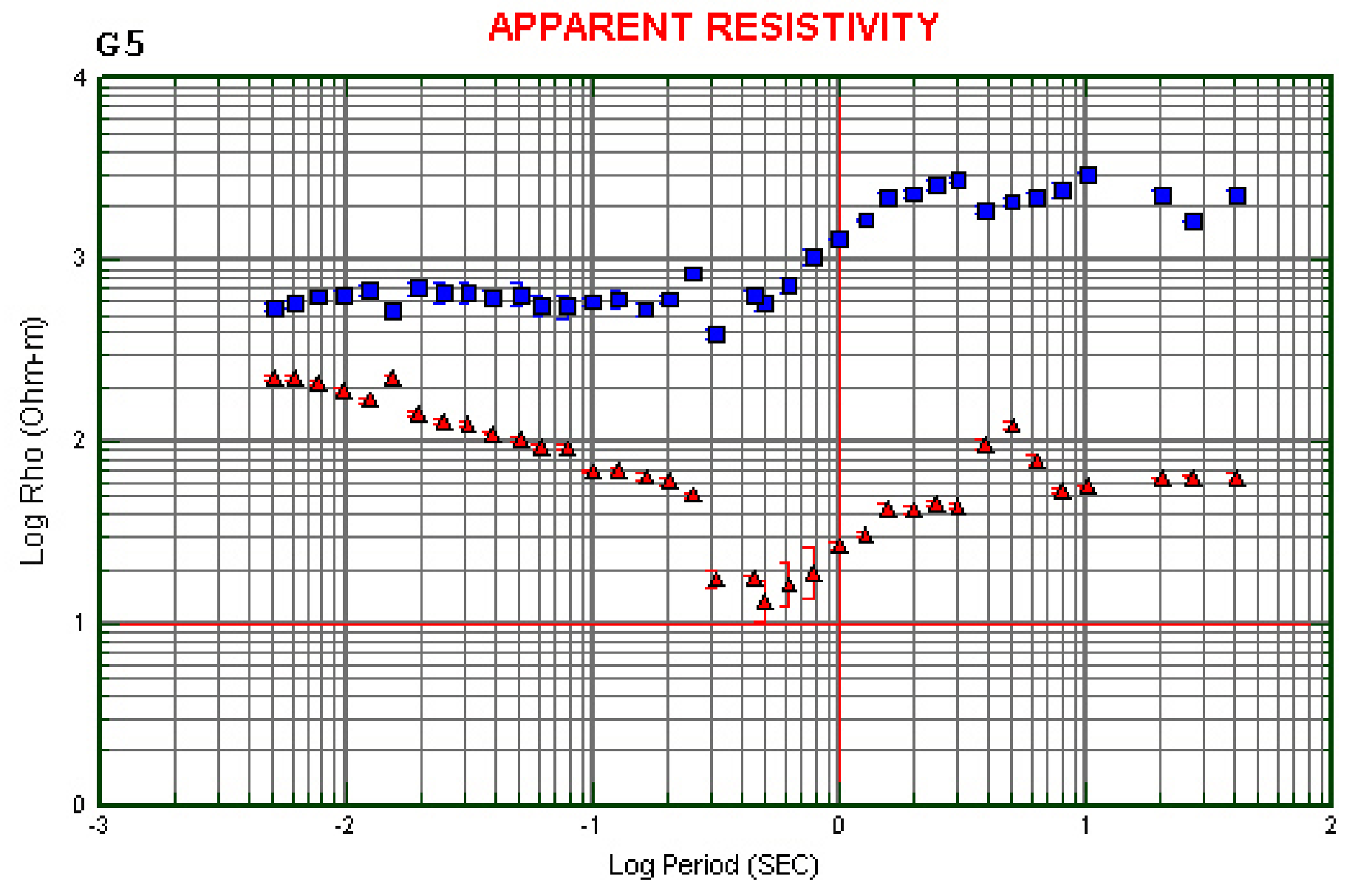

- Rho $X Y$

$\Delta$ Rho $Y x$ 


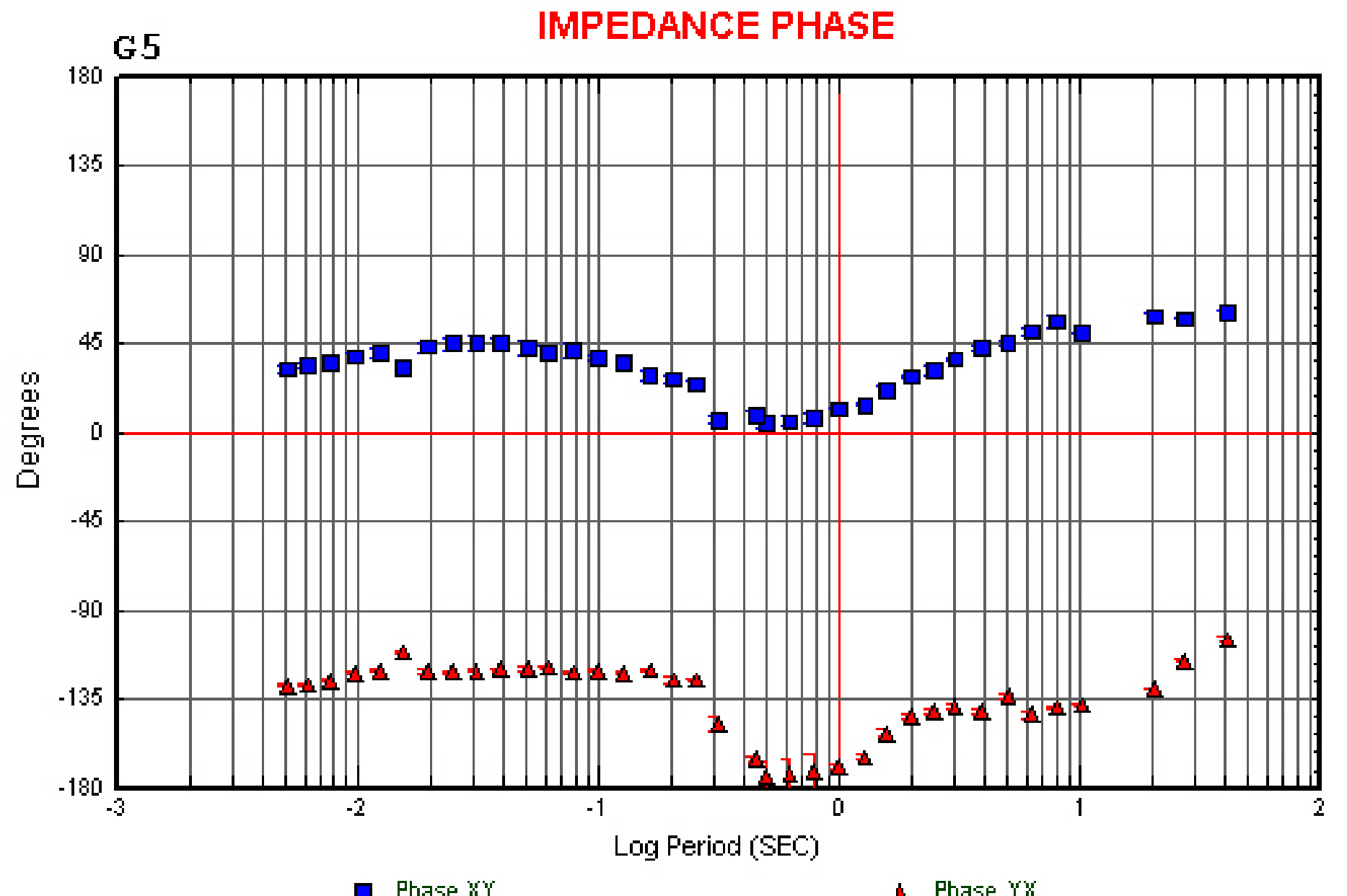




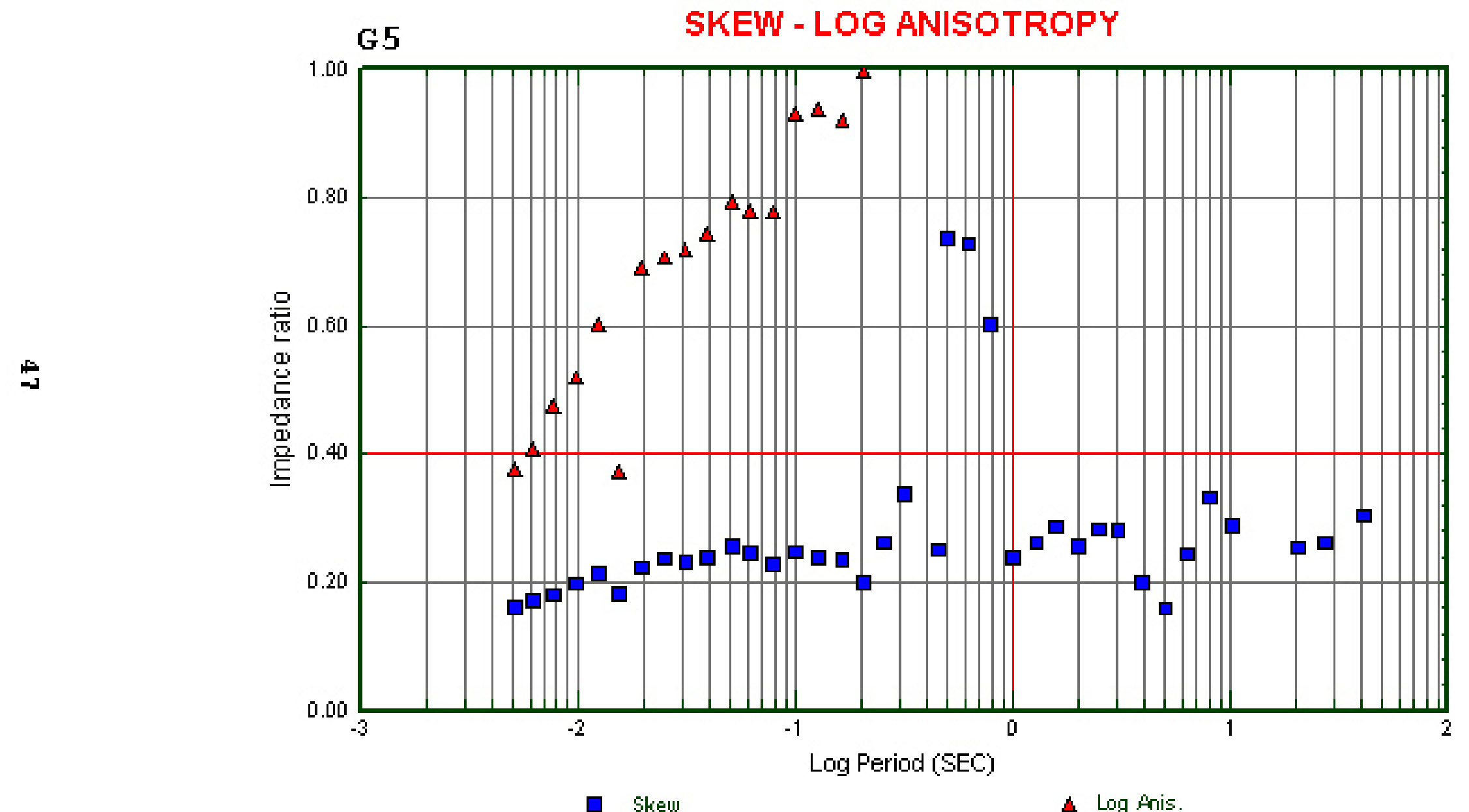




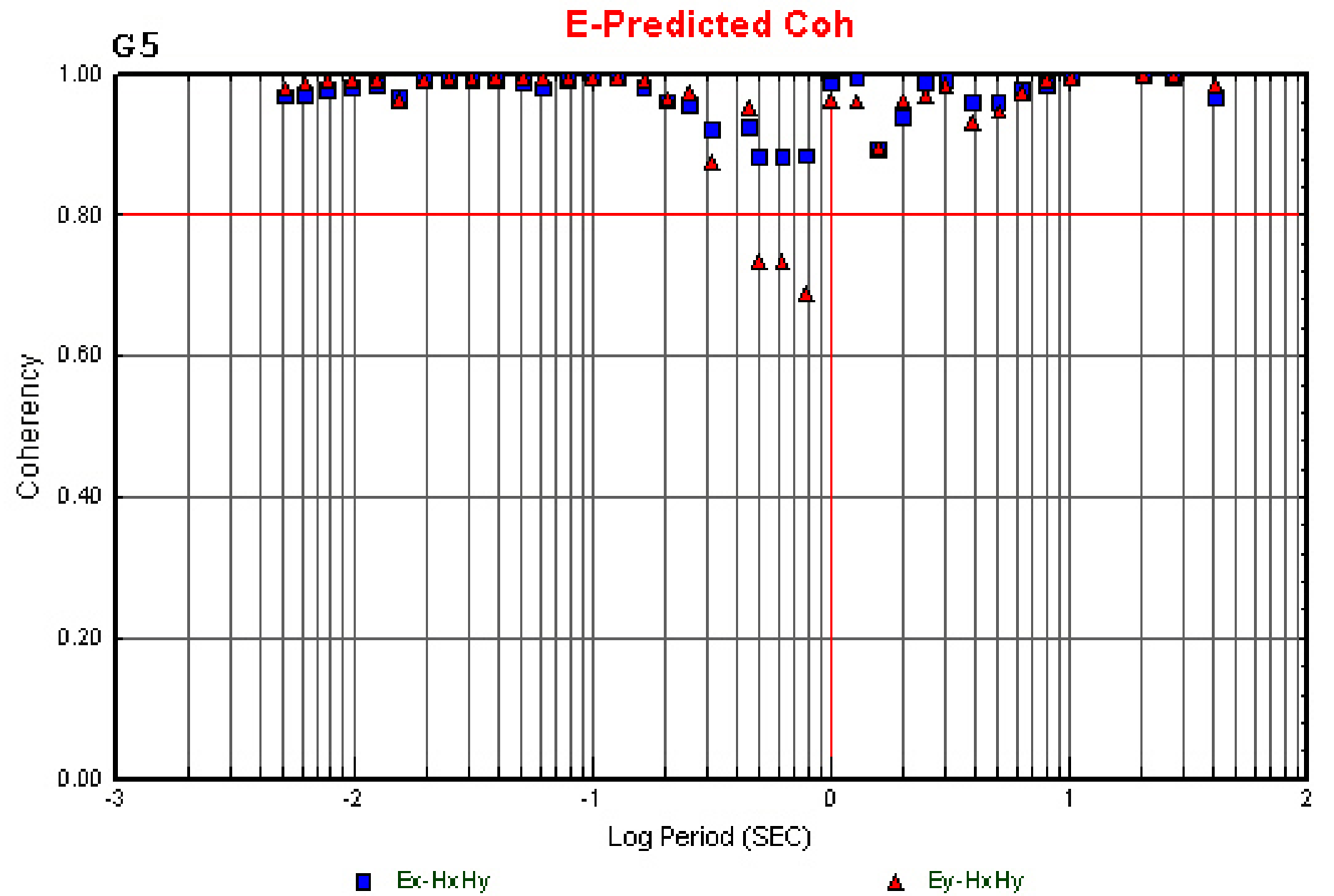




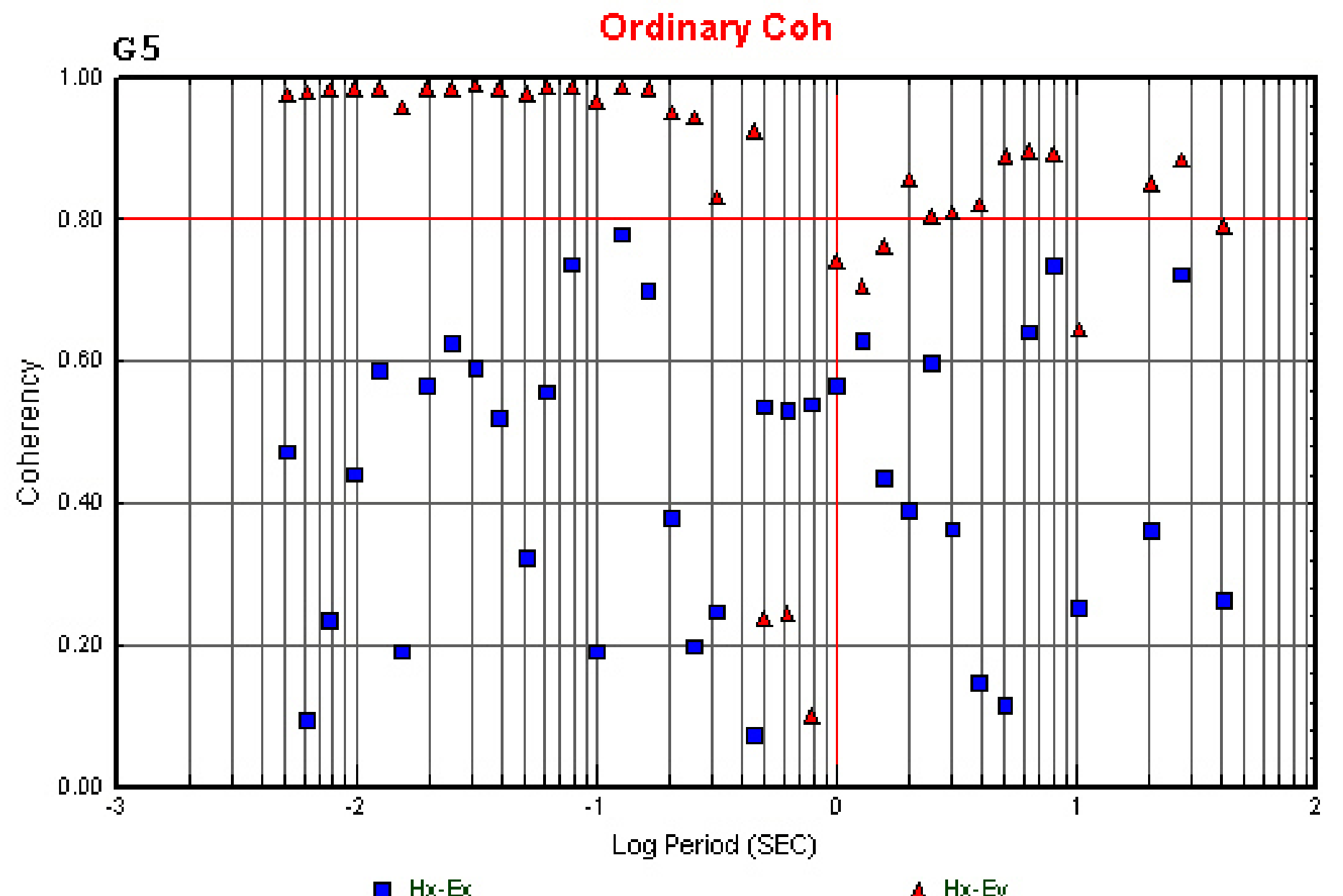




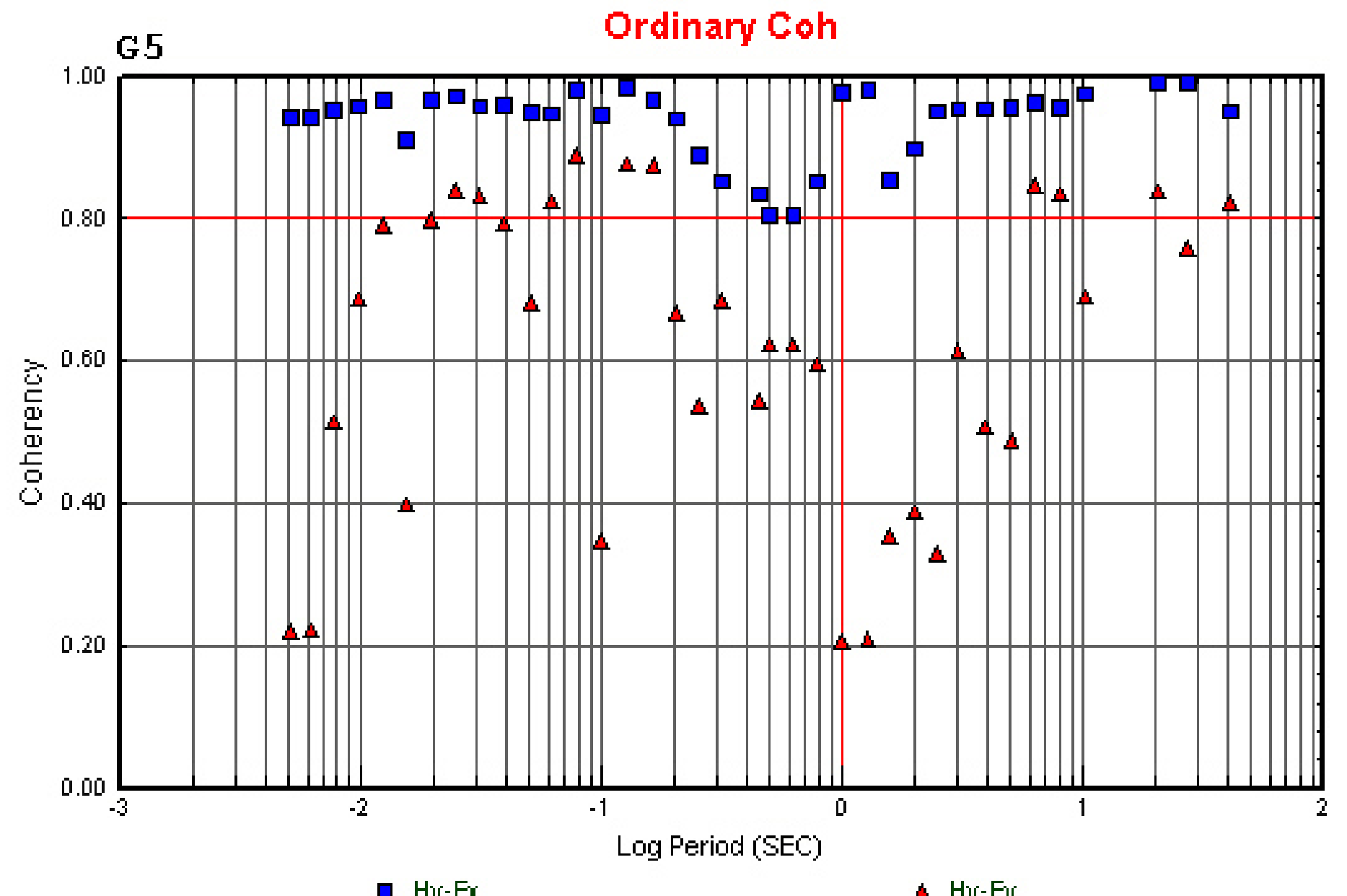




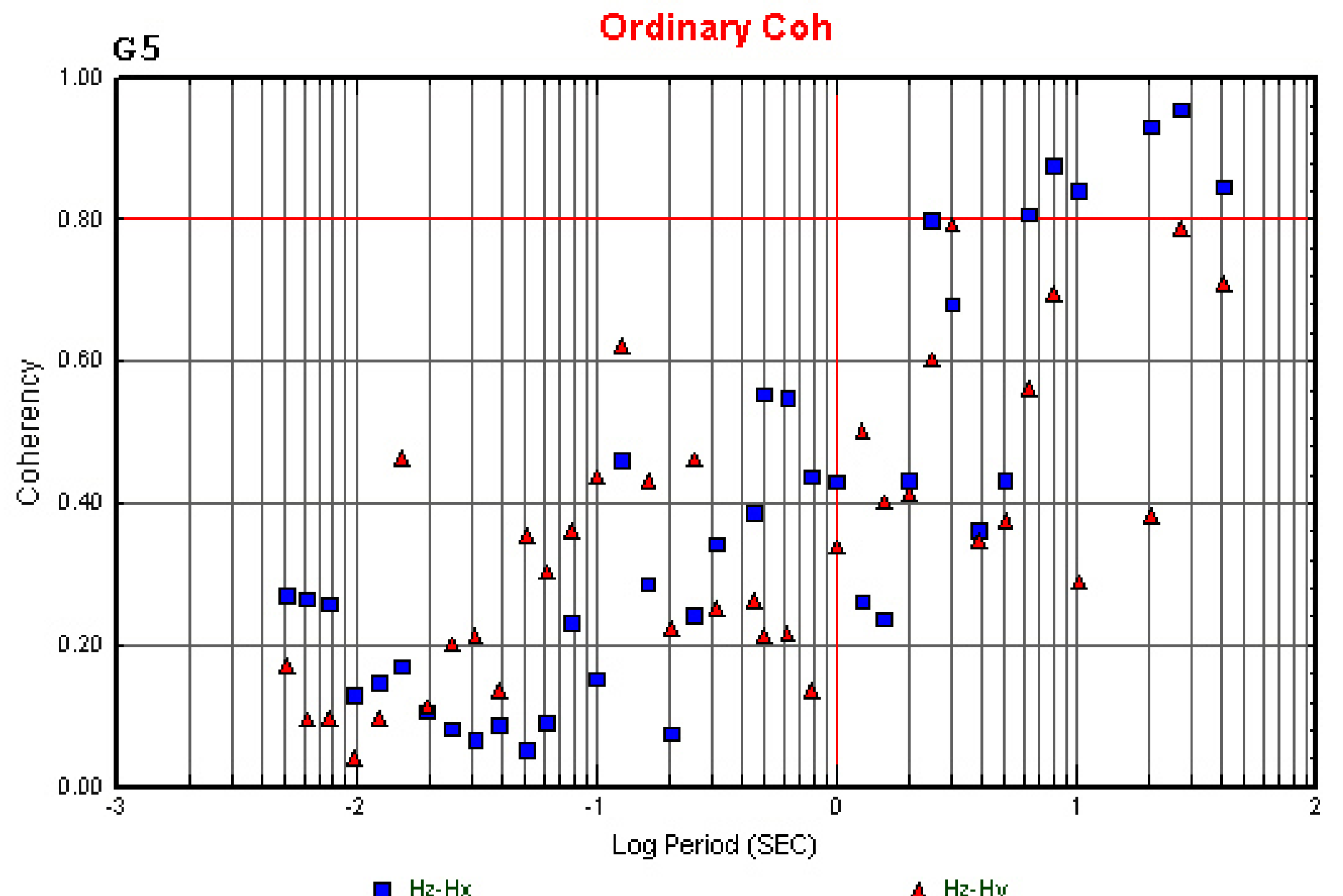




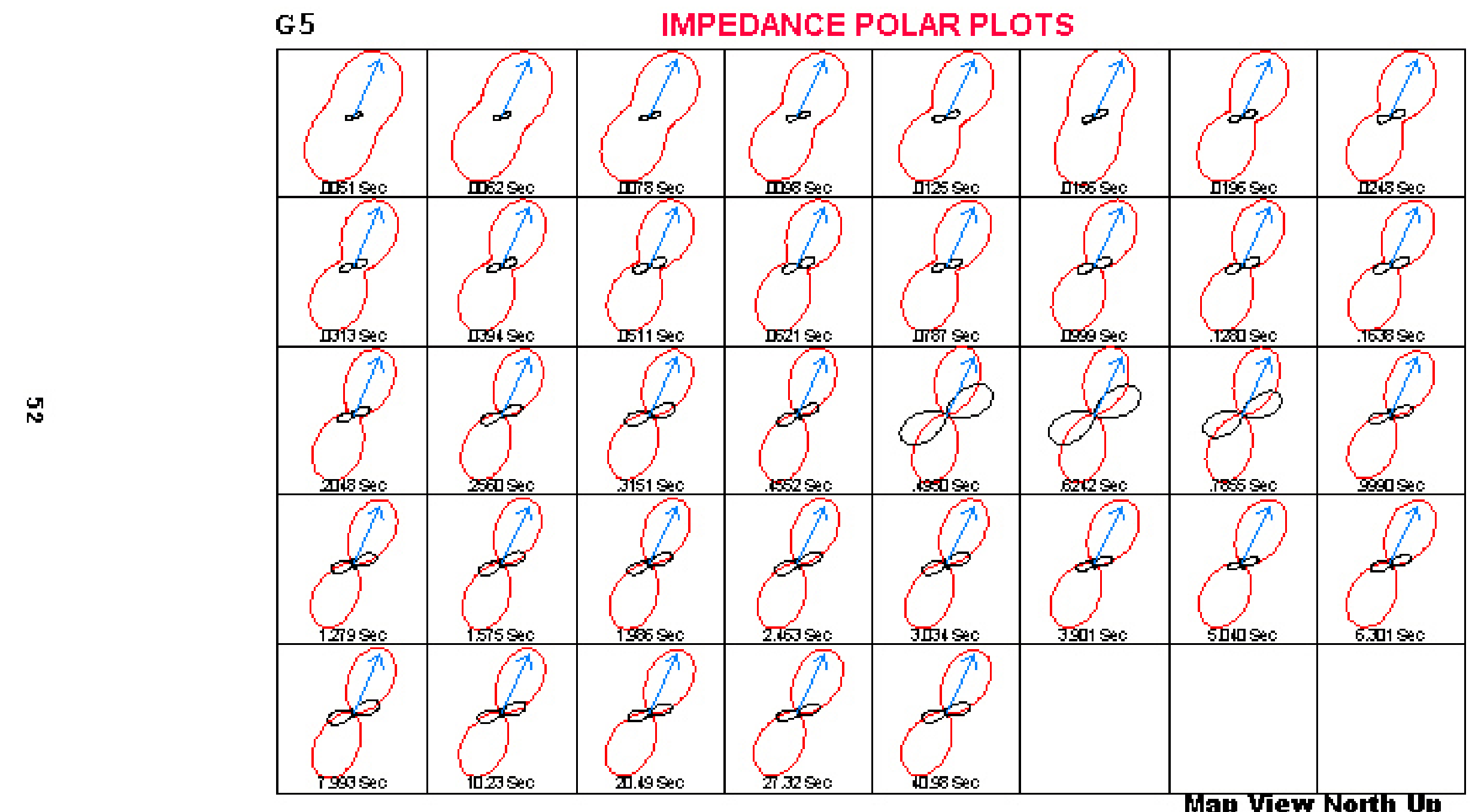

Map Vew North Up 


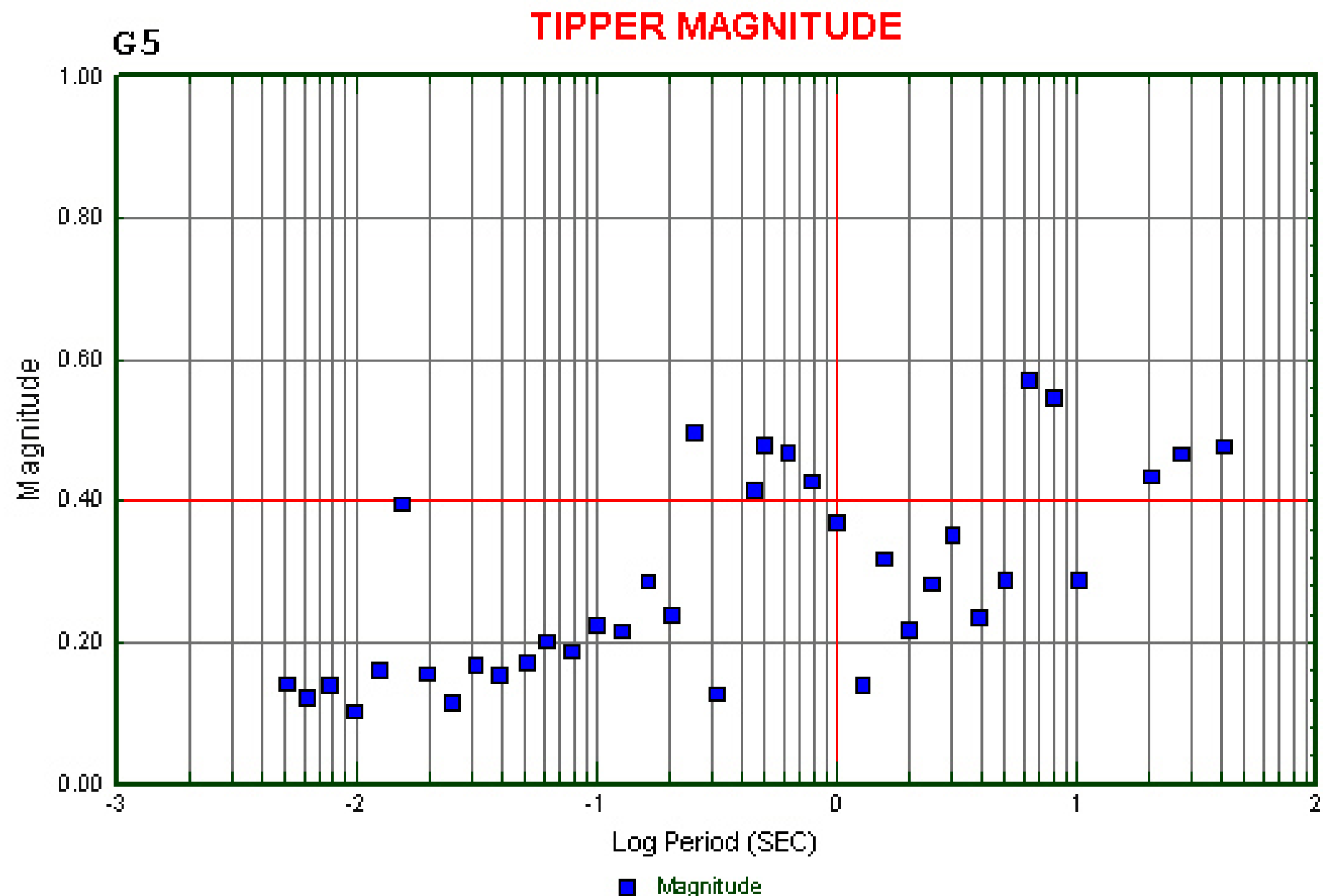




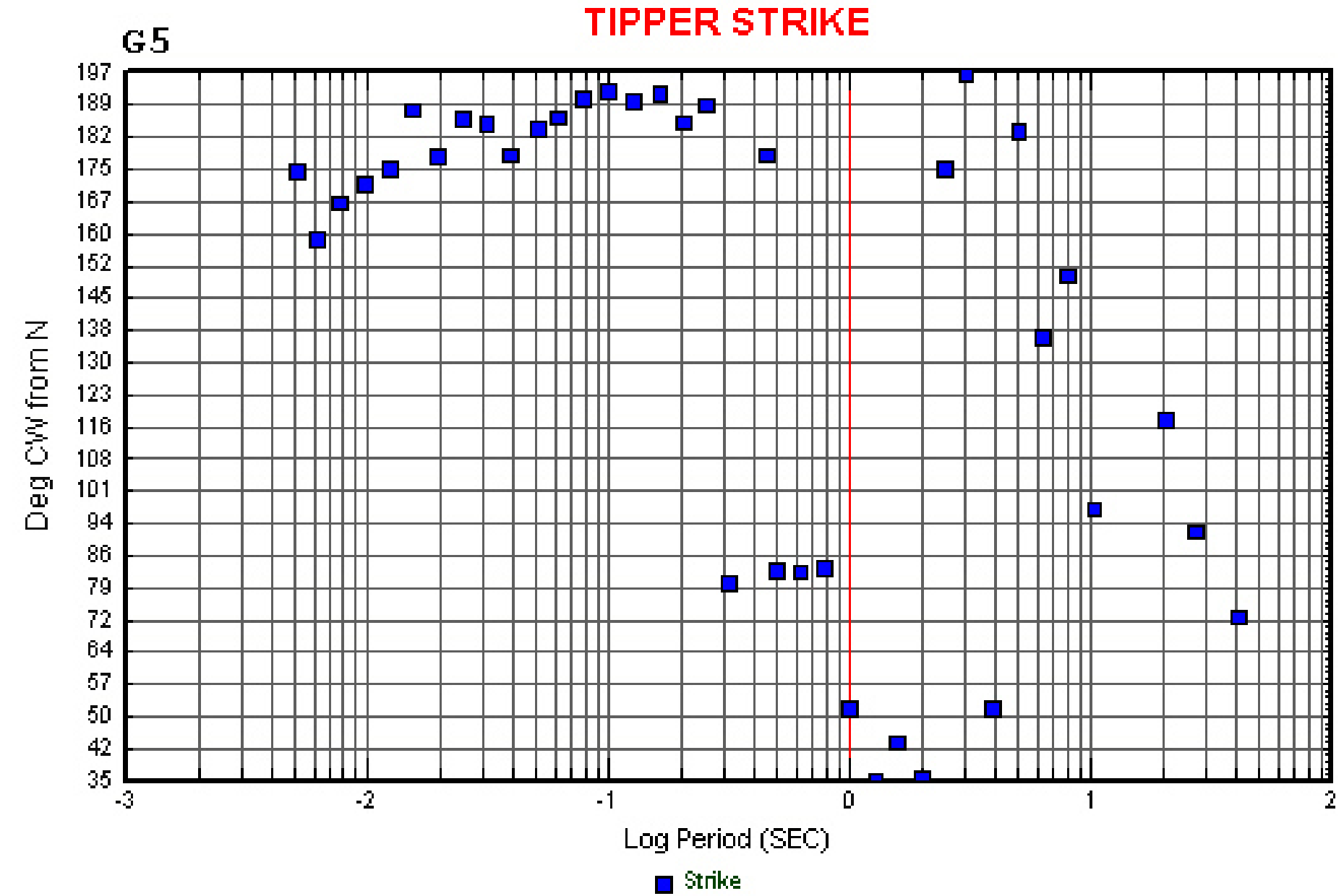

- Strike 


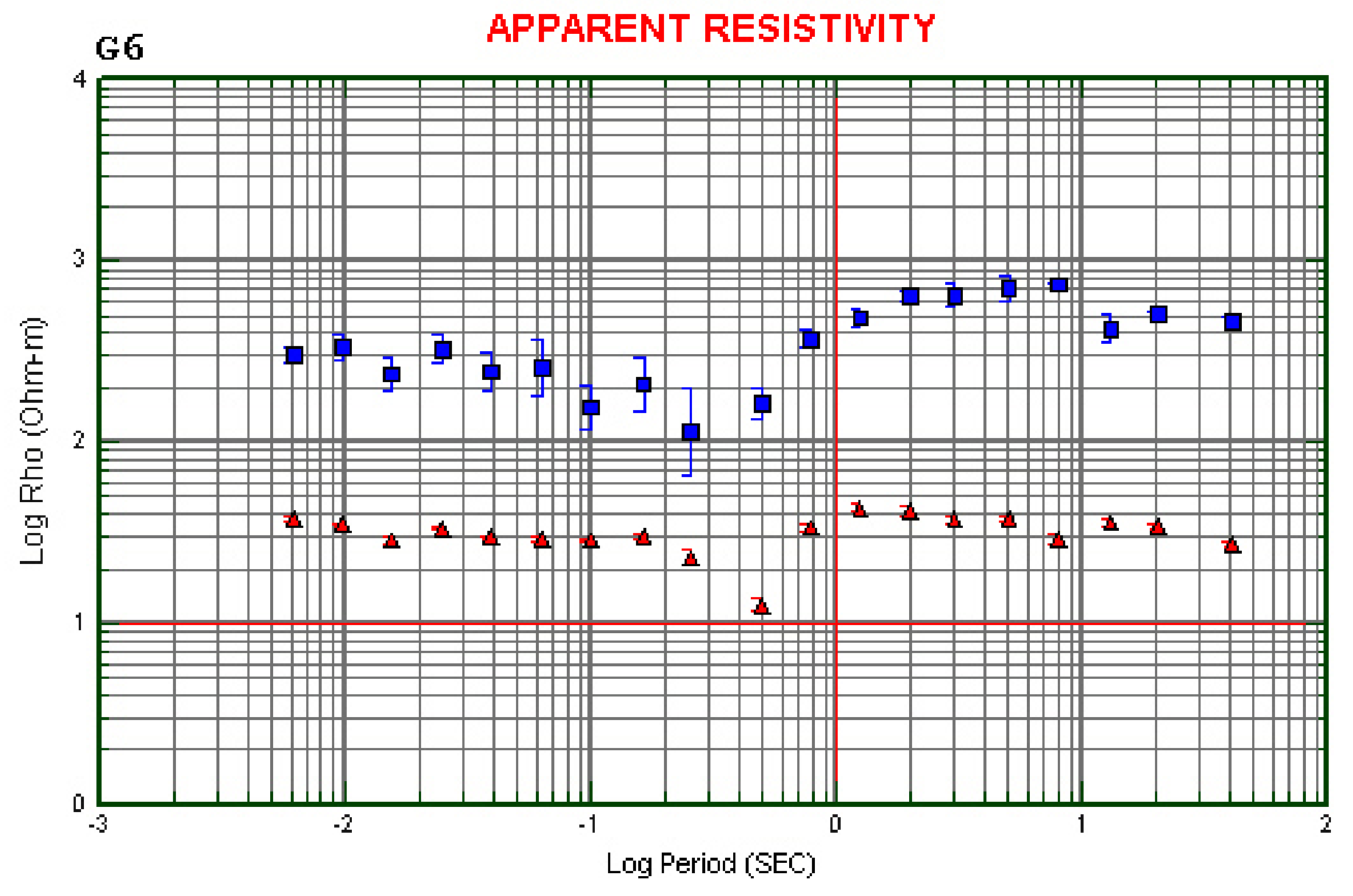

- Rho $X Y$

$\Delta$ Rho $Y x$ 
ज

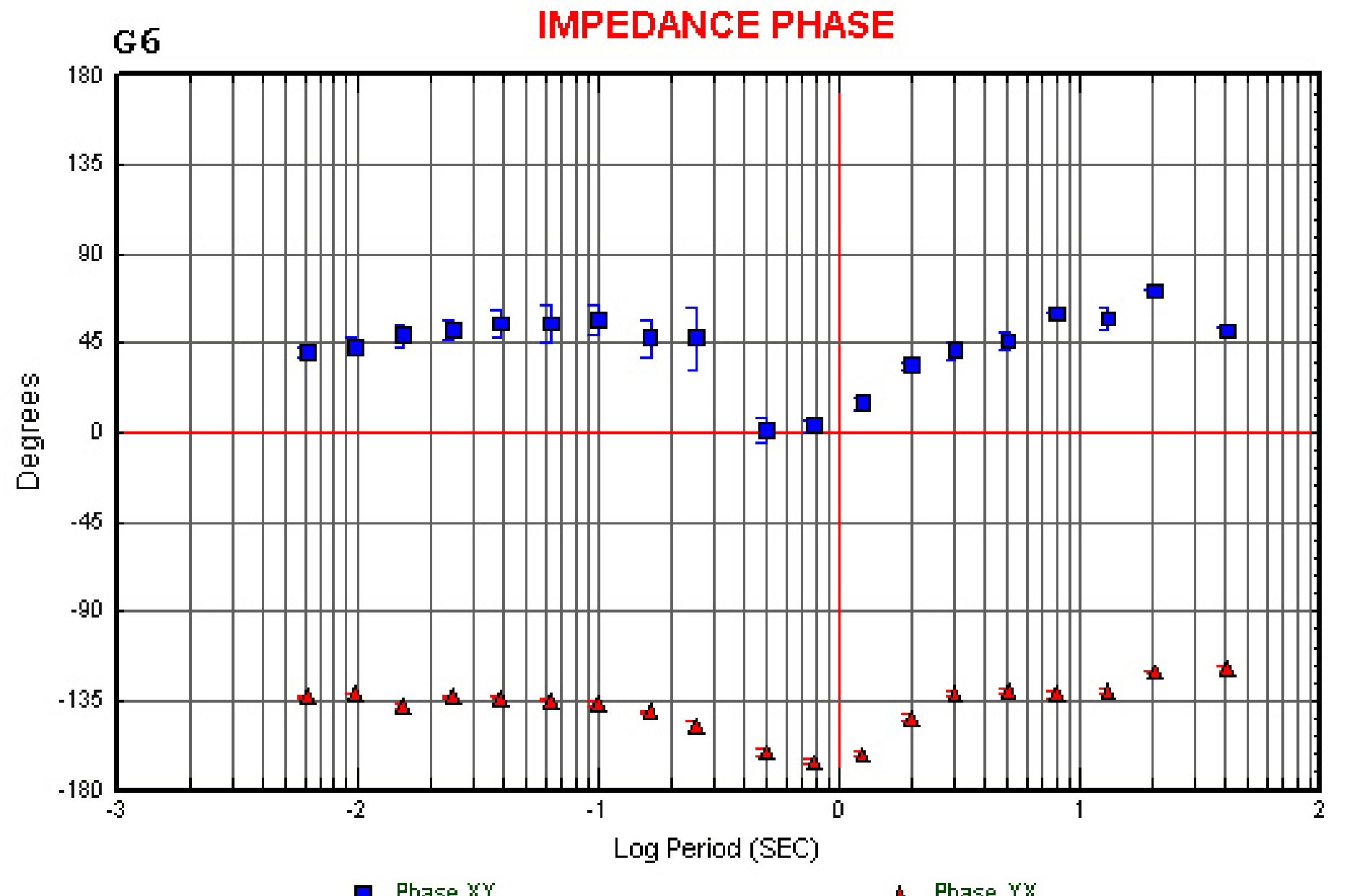




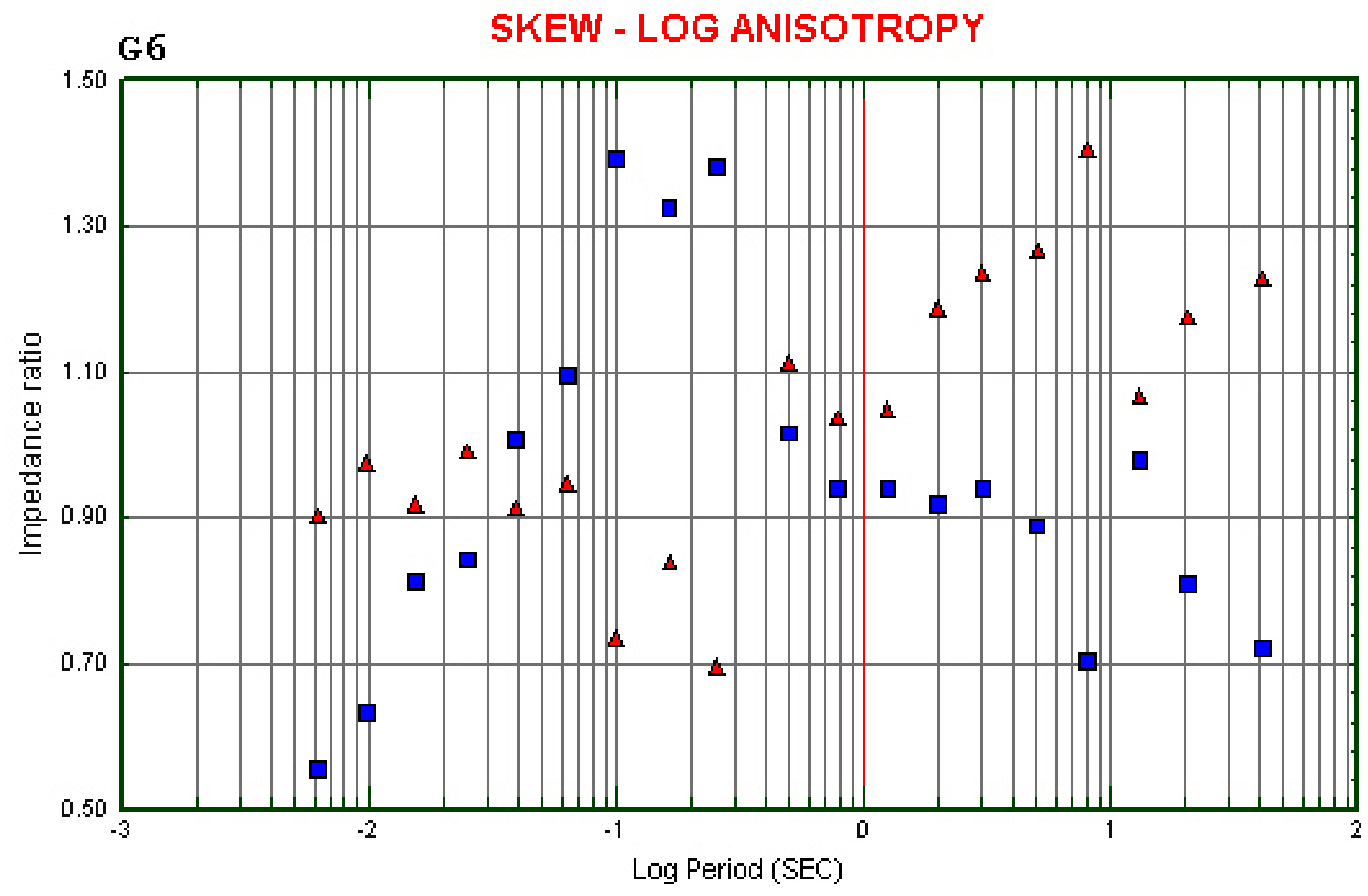




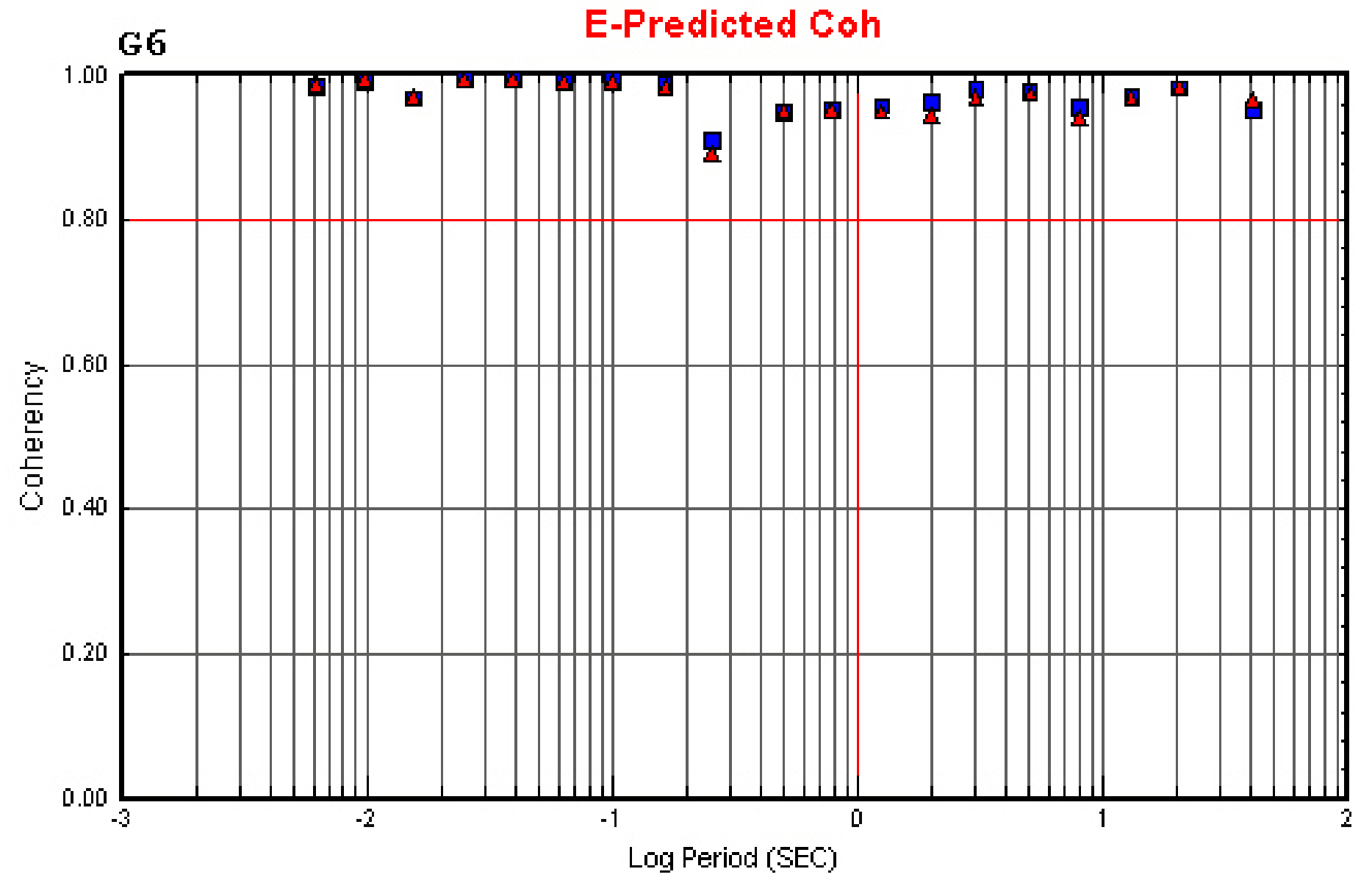

- Ex-HxHy

A Ey- $\mathrm{HxHy}$ 


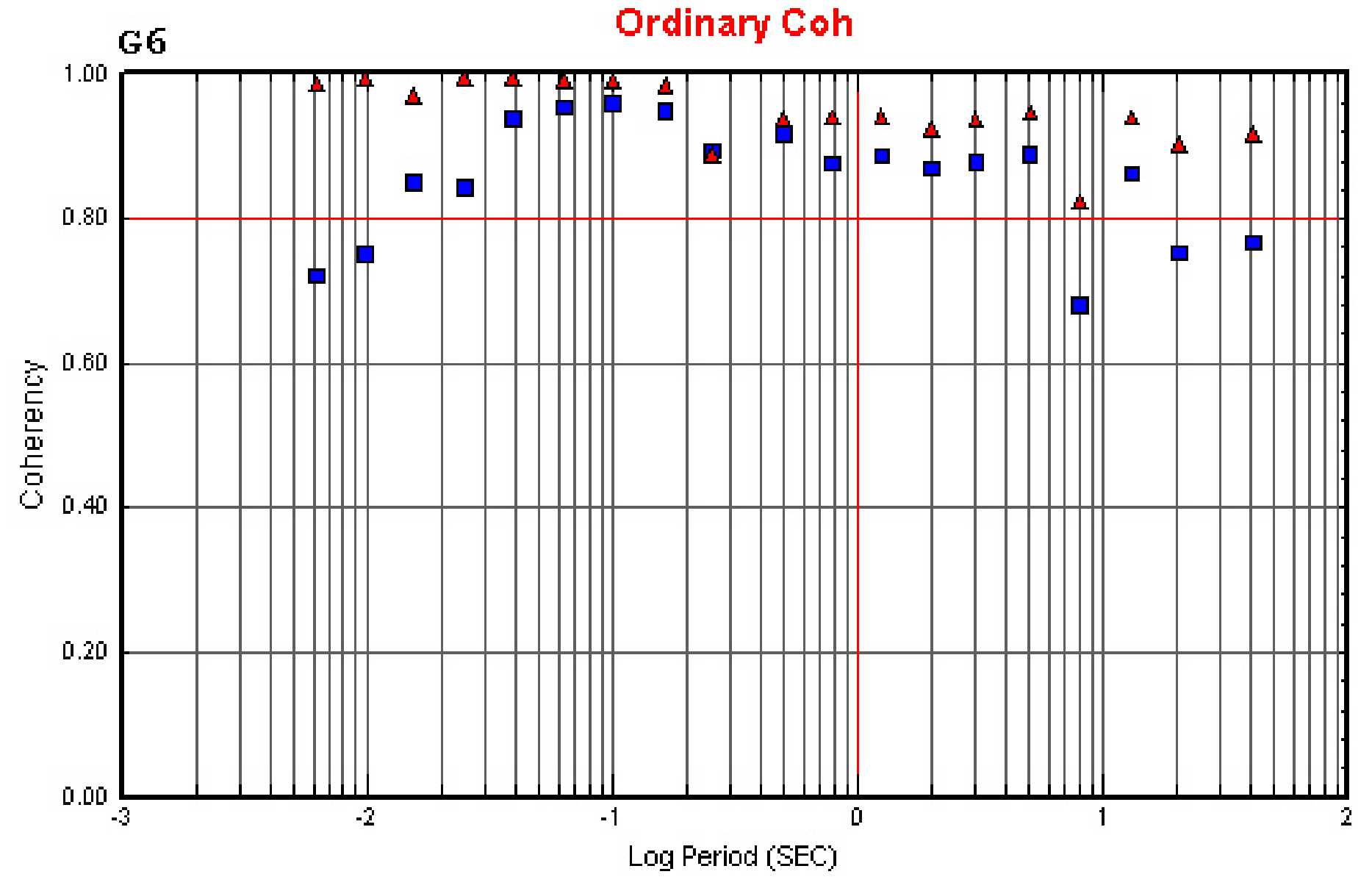

a $\mathrm{H} x-\mathrm{Ex}$

A $\mathrm{Hx}-\mathrm{Ey}$ 
g

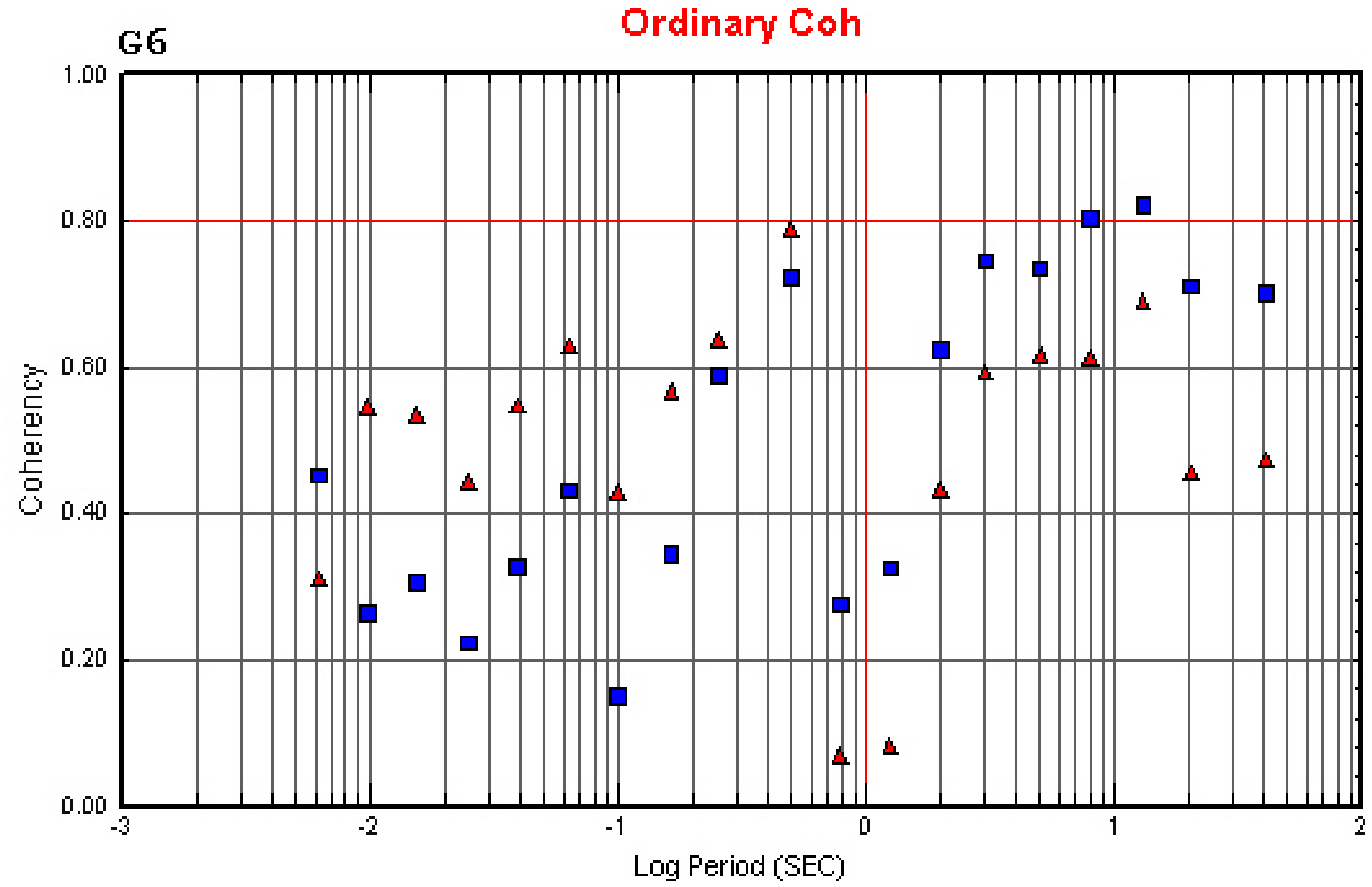

- $H y-E x$

A Hy-Ey 
9

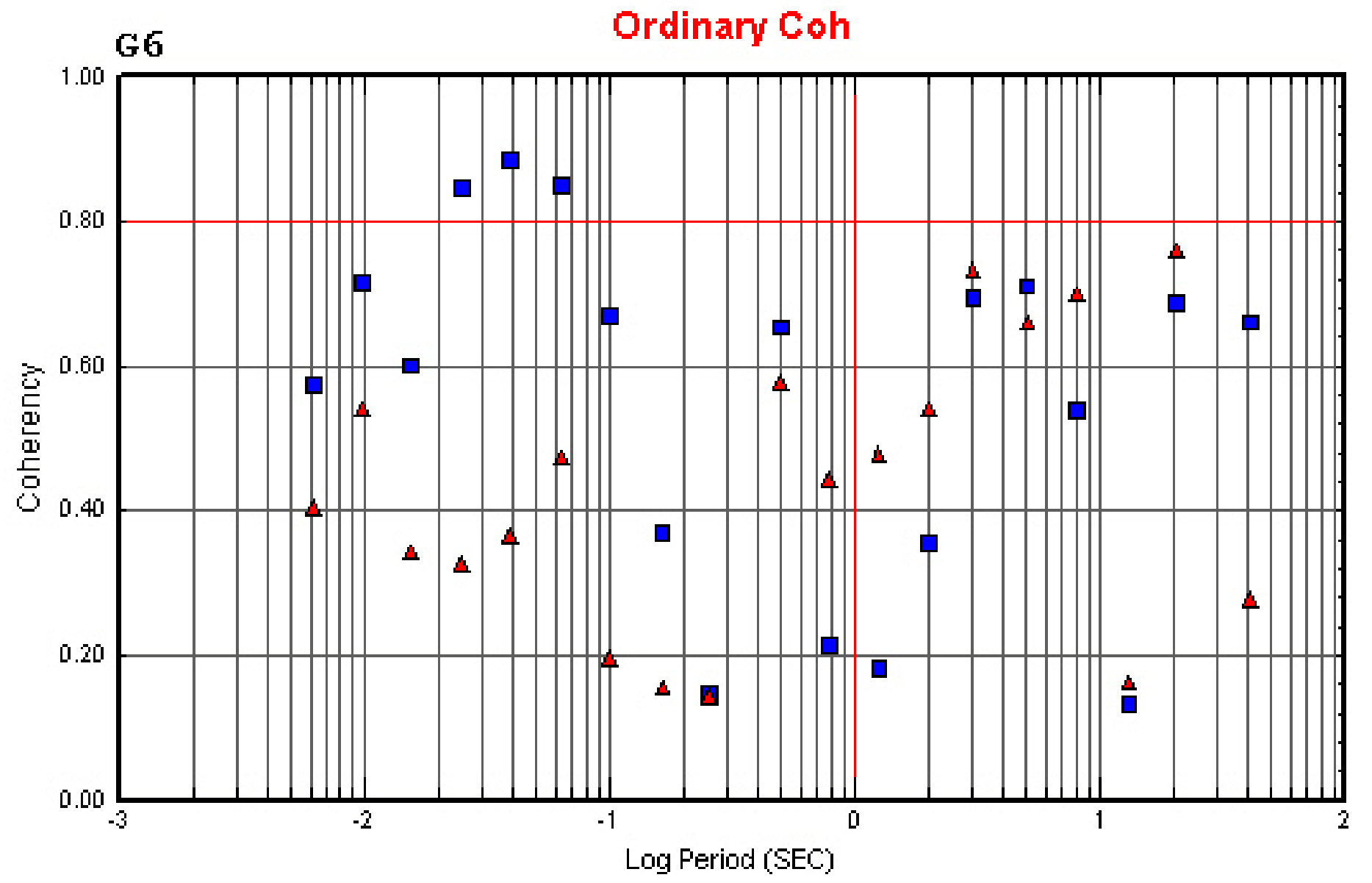

A $\mathrm{Hz}-\mathrm{Hy}$ 


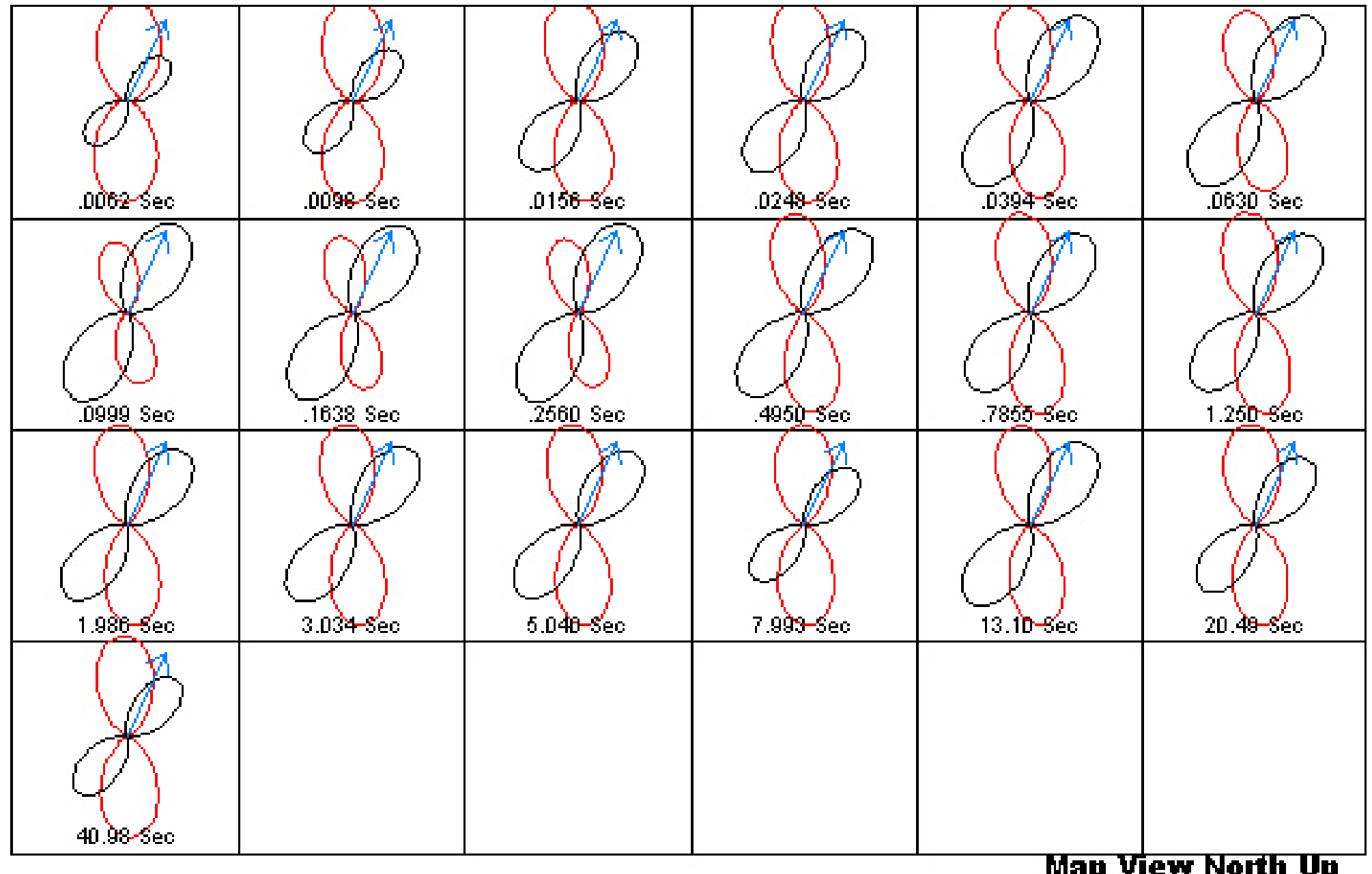


क

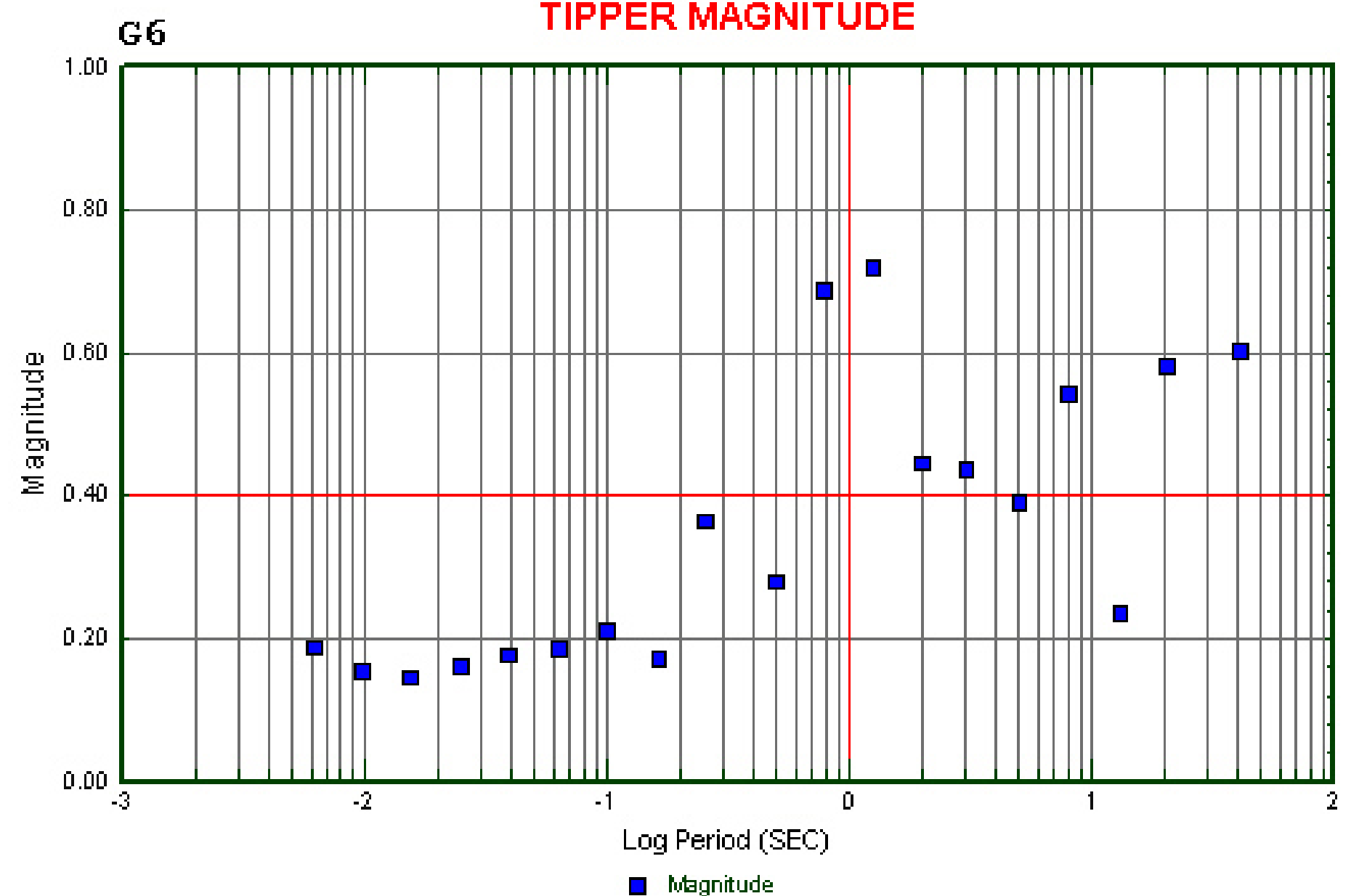


TIPPER STRIKE

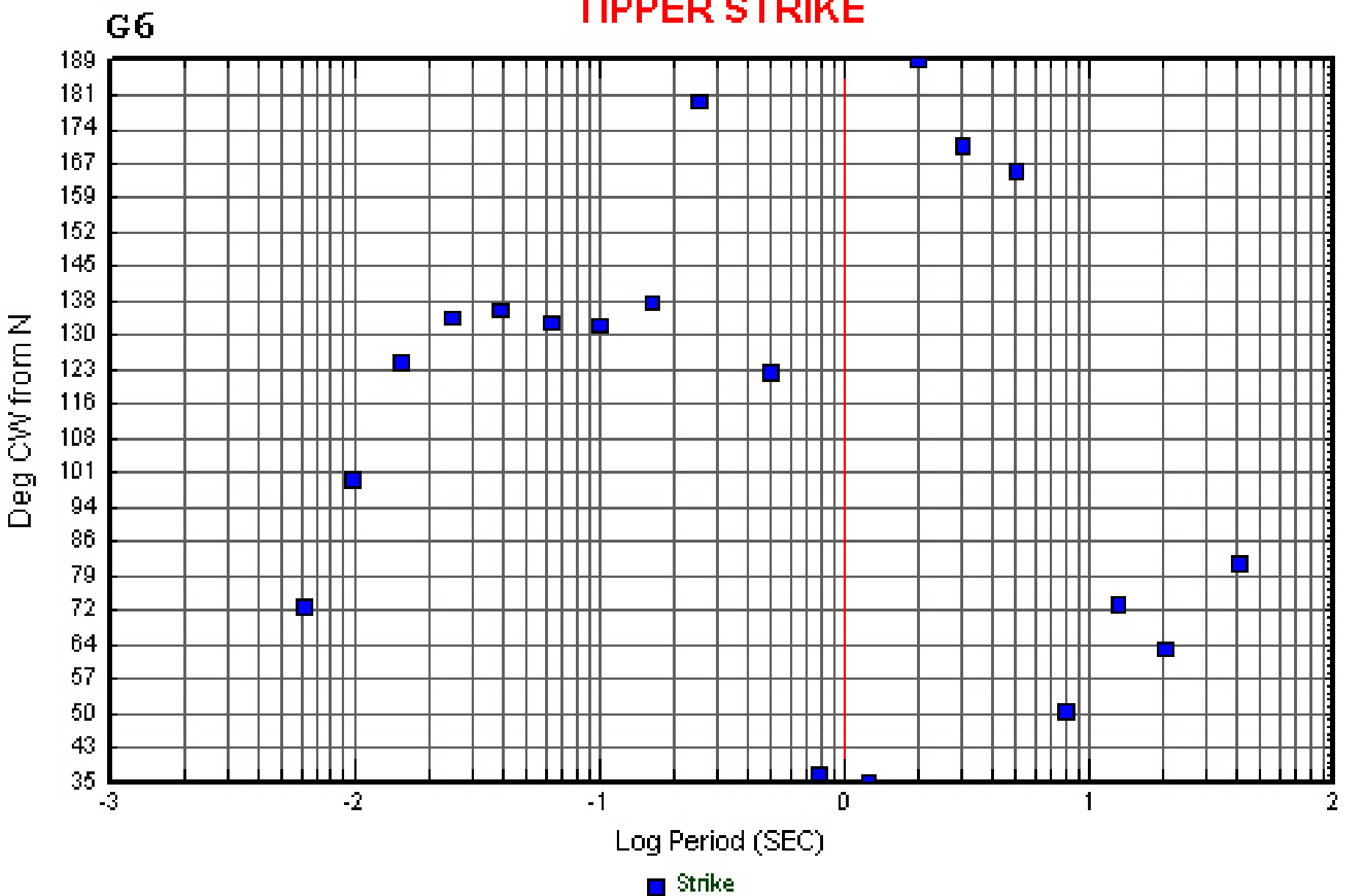




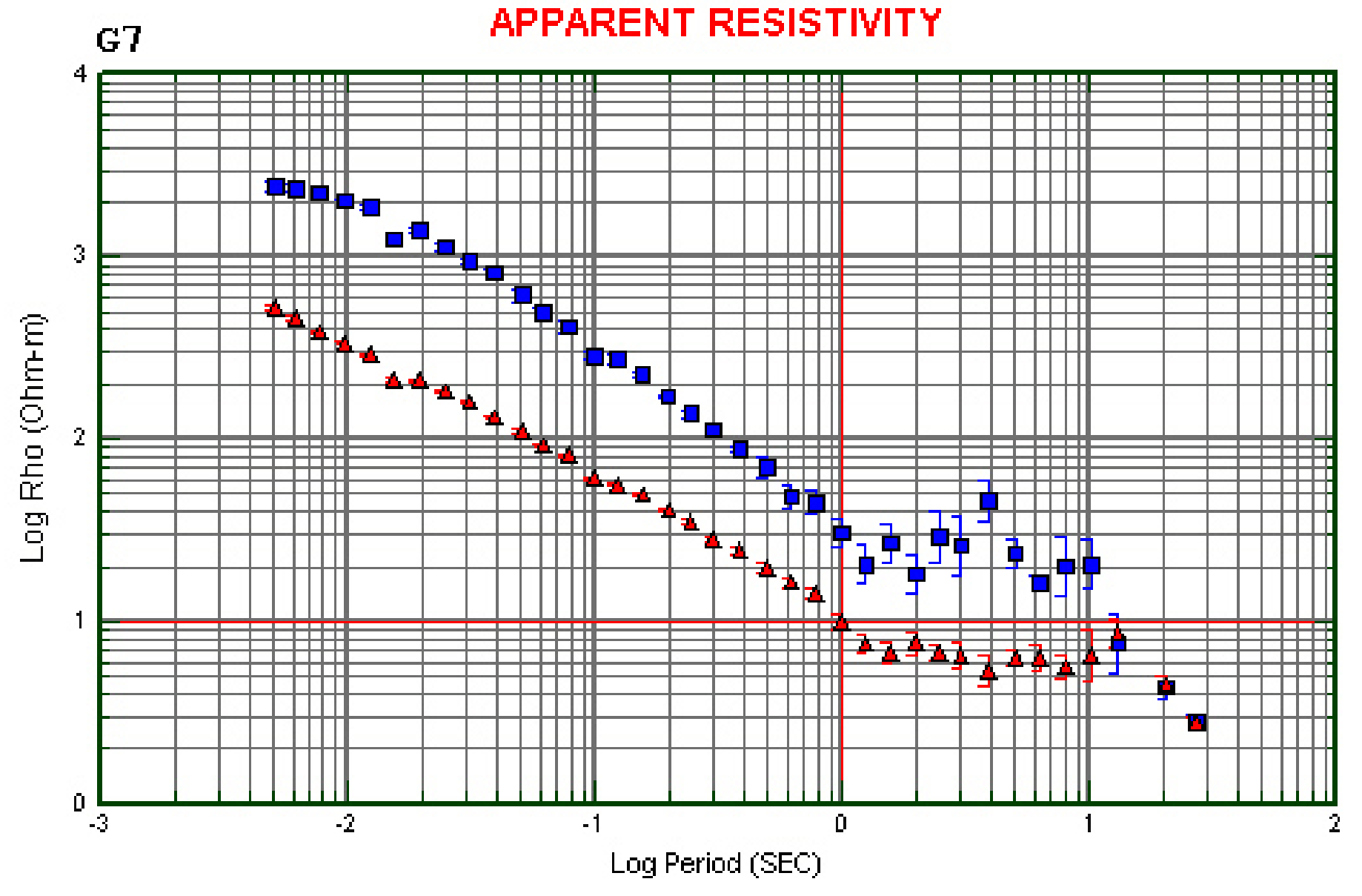

a Rho $X Y$

$\Delta$ Rho $Y x$ 
g

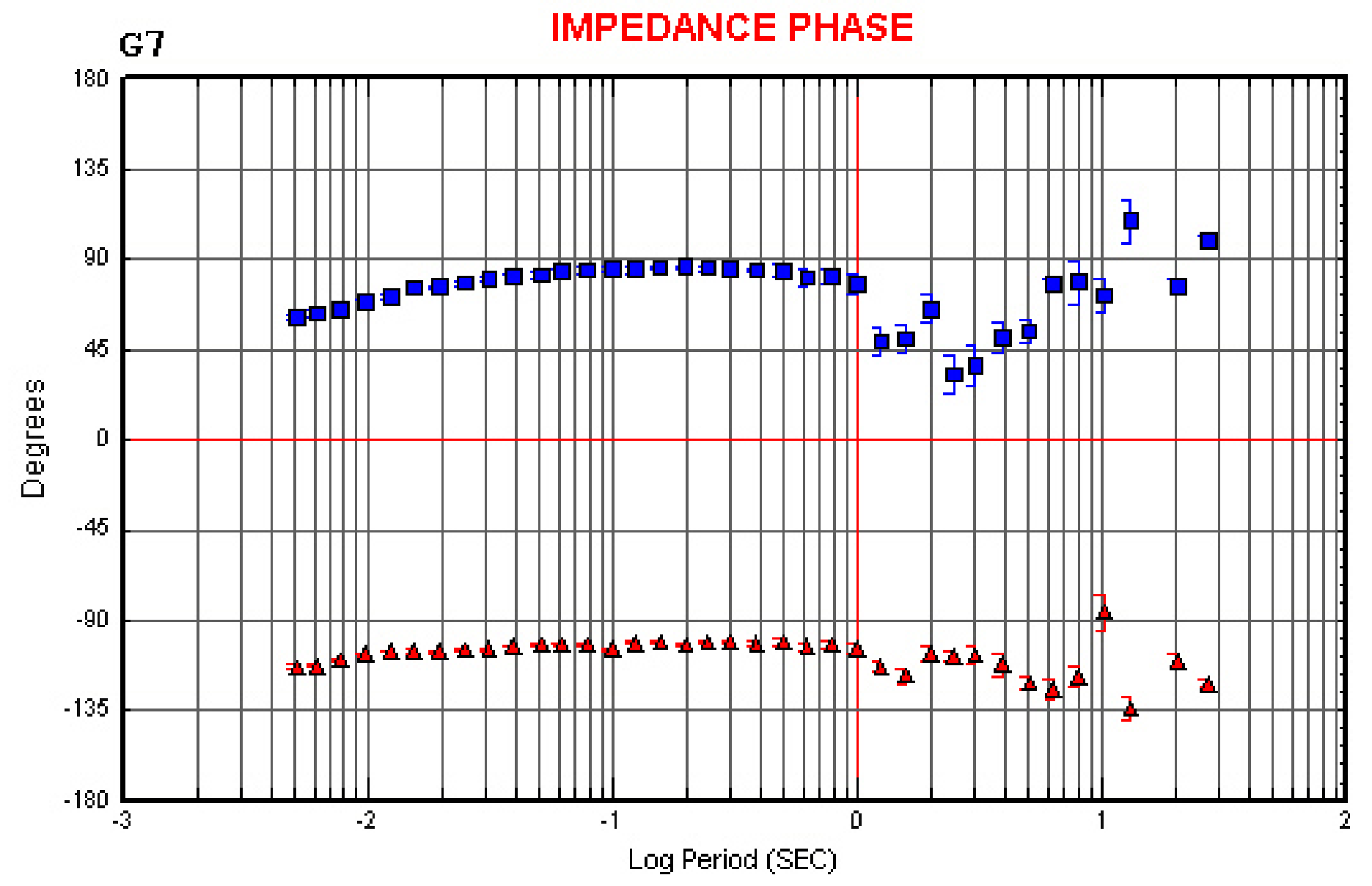

- Phase $X Y$

i Phase $Y x$ 


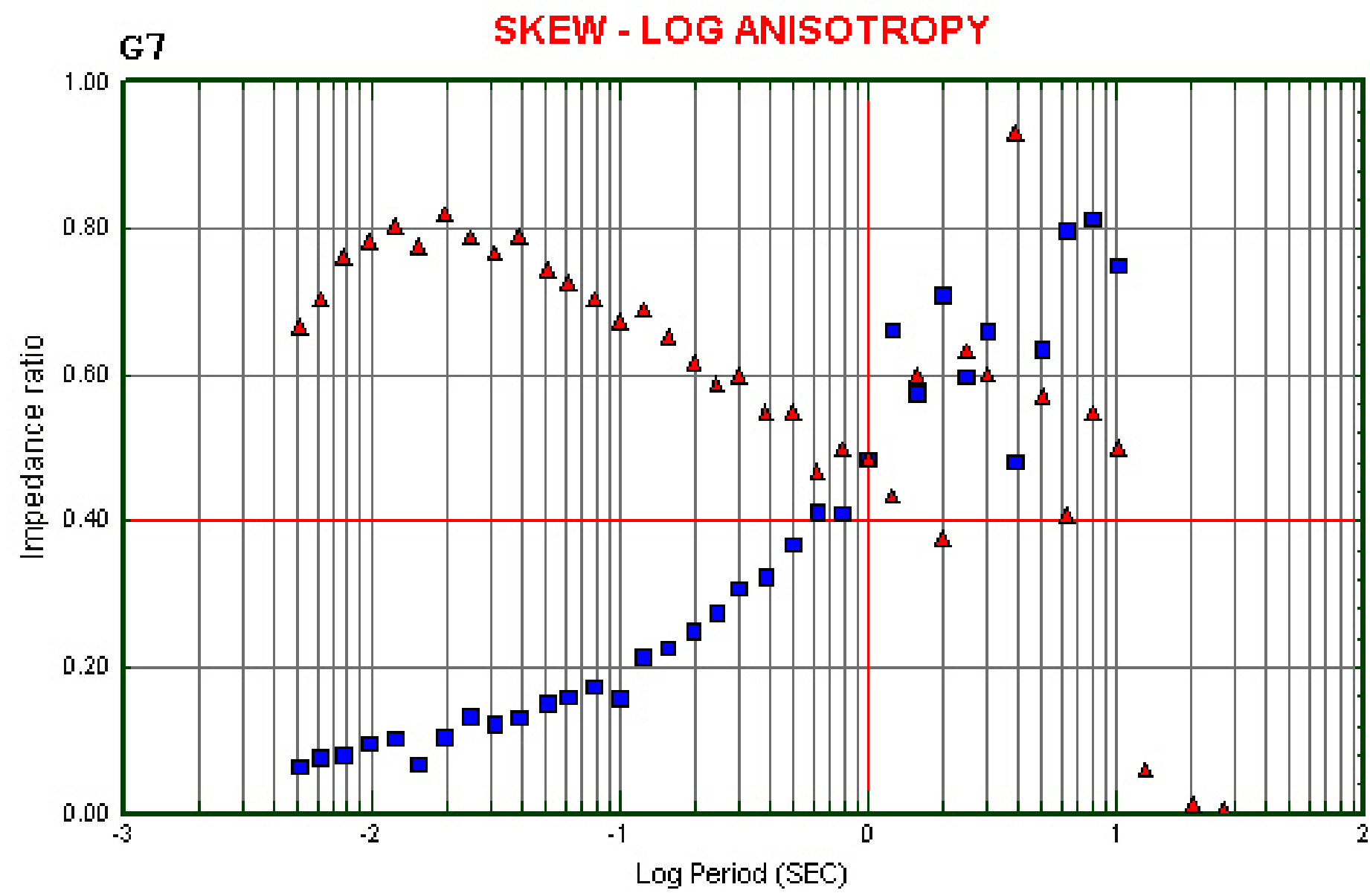

A Log Anis 
잉

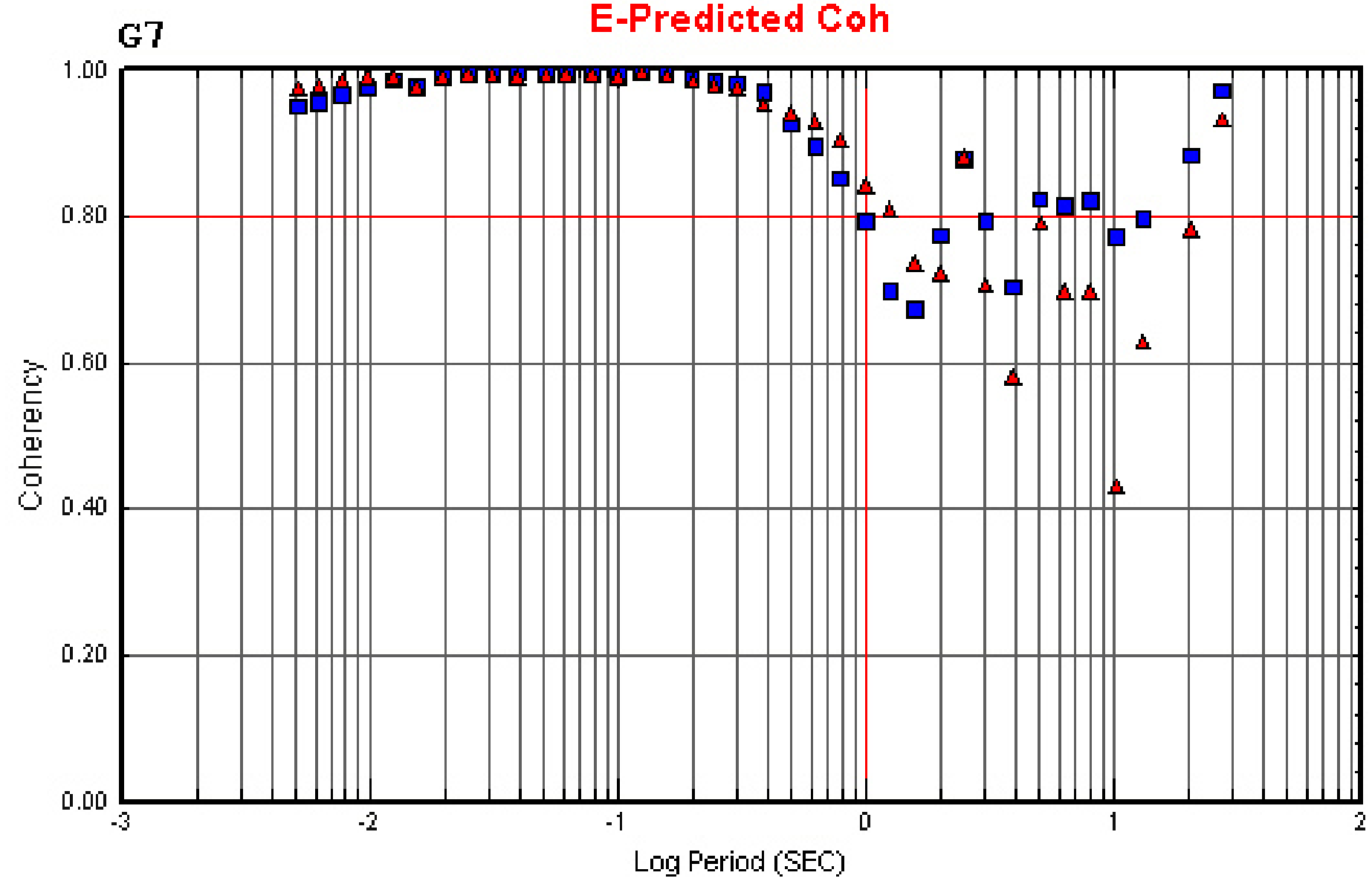

- Ex-HxHy

A Ey- $\mathrm{HxHy}$ 


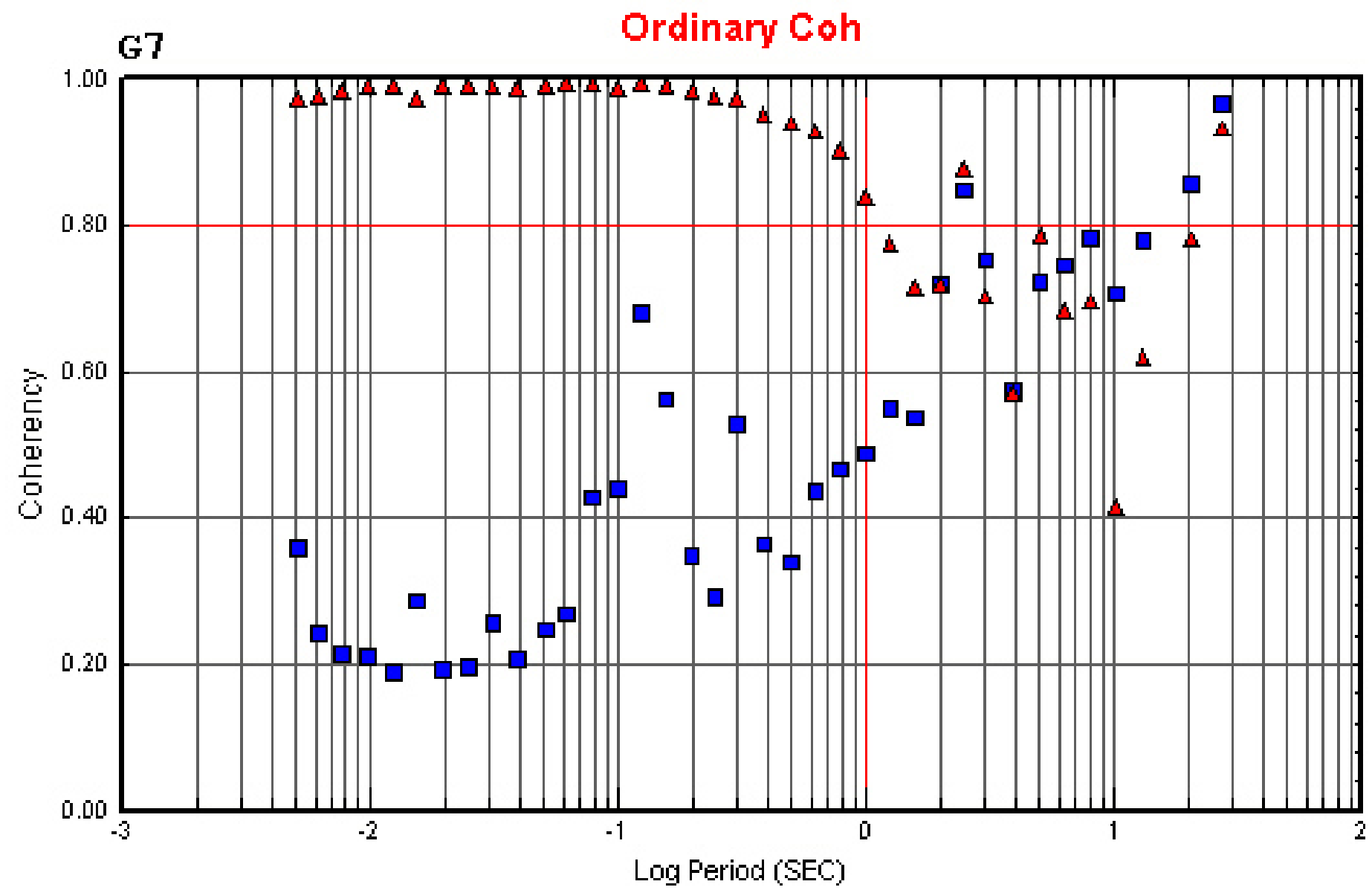

a $\mathrm{Hx}-\mathrm{Ex}$

$\Delta \mathrm{Hx}-\mathrm{Ey}$ 


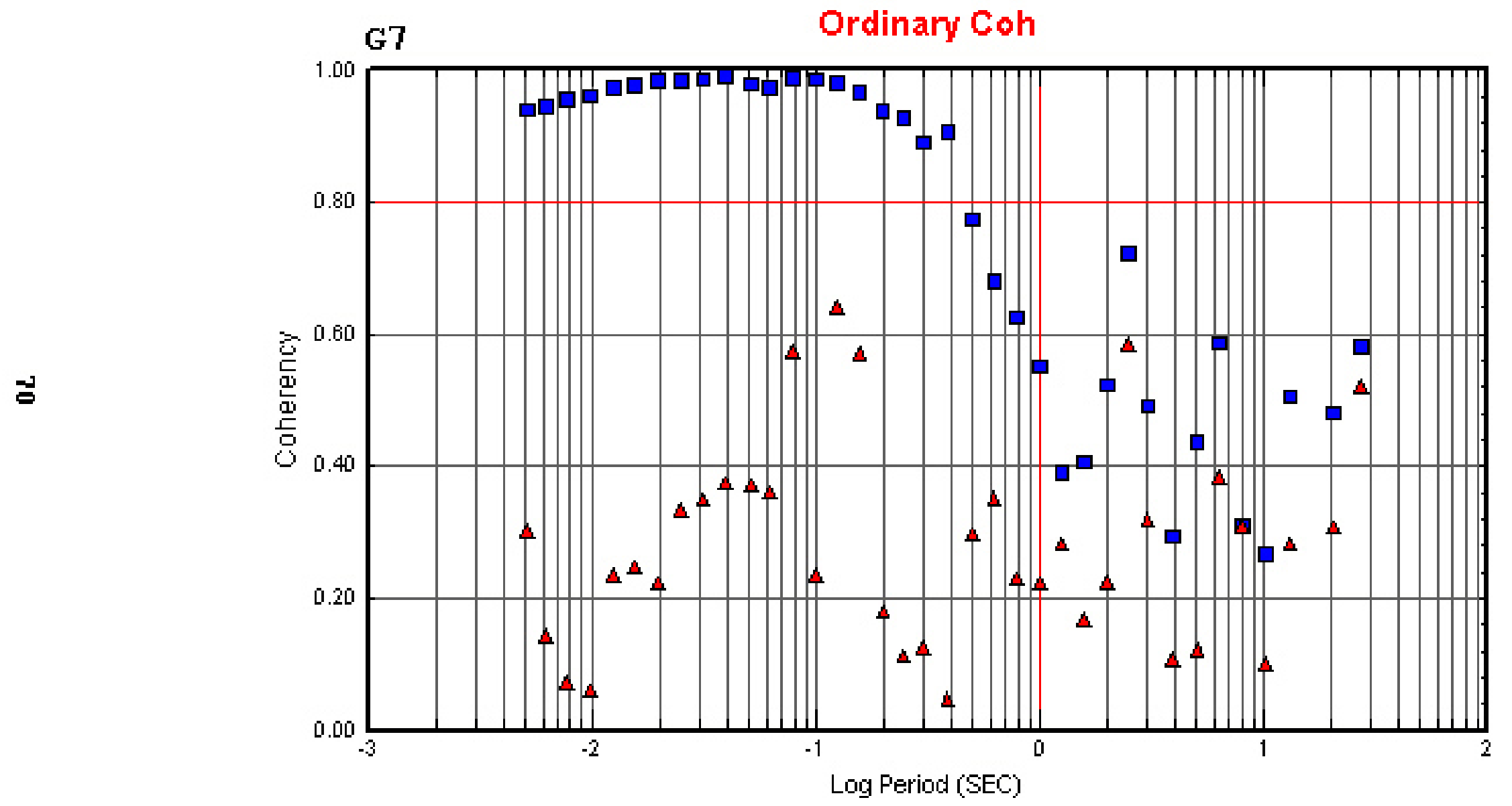

- $H y-E x$

A $H y-E y$ 


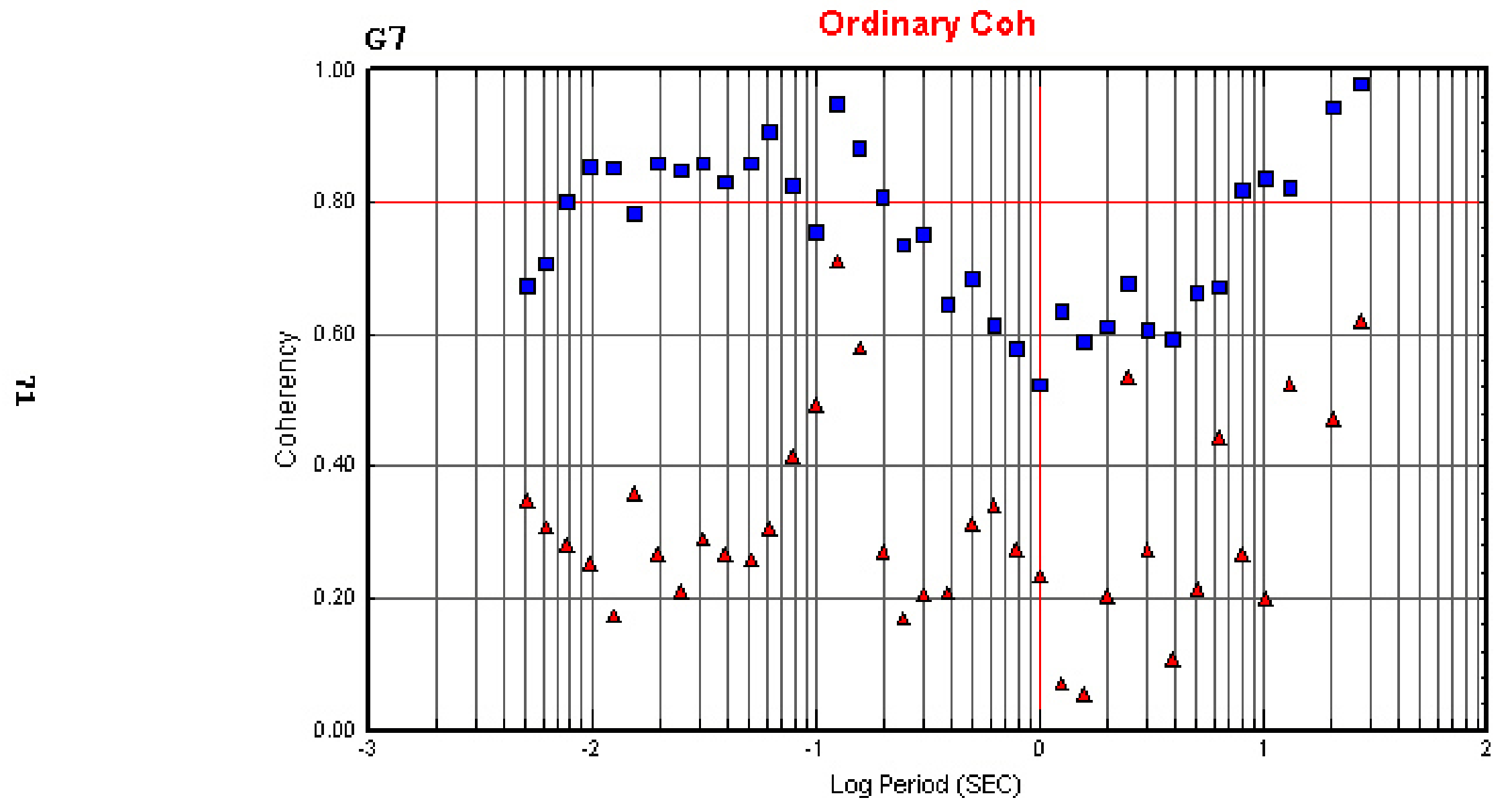

a $\mathrm{Hz}-\mathrm{Hx}$ 


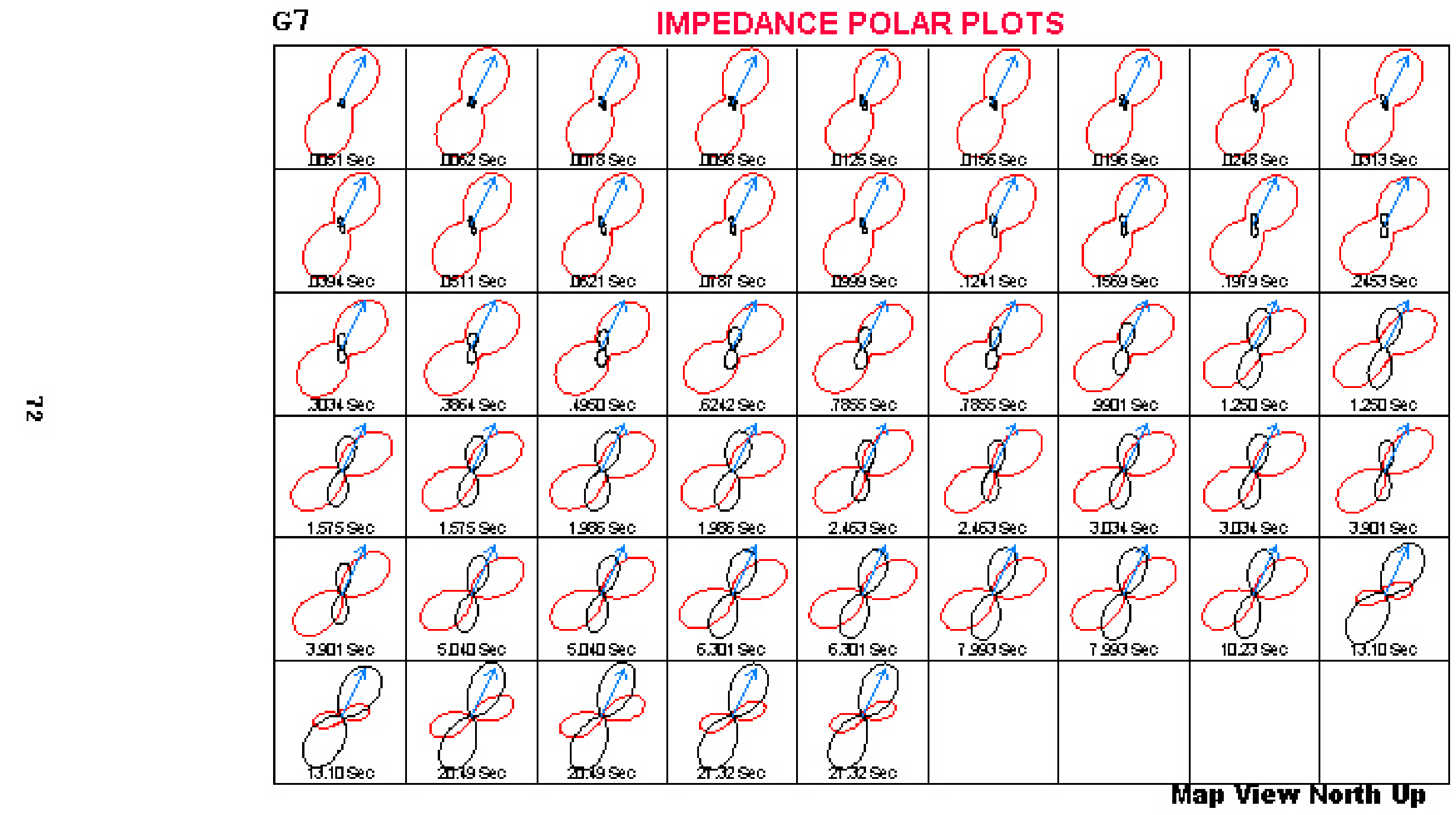




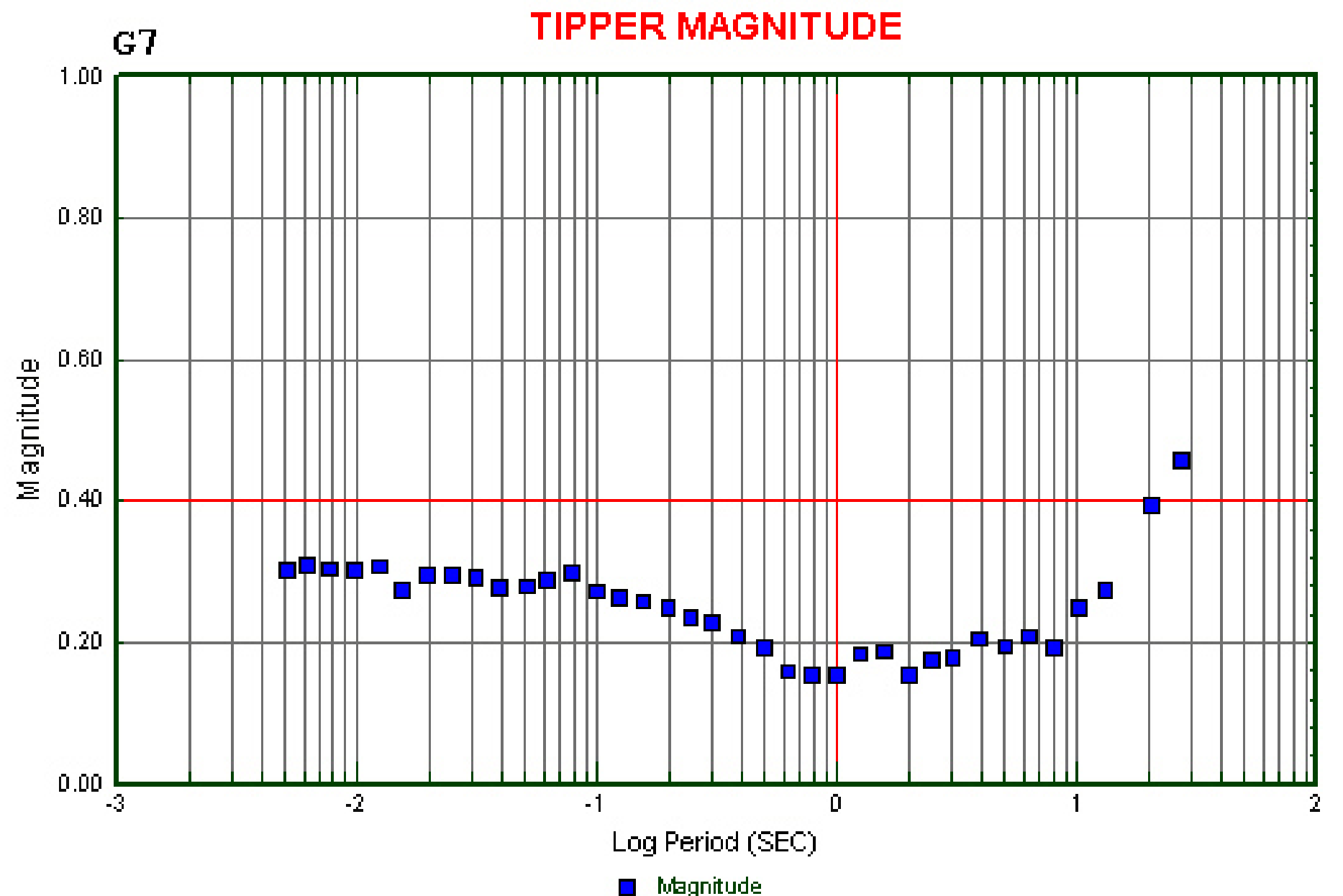




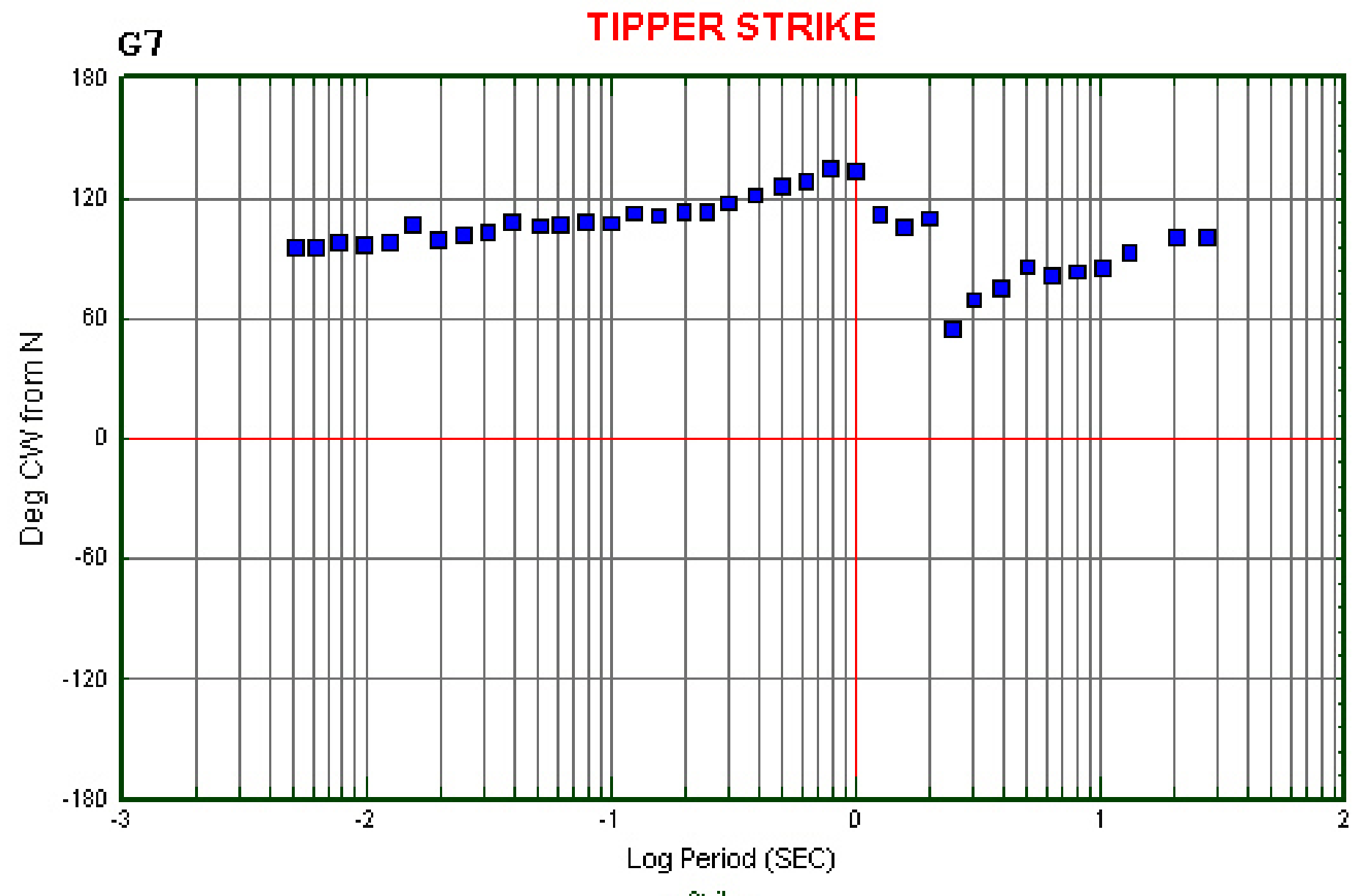




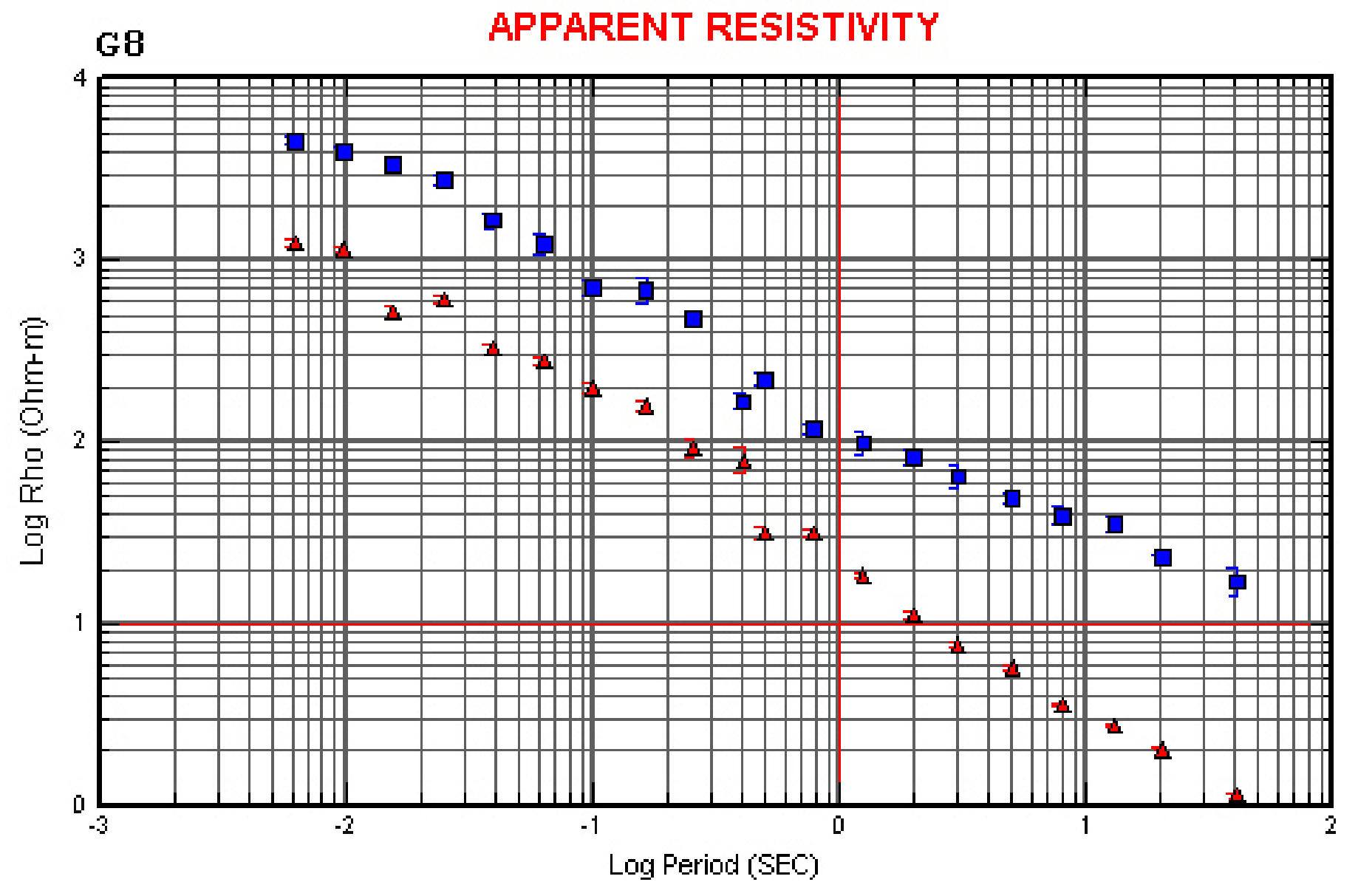

- Rho $X Y$

$\Delta$ Rho $Y x$ 


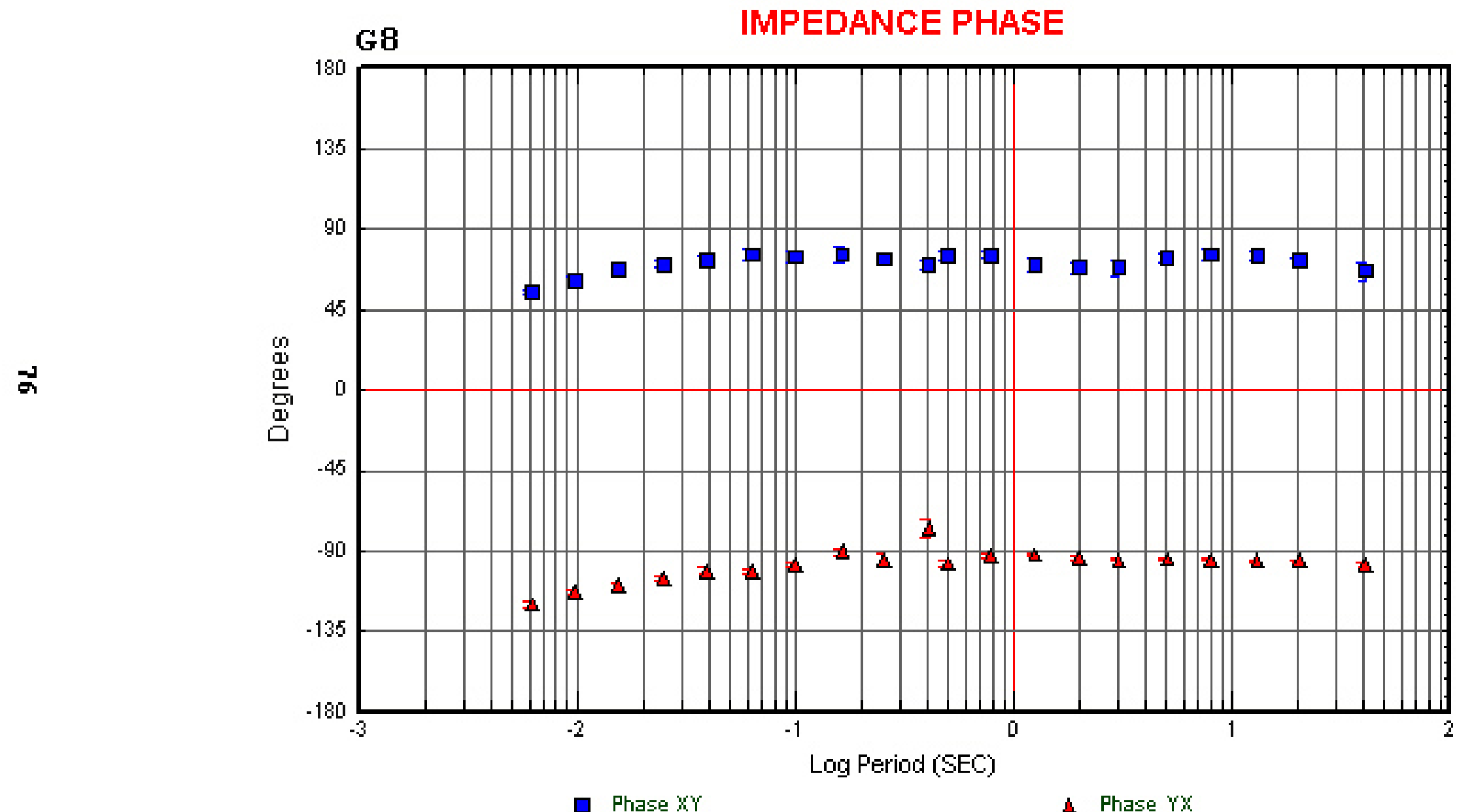




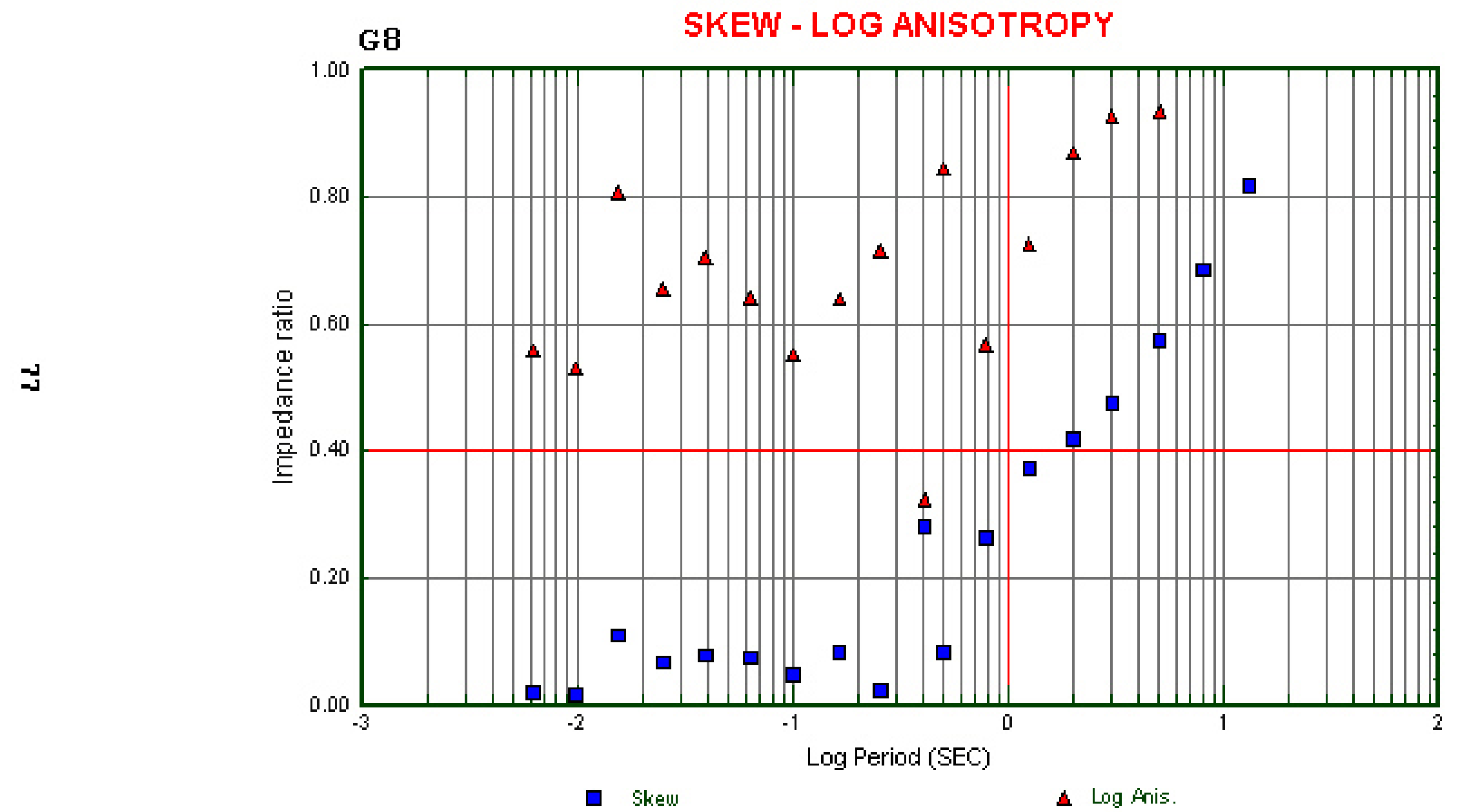




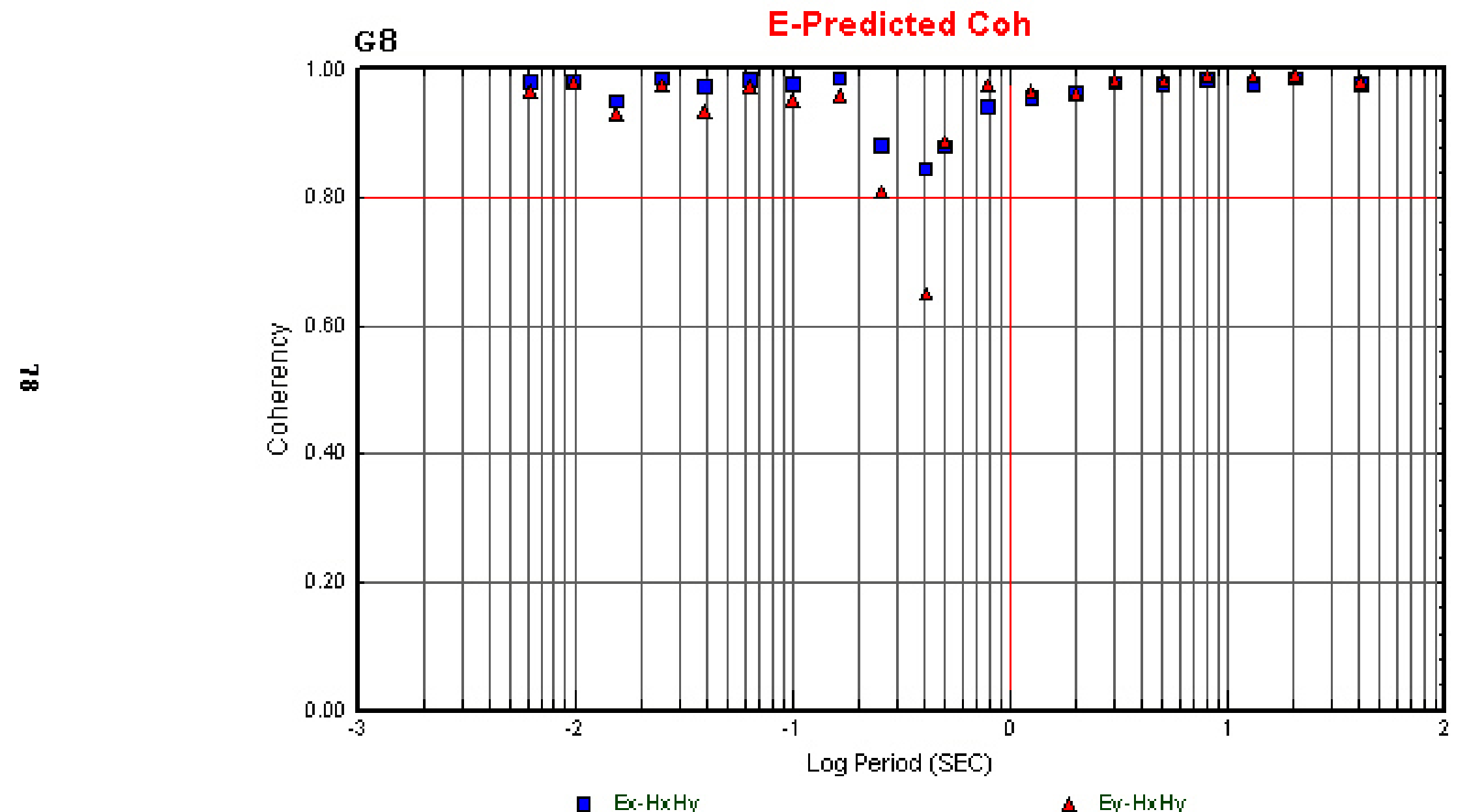




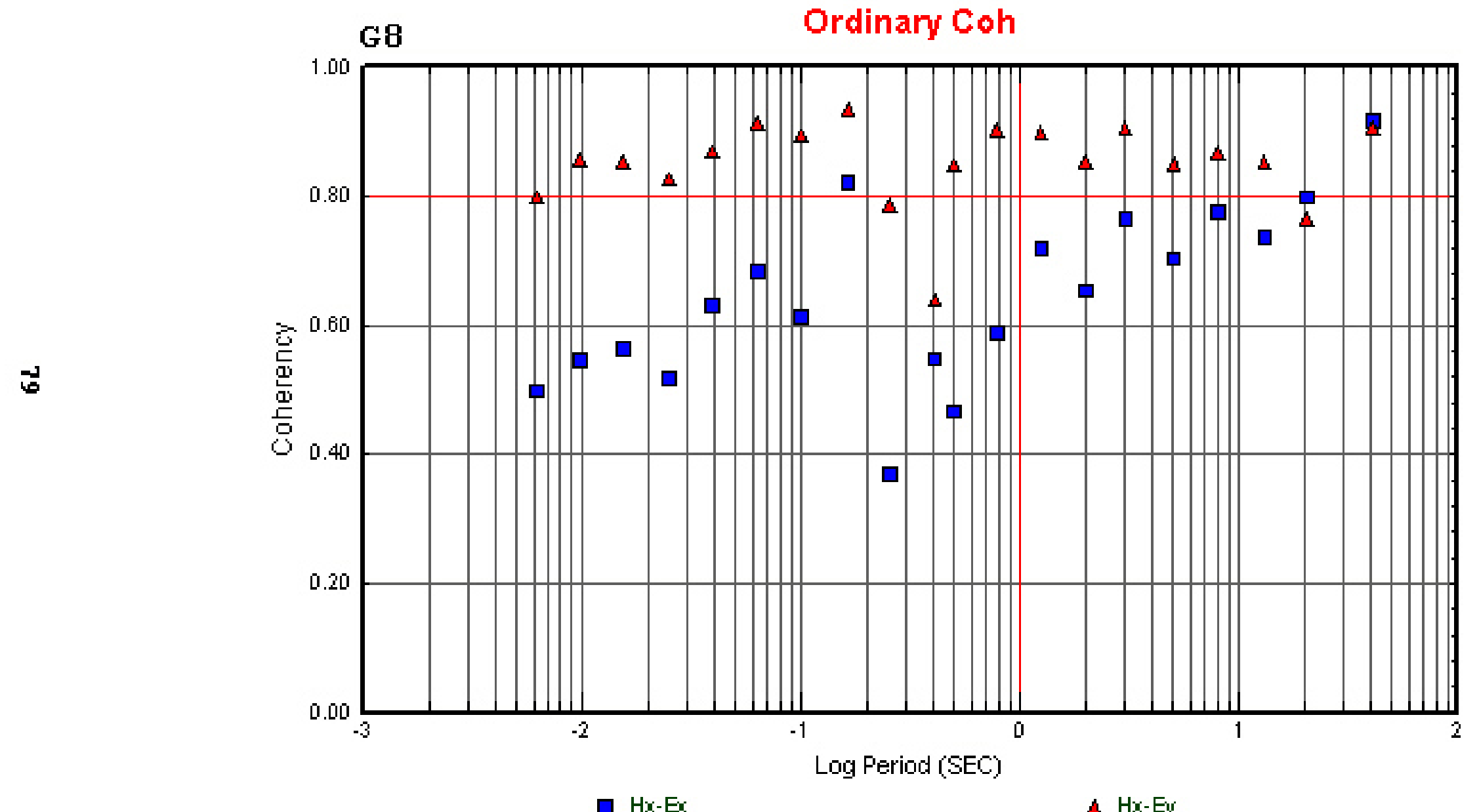




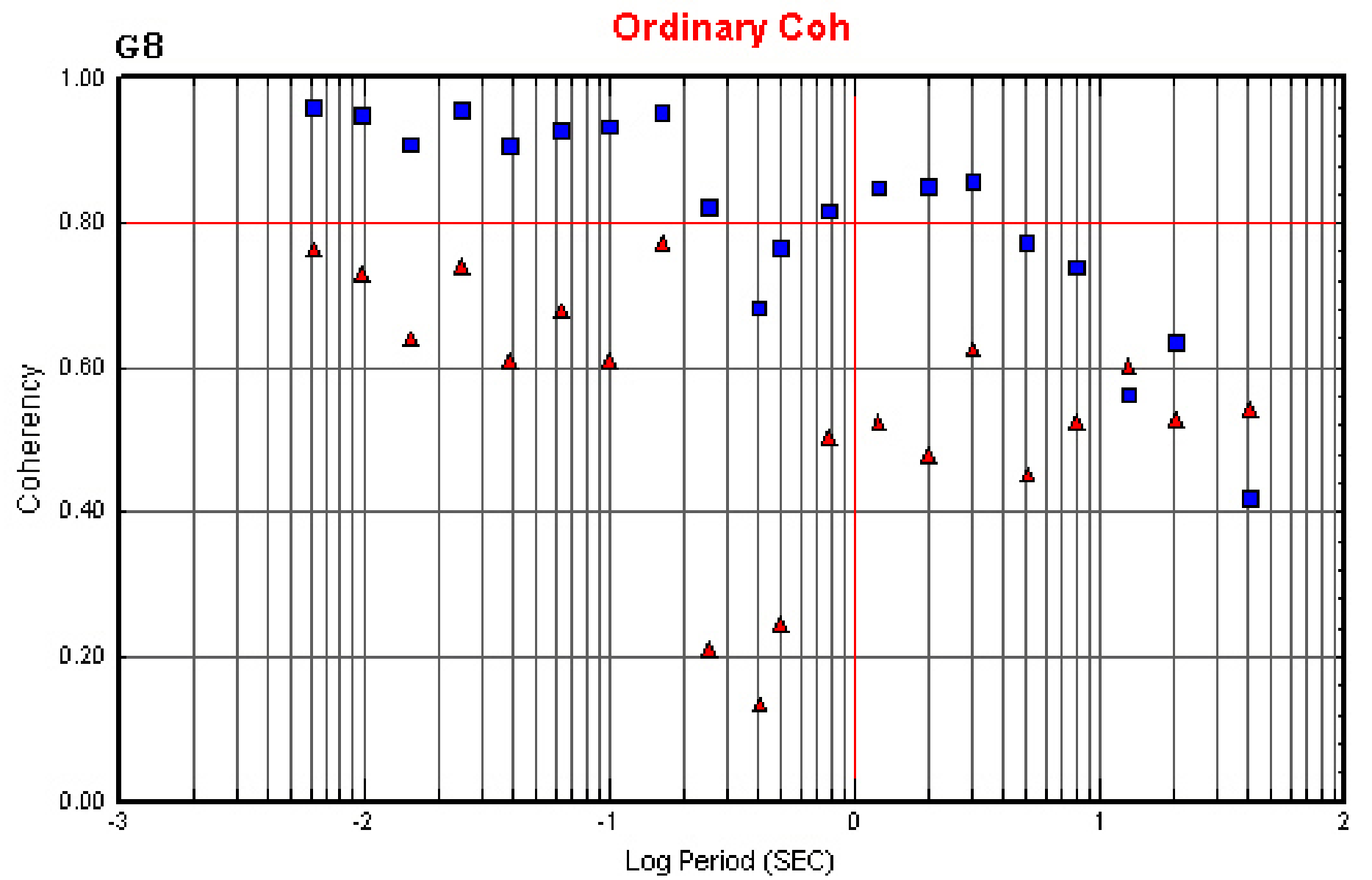

- $\mathrm{Hy}$-Ex

A Hy-Ey 


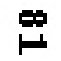

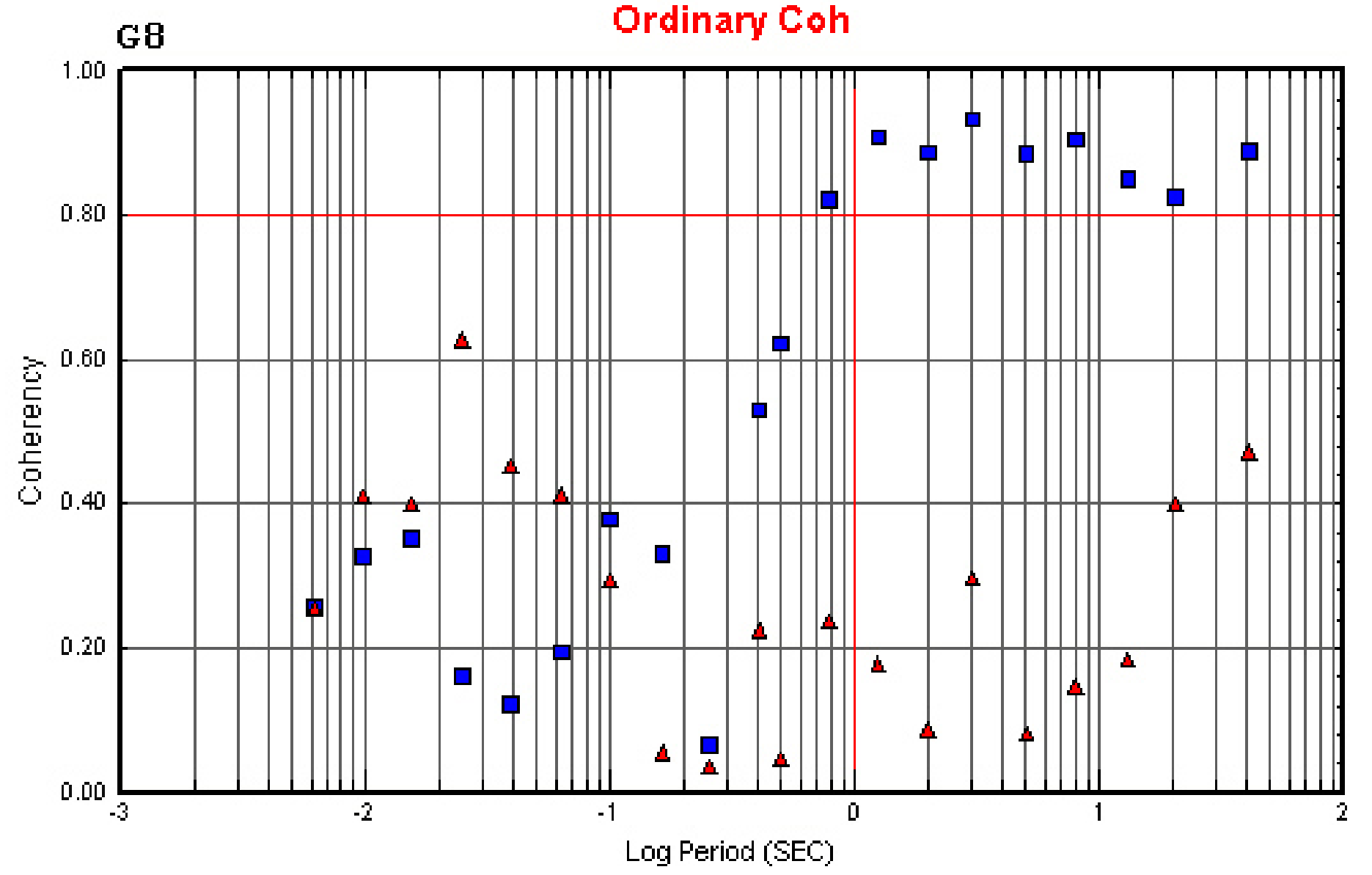

- $\mathrm{Hz}-\mathrm{Hx}$

A $\mathrm{Hz}-\mathrm{Hy}$ 


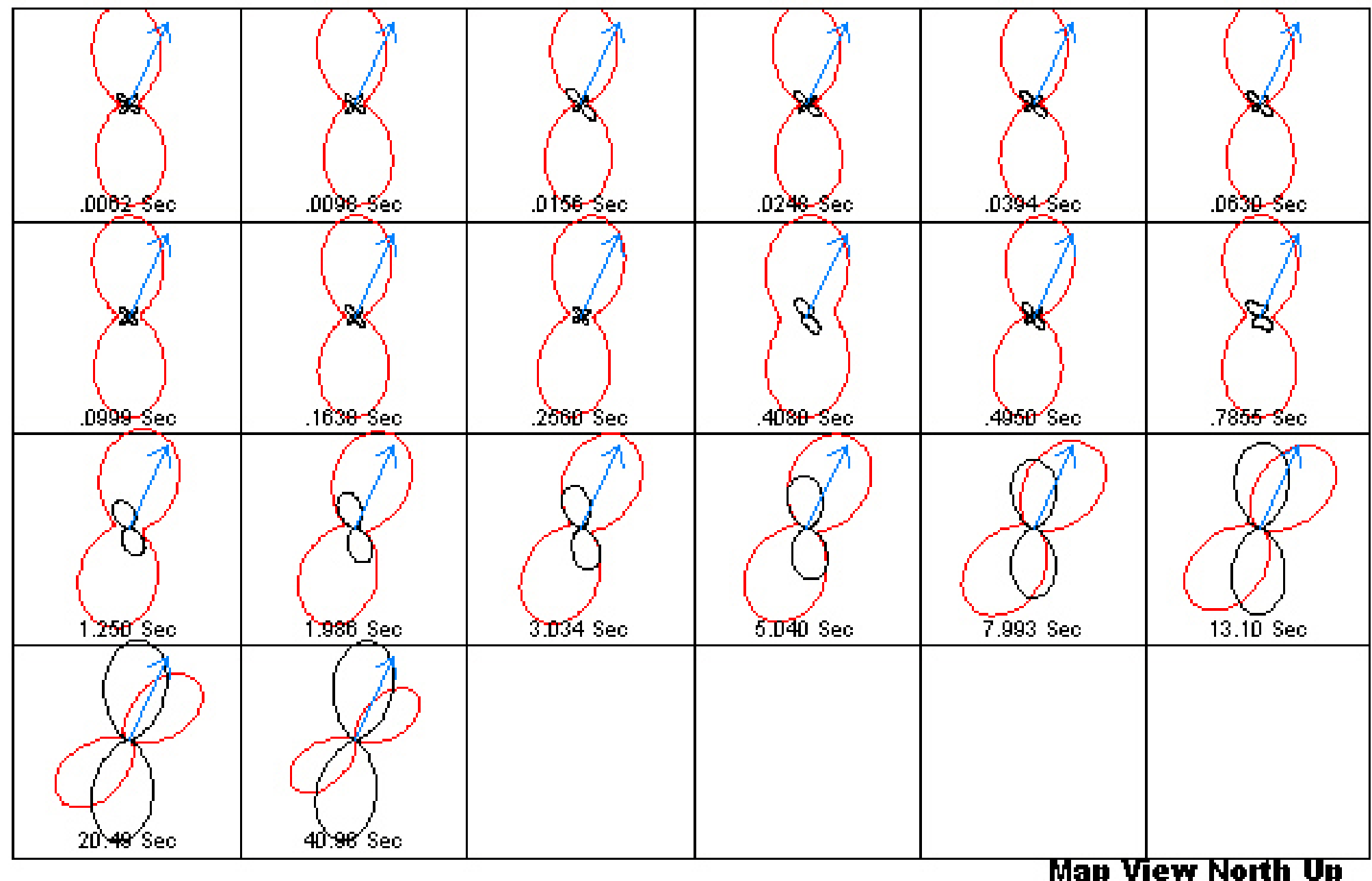




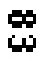

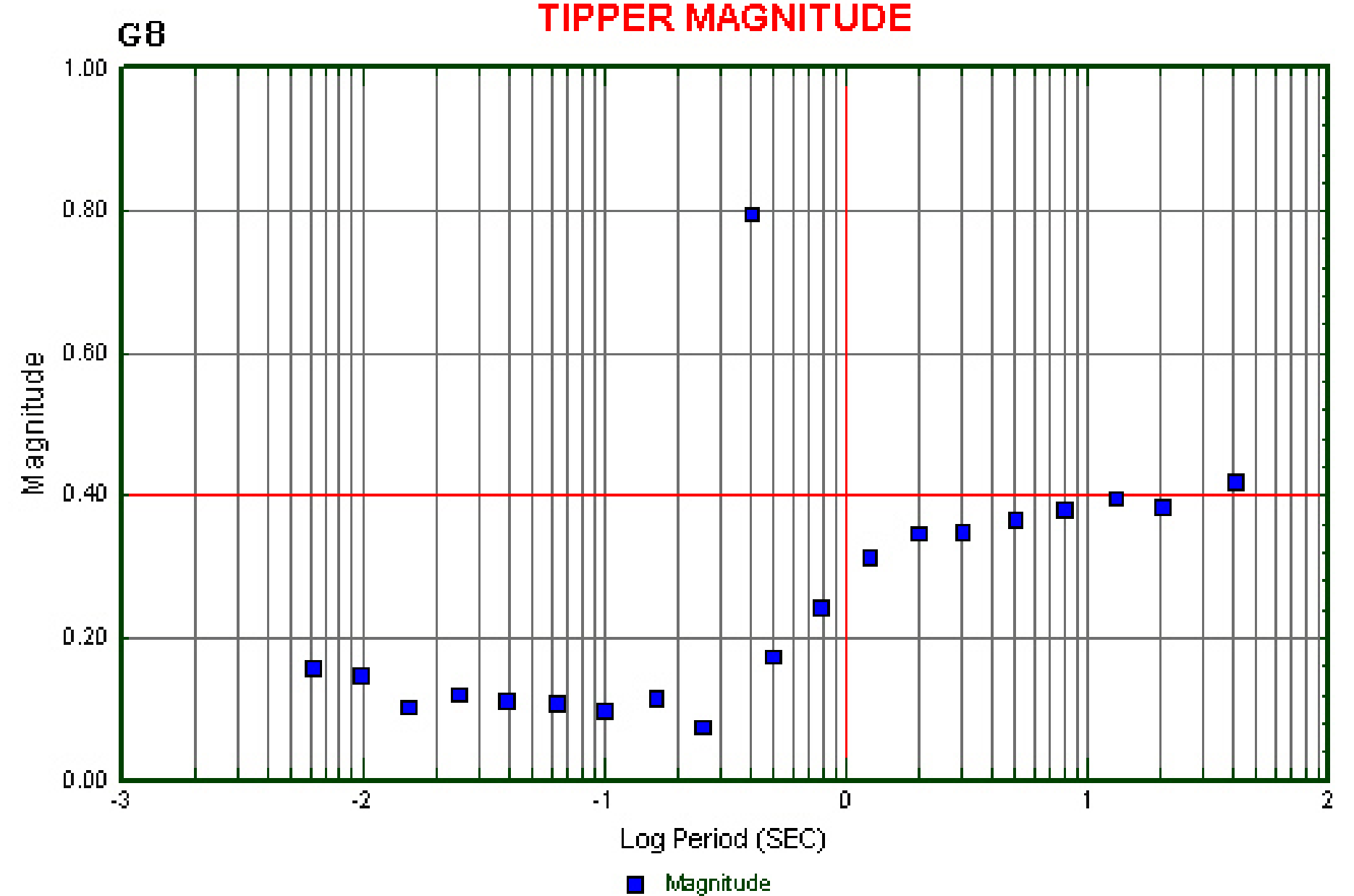




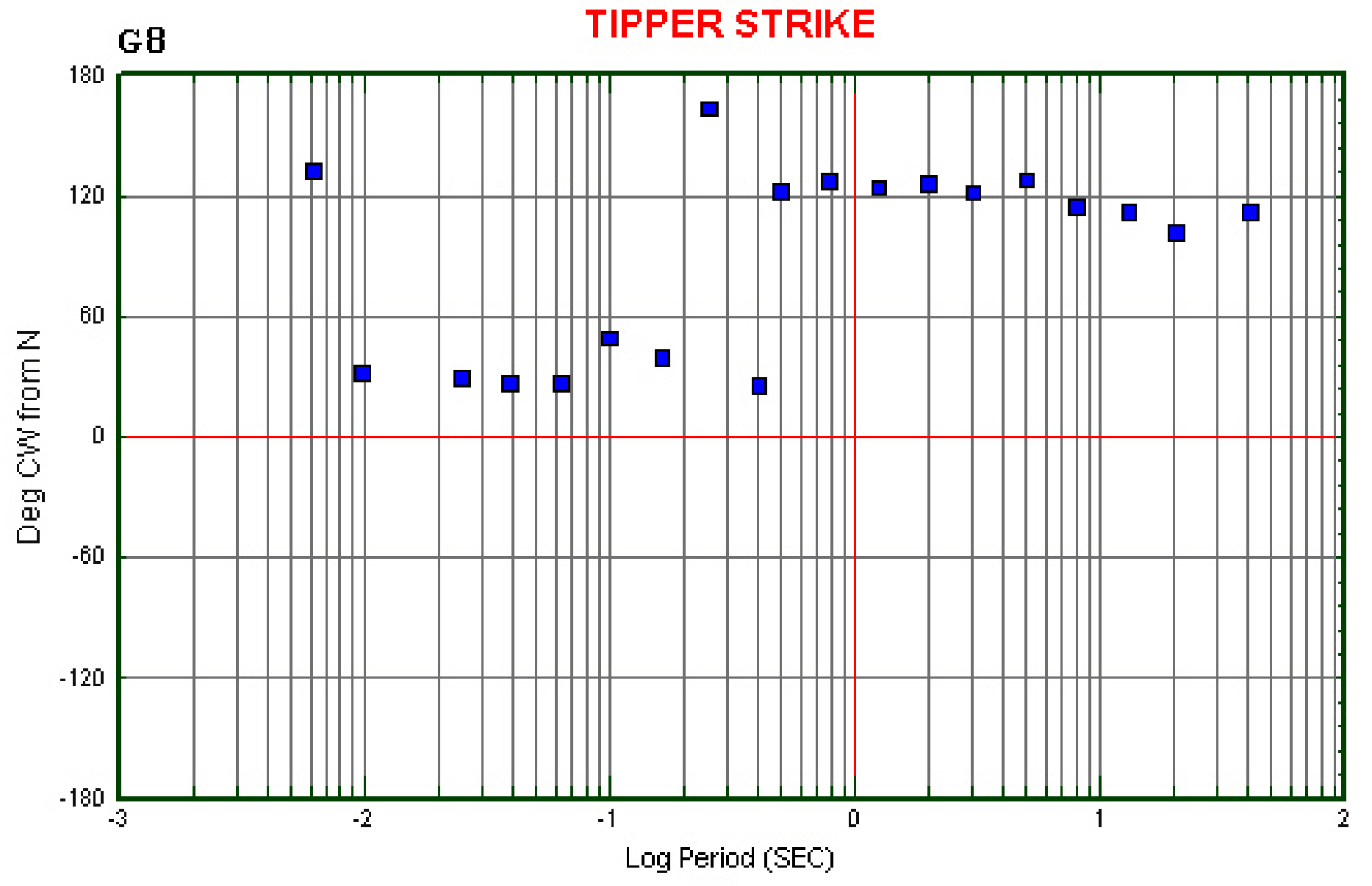




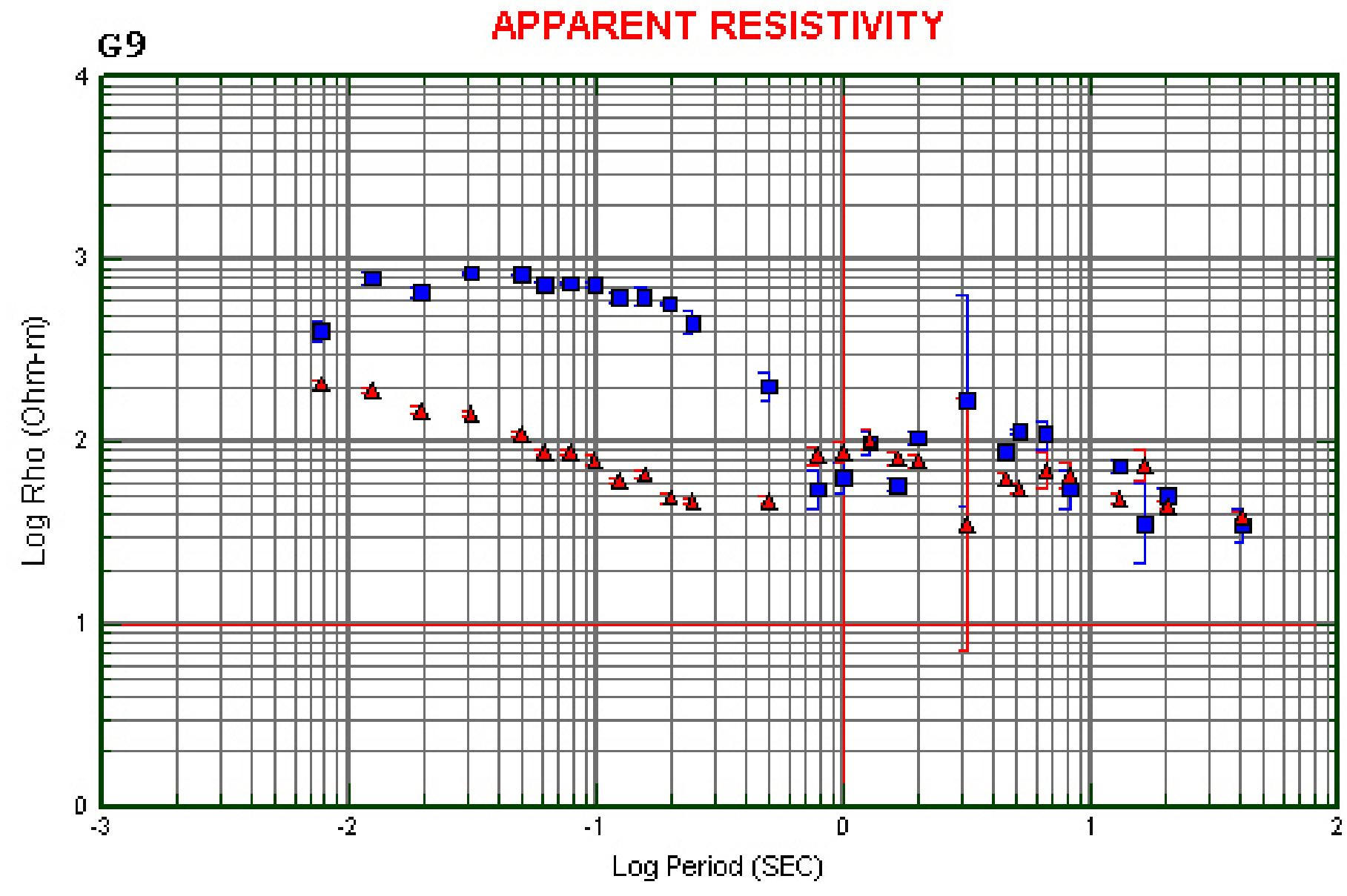

- Rho $X Y$

$\Delta$ Rho $Y$ 


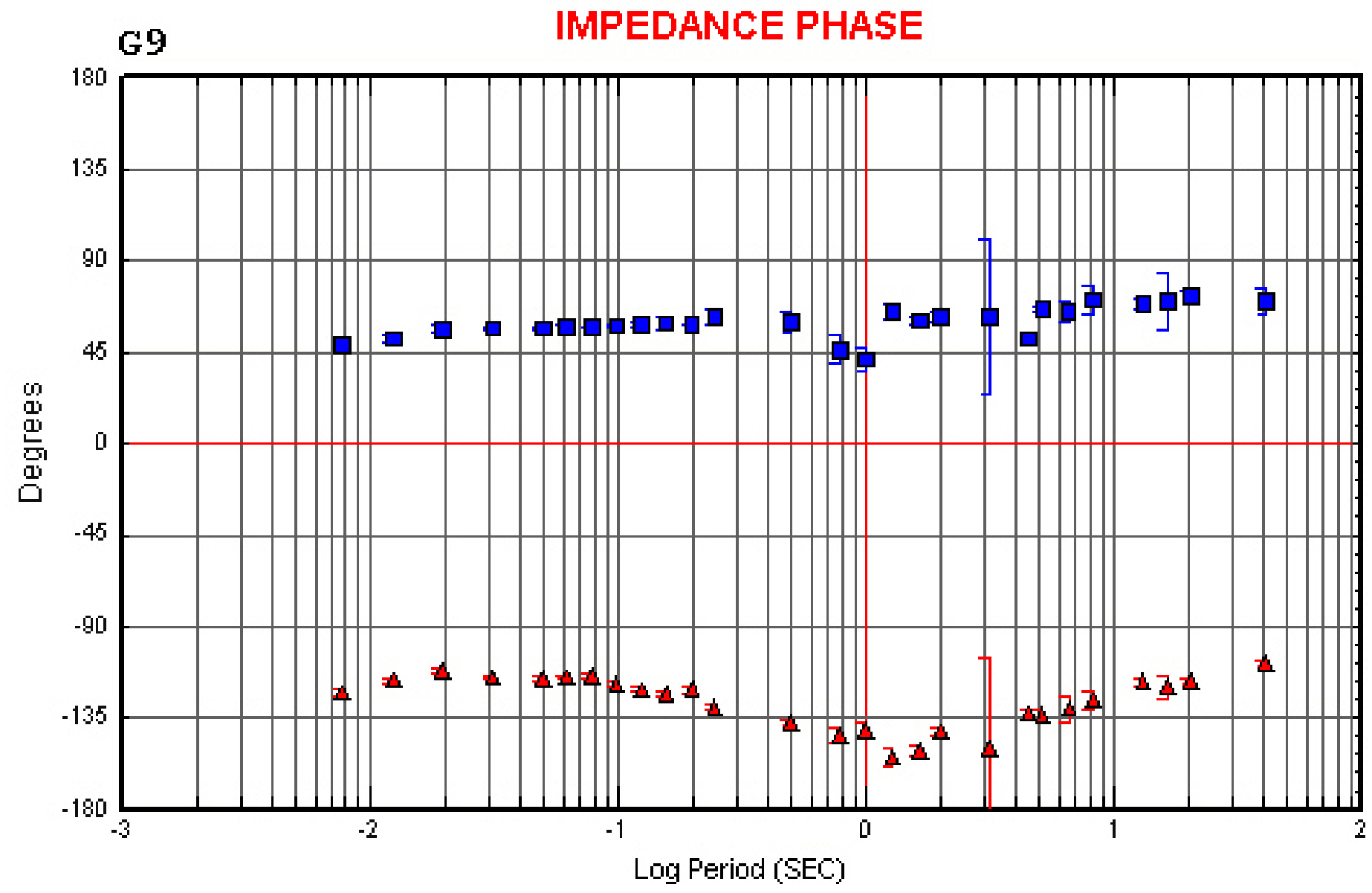

- Phase $X Y$

i Phase $Y x$ 


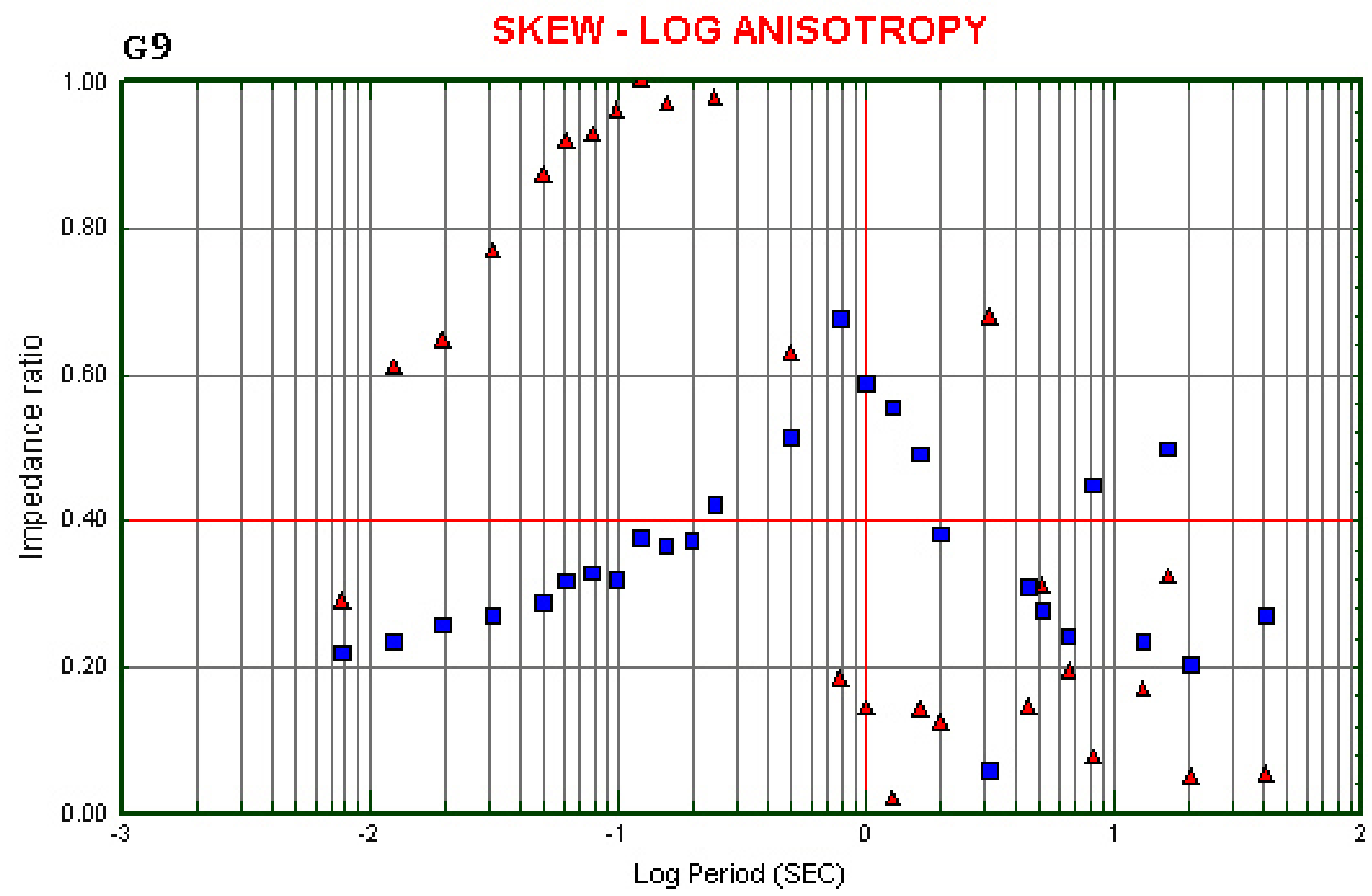




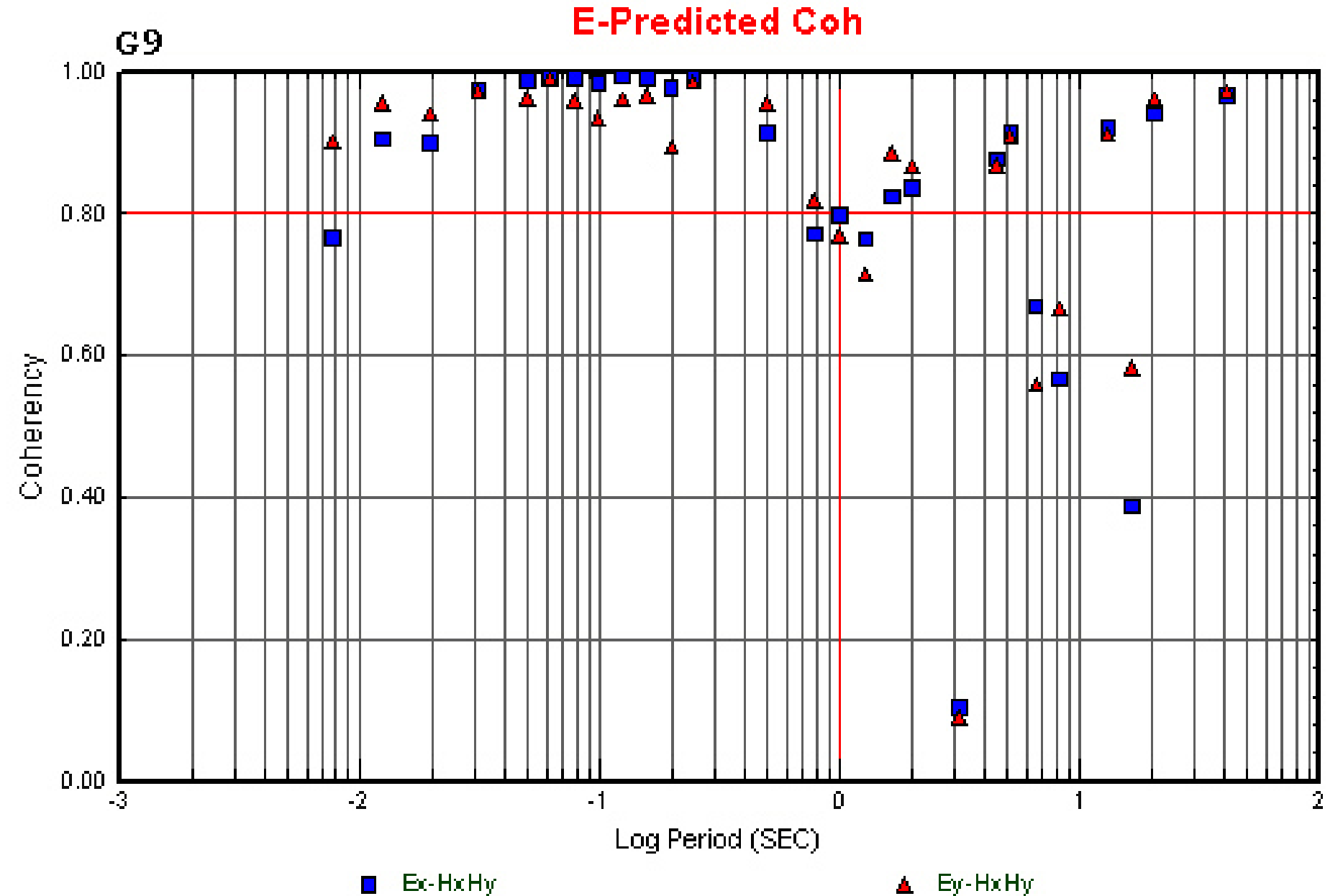




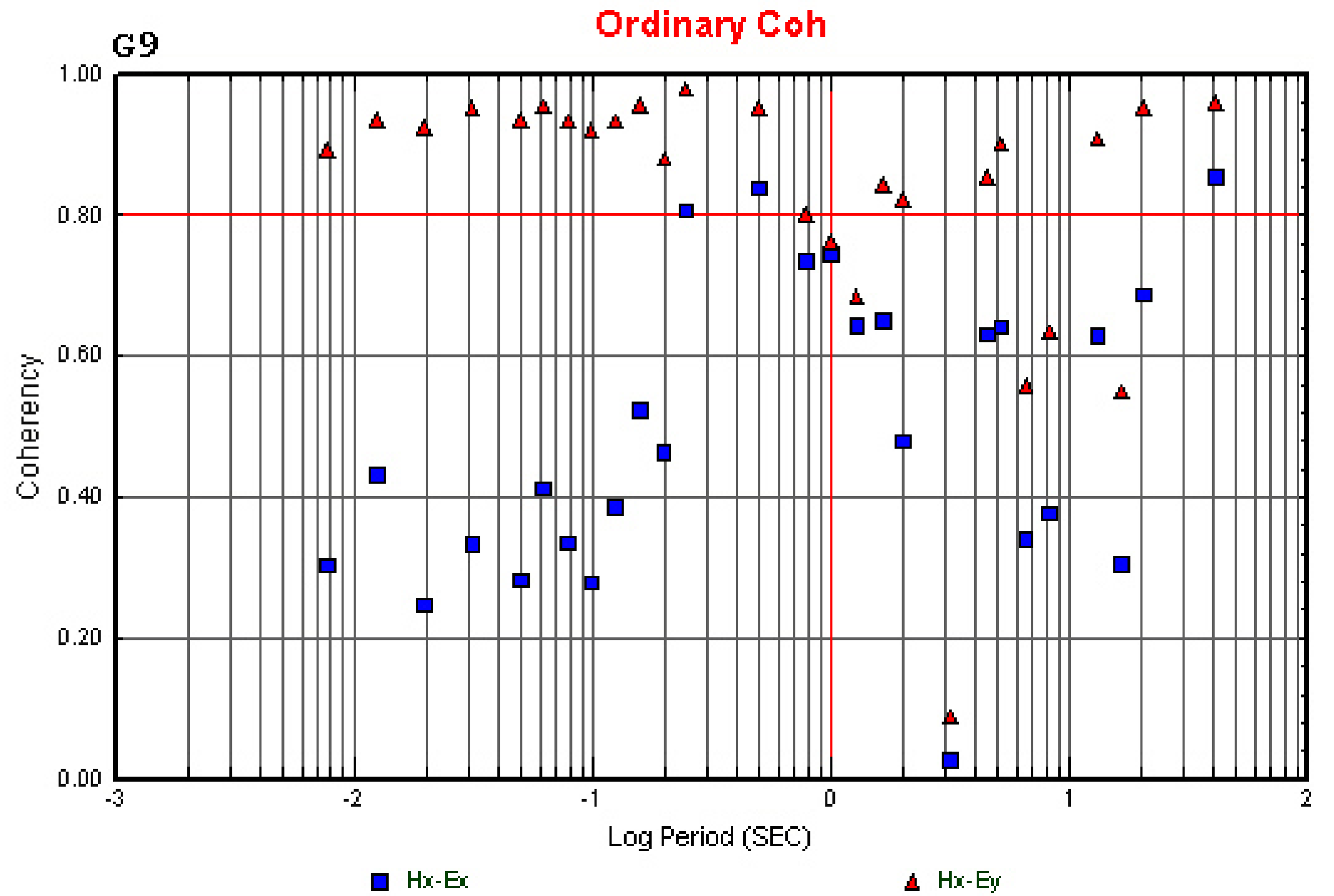




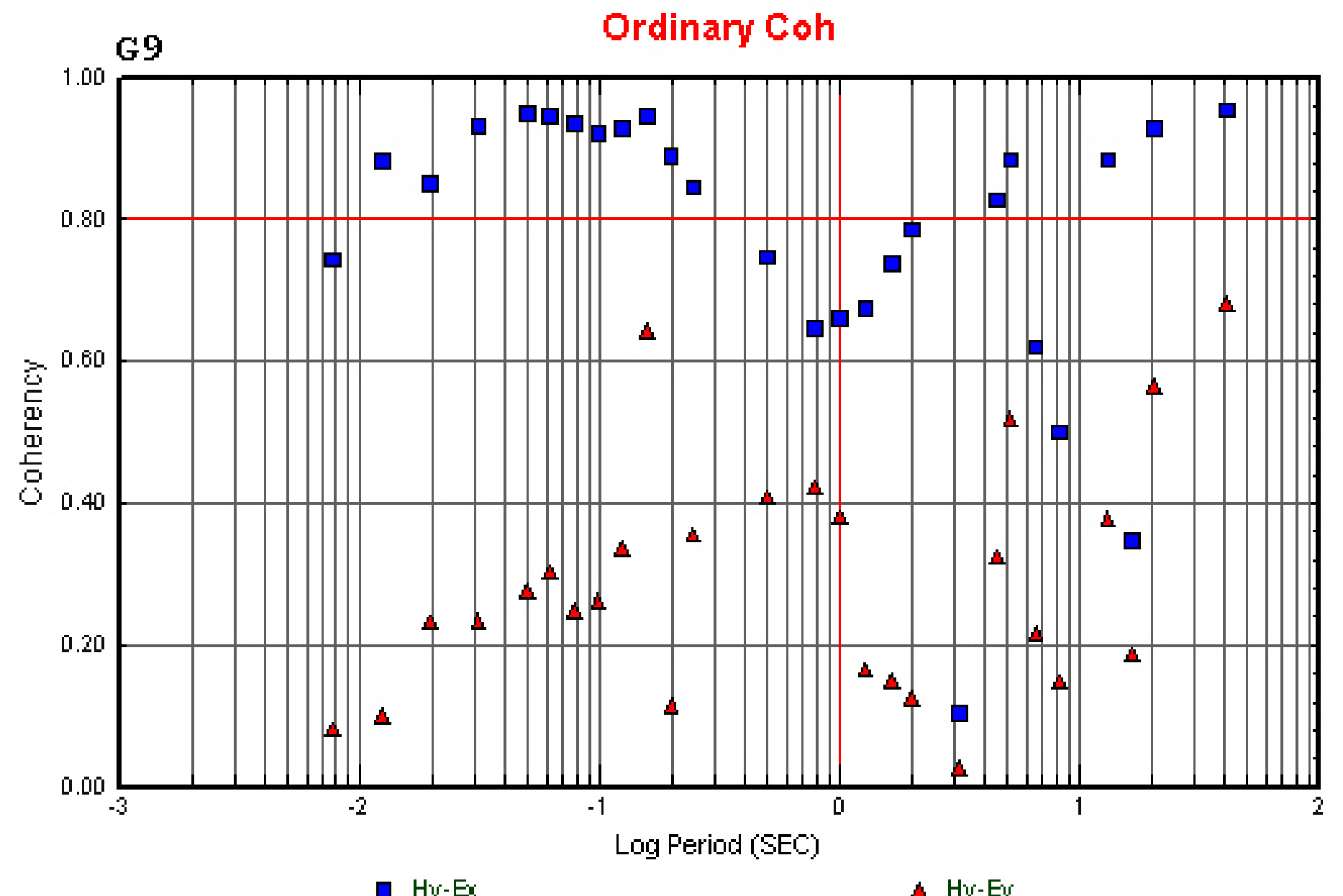




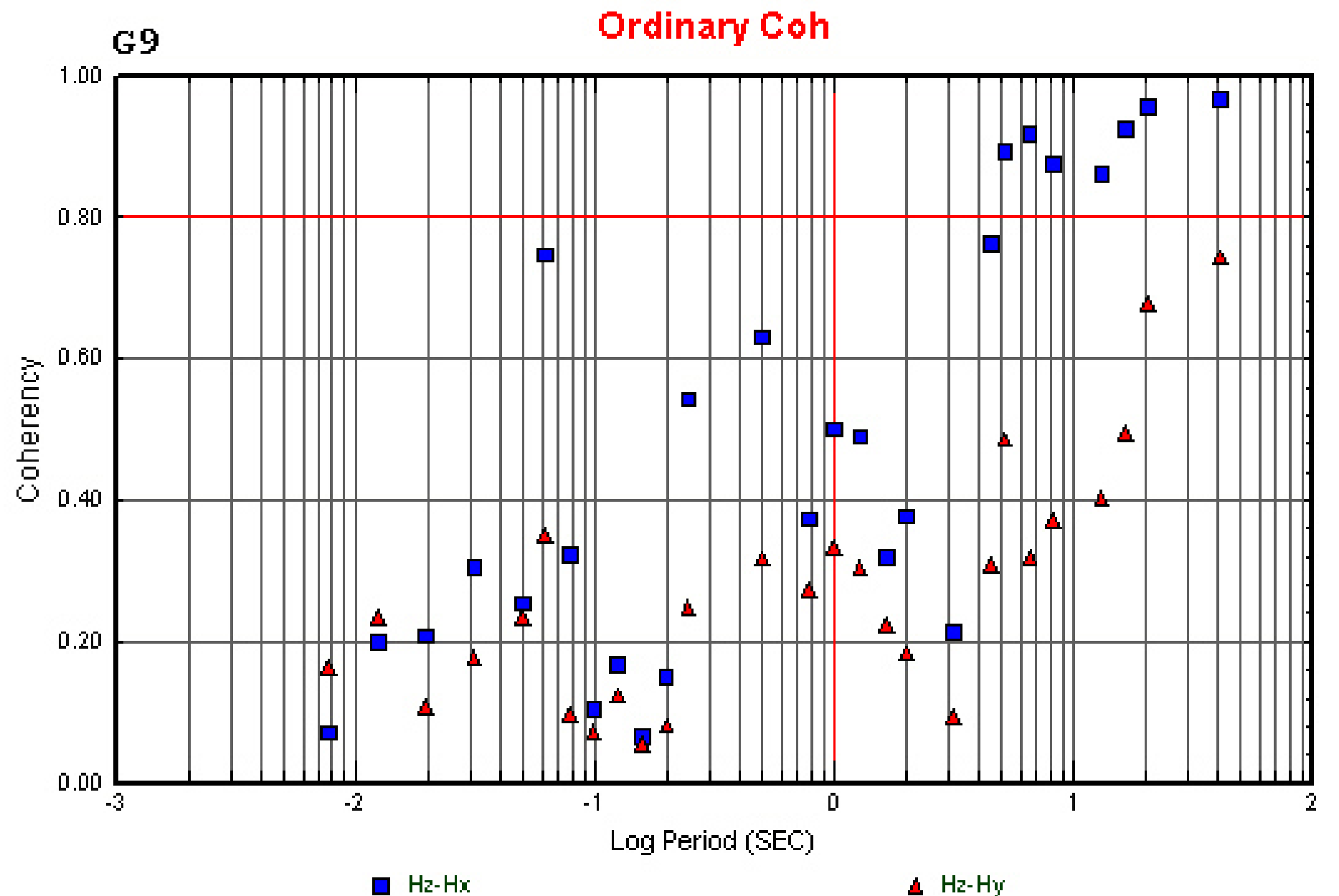




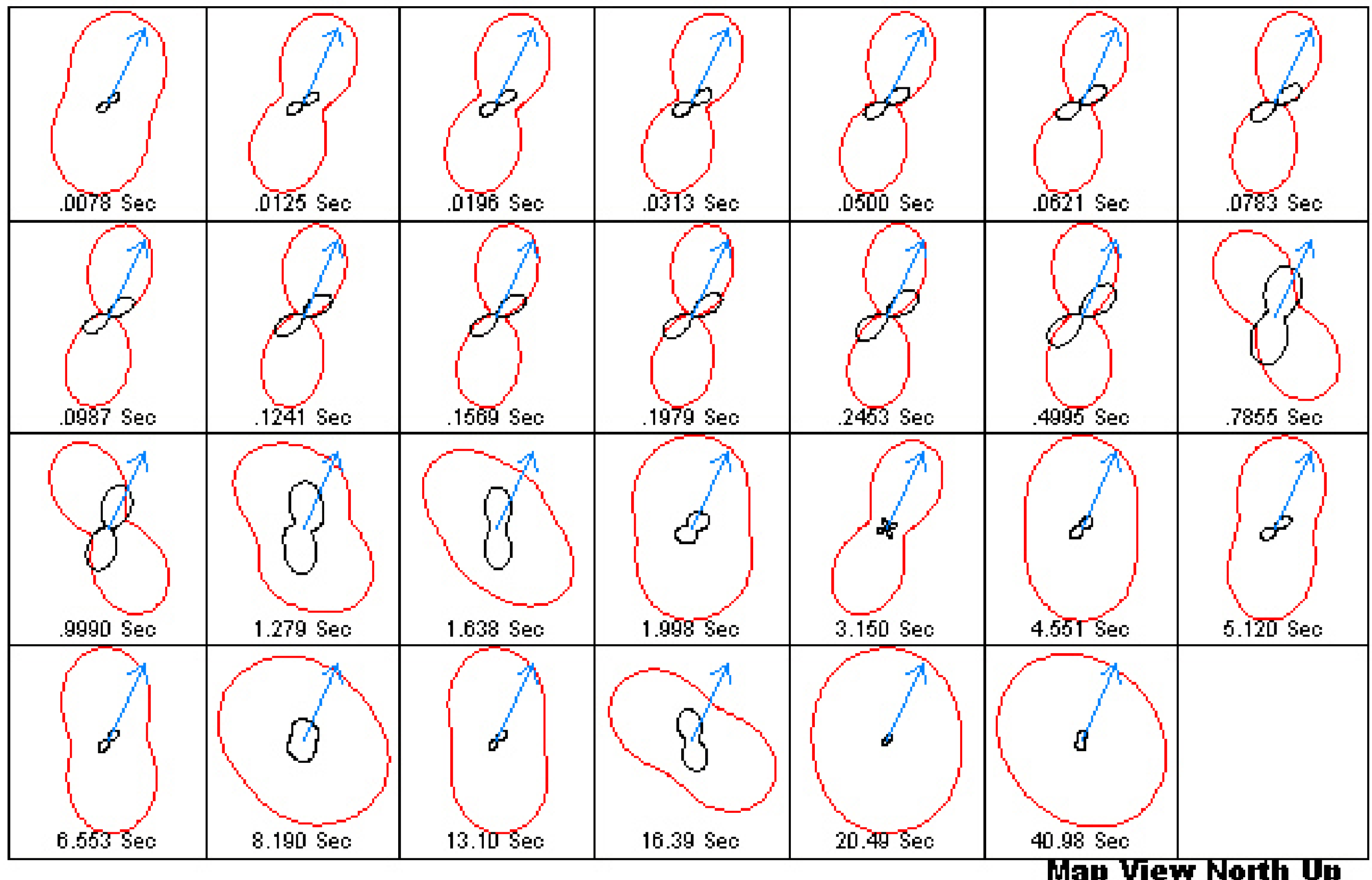




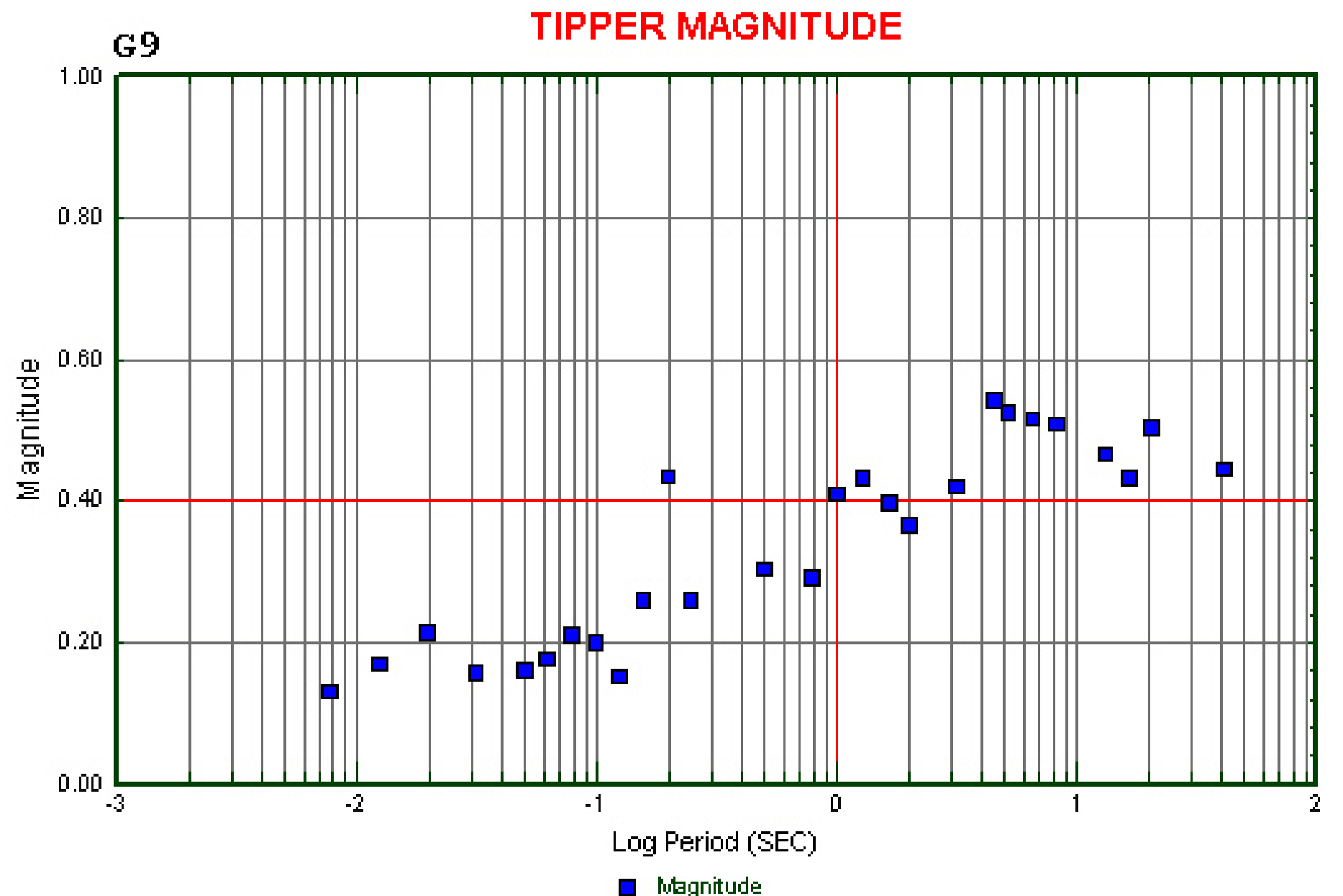




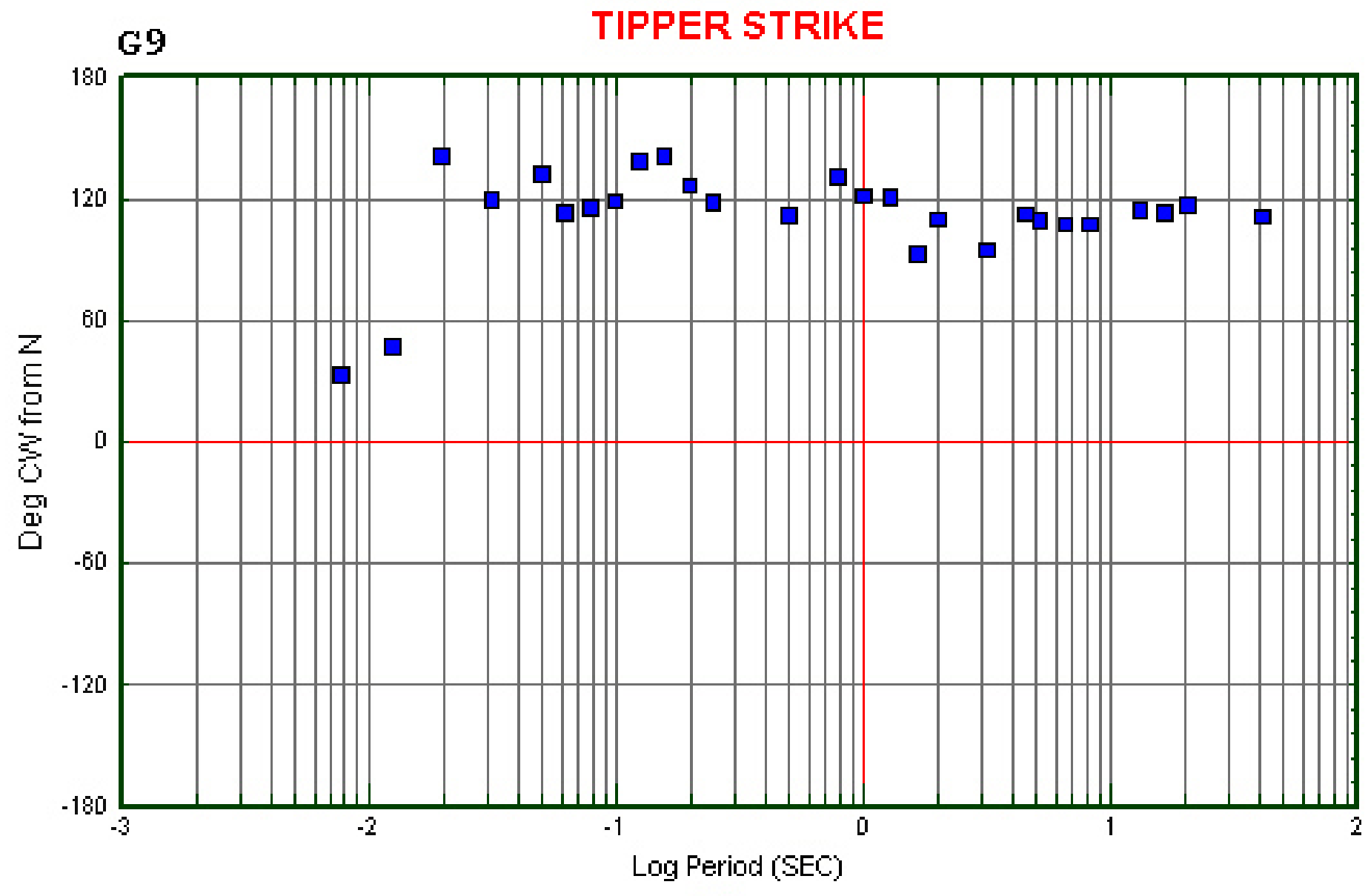




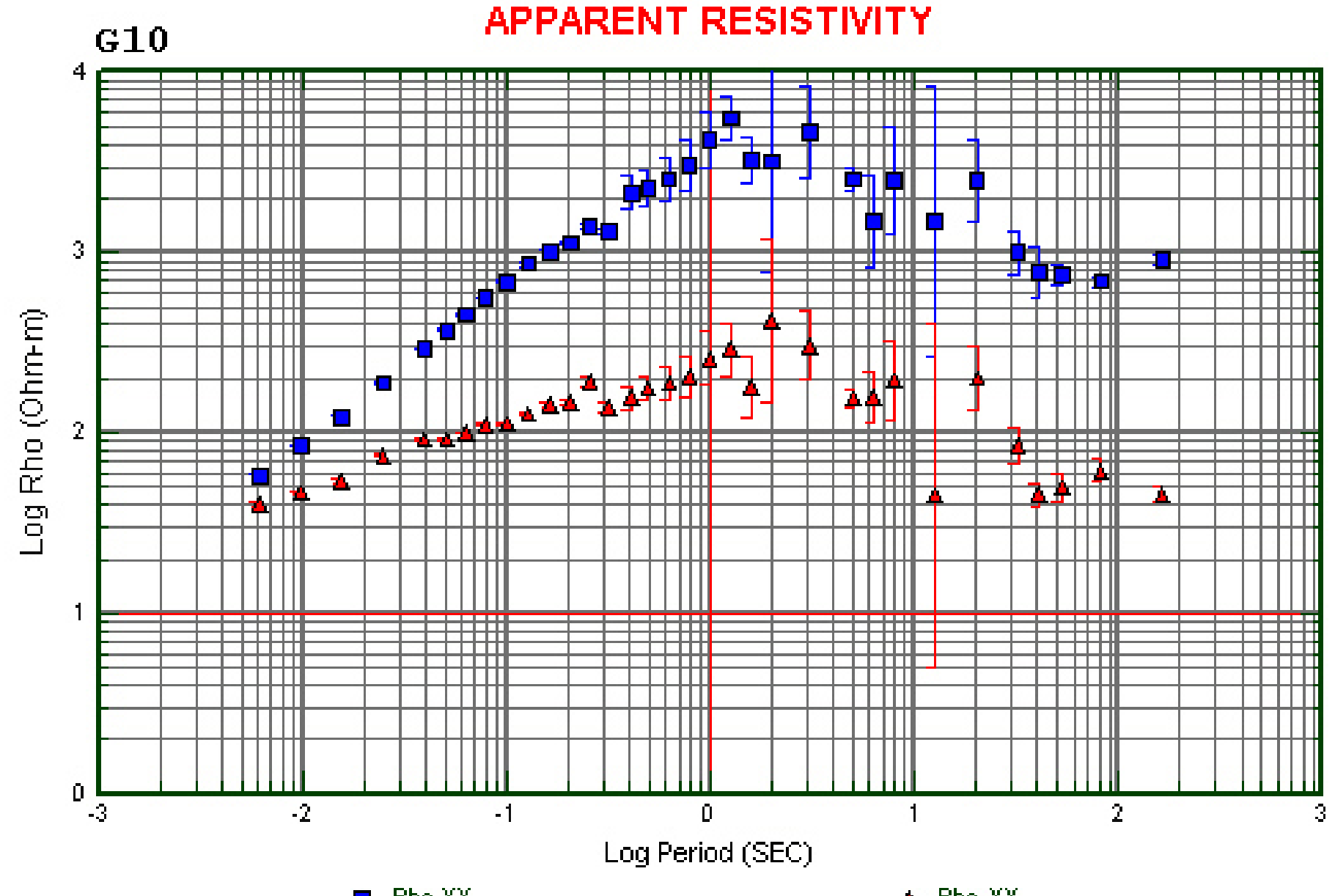

$\Delta$ Rho $W$ 


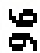

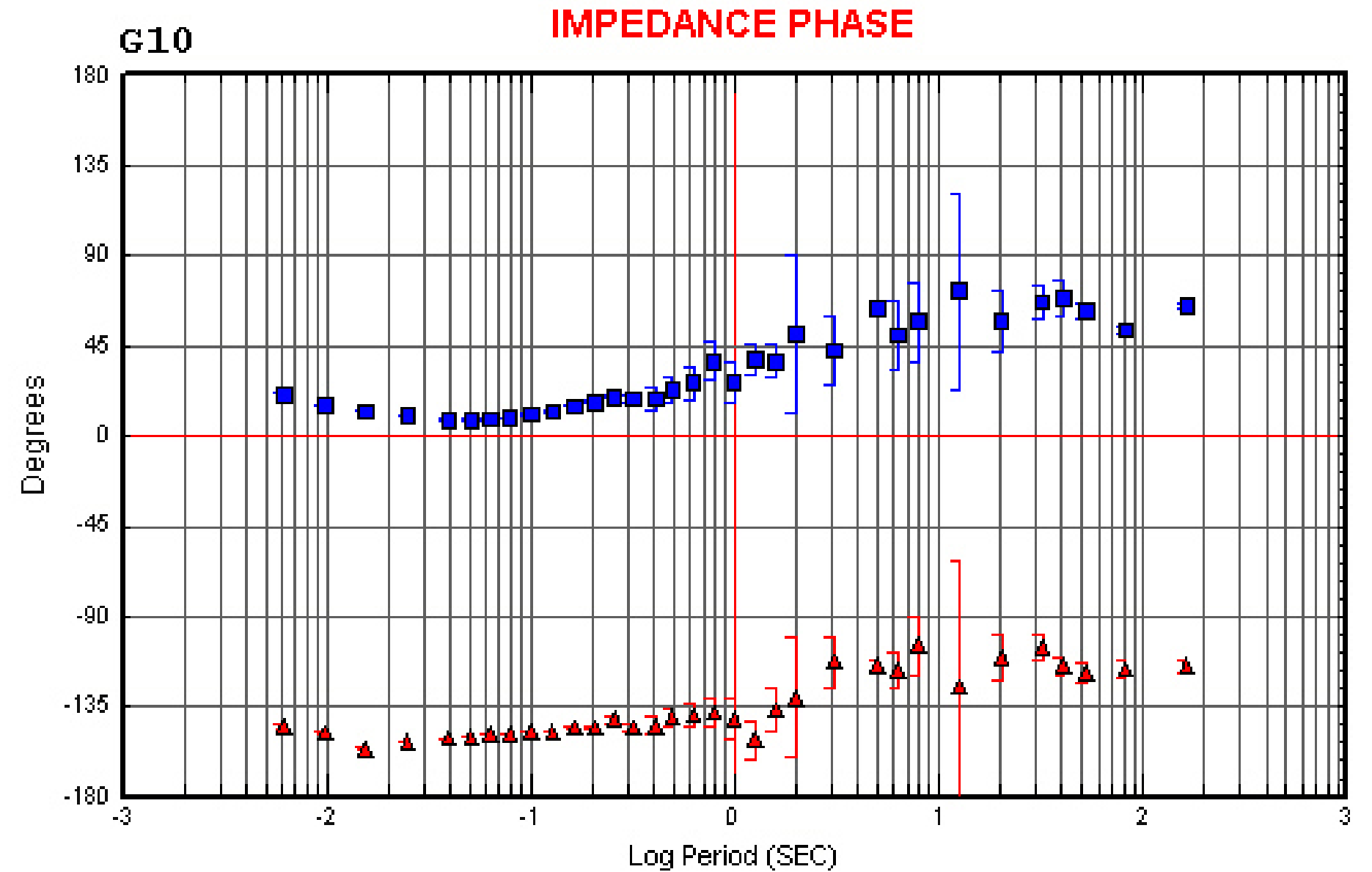

- Phase $X Y$ 


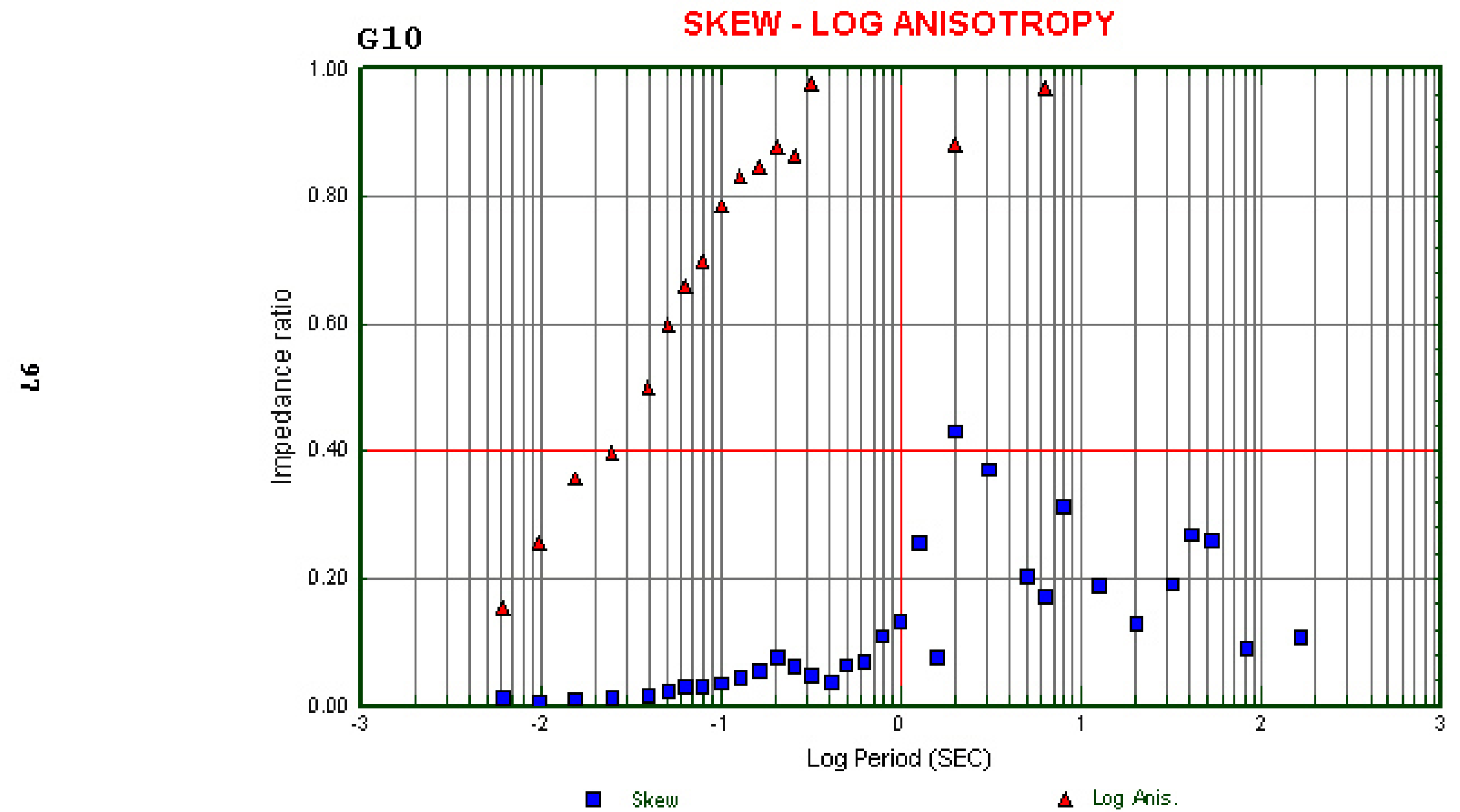




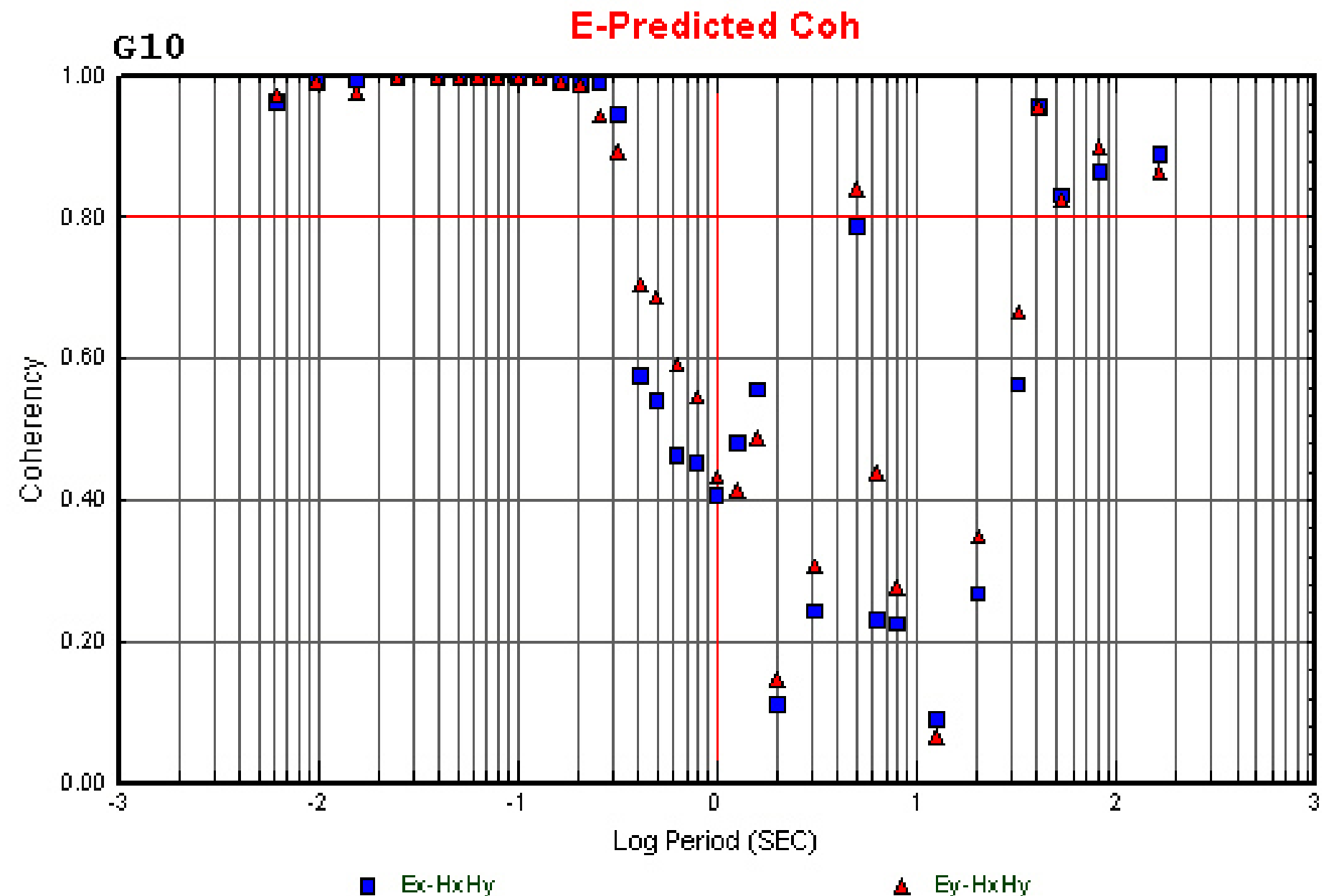




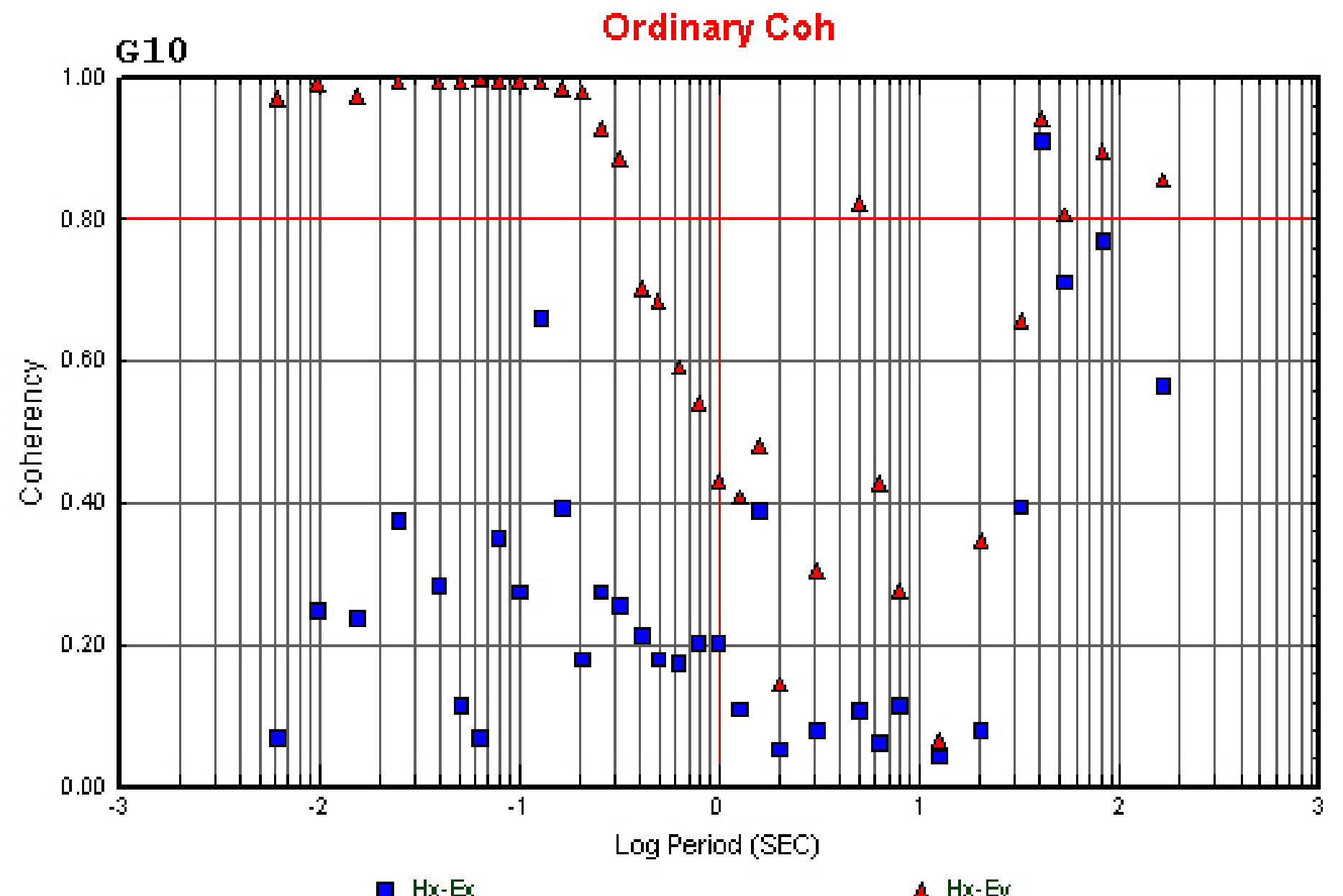


E

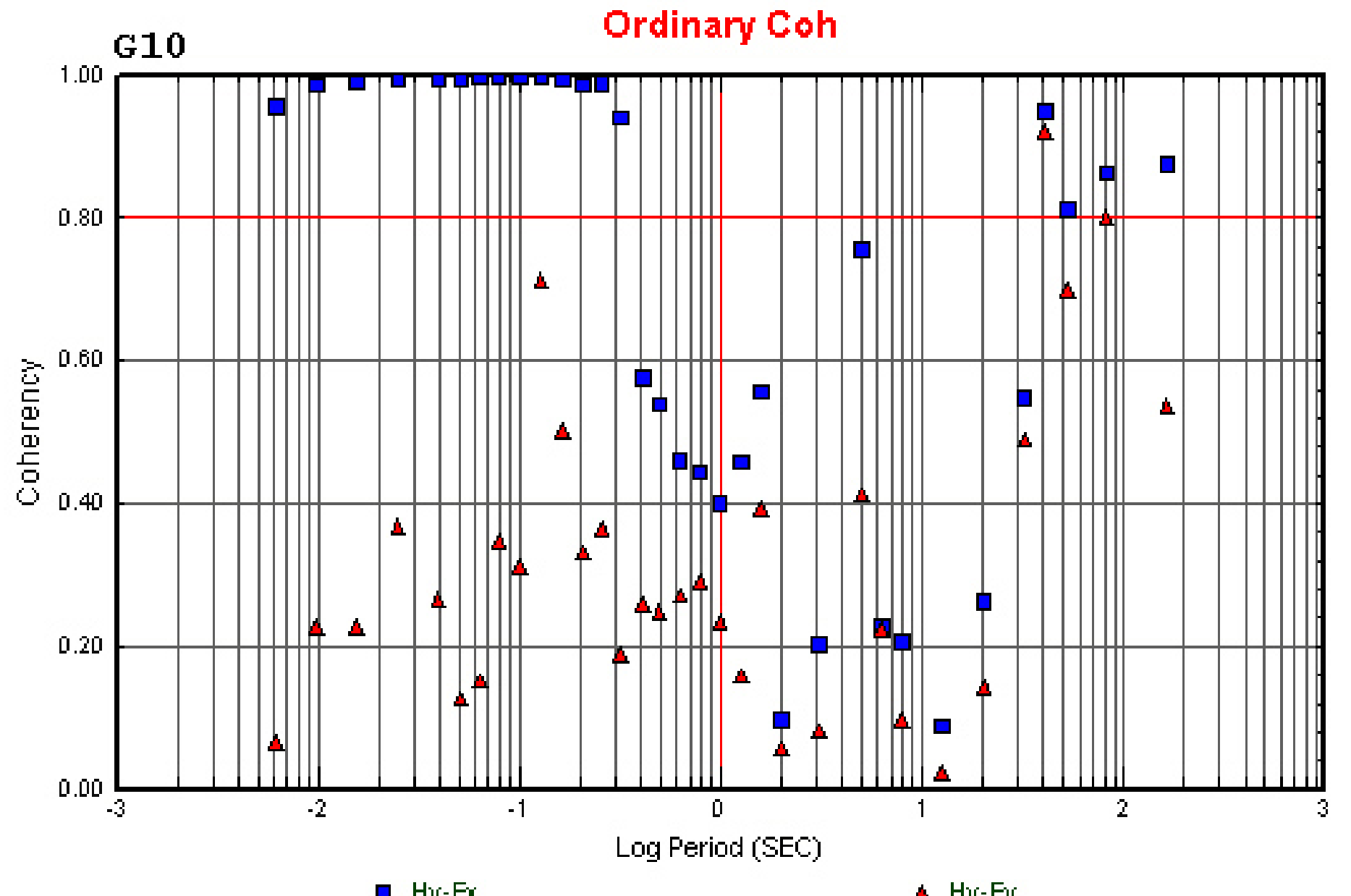




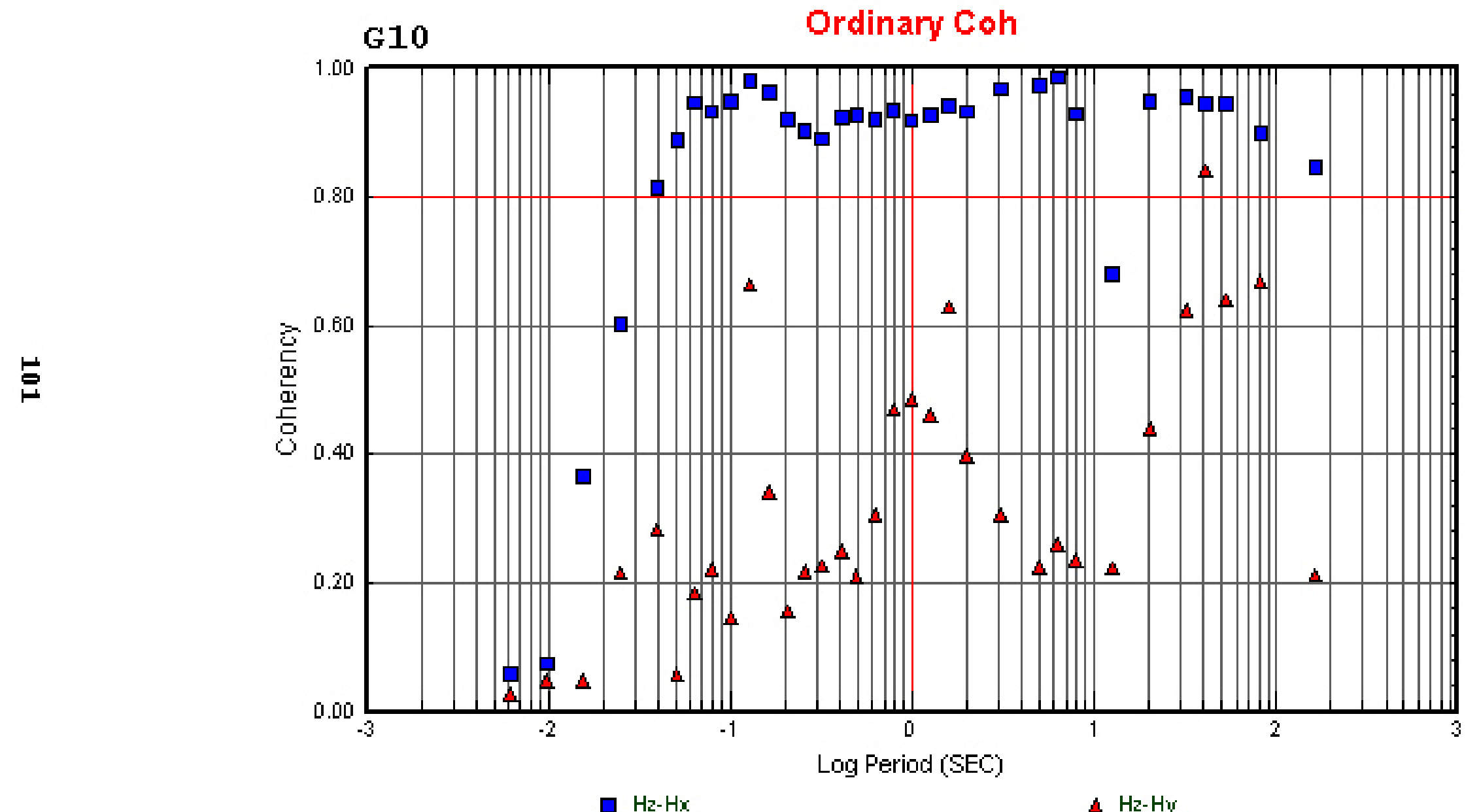




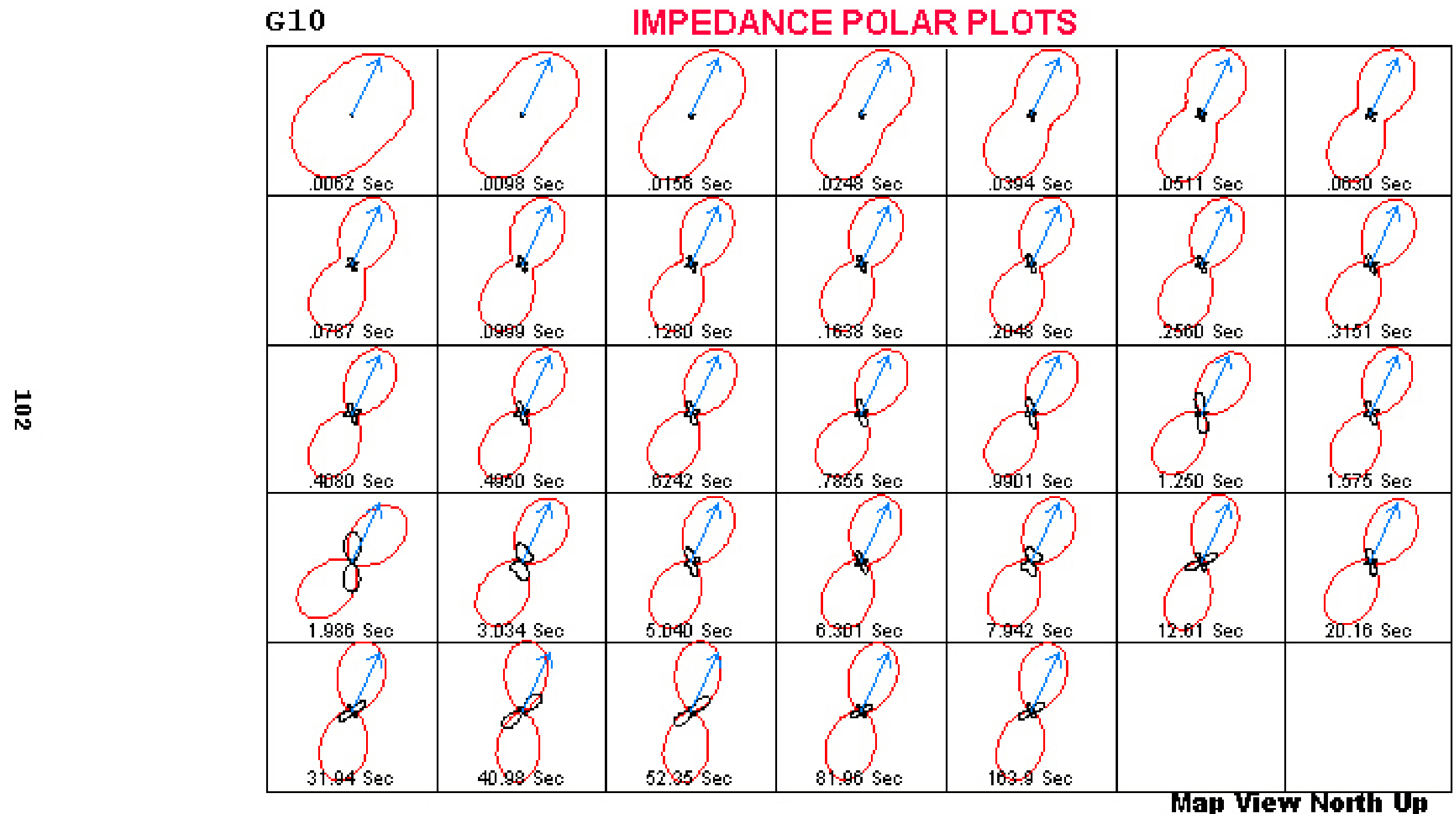




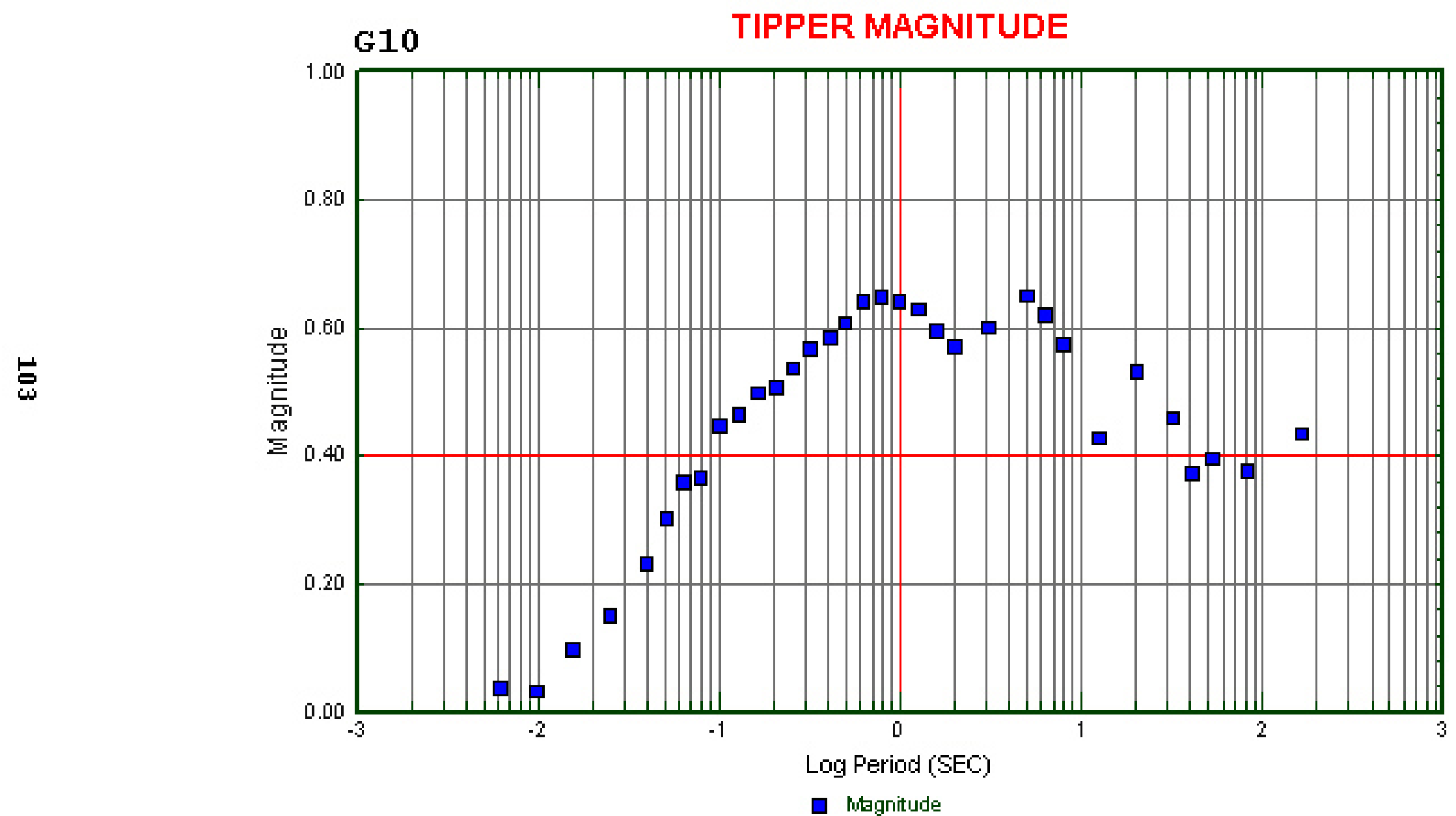


点

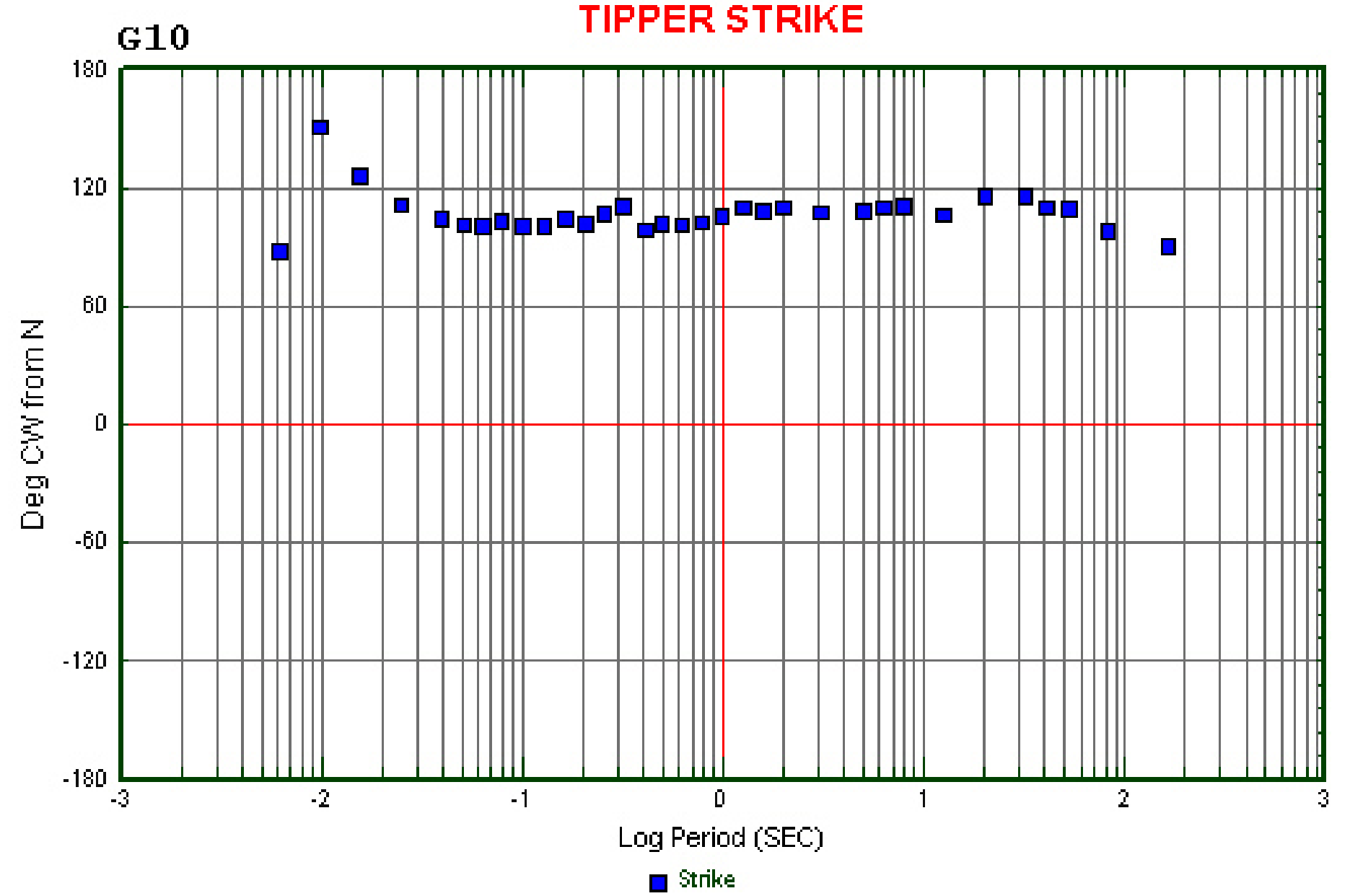




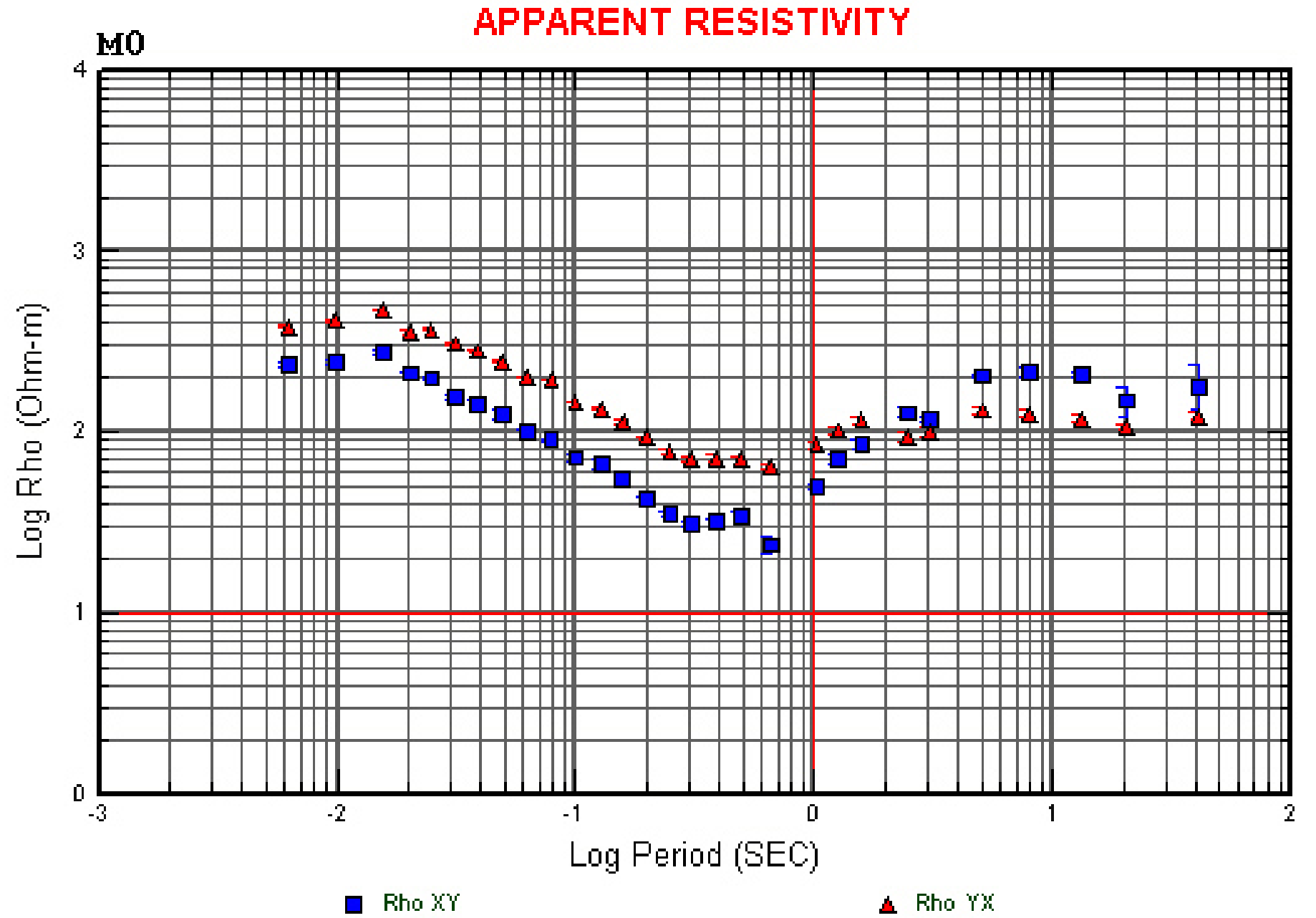


Бू

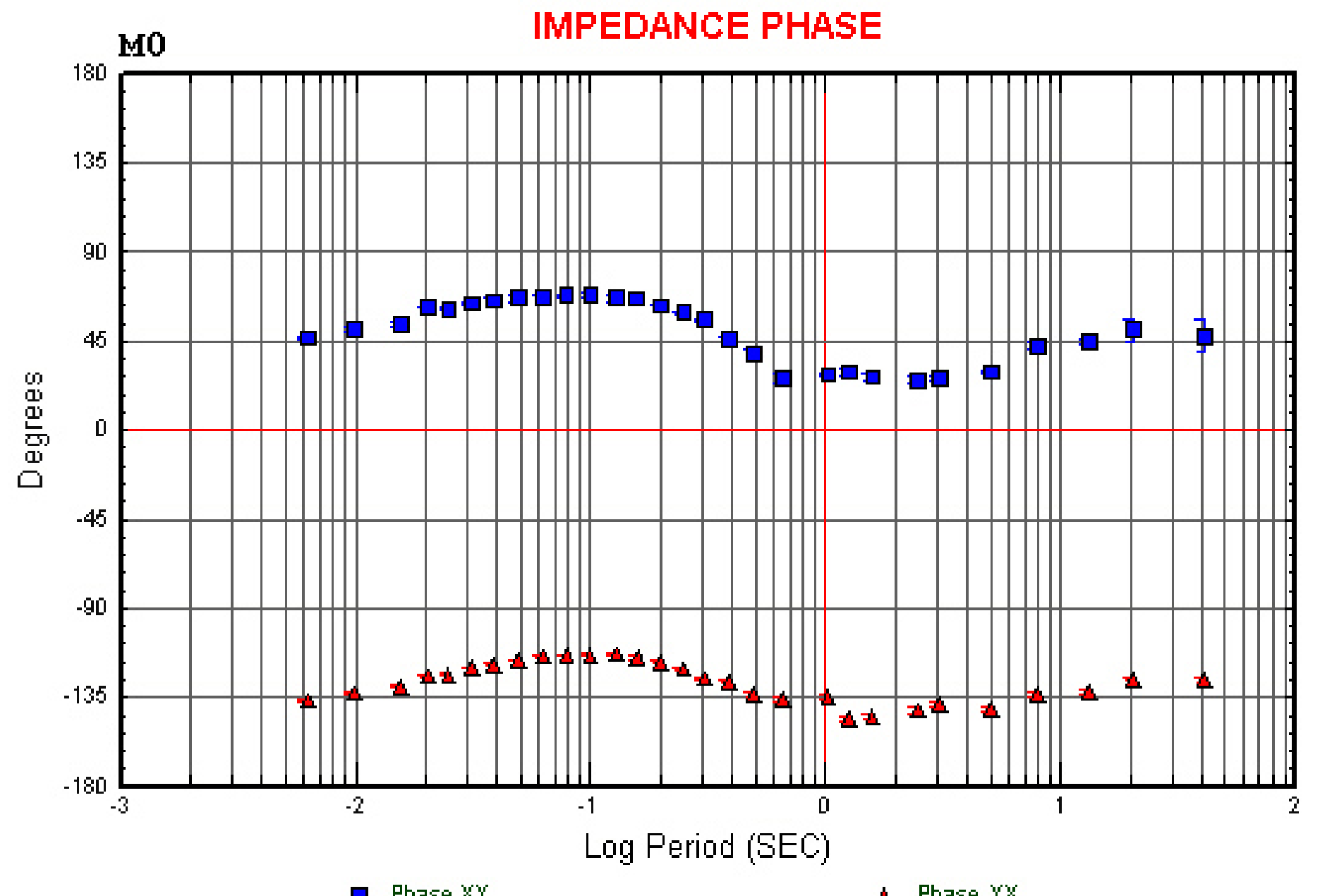




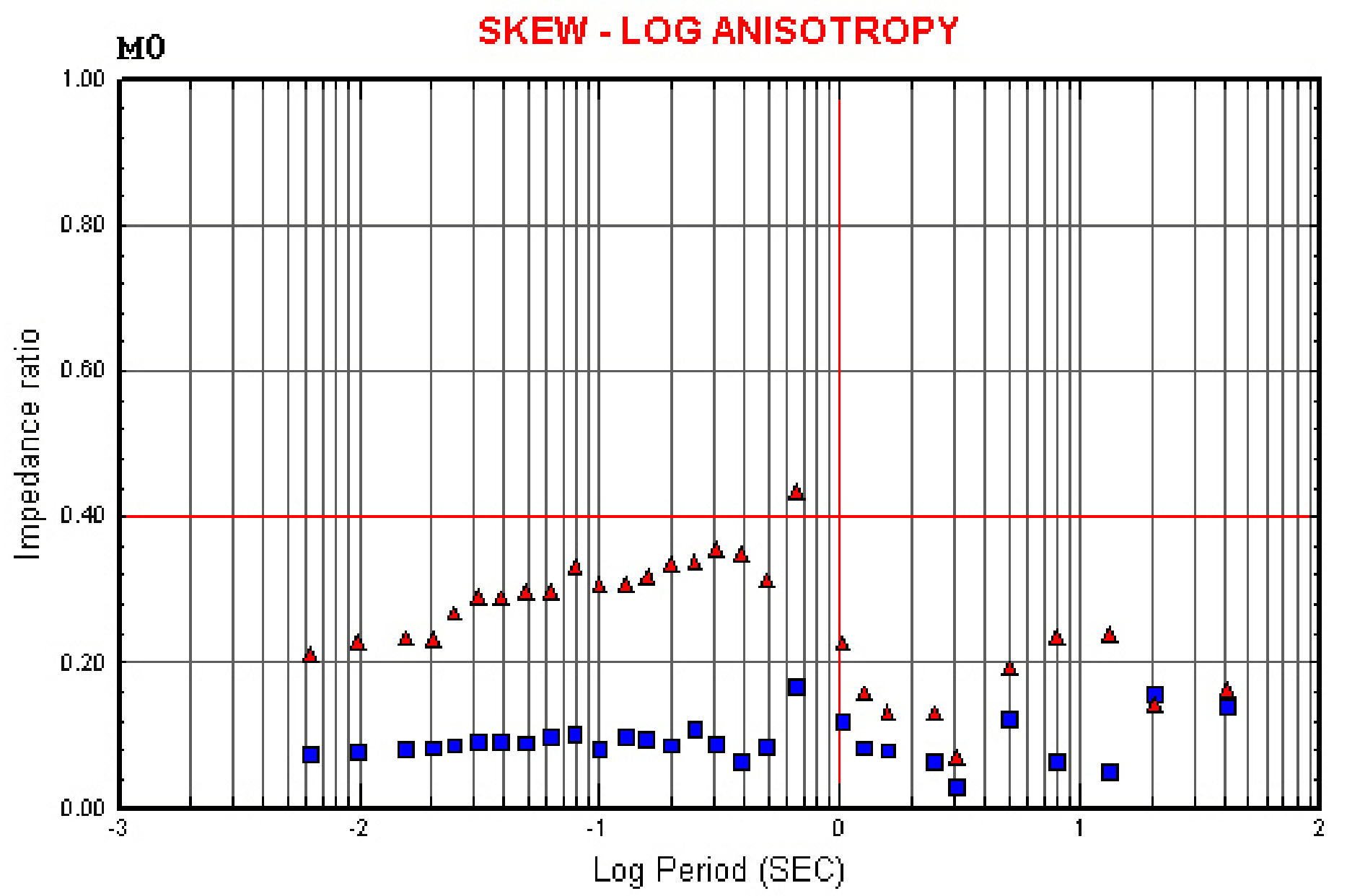

口 Skew A Log Anis 


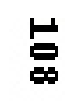

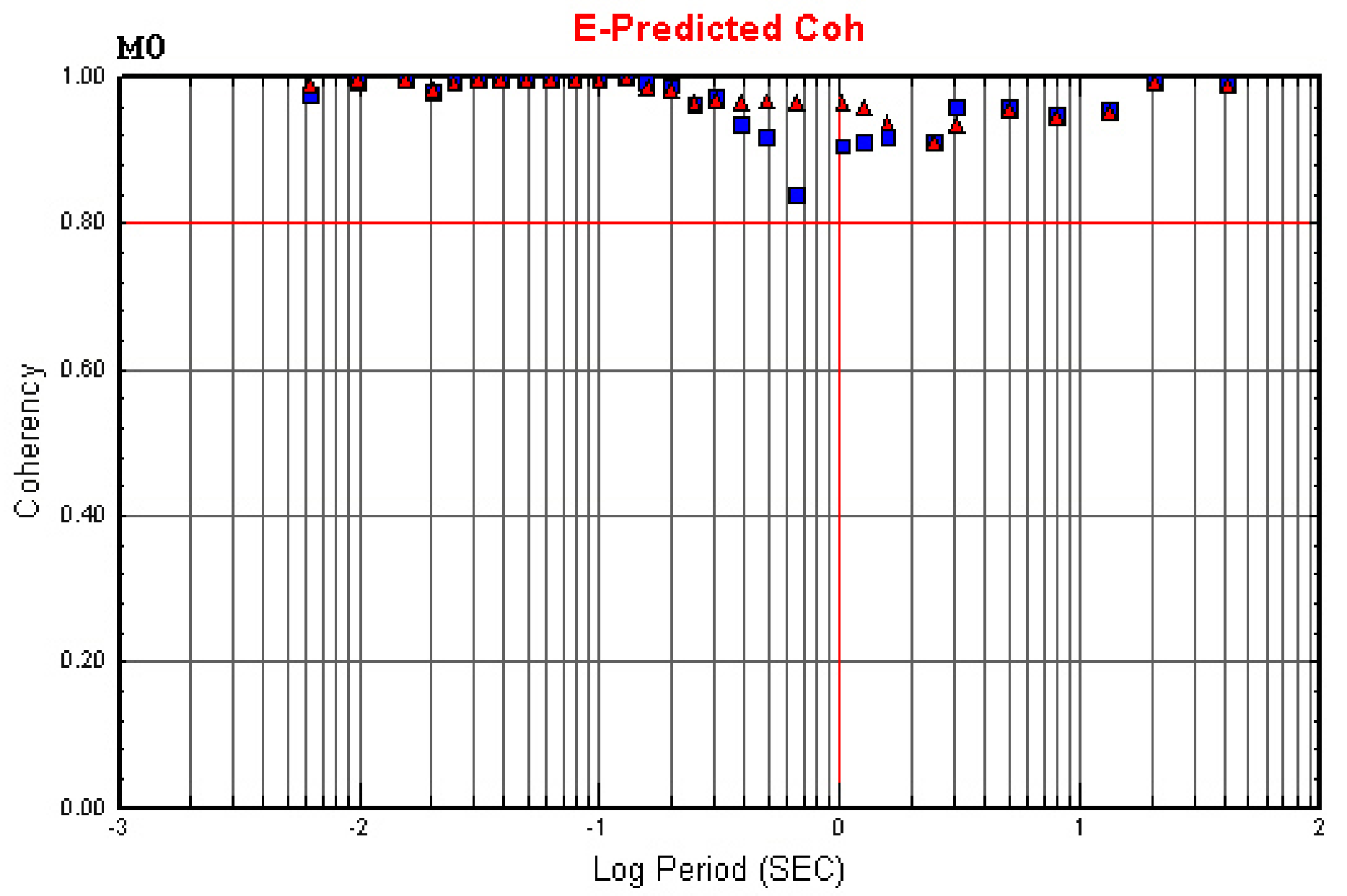

a $\mathrm{Ex}-\mathrm{Hx} \mathrm{Hy}$

A $\mathrm{Ey}-\mathrm{HxHy}$ 


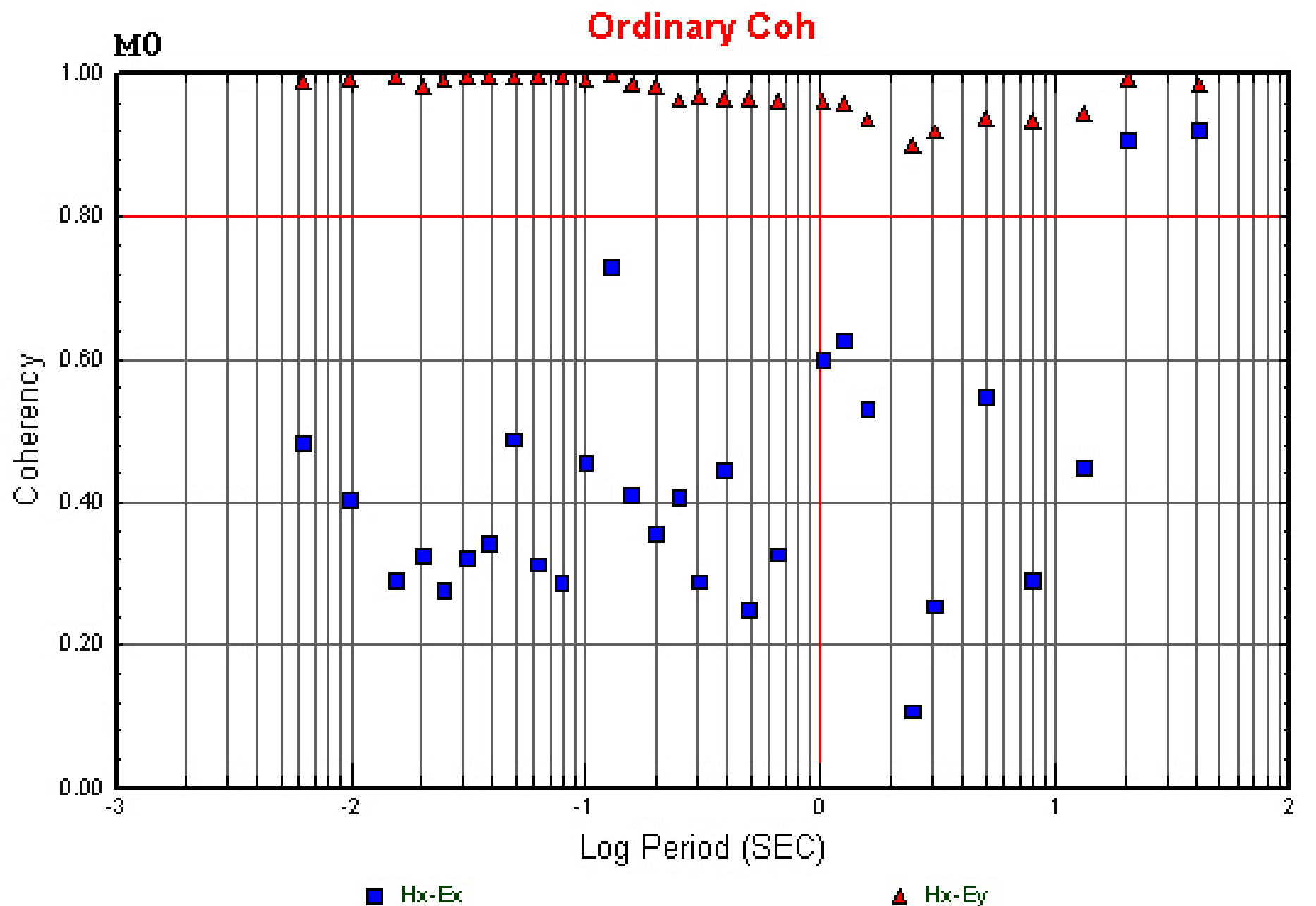


$E$

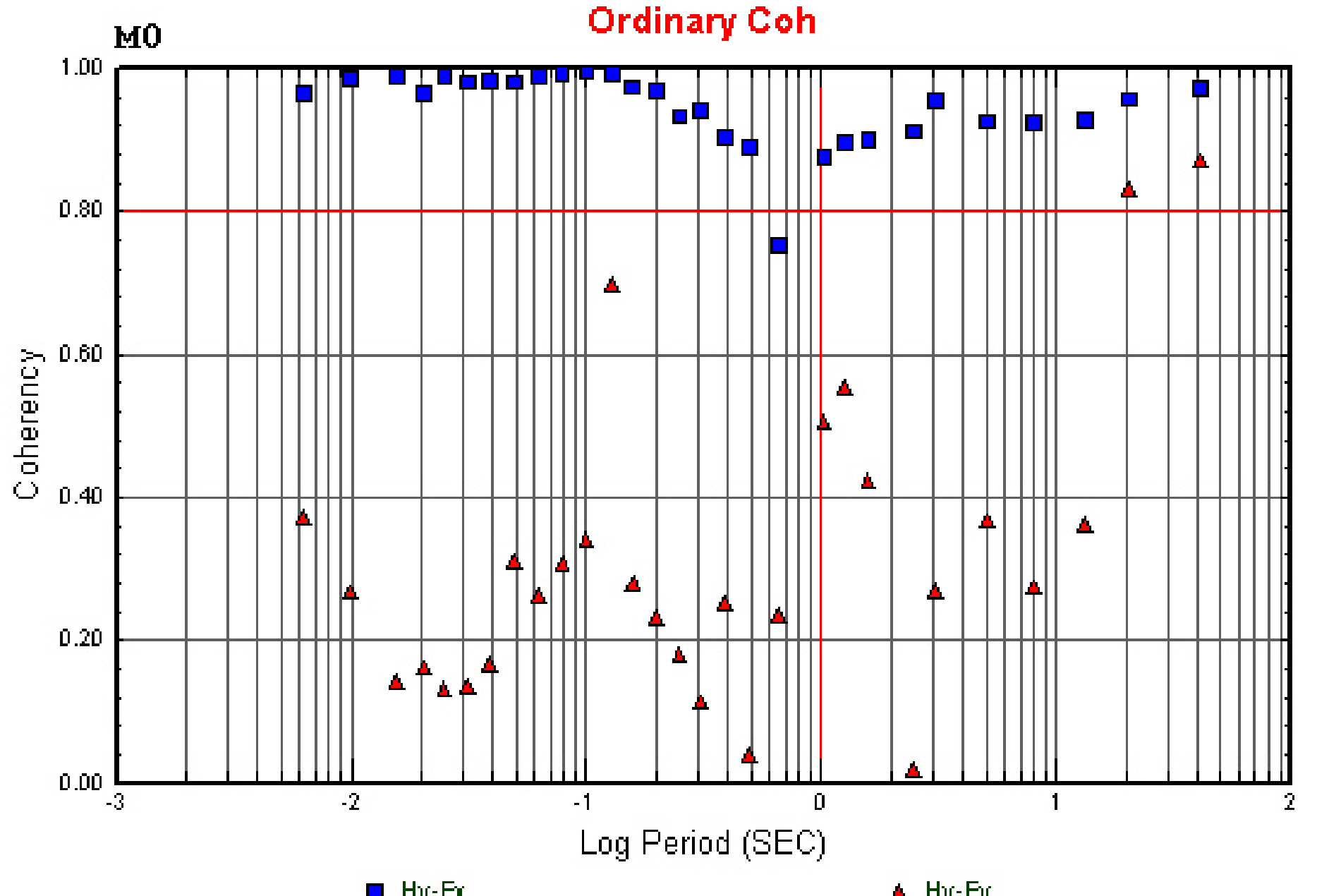




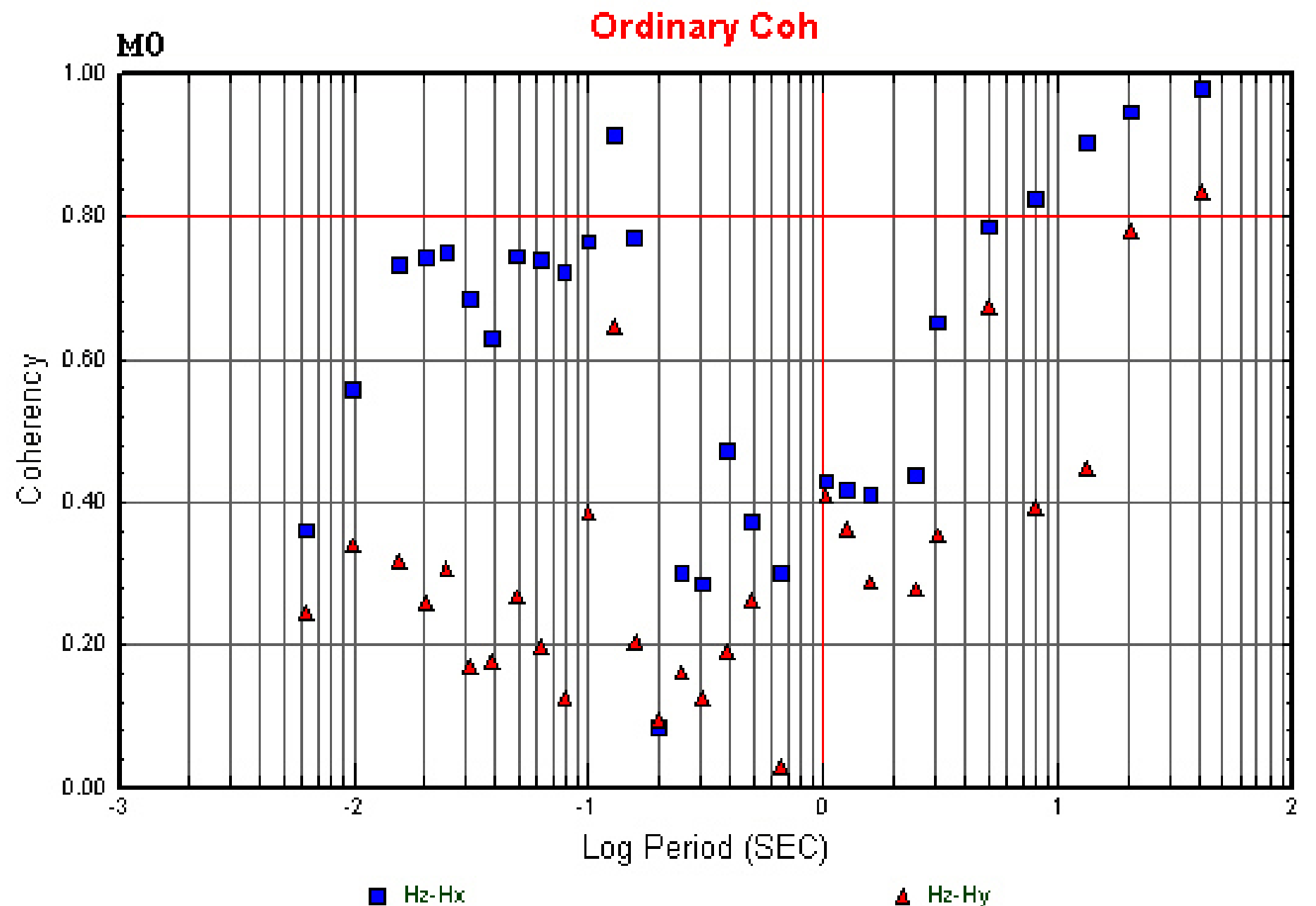




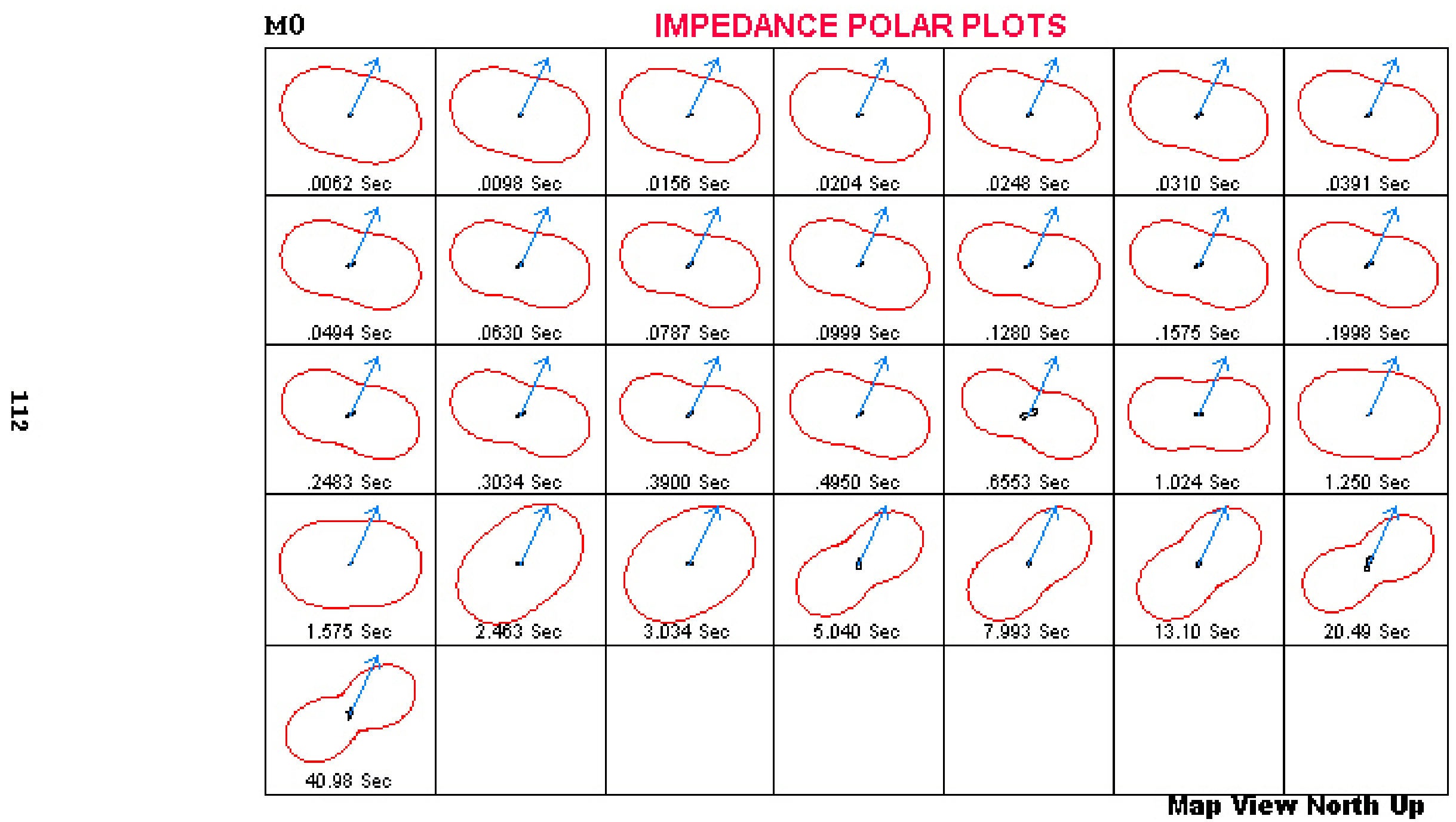


$\Xi$

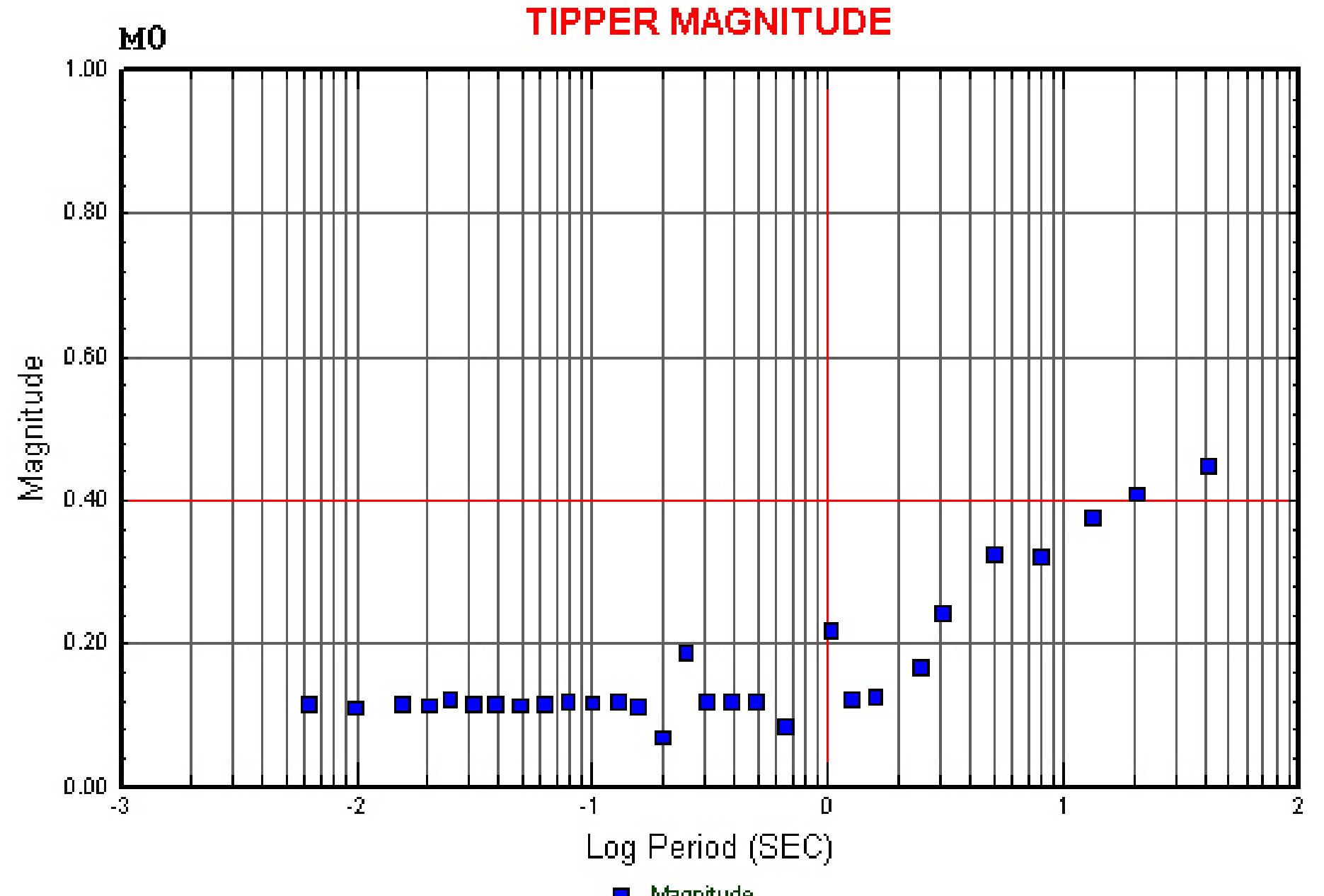




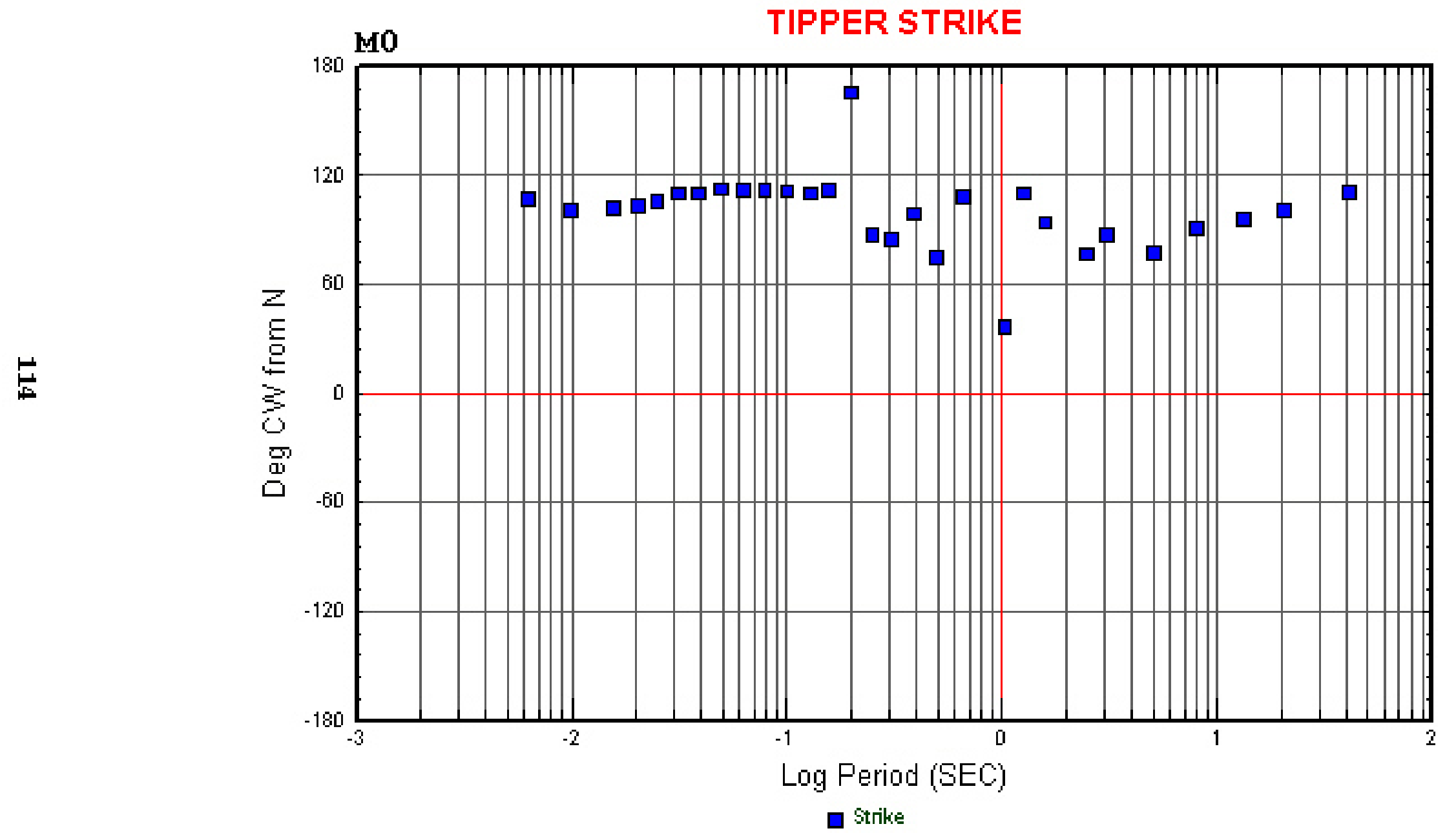




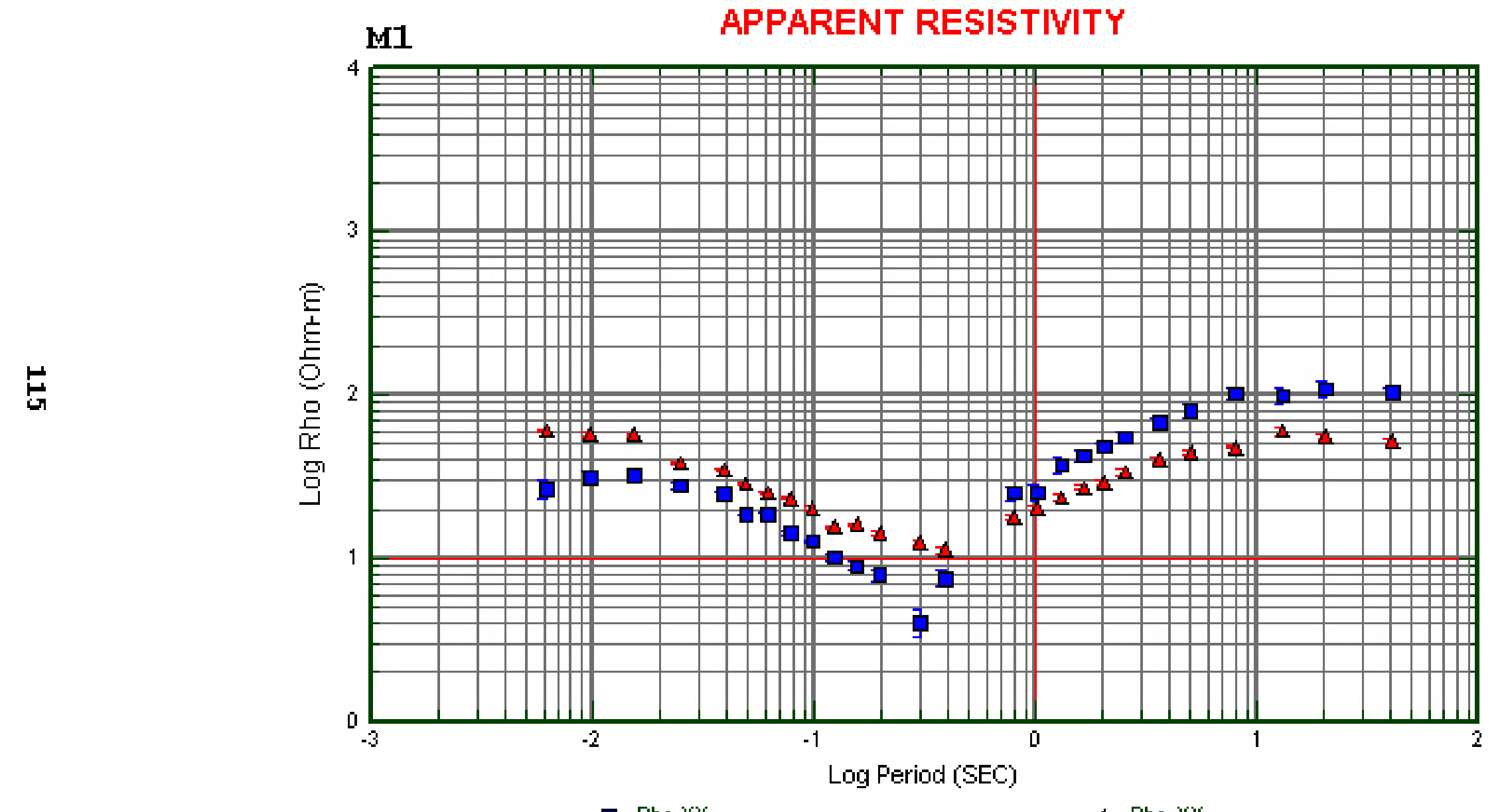

- Rho $X Y$

$\Delta$ Rho $Y x$ 


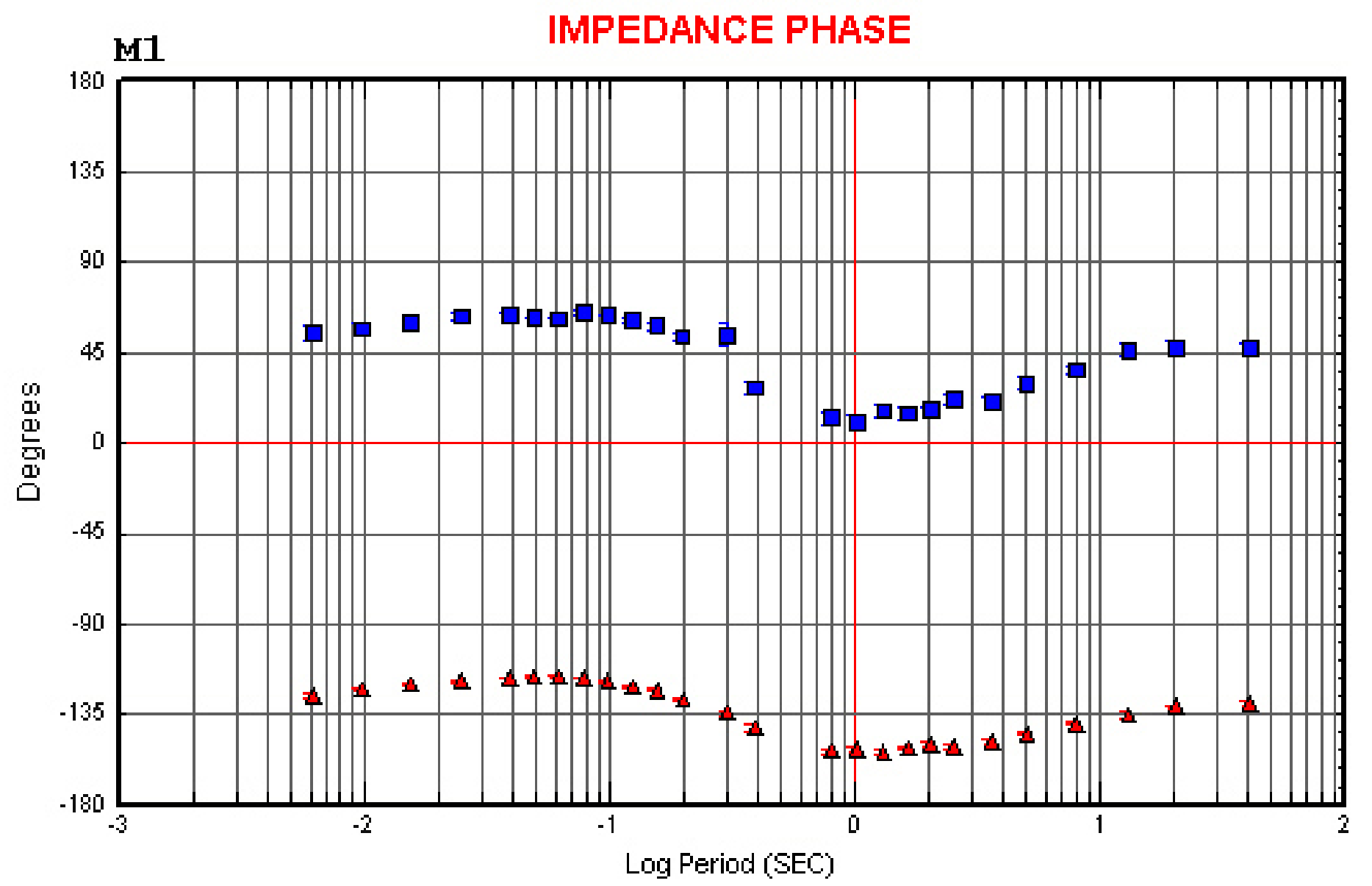

- Phase $X Y$ 


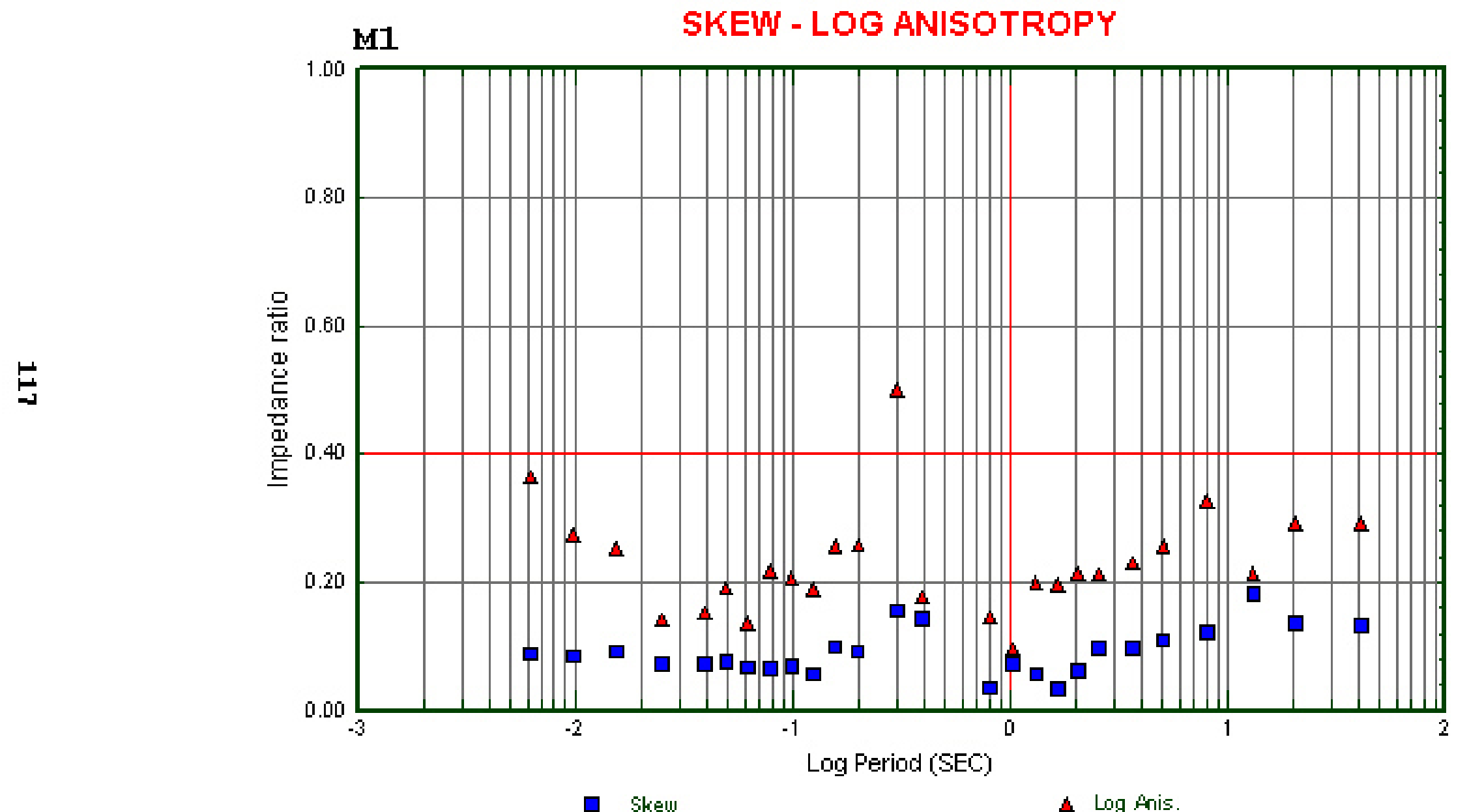


5

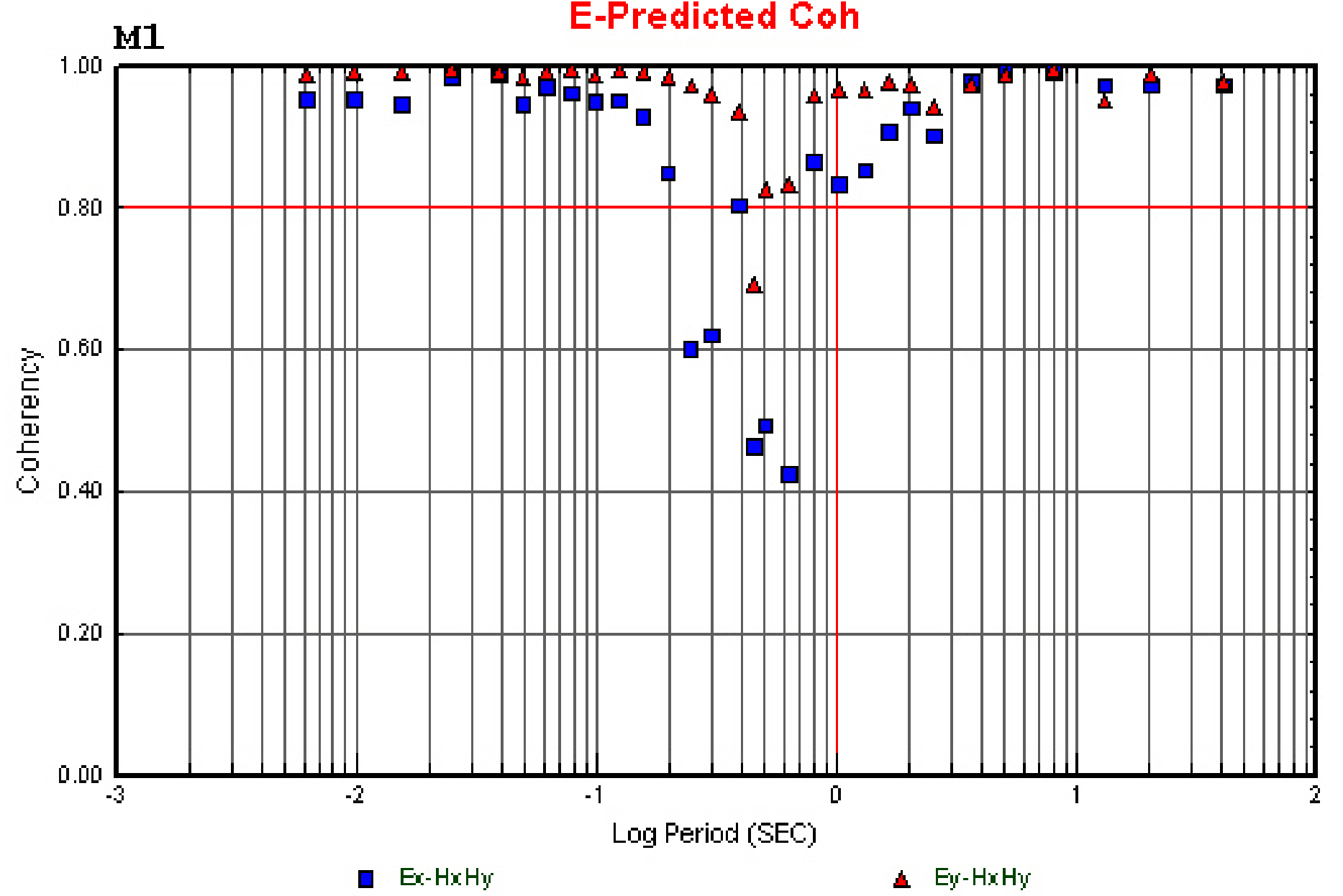


占

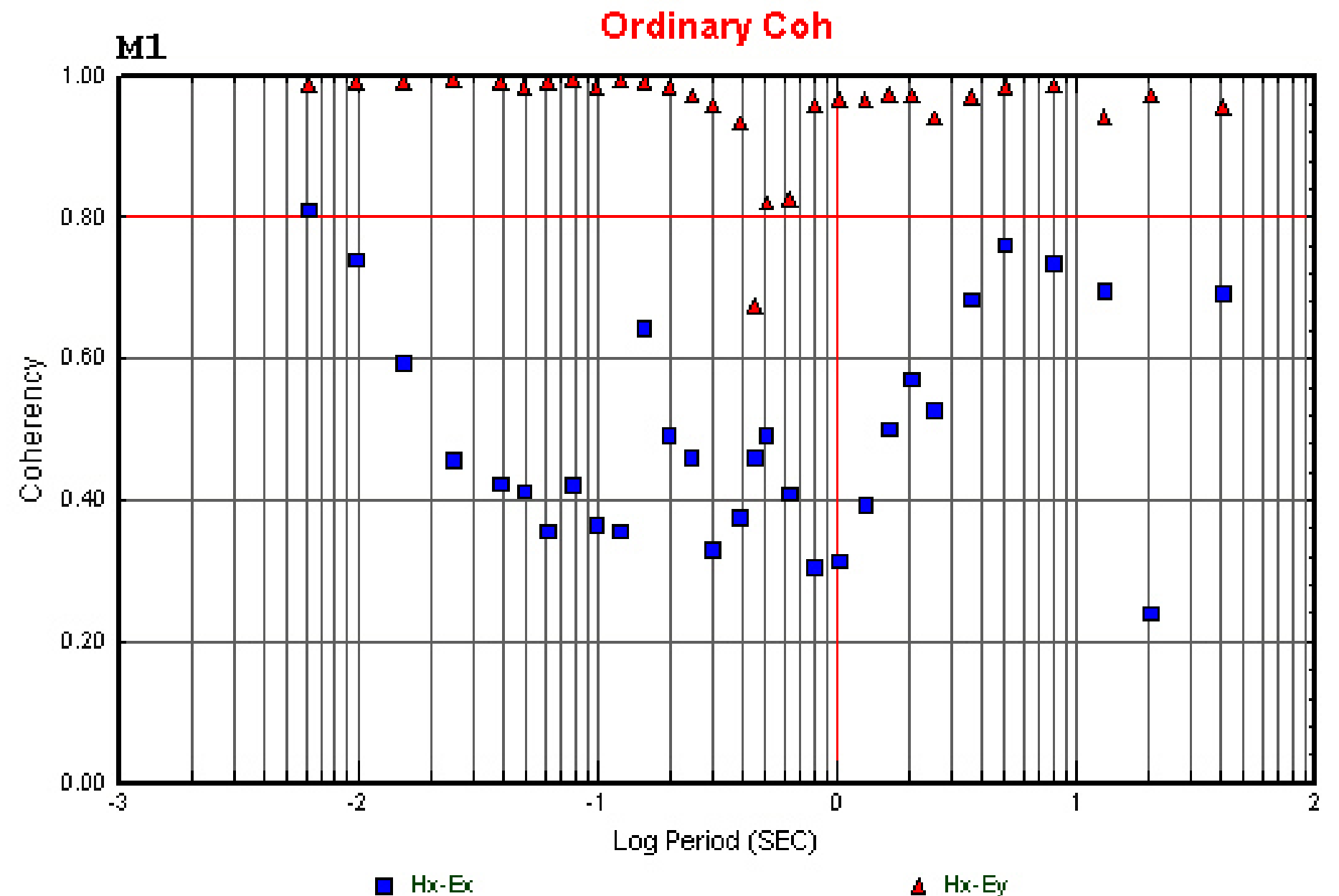




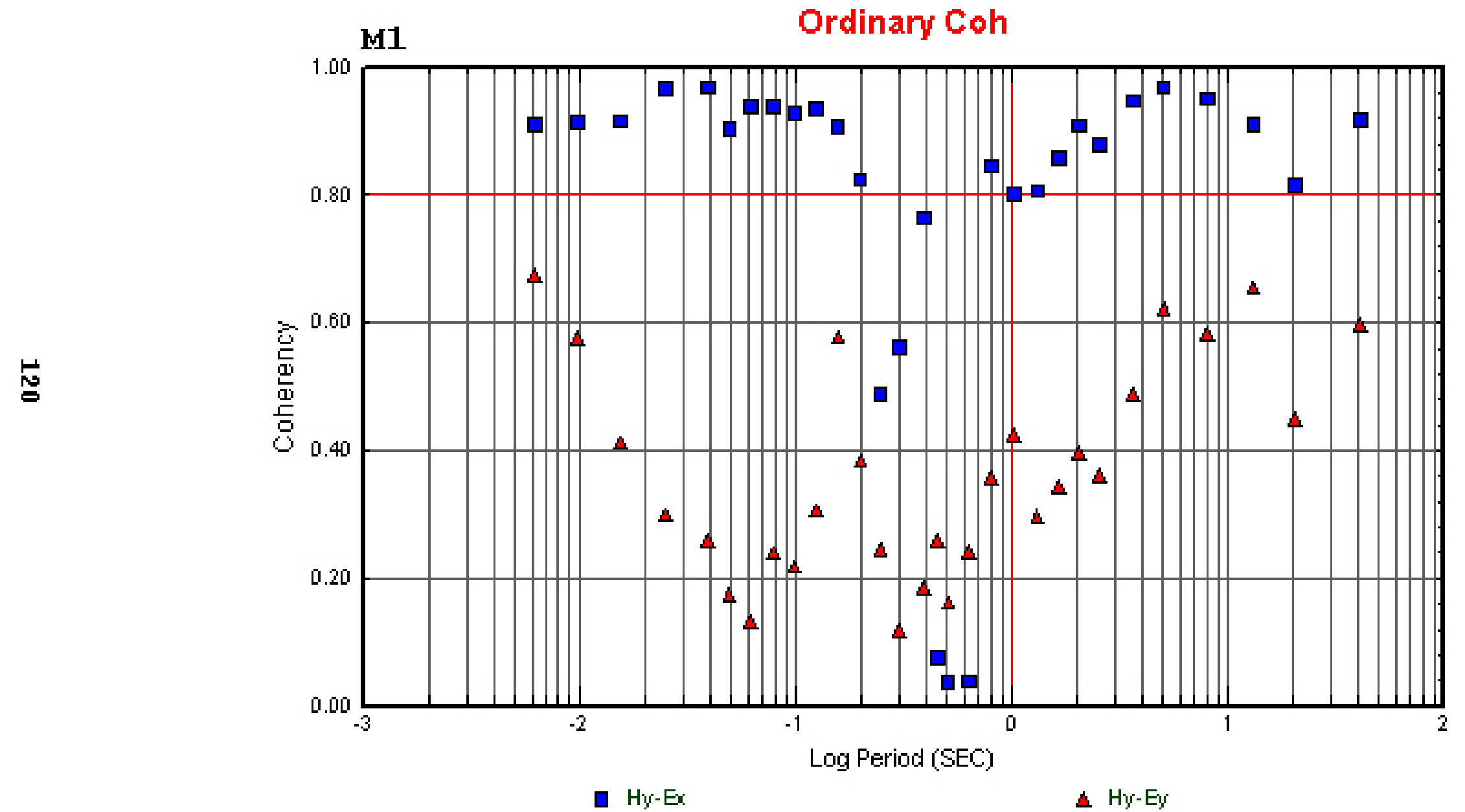




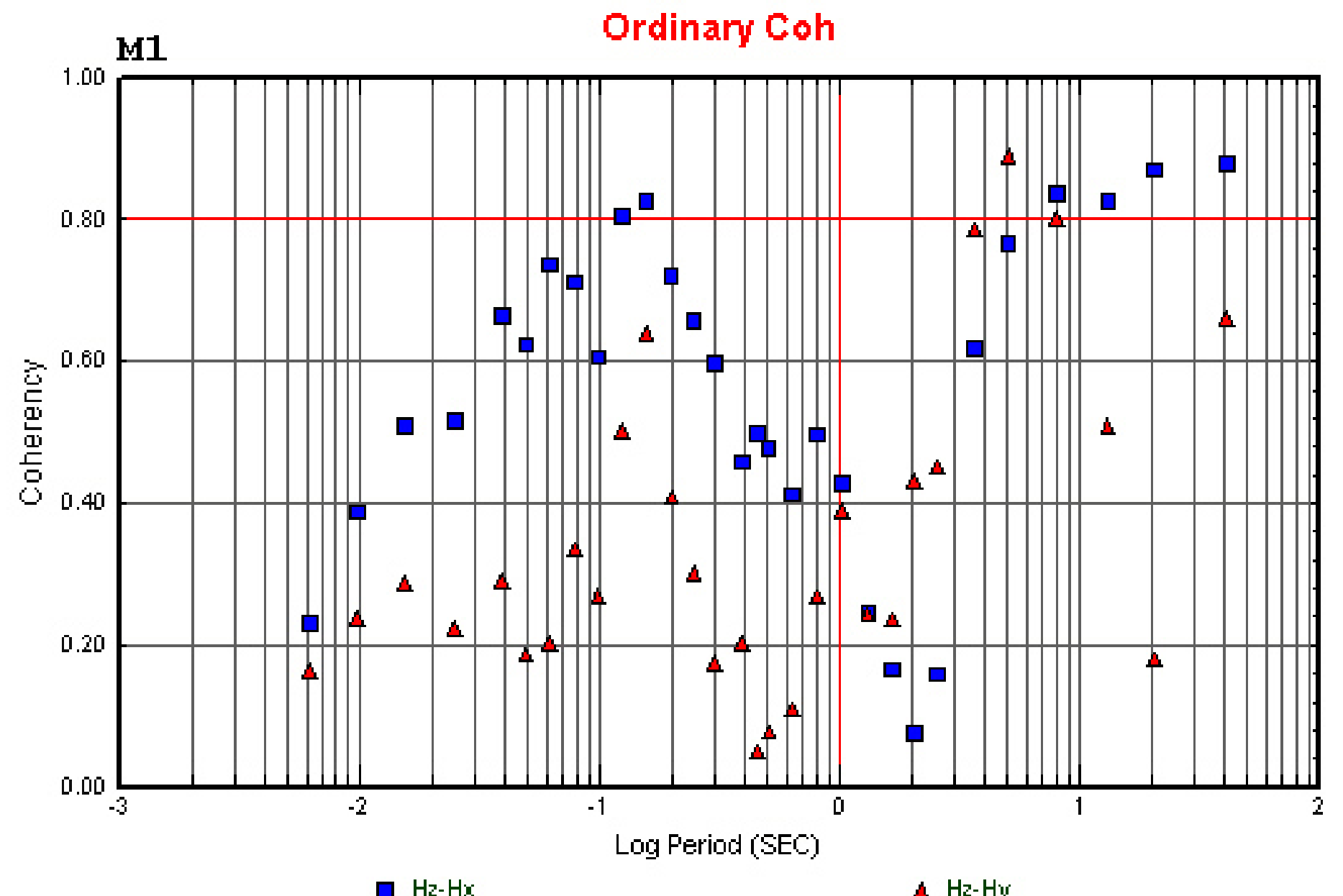




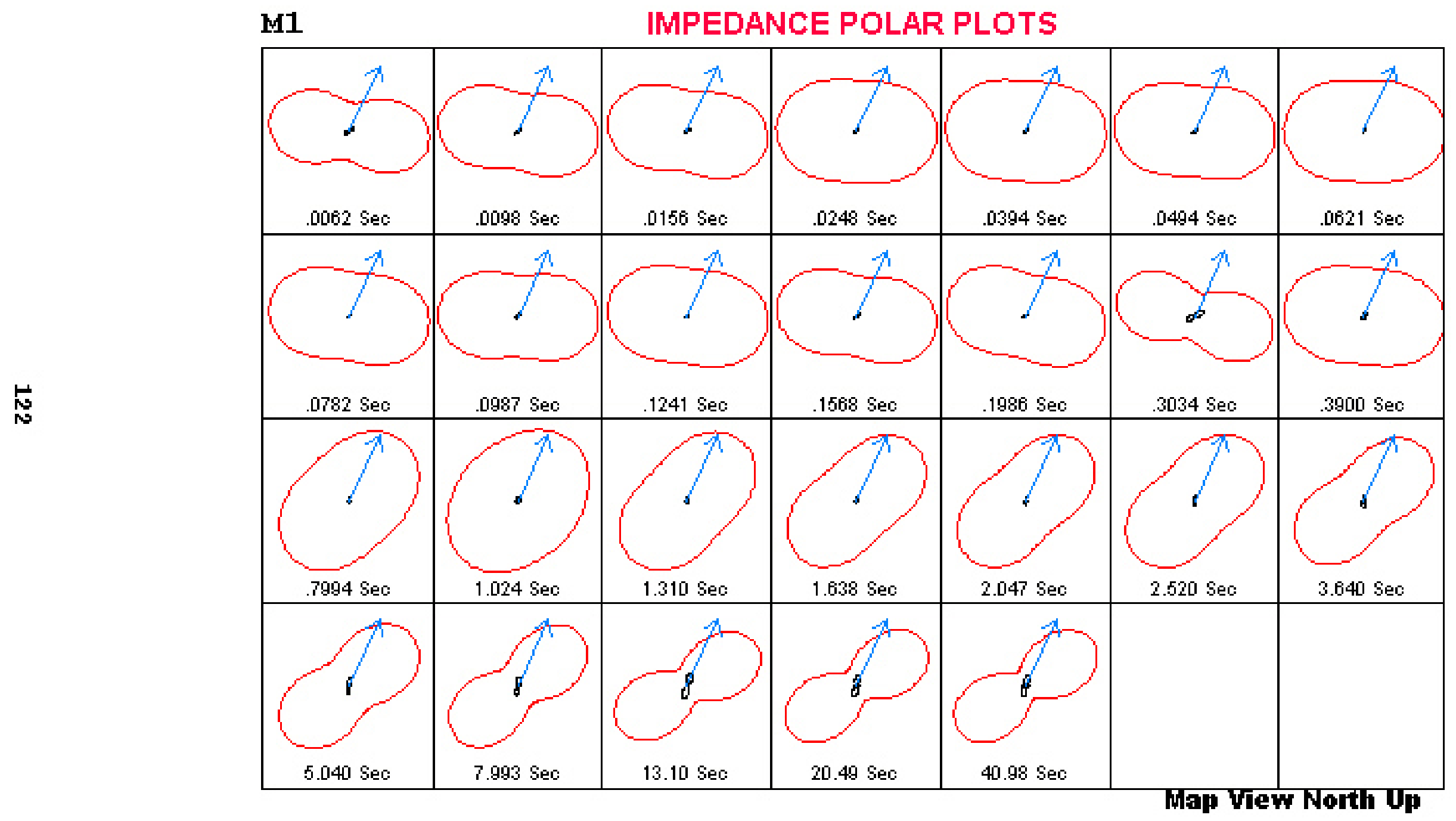




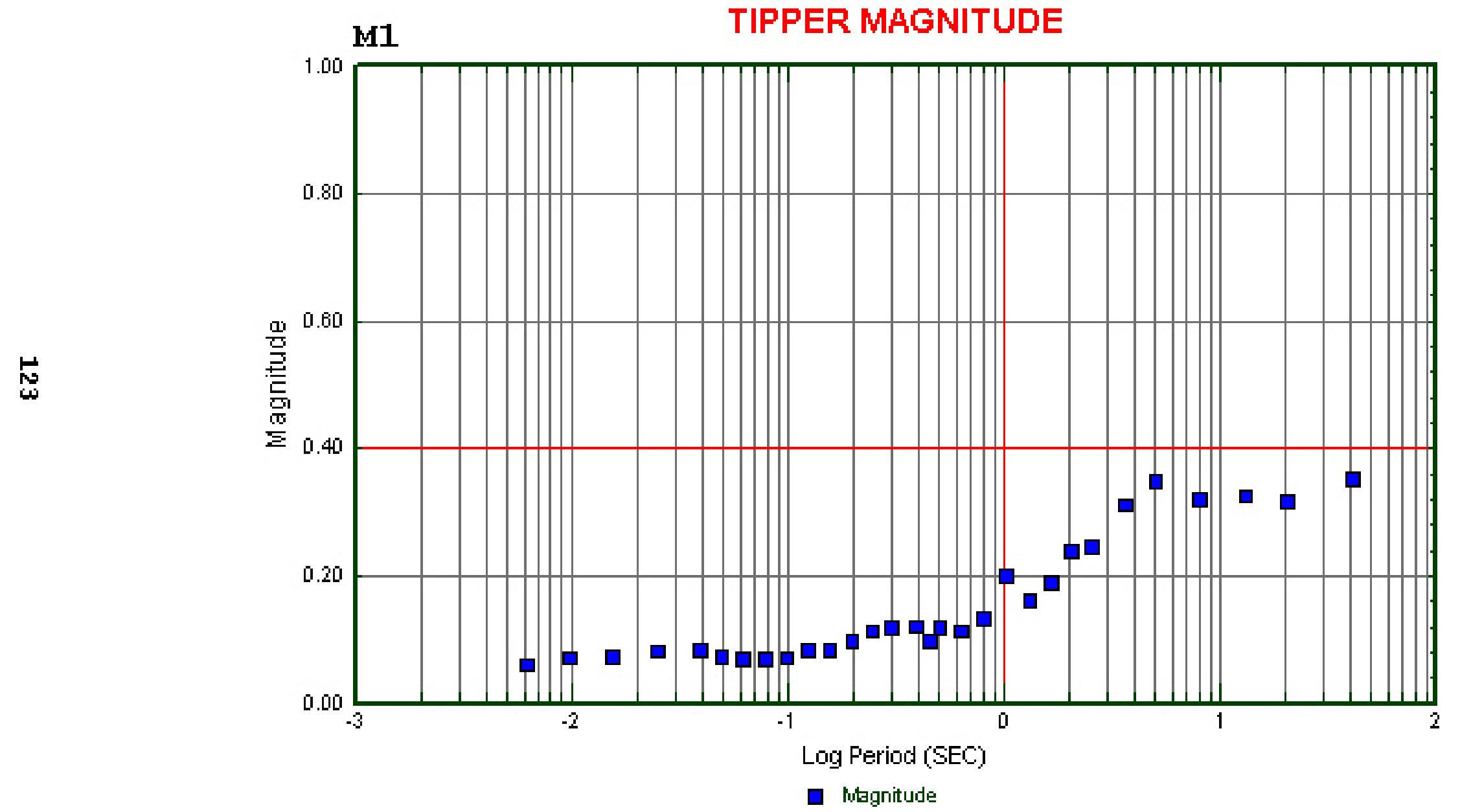




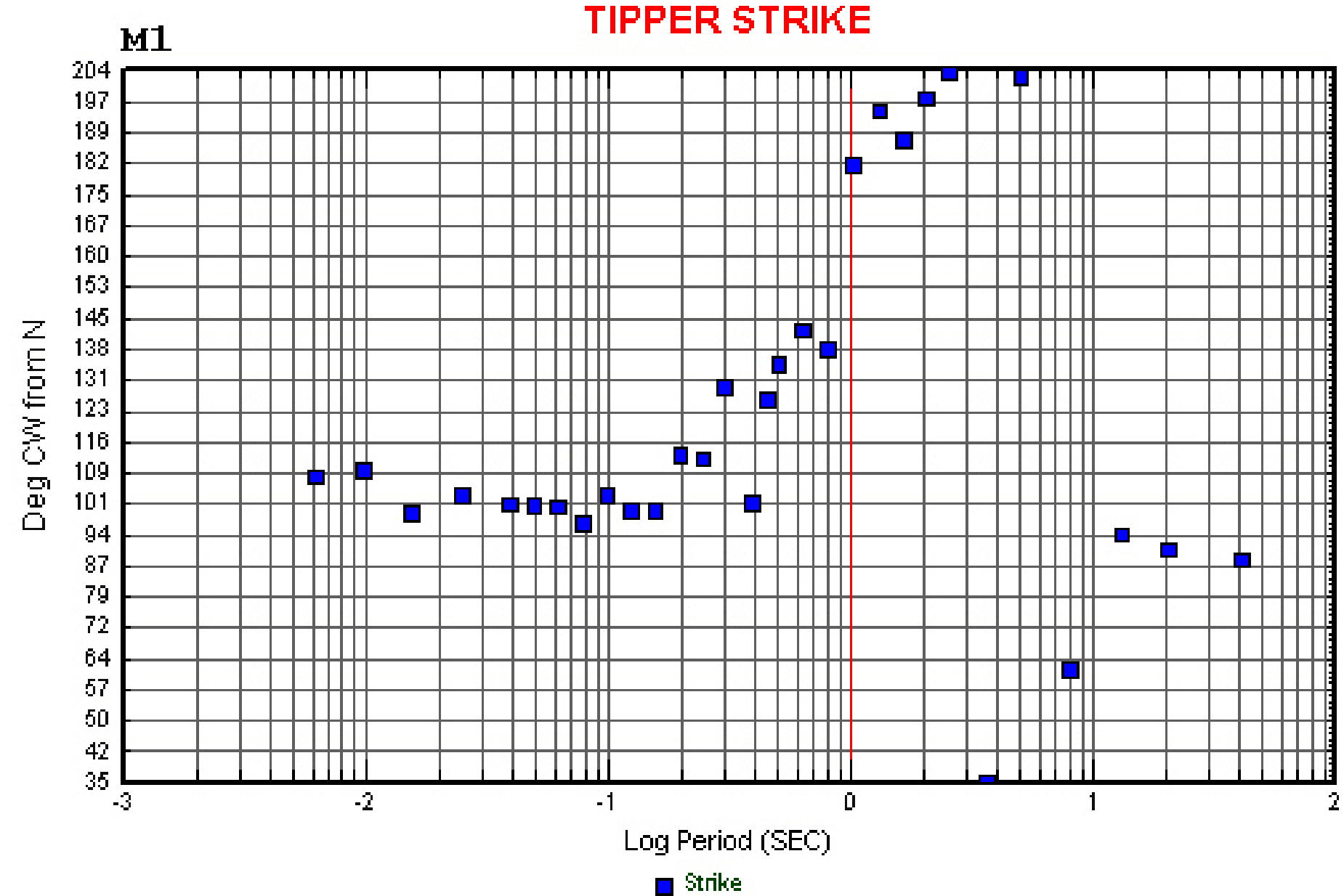

- Strike 


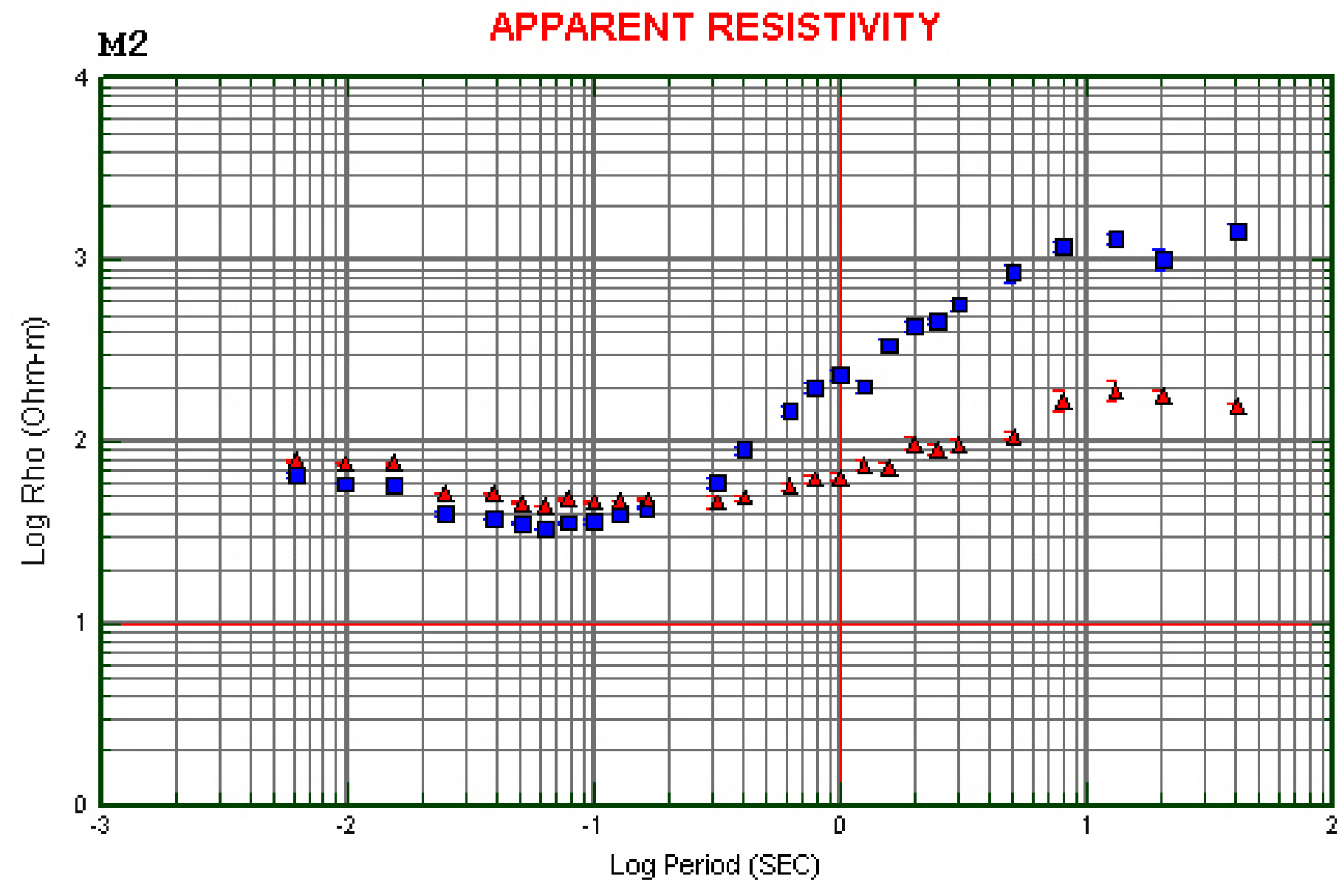

- Rho $X Y$

$\Delta$ Rho $Y x$ 


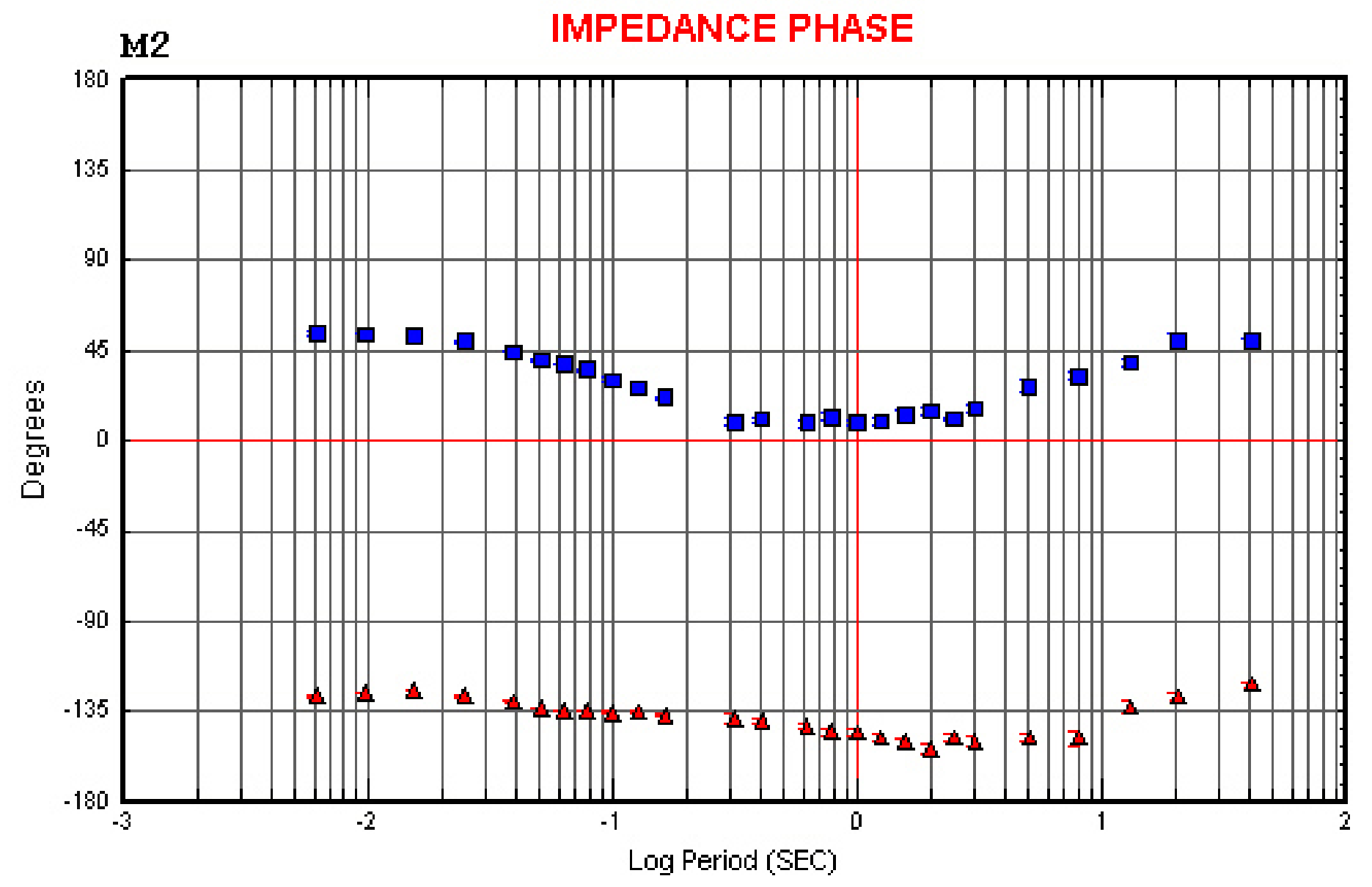

- Phase $X Y$ 


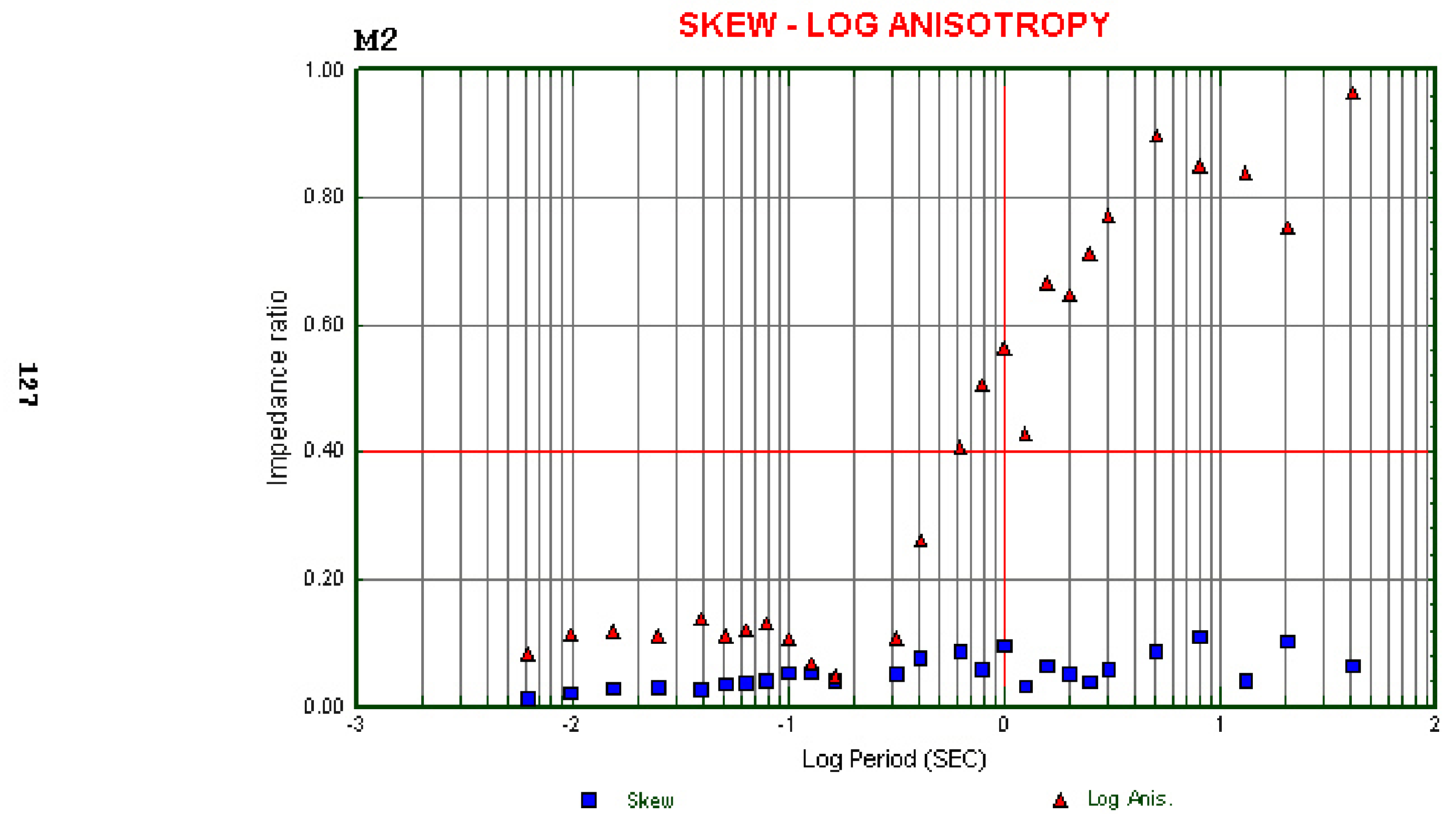




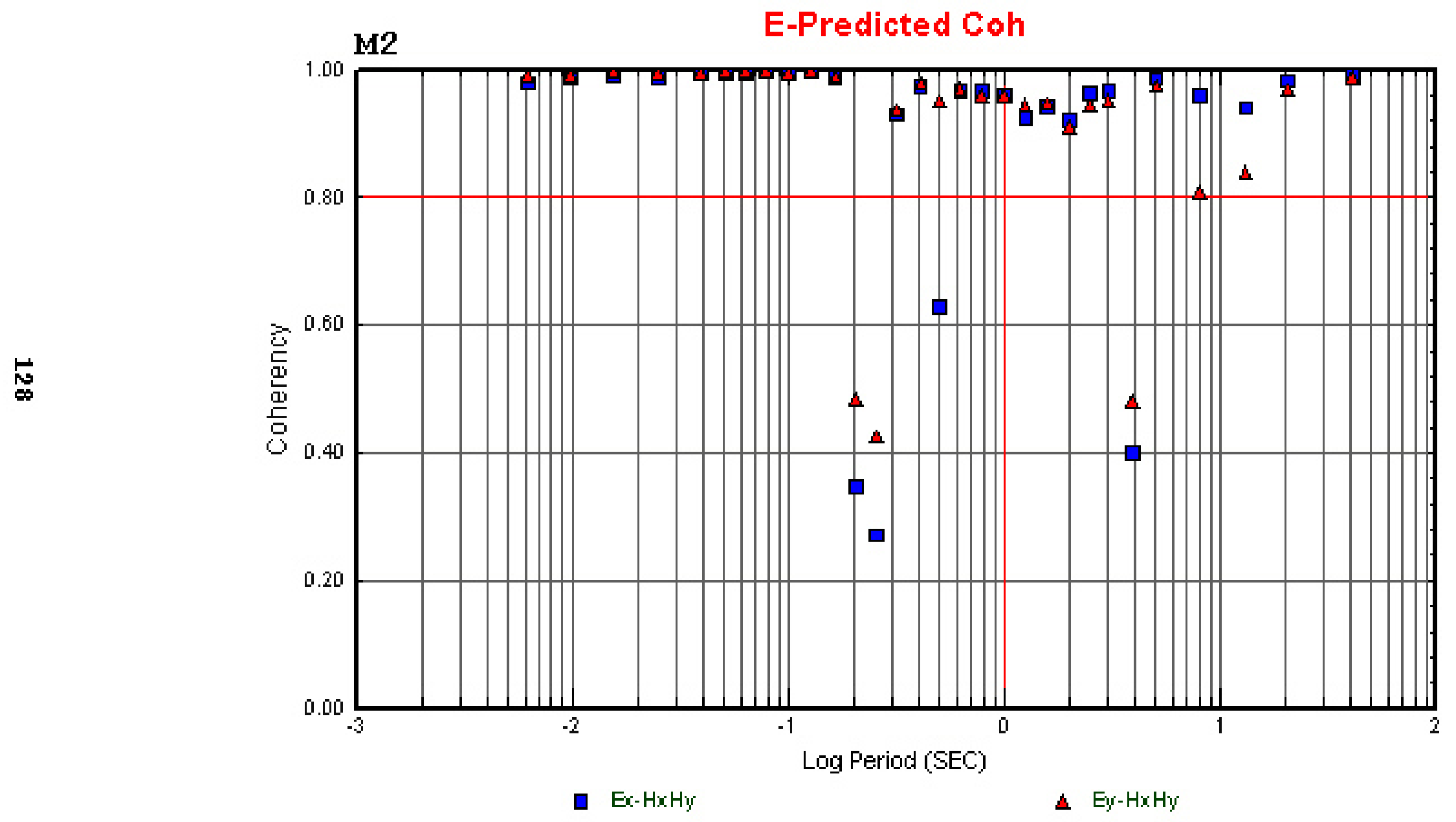




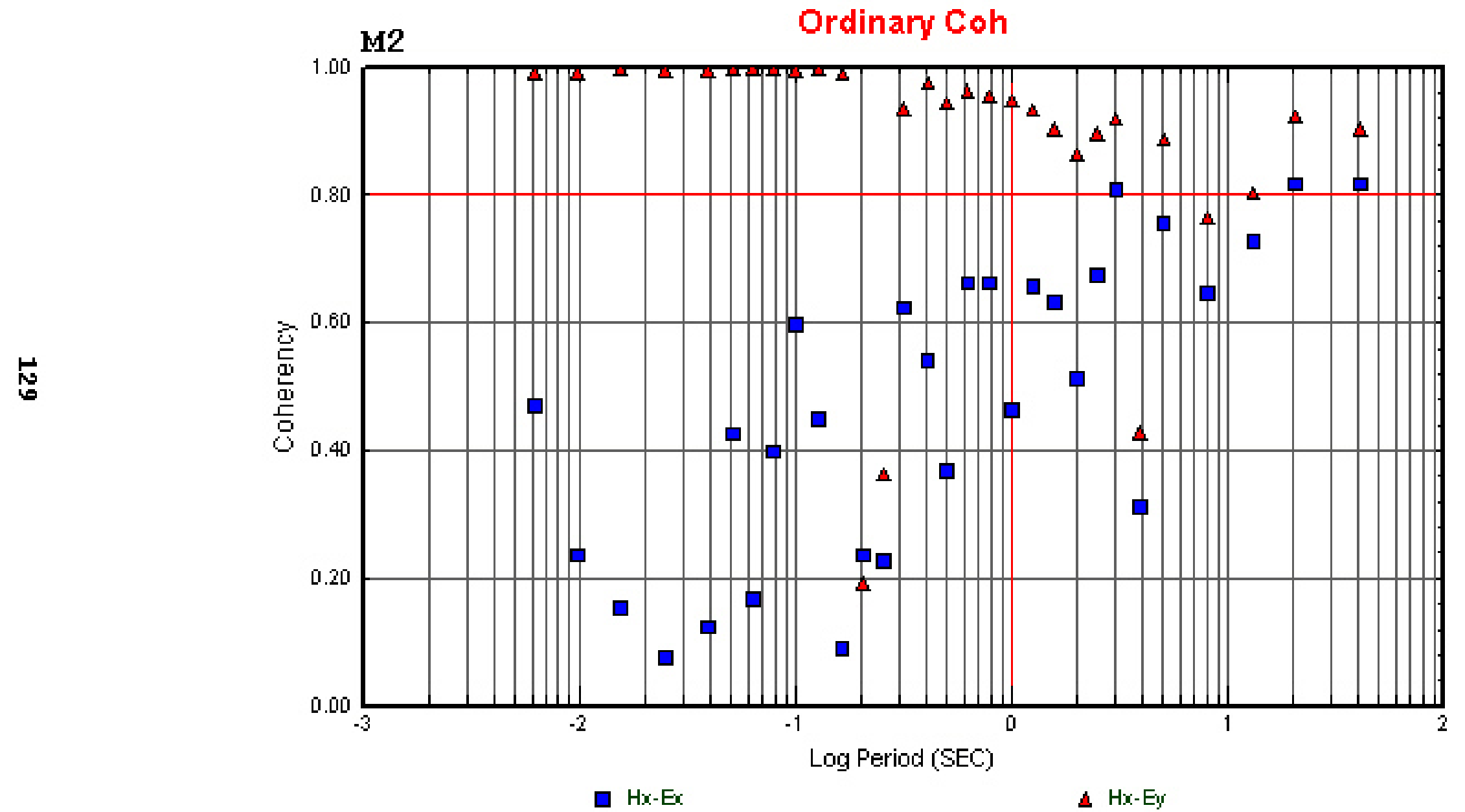




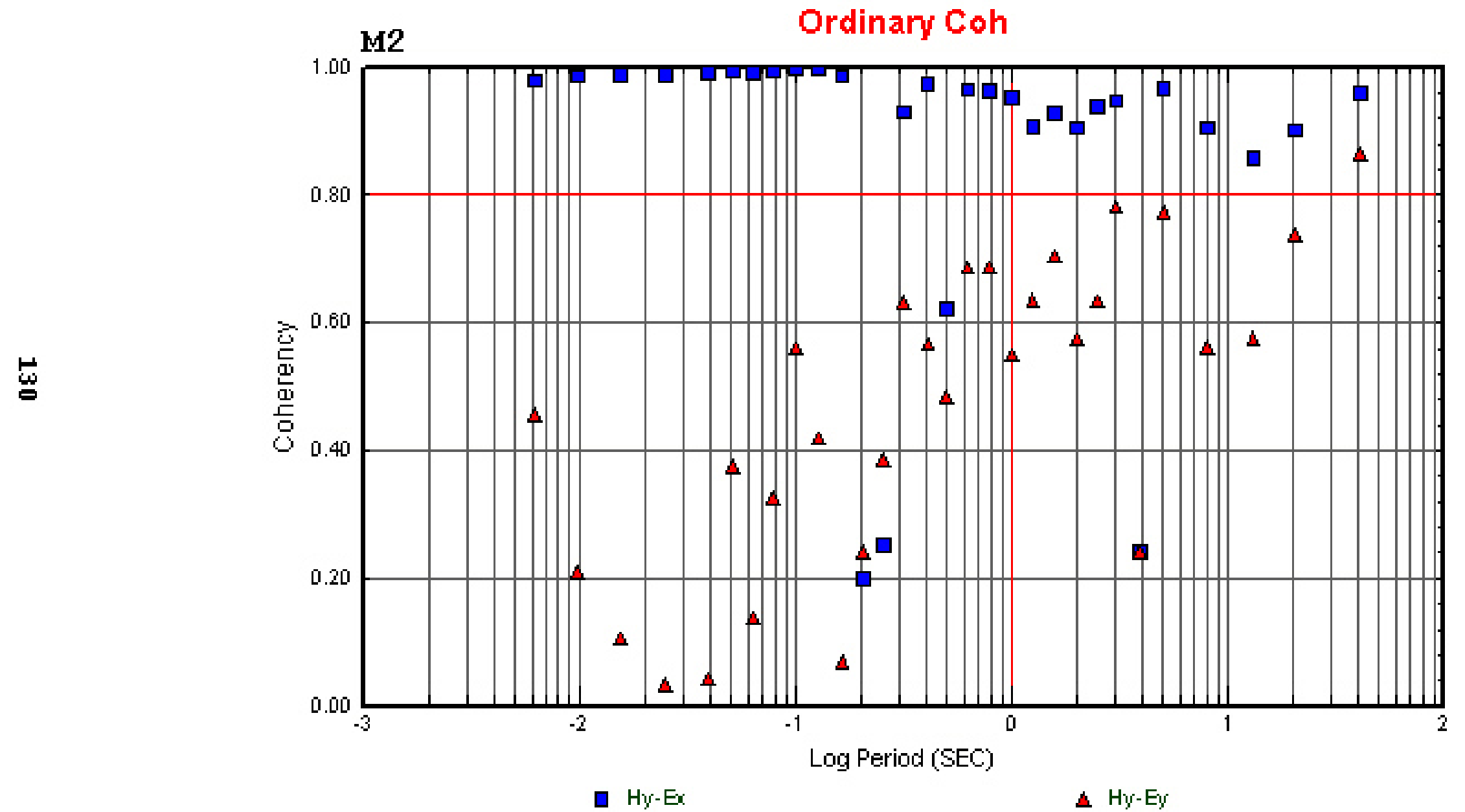




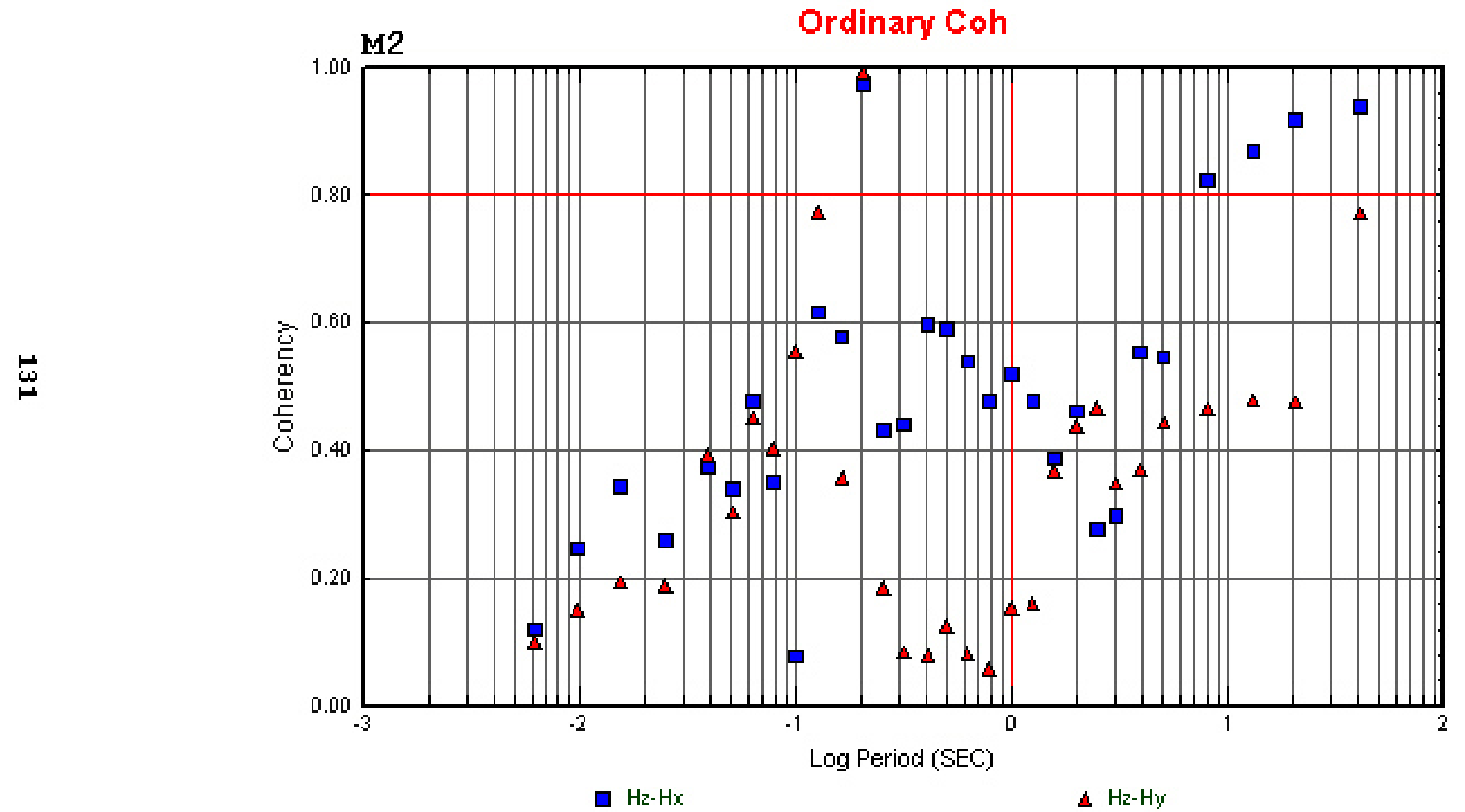




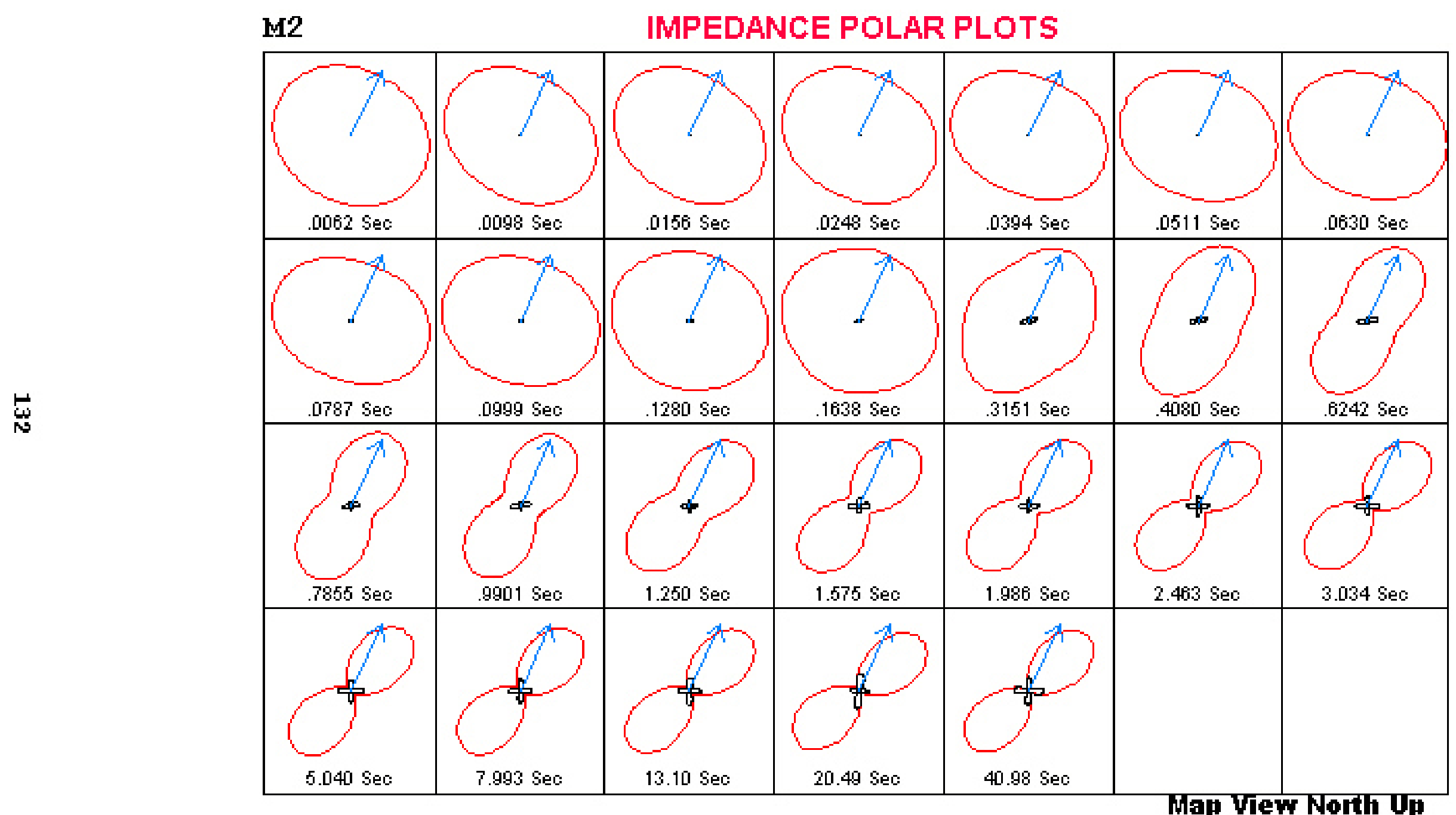


$\underset{\omega}{\uplus}$

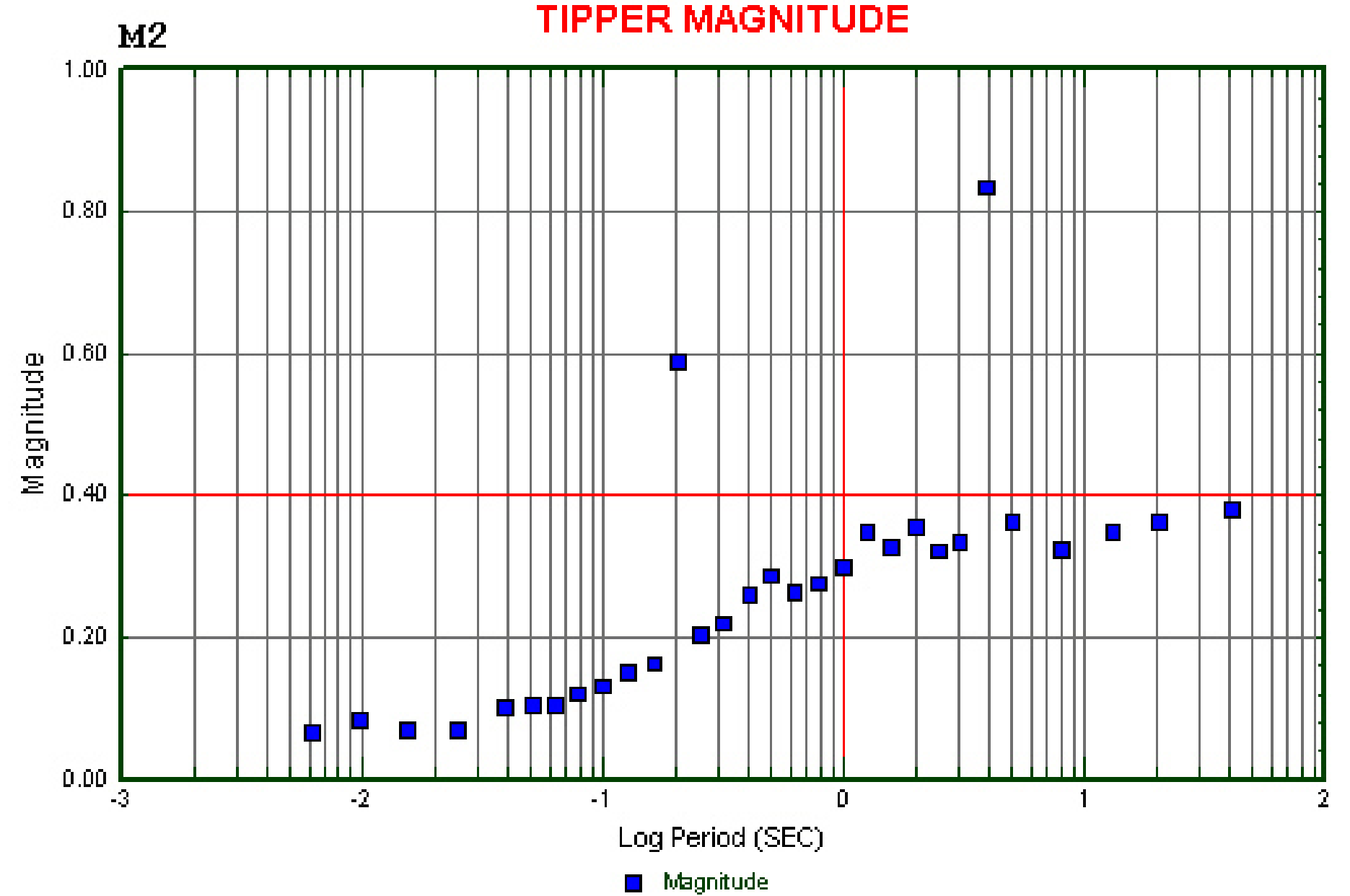




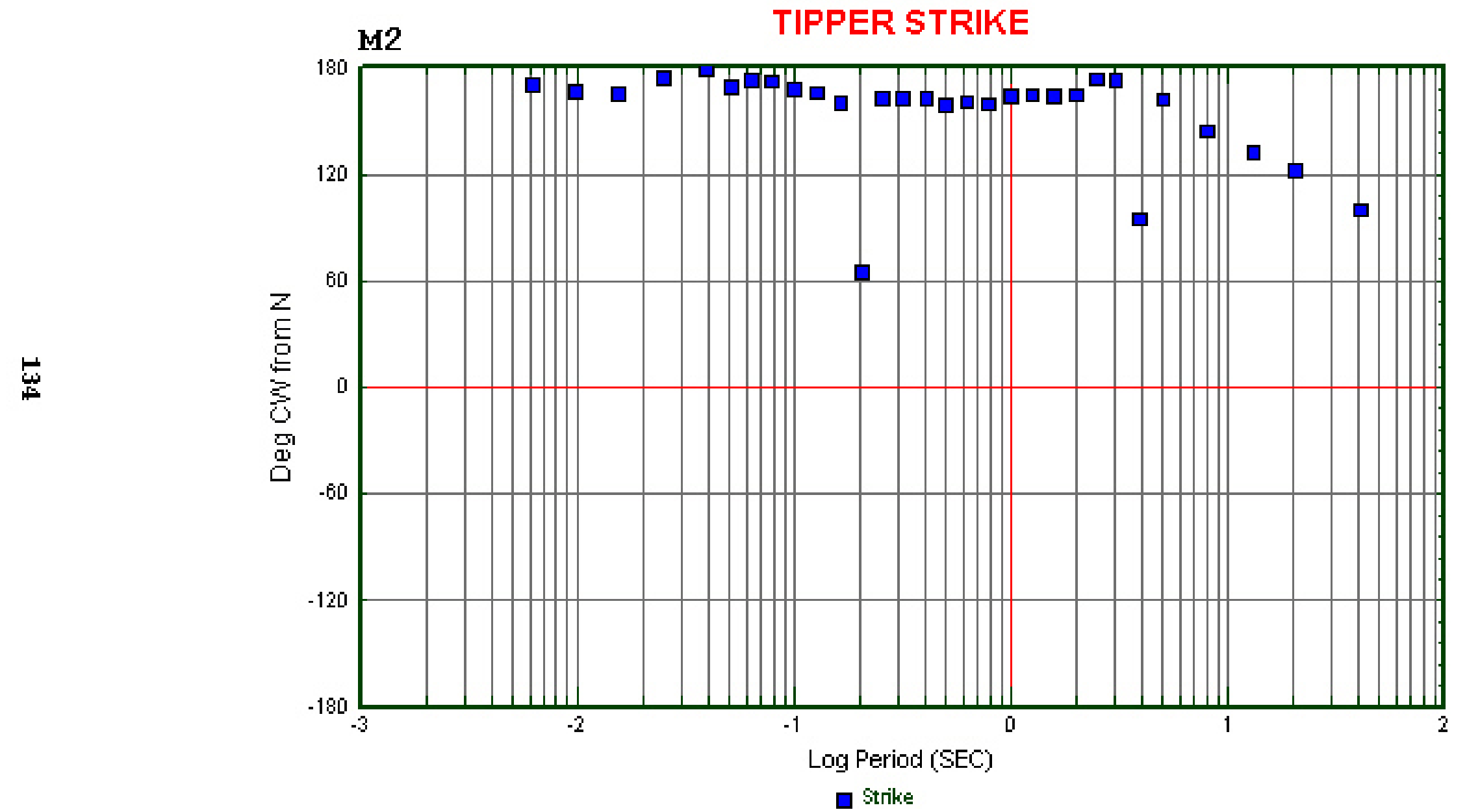




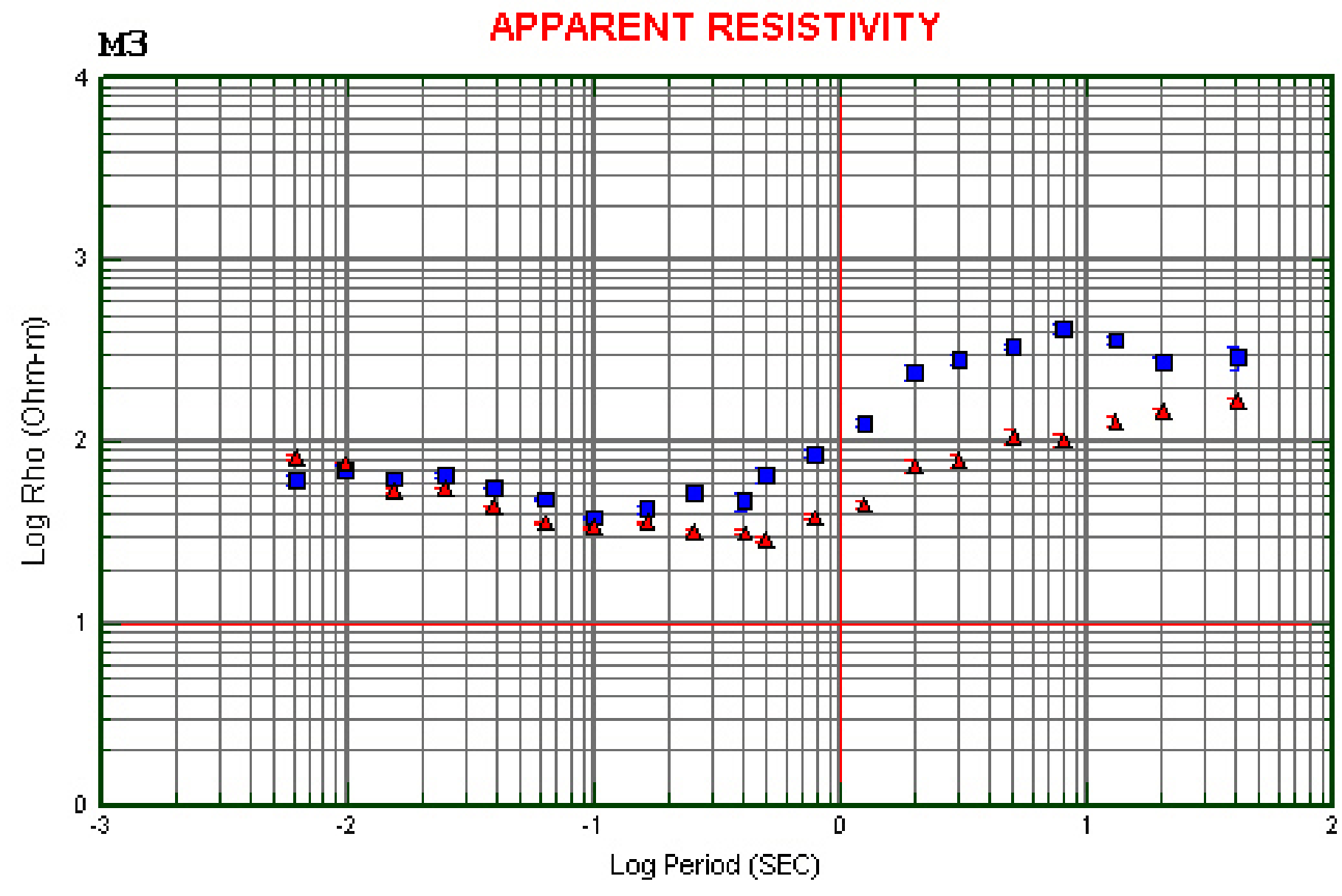

- Rho $X Y$

$\Delta$ Rho $Y x$ 


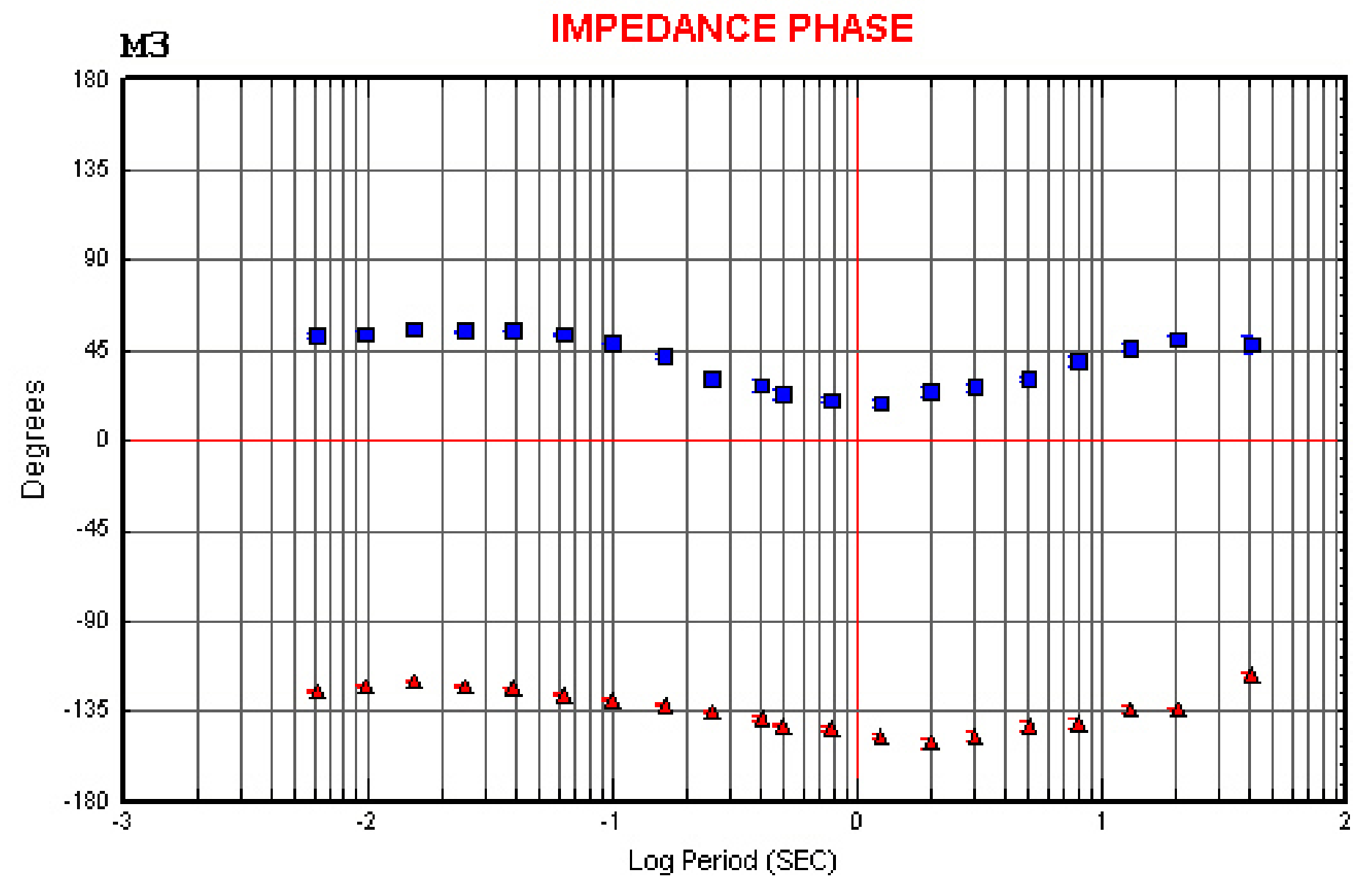

- Phase $X Y$

i Phase $Y x$ 


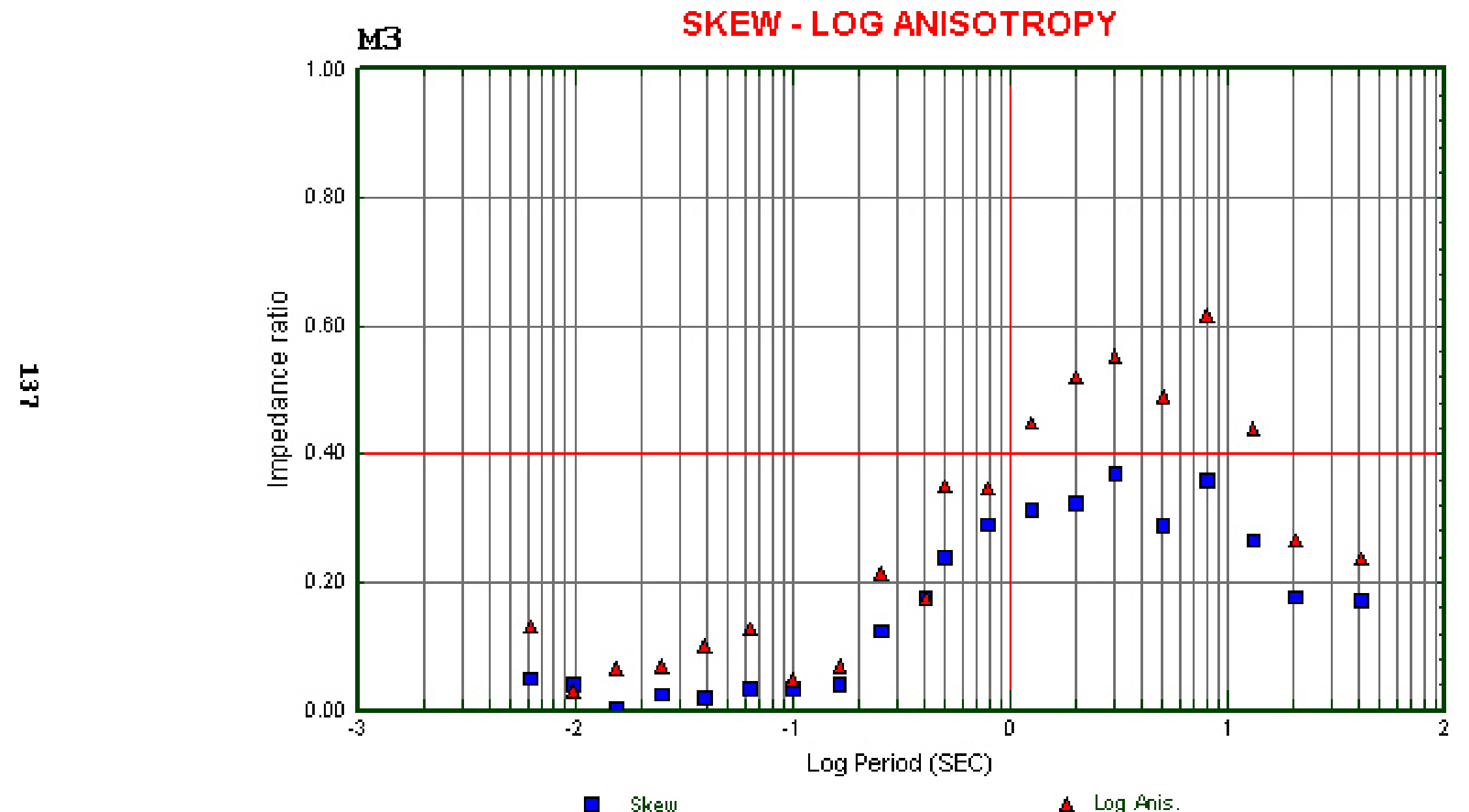




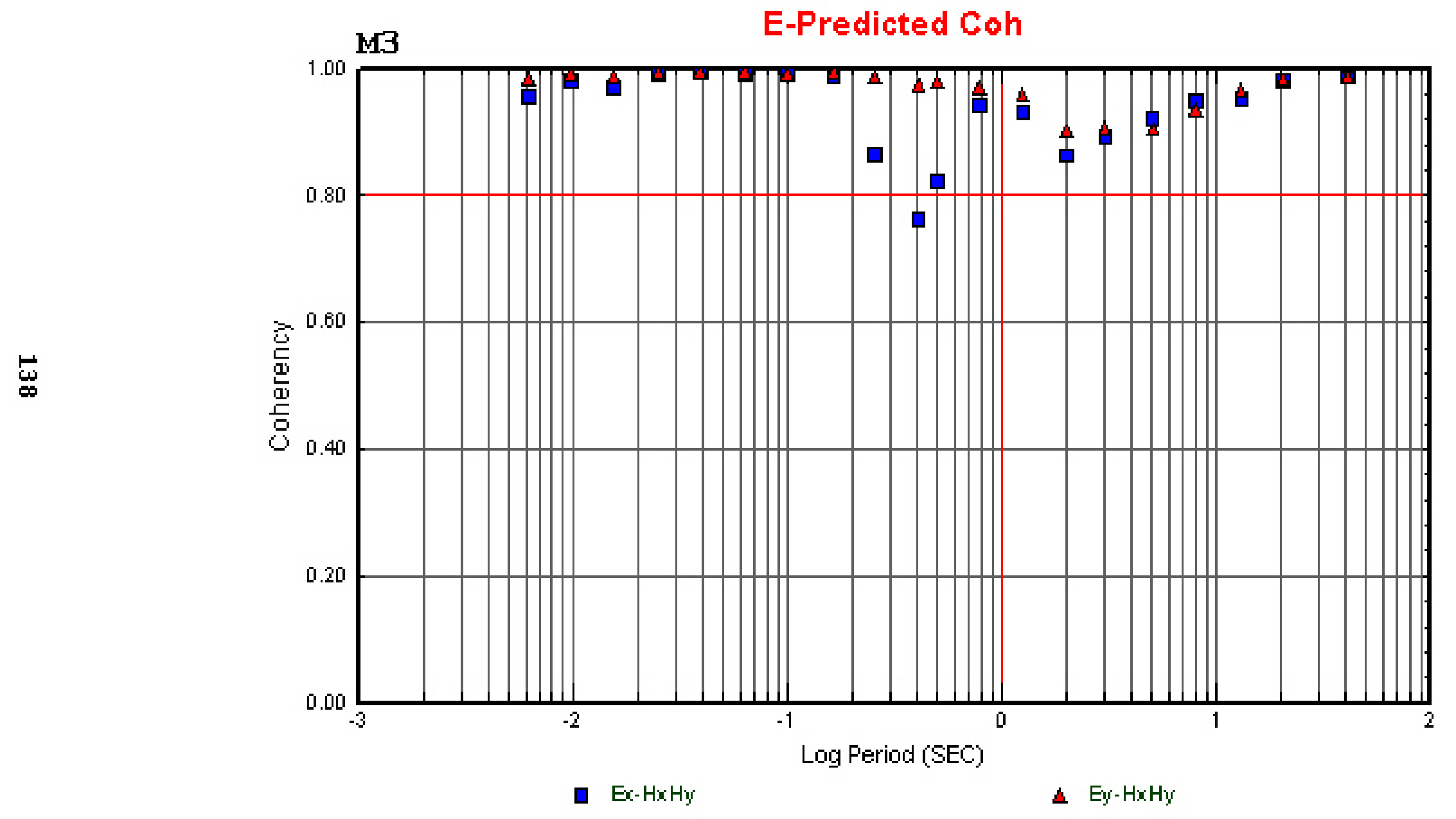




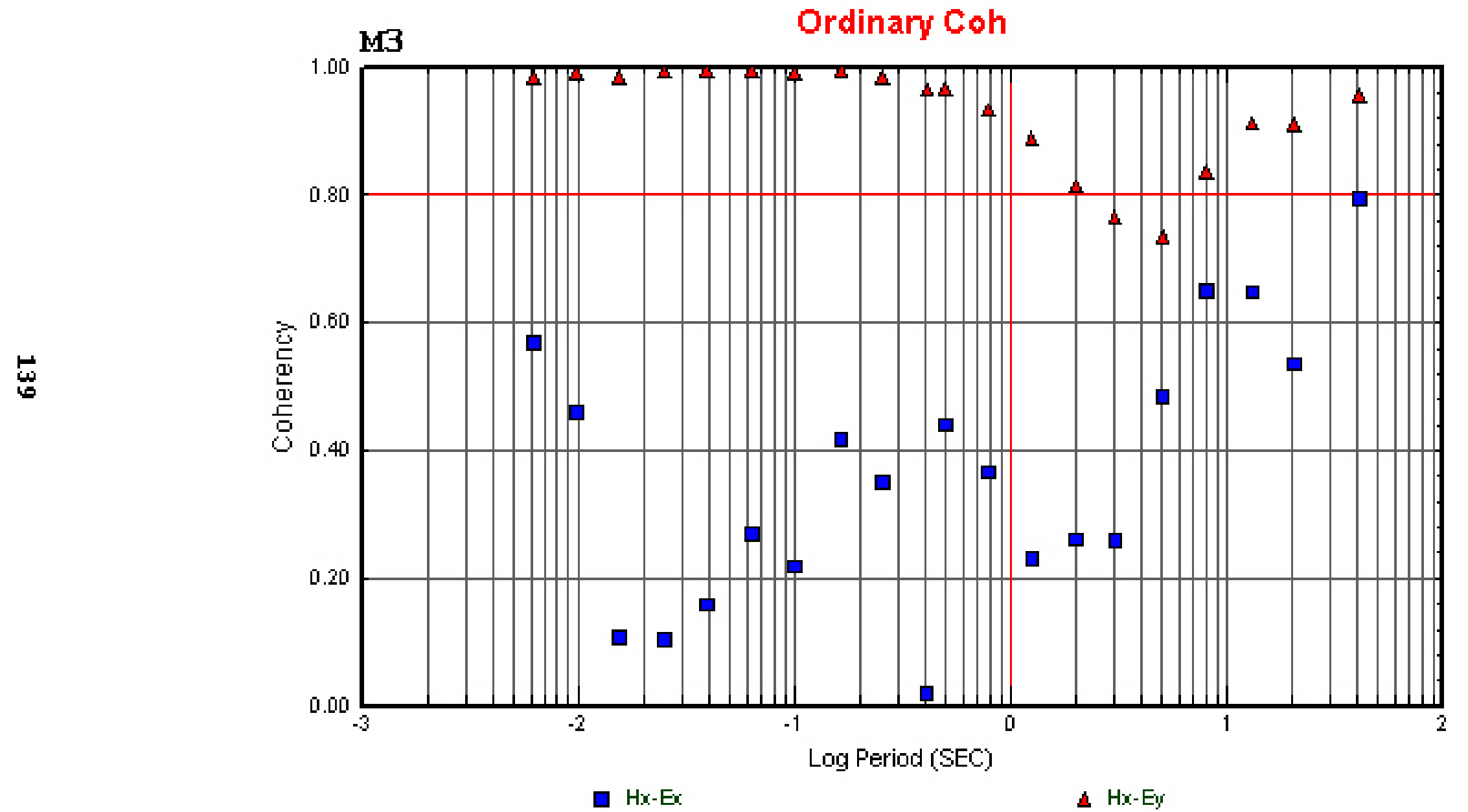




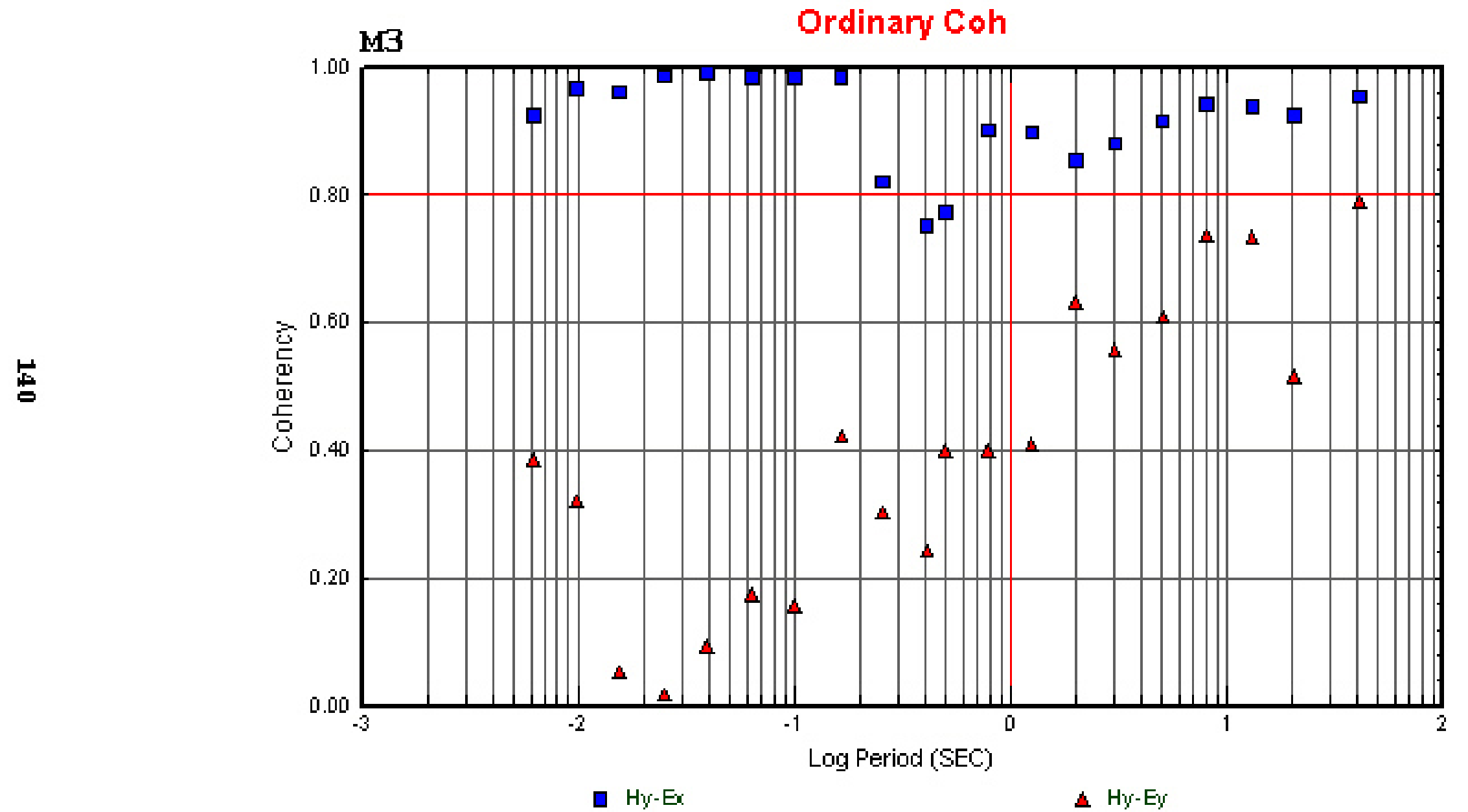




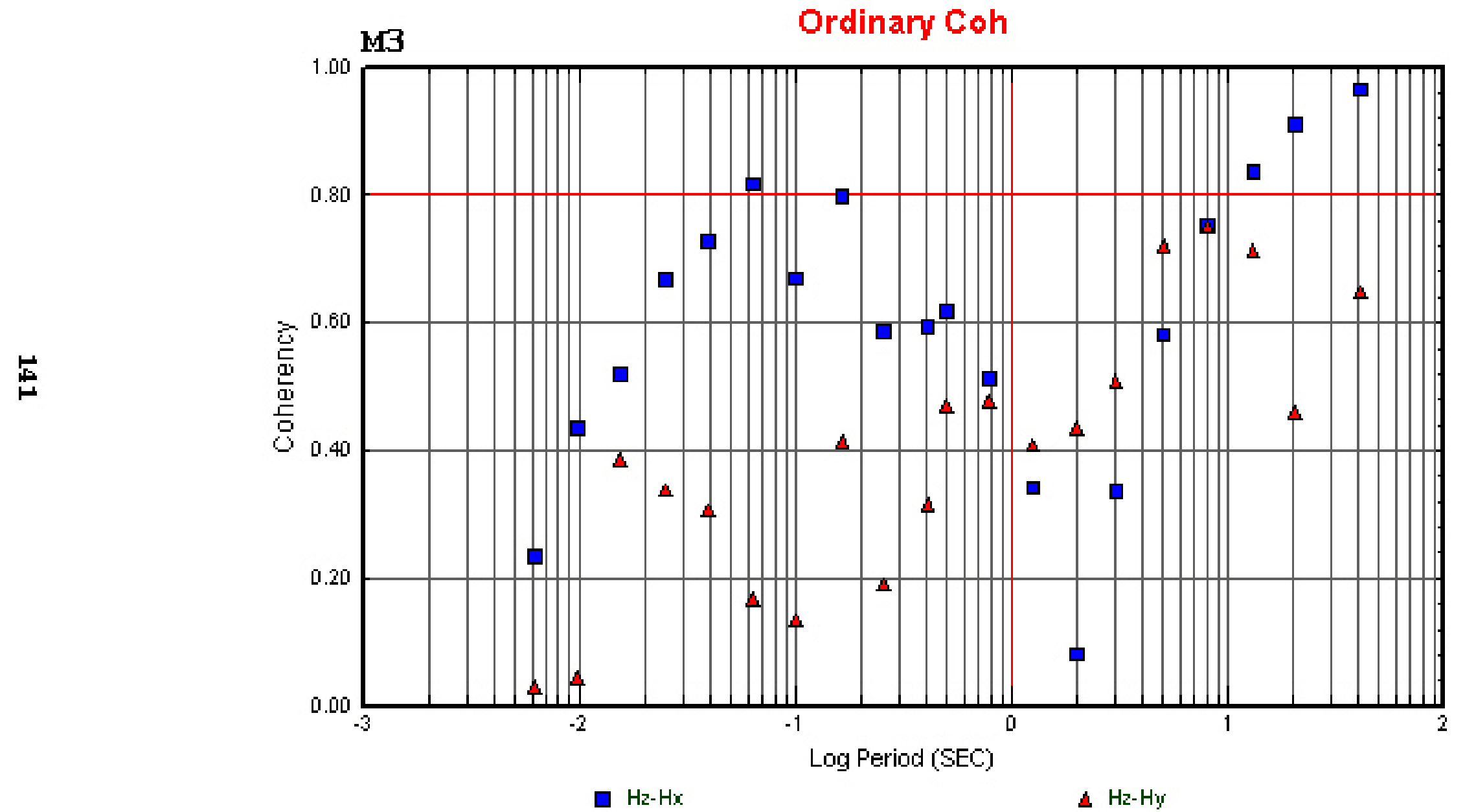




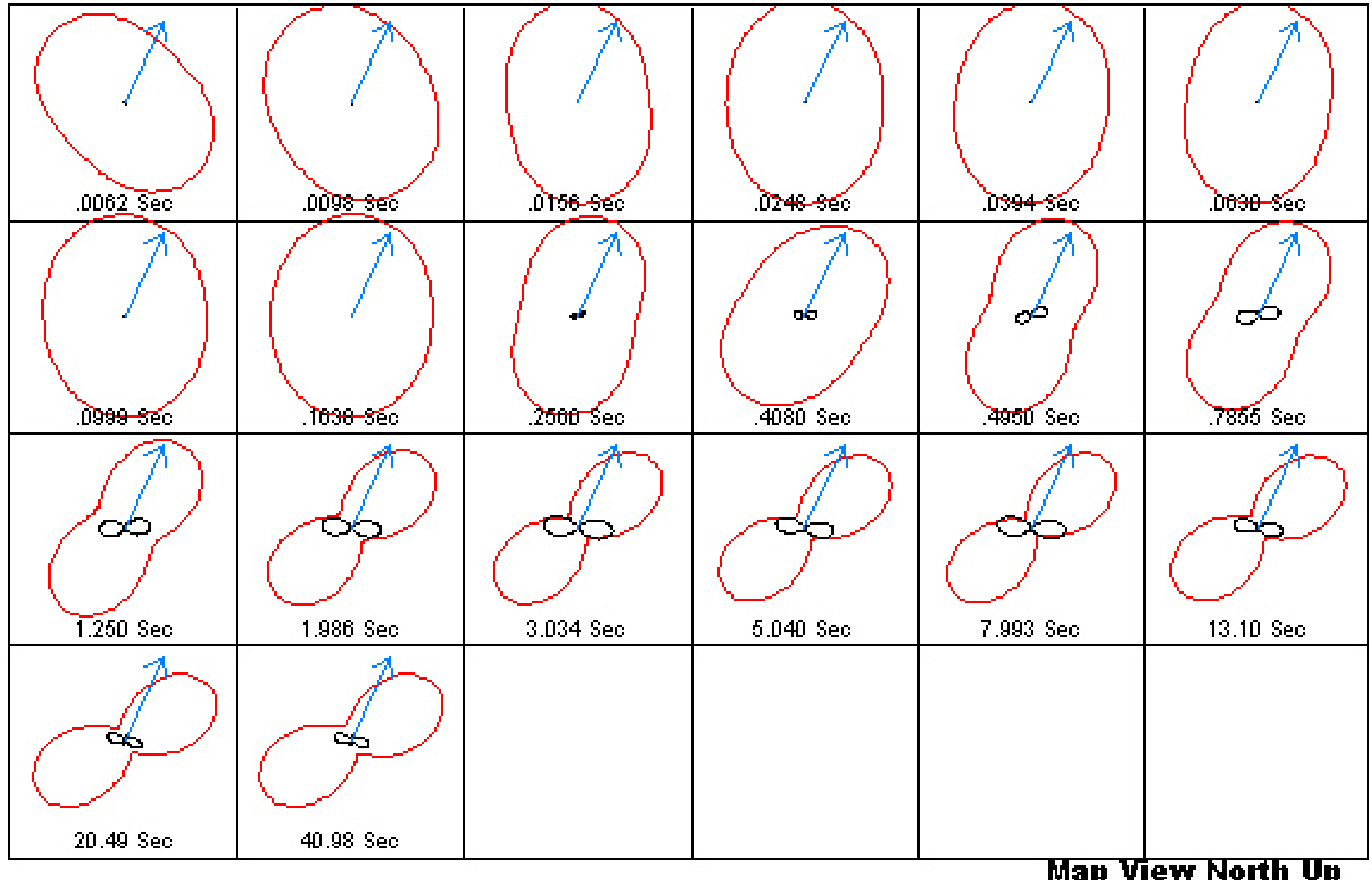




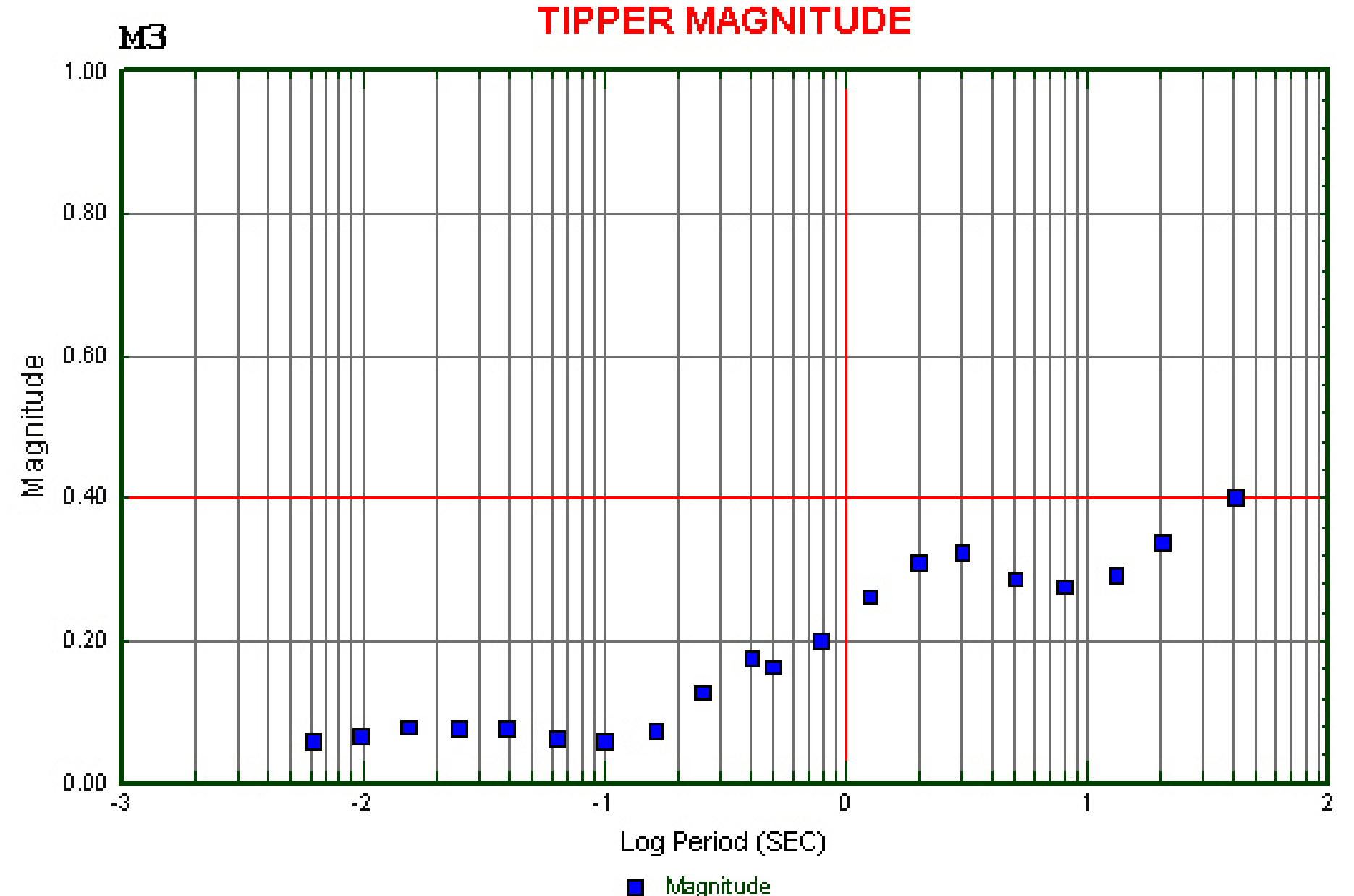


TIPPER STRIKE

E

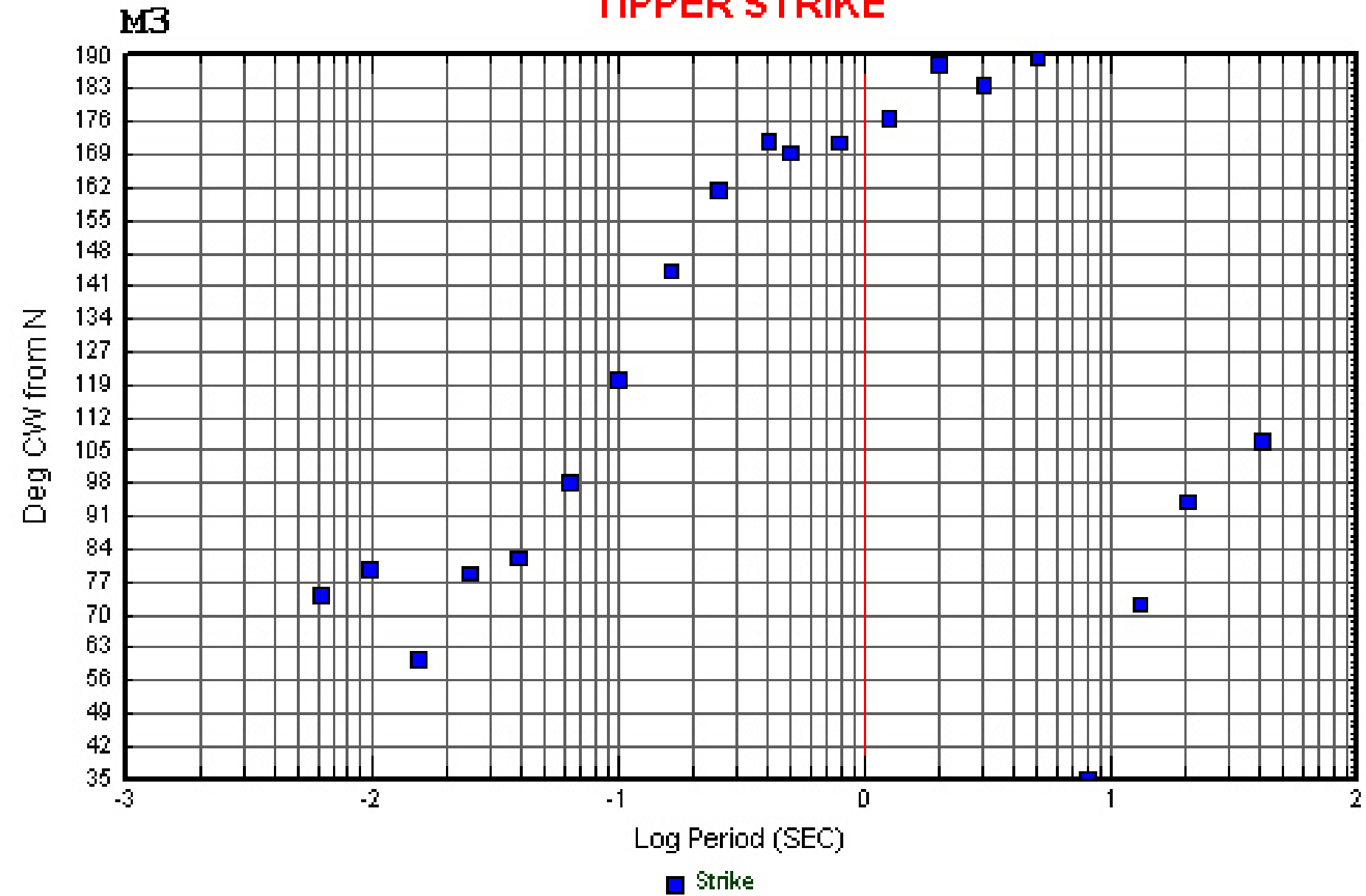

口 Strike 


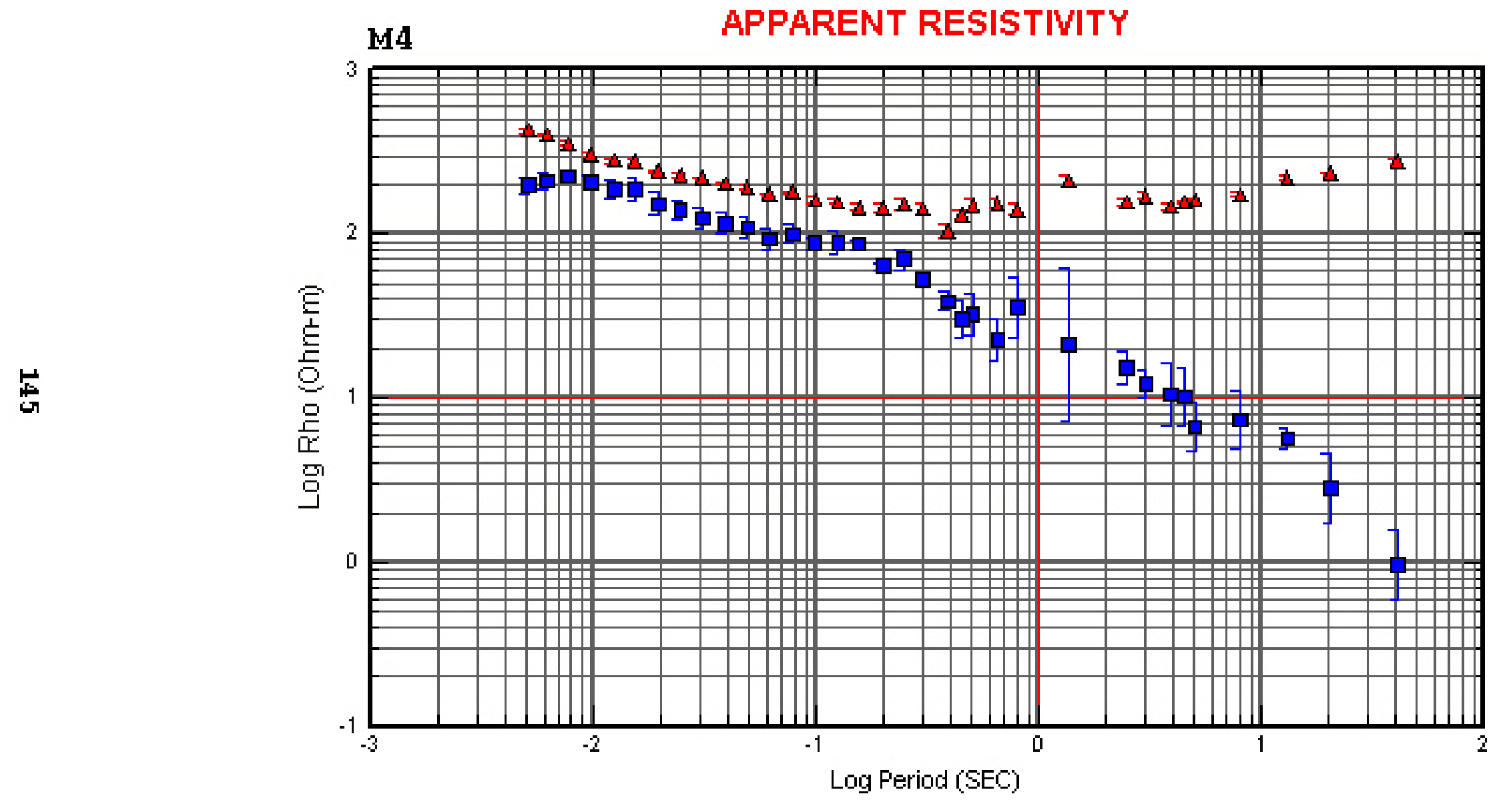

- Rho $X Y$

$\Delta$ Rho $Y x$ 


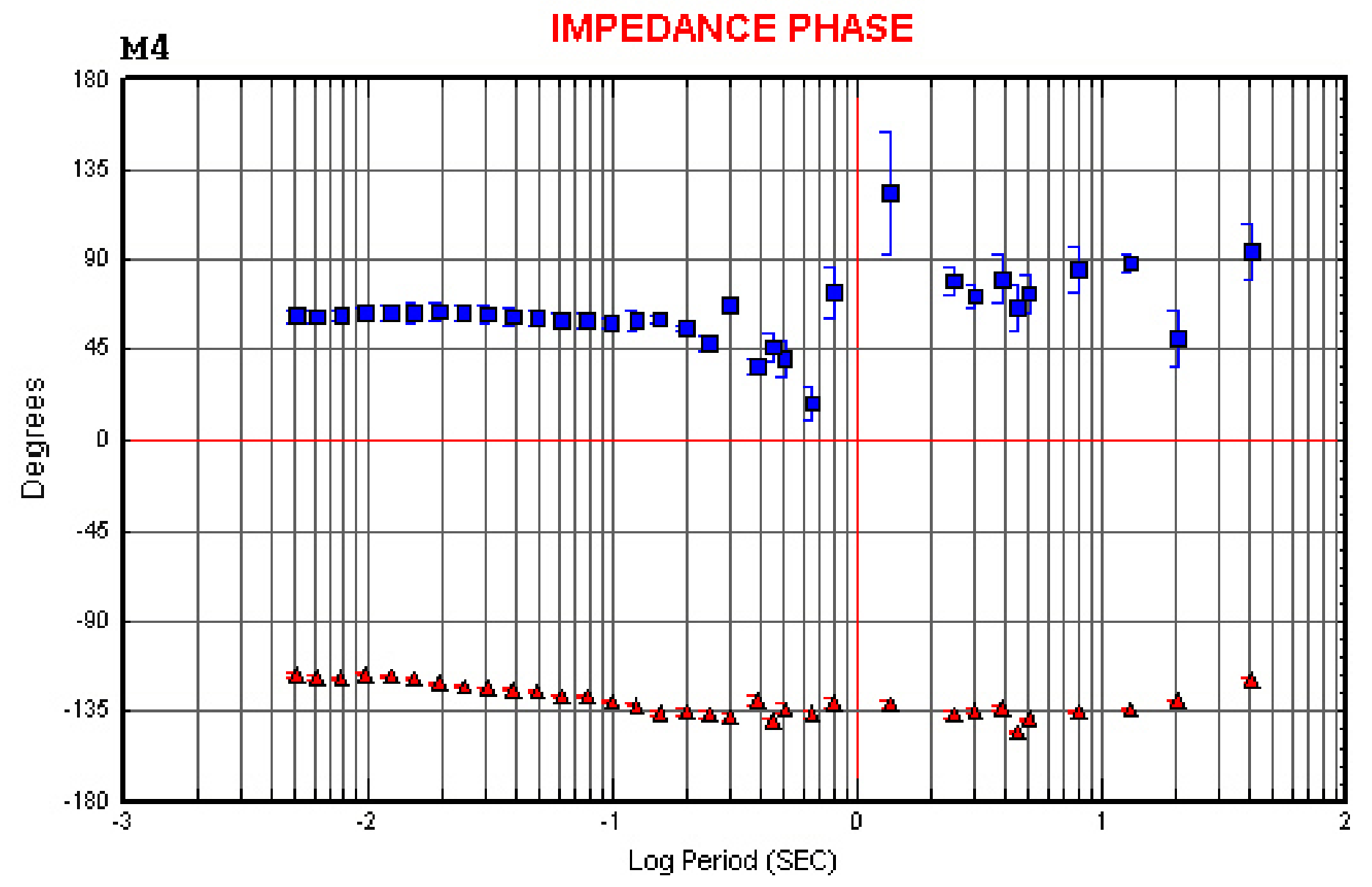

- Phase $X Y$ 


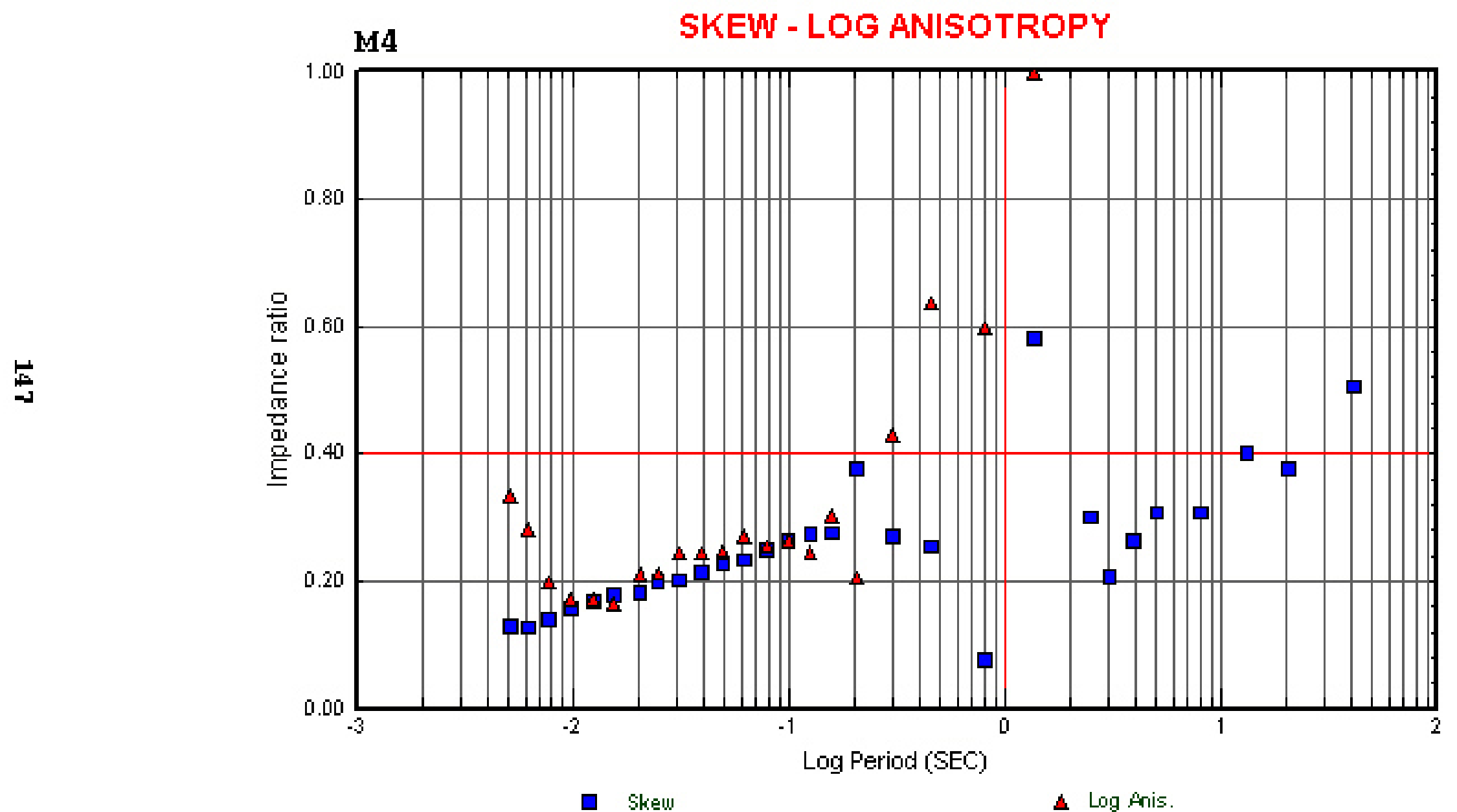




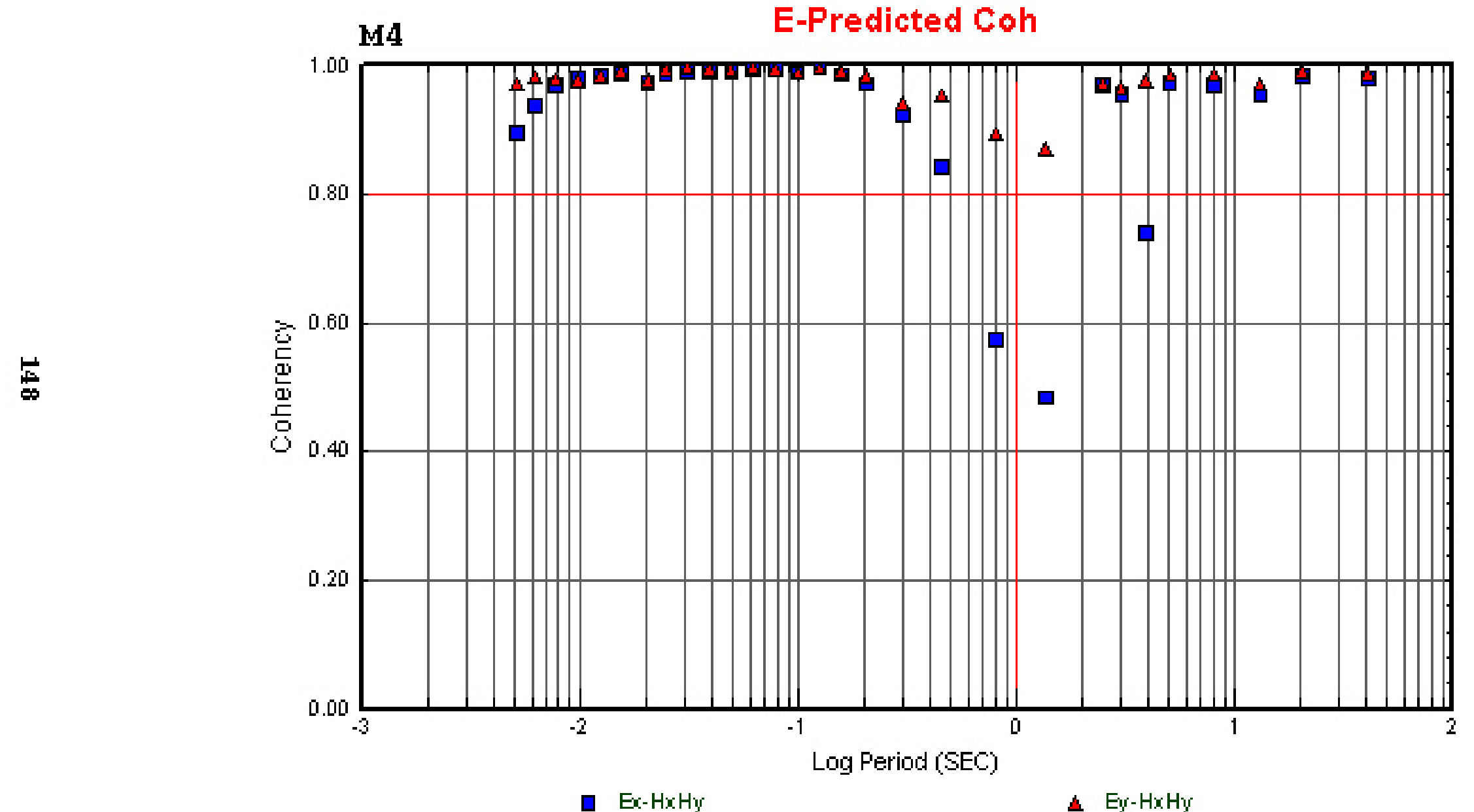




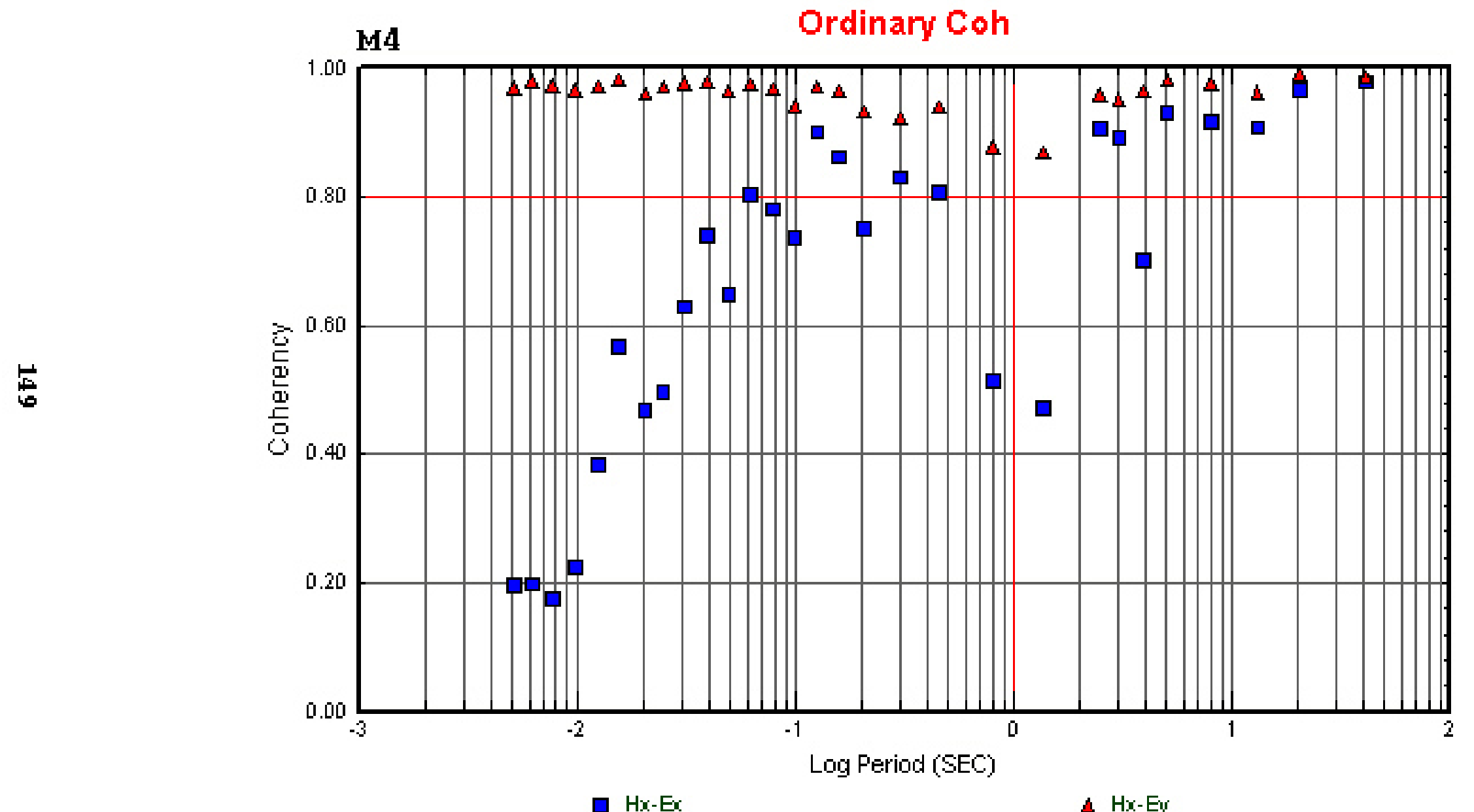




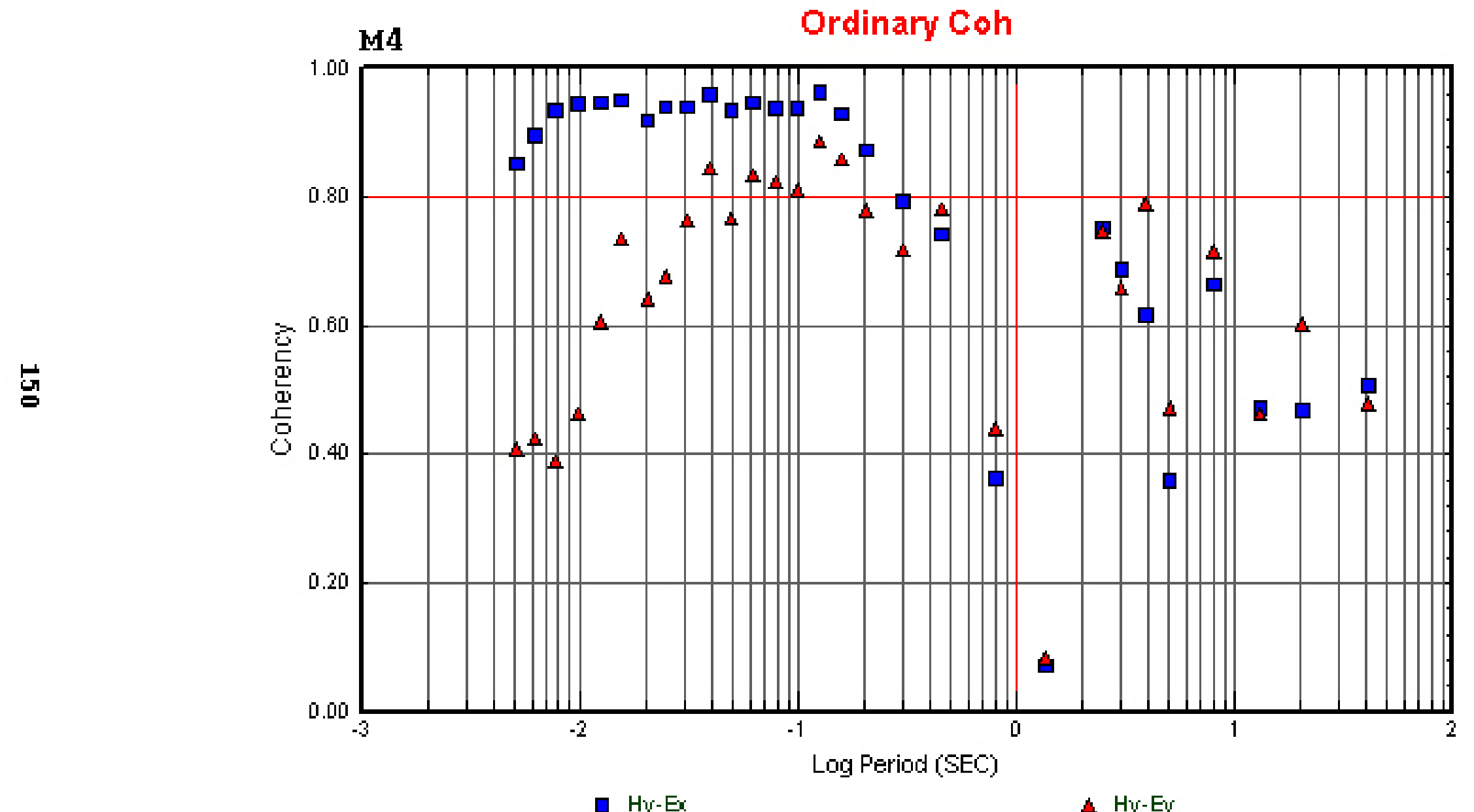




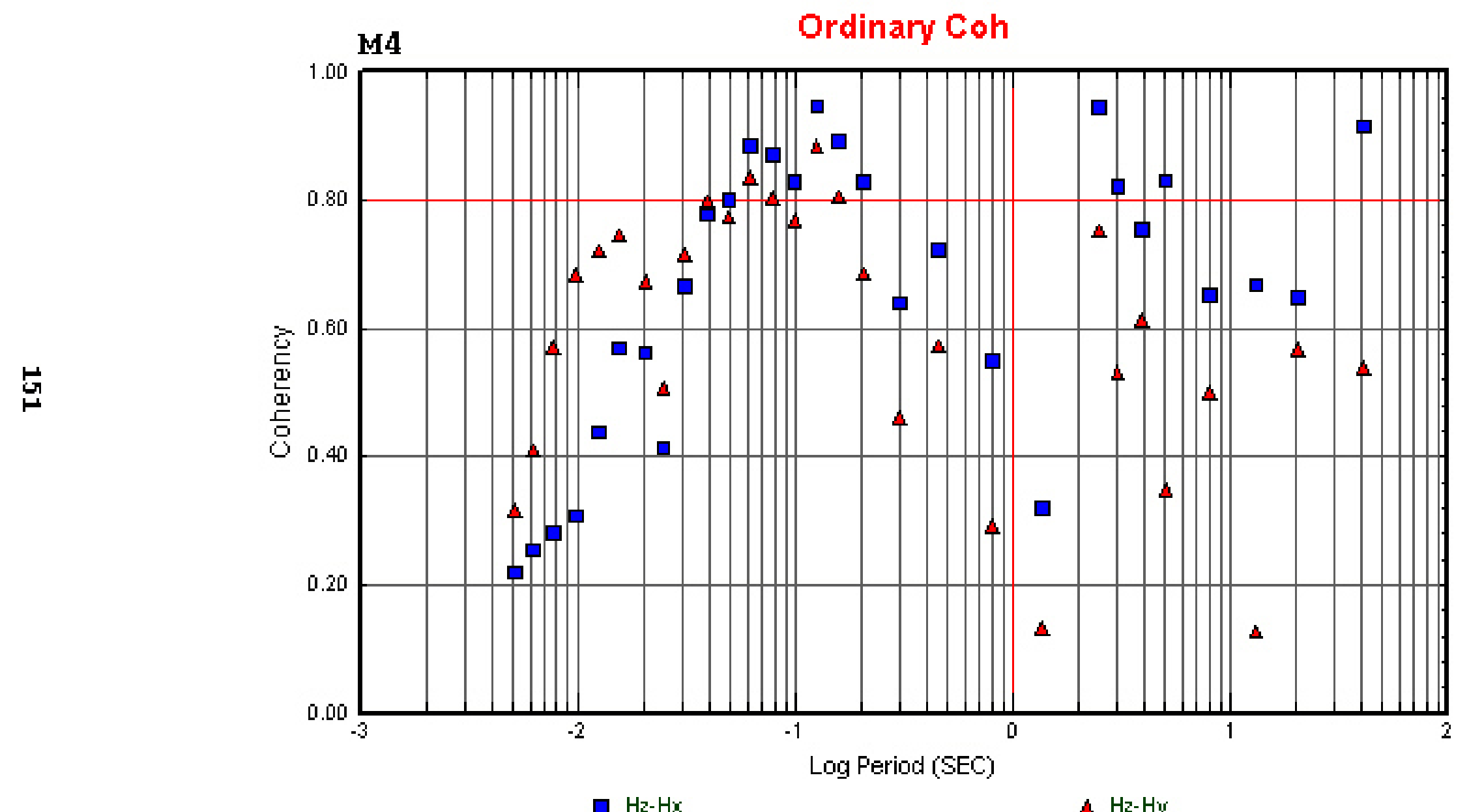




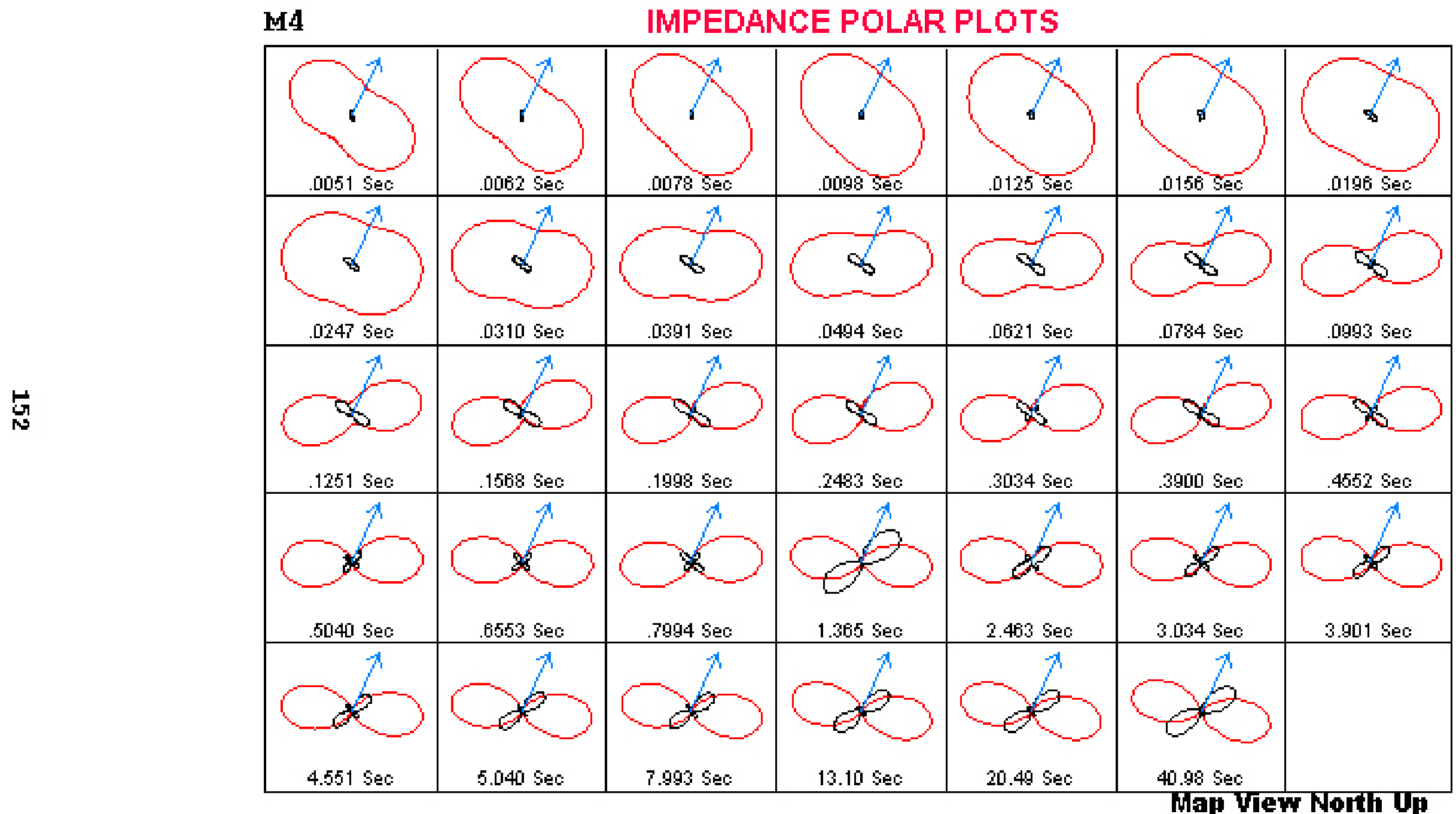


䓌

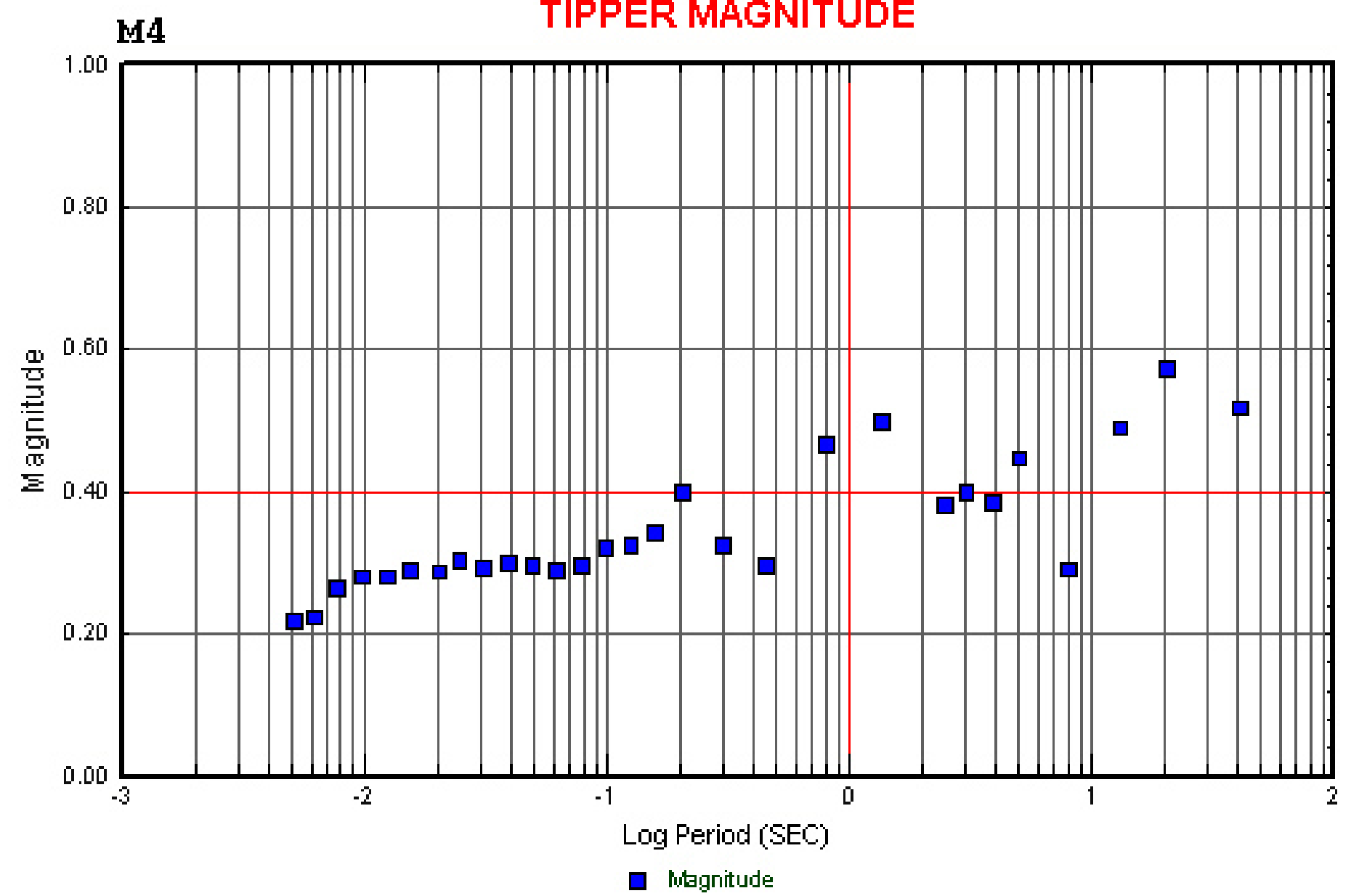




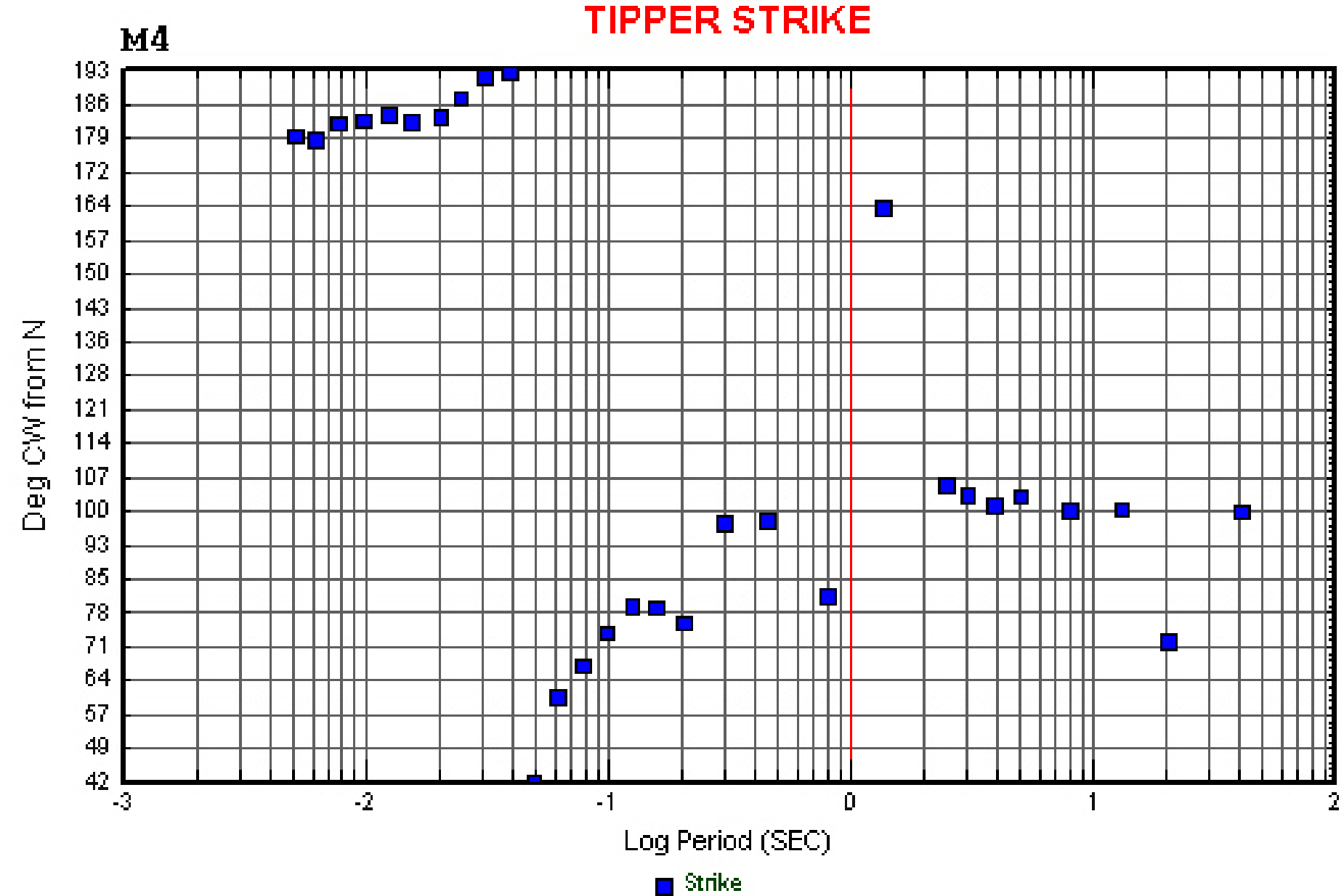

口 Strike 


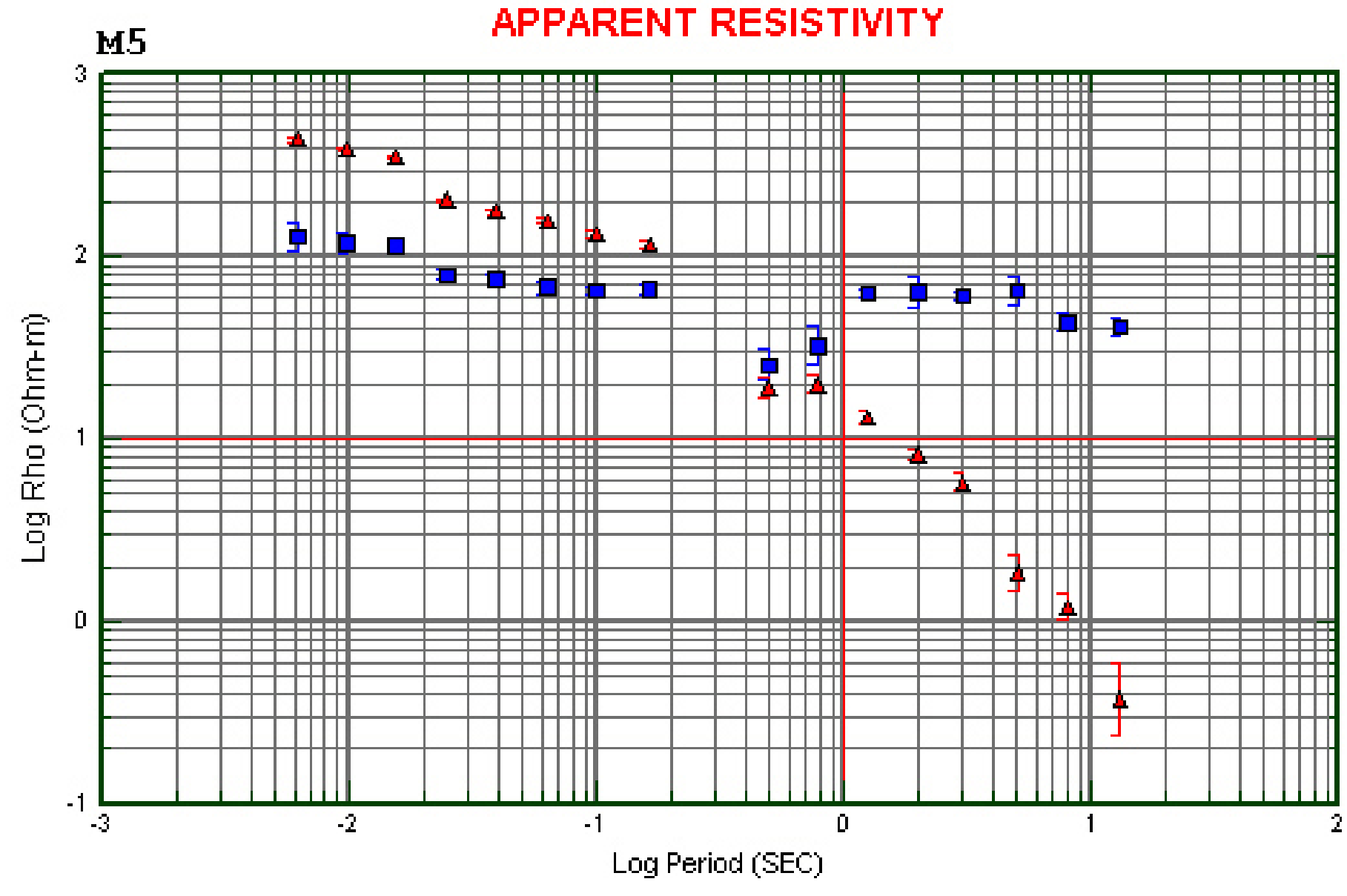

- Rho $X Y$

$\Delta$ Rho $Y x$ 
ज్

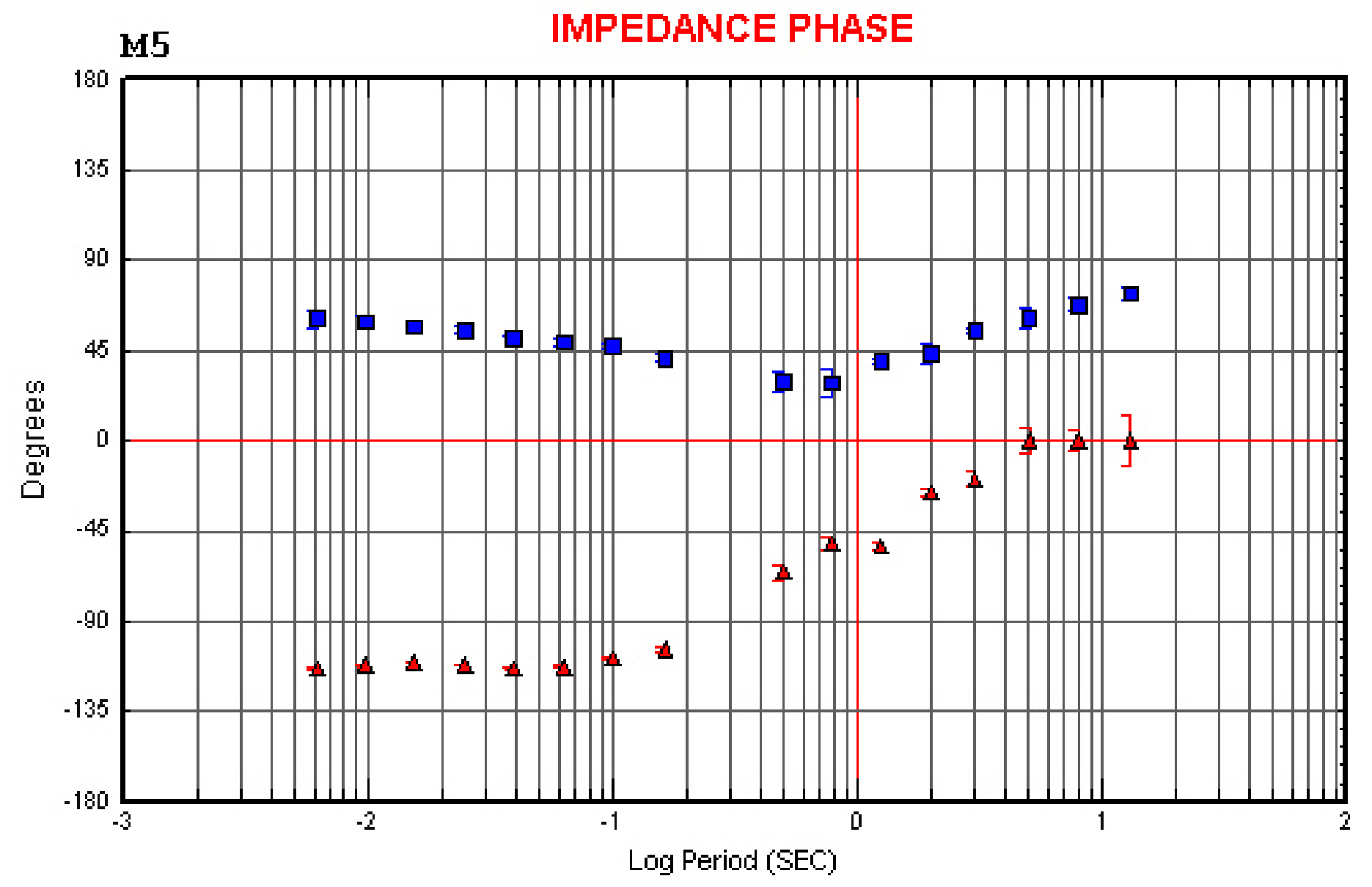

- Phase $X Y$

i Phase $Y x$ 


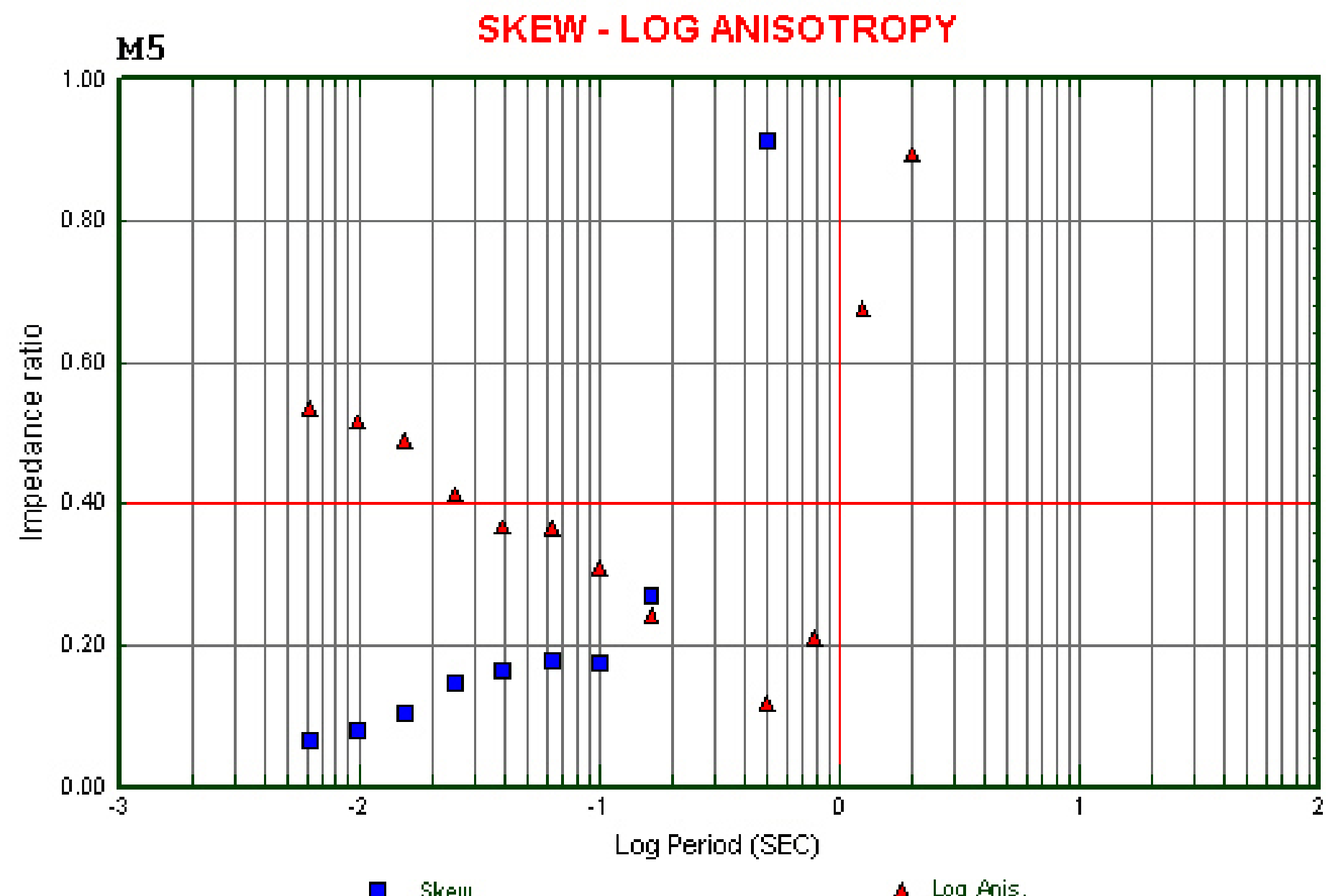




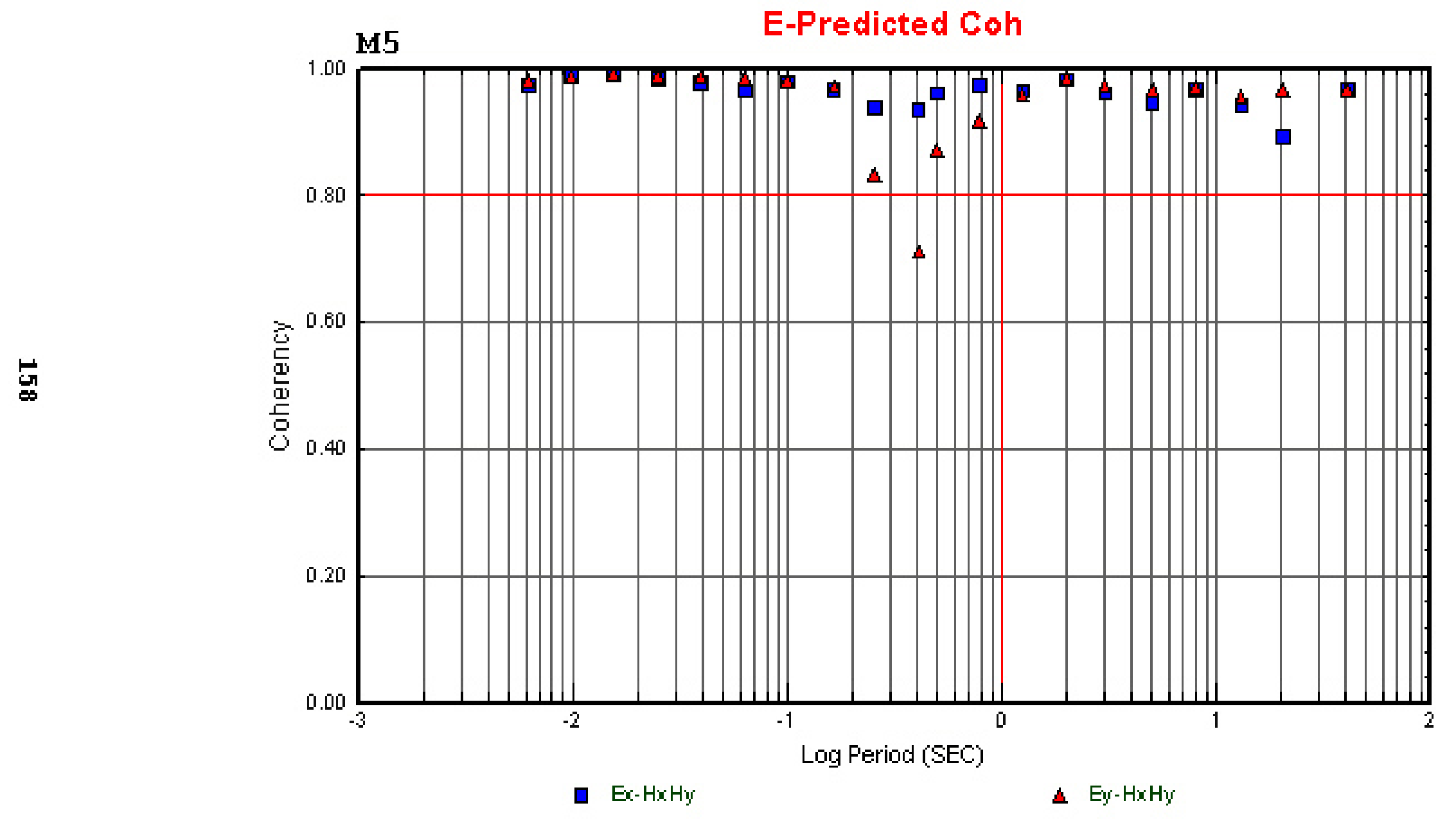




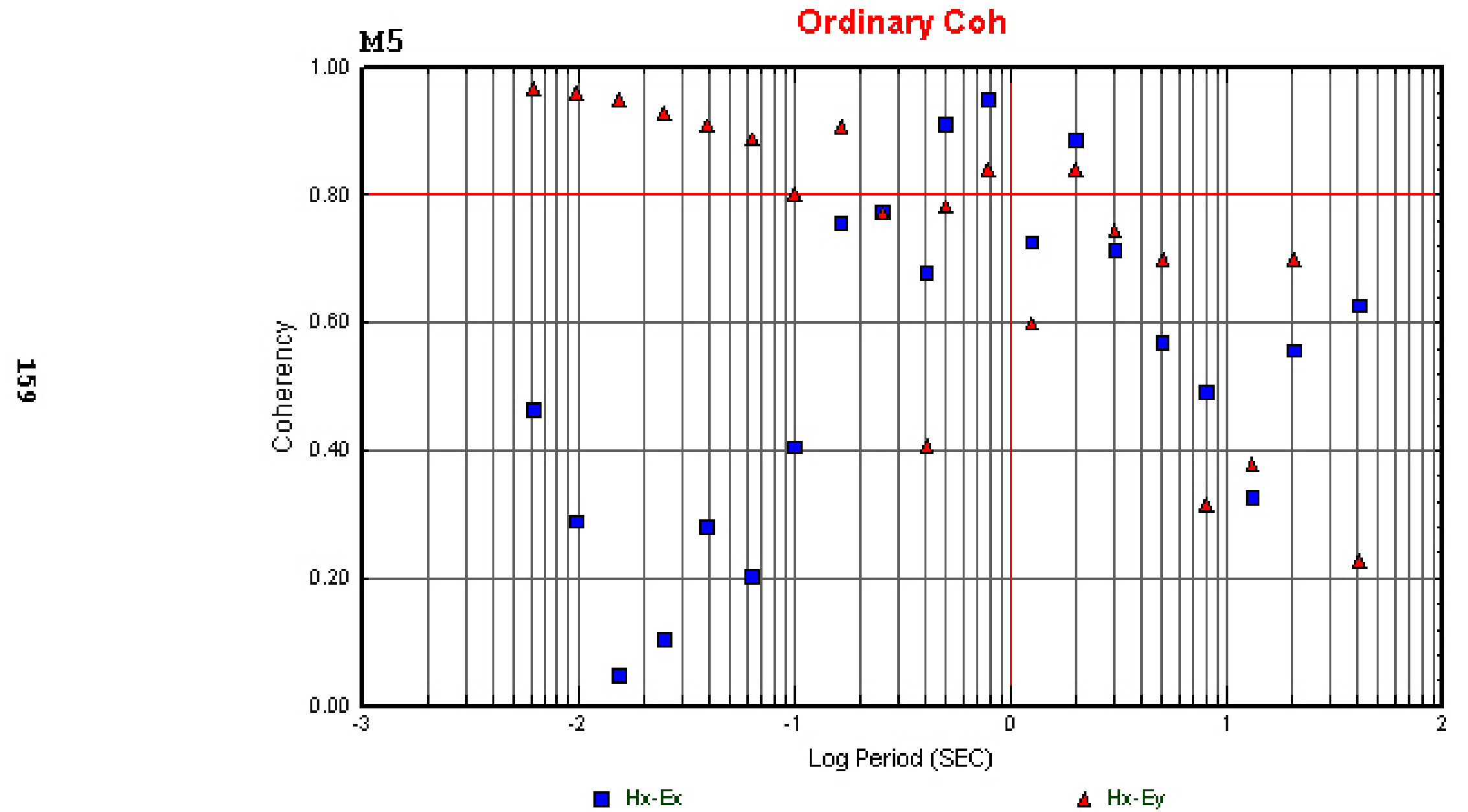




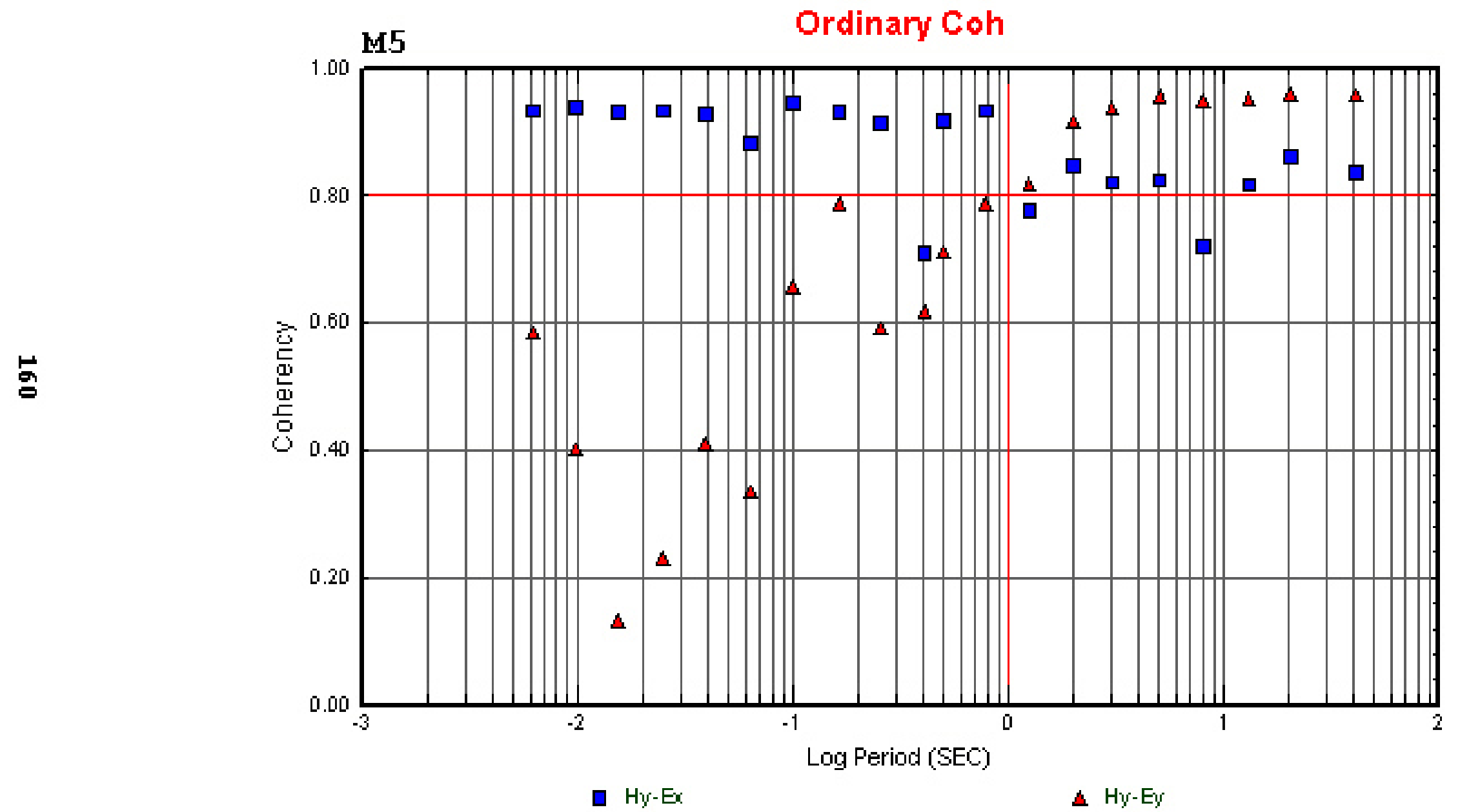




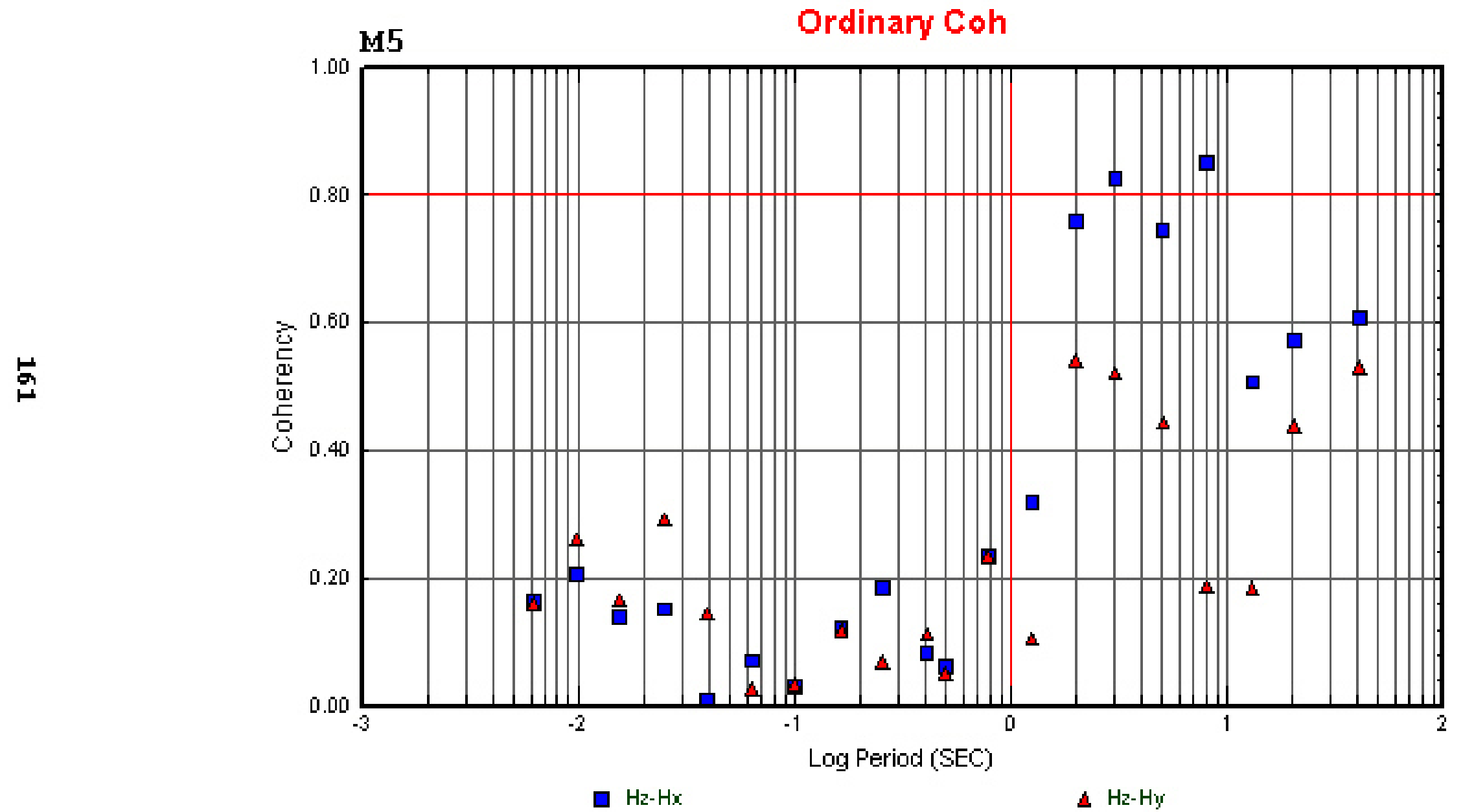




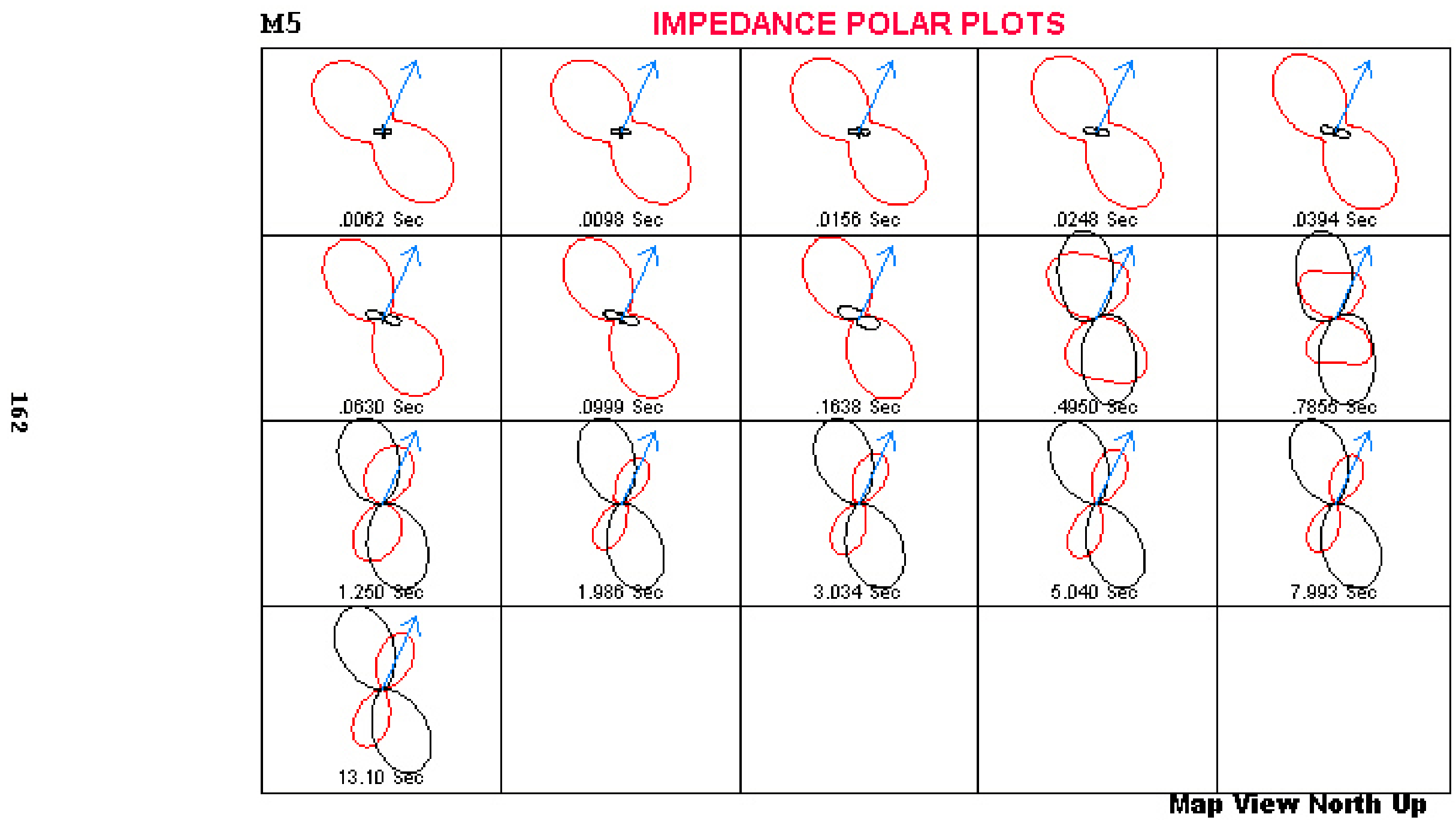




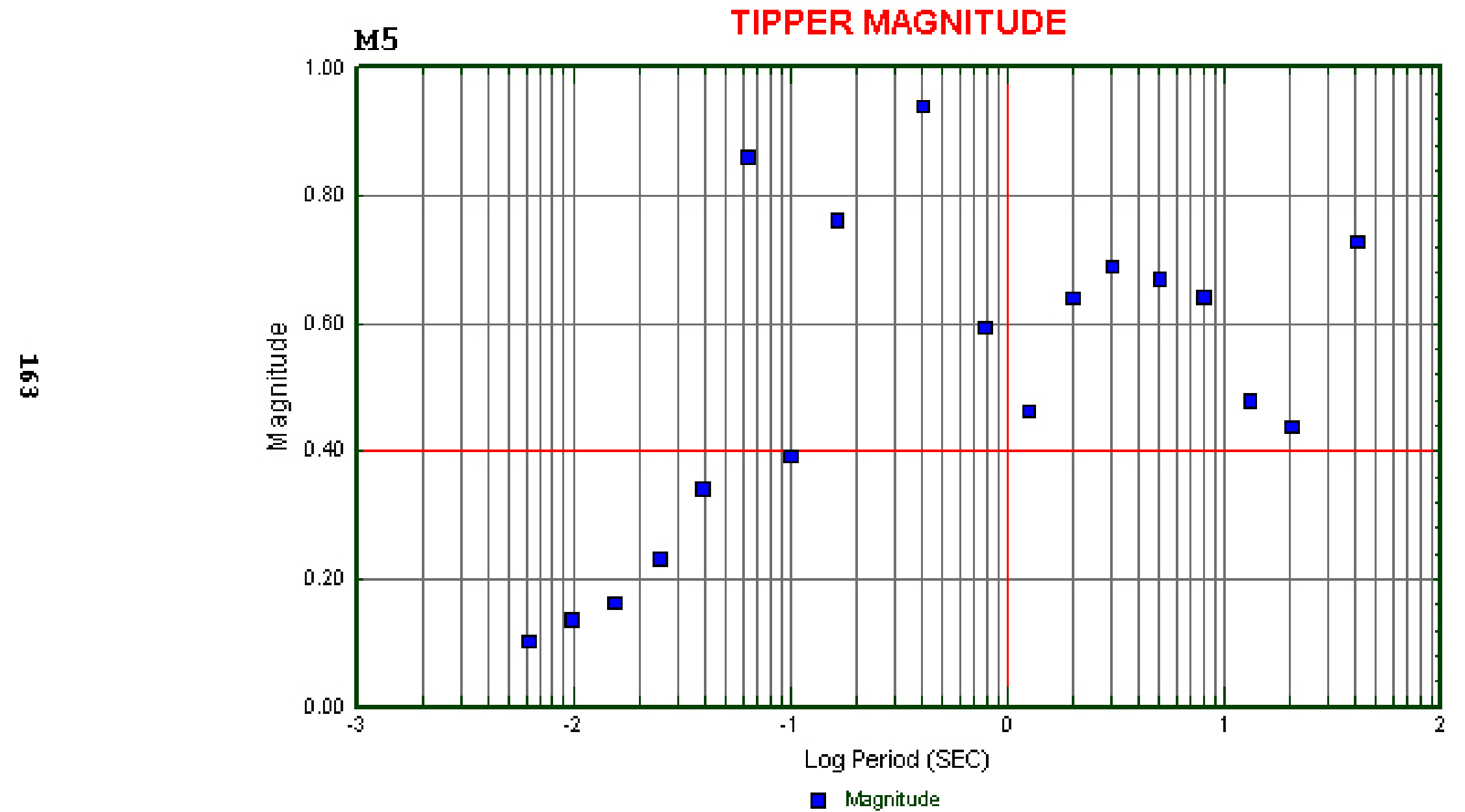




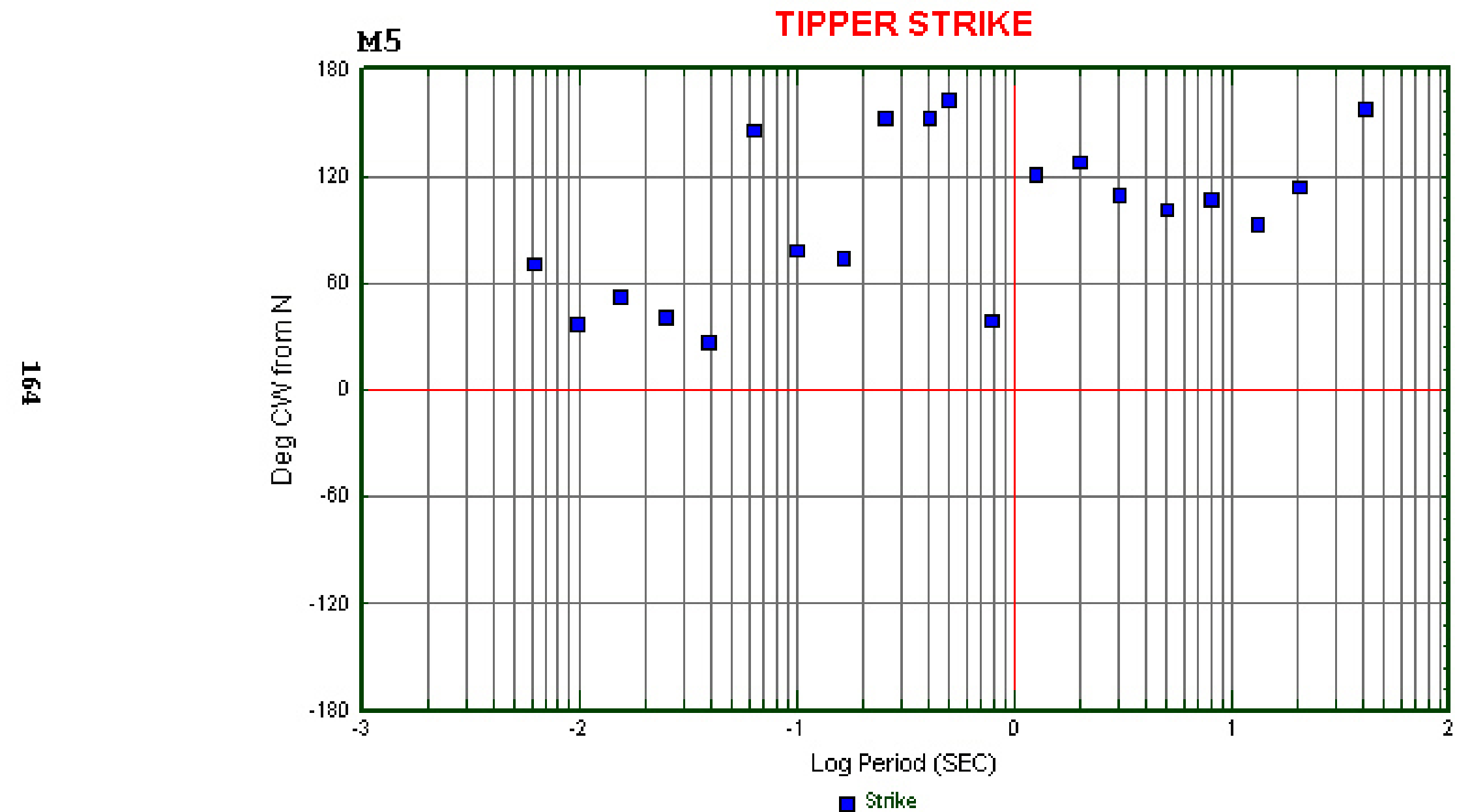




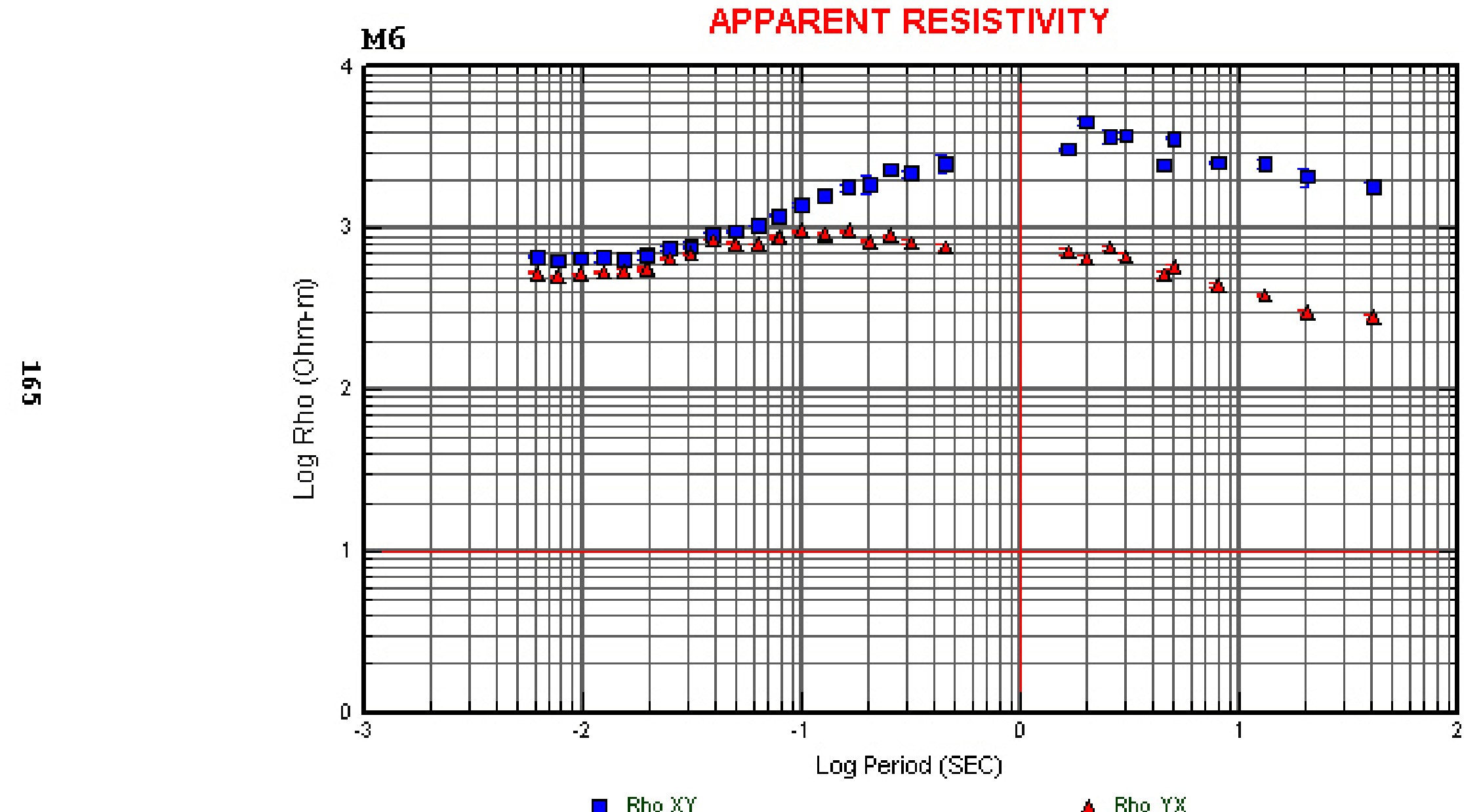

$\Delta$ Rho $Y x$ 
5

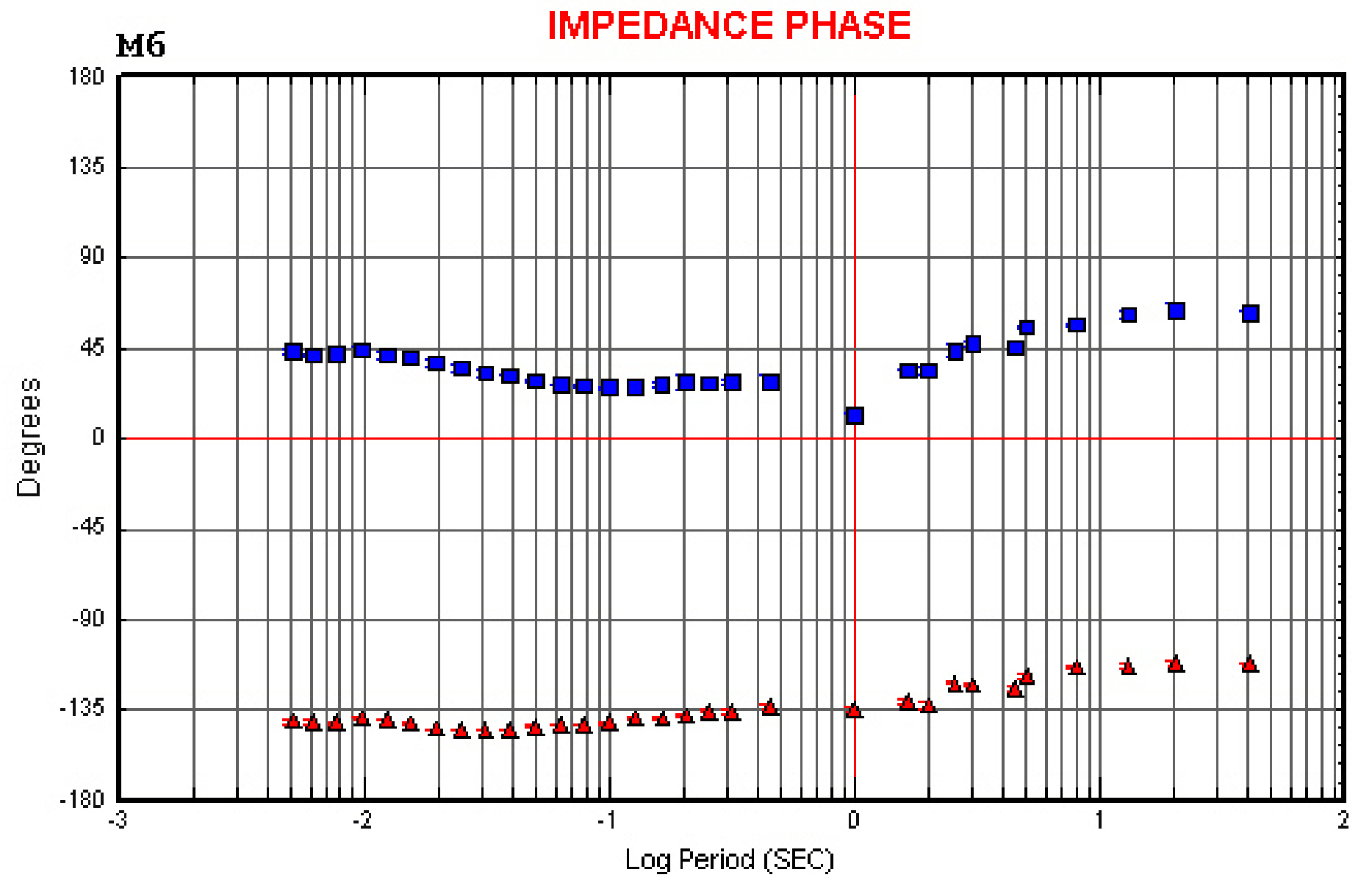

- Phase $X Y$

i Phase $Y x$ 


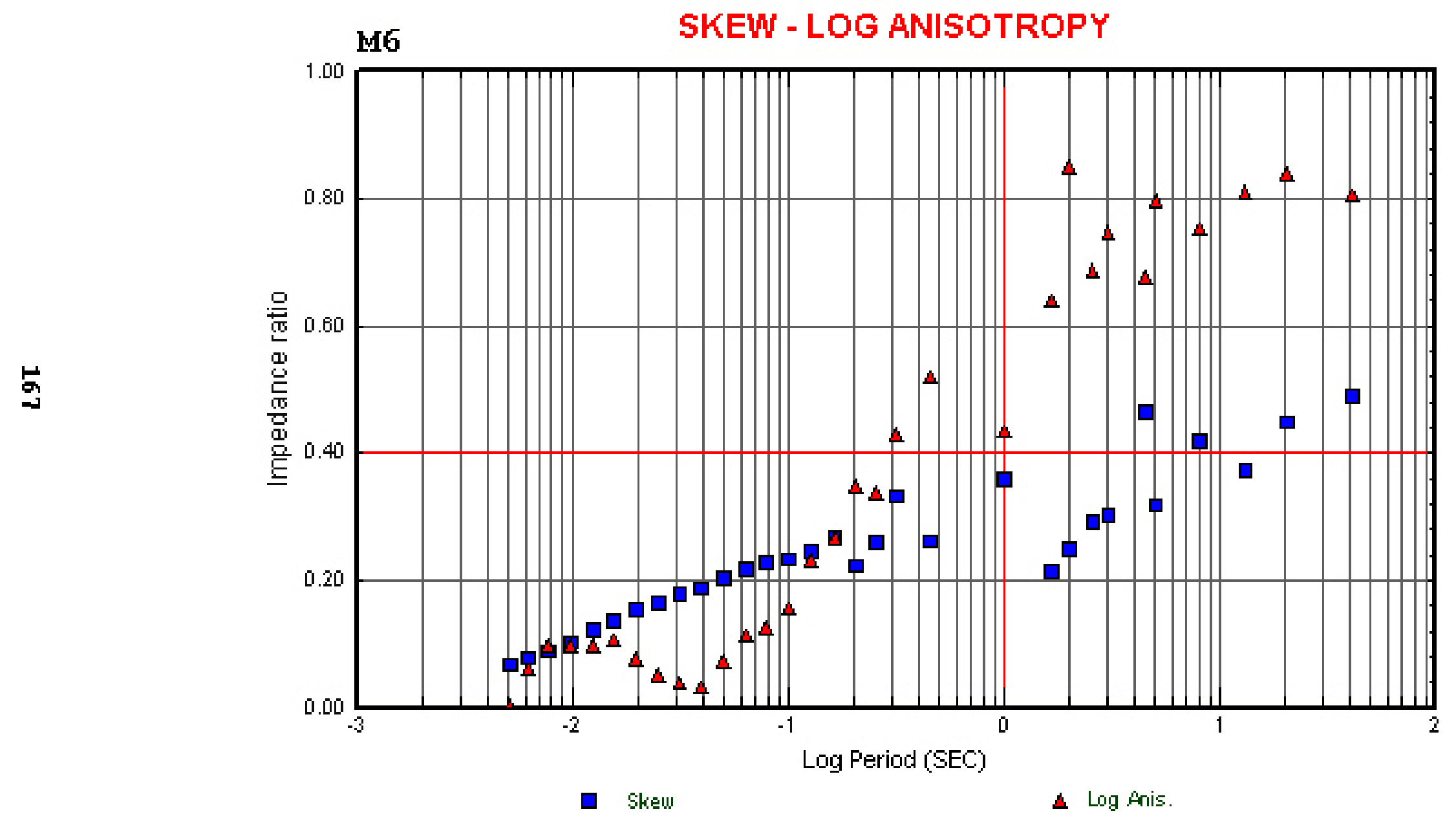




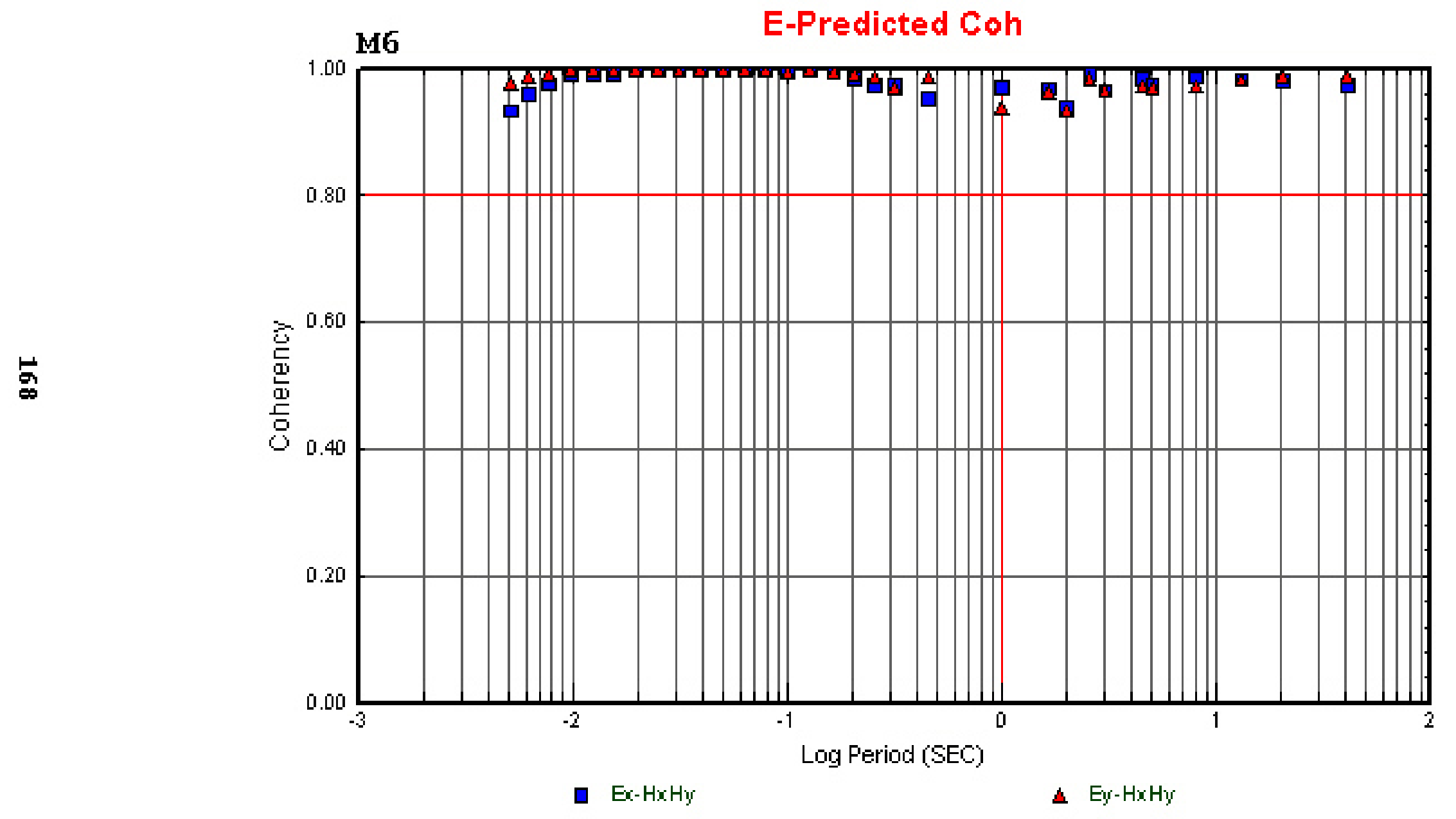




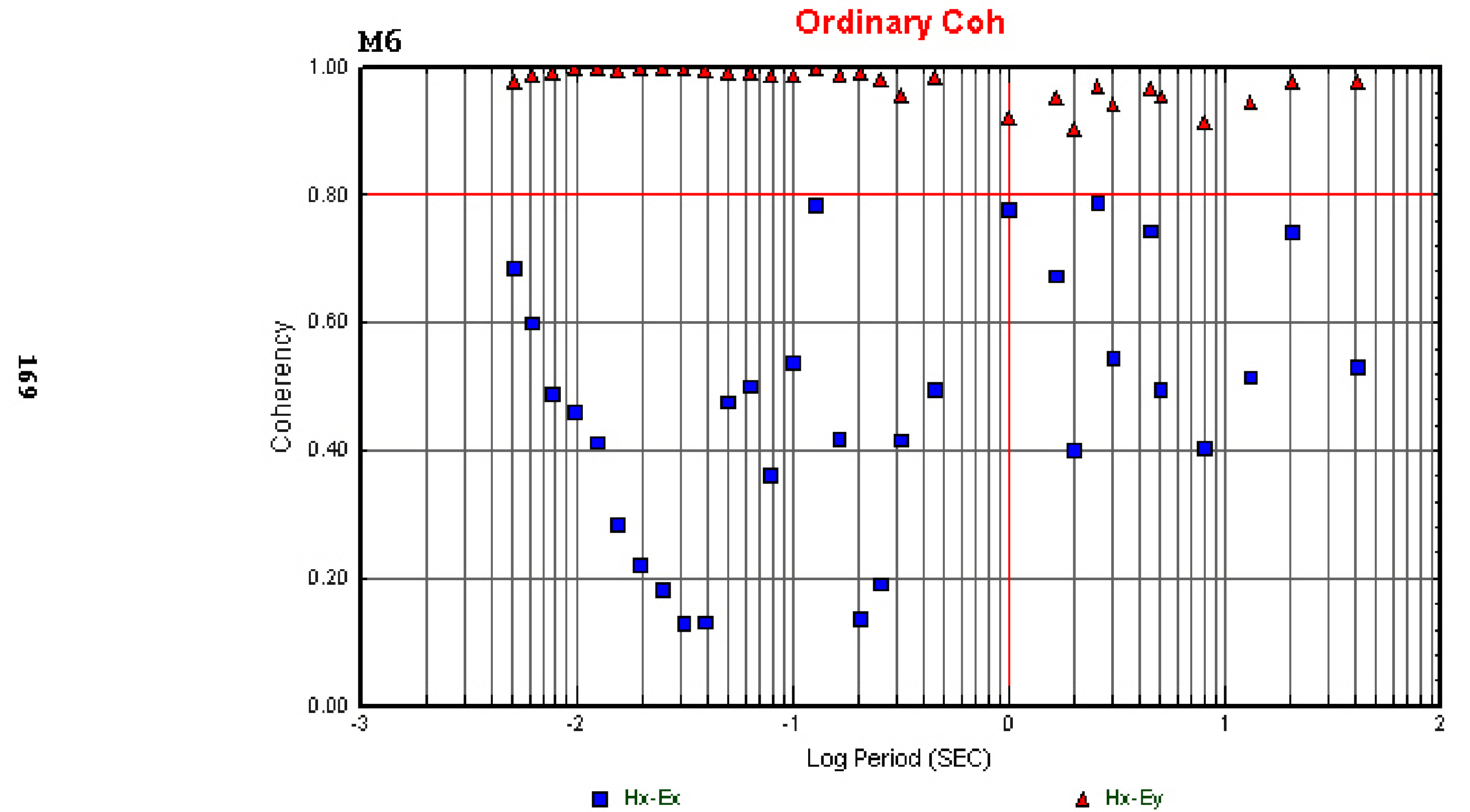




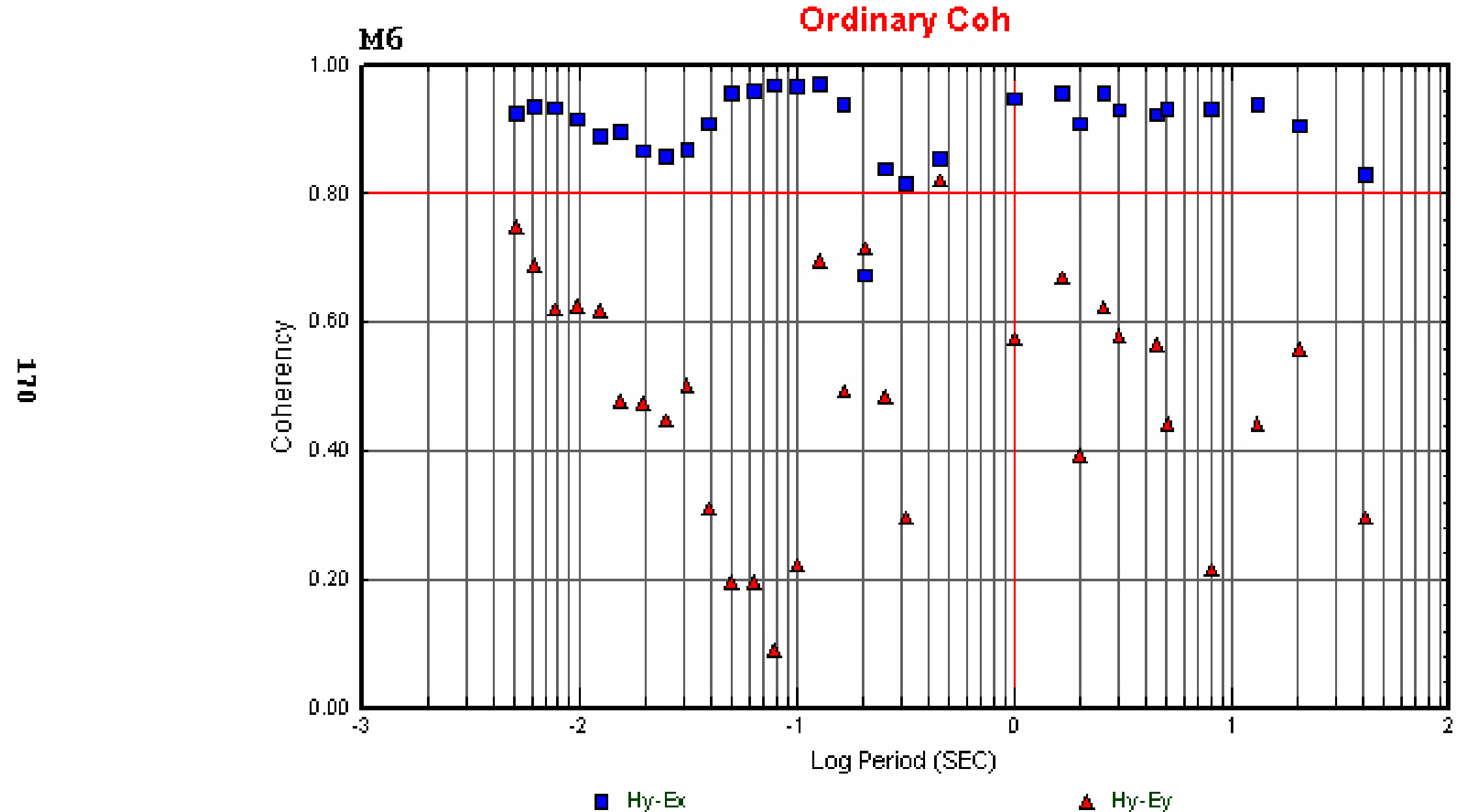




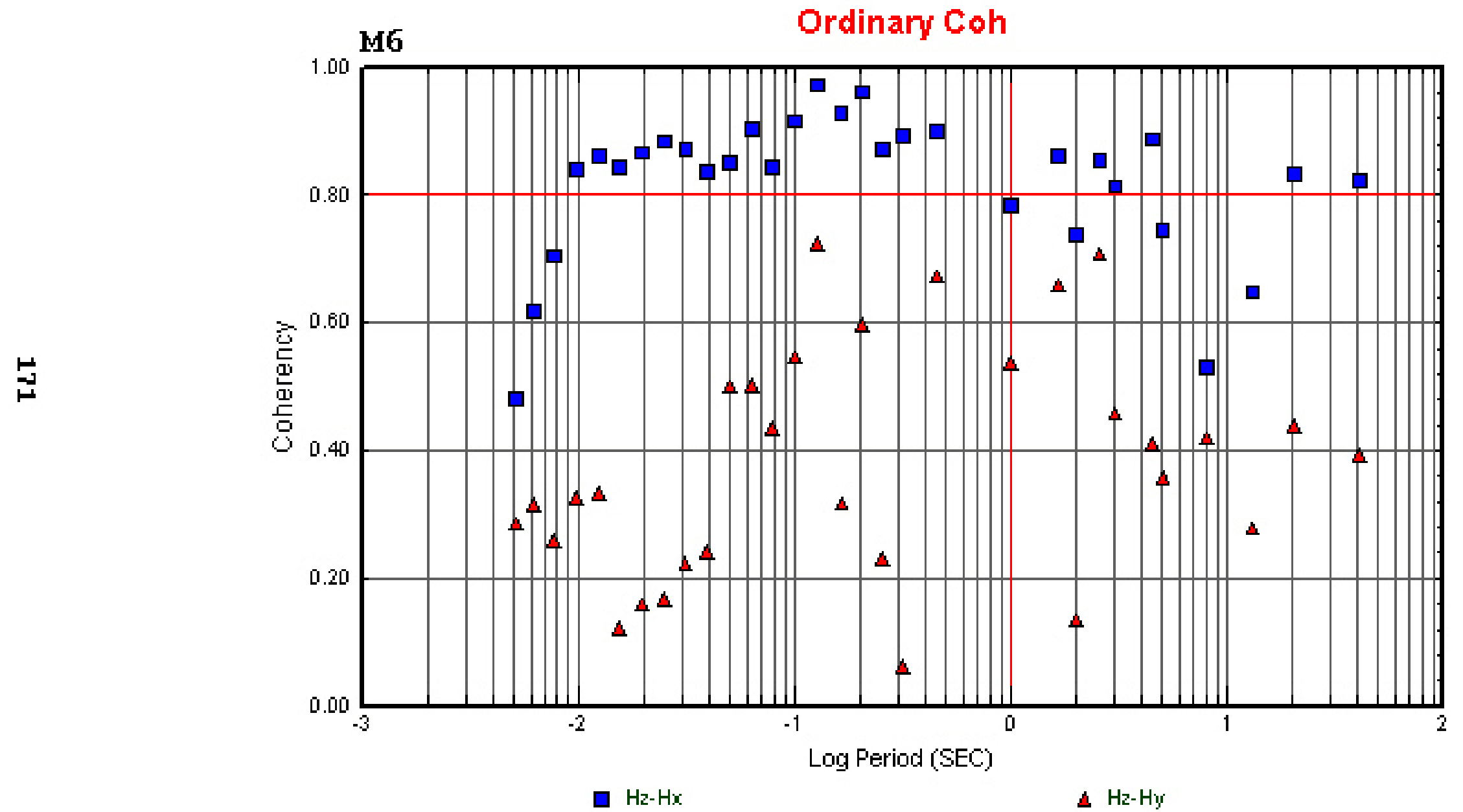




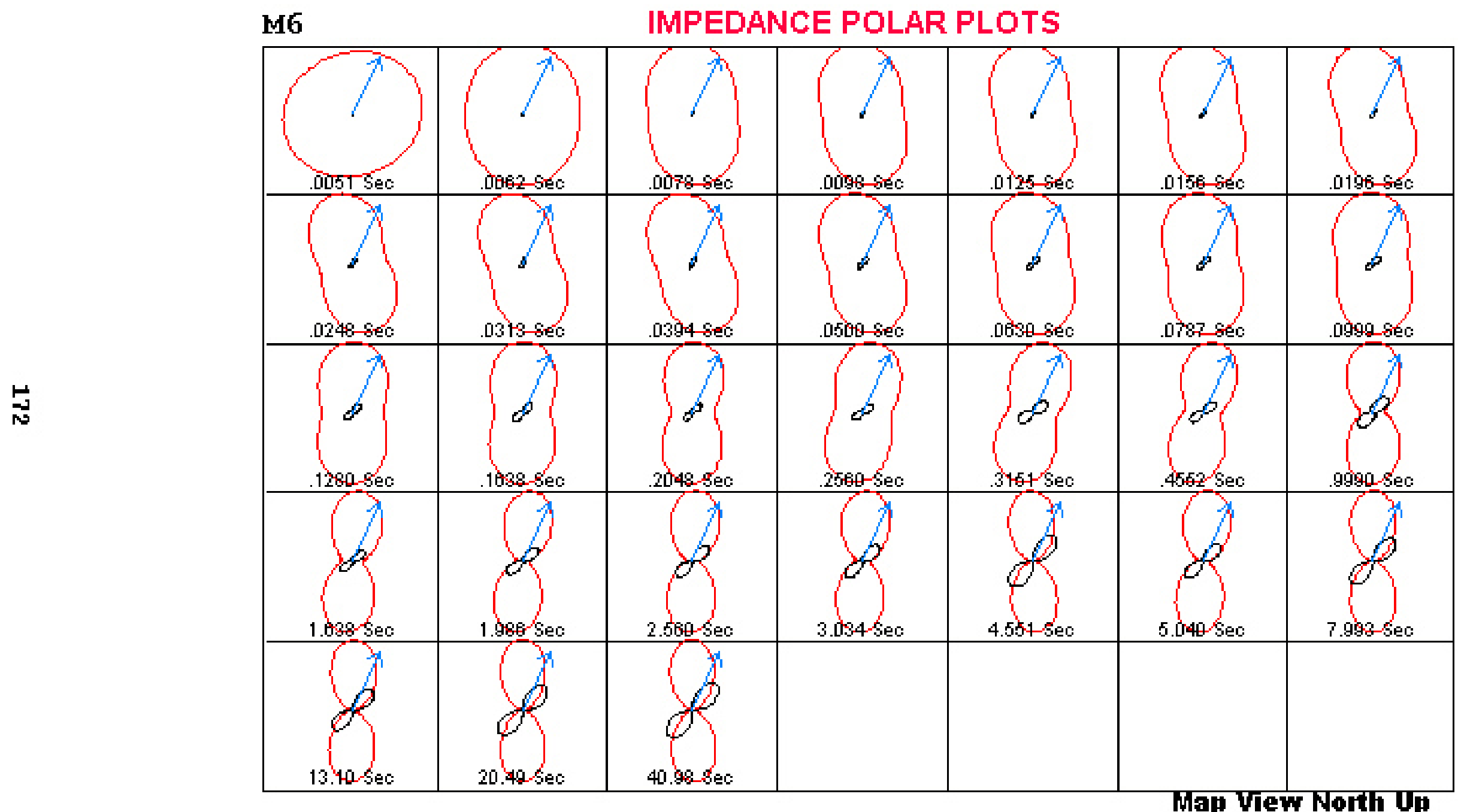




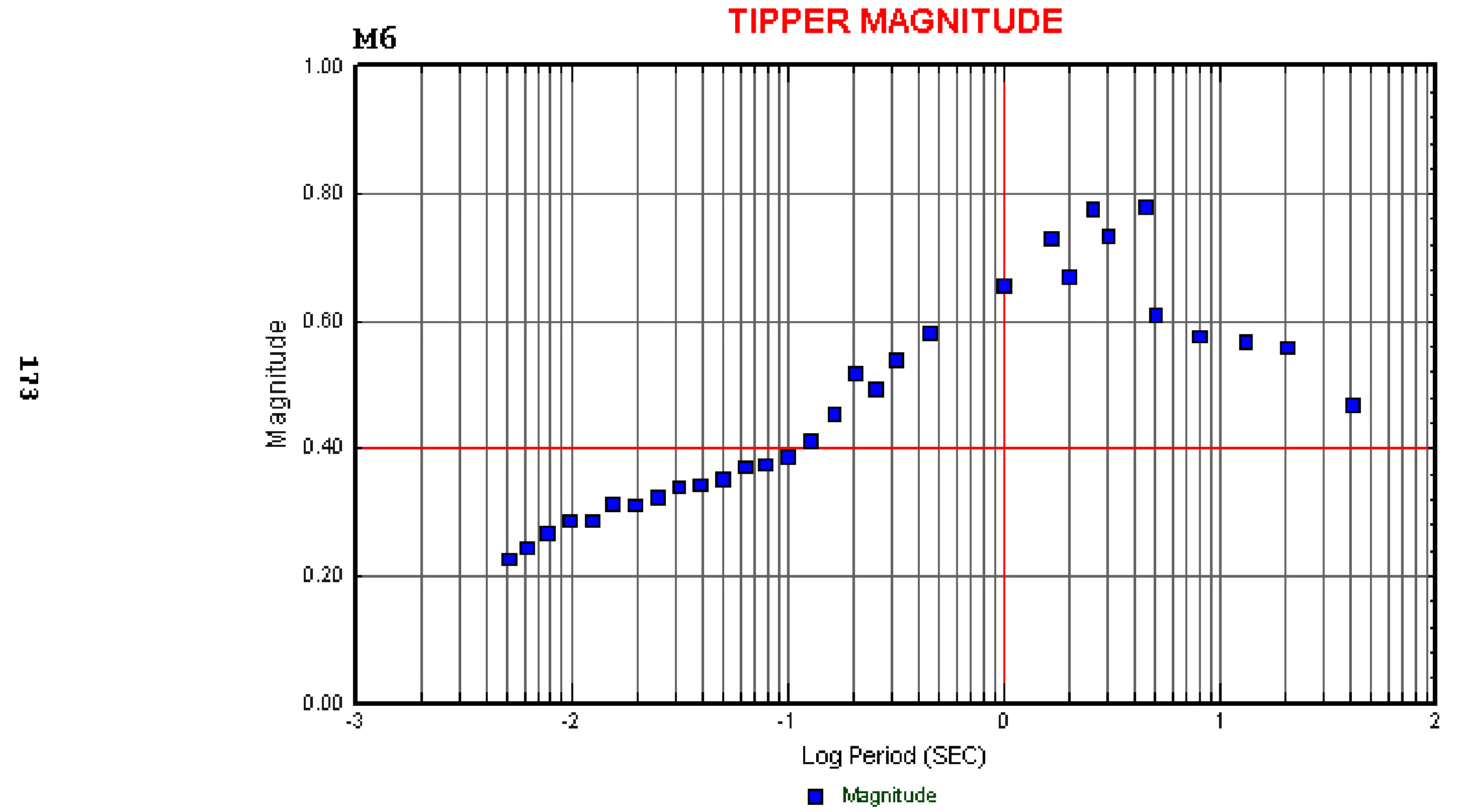




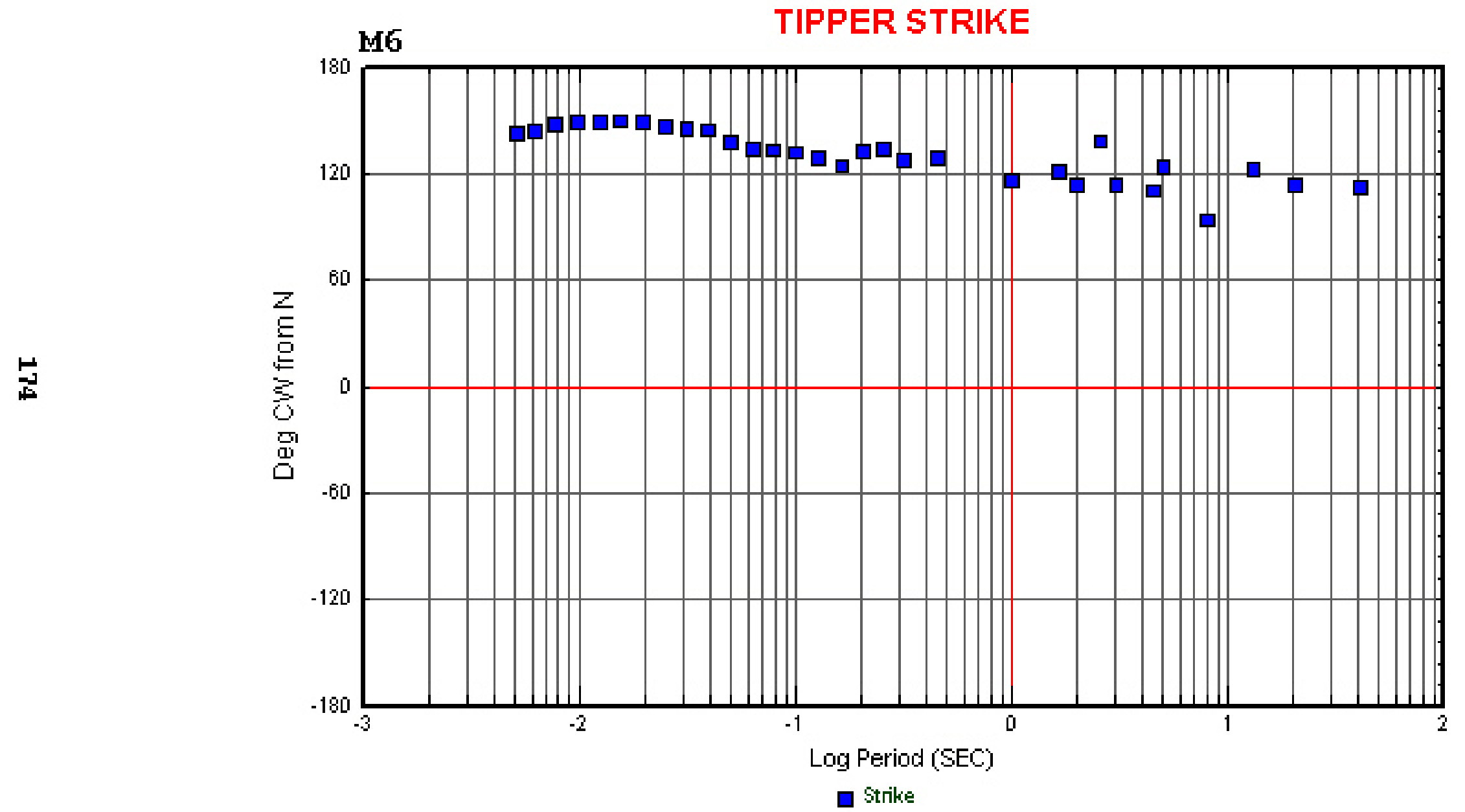




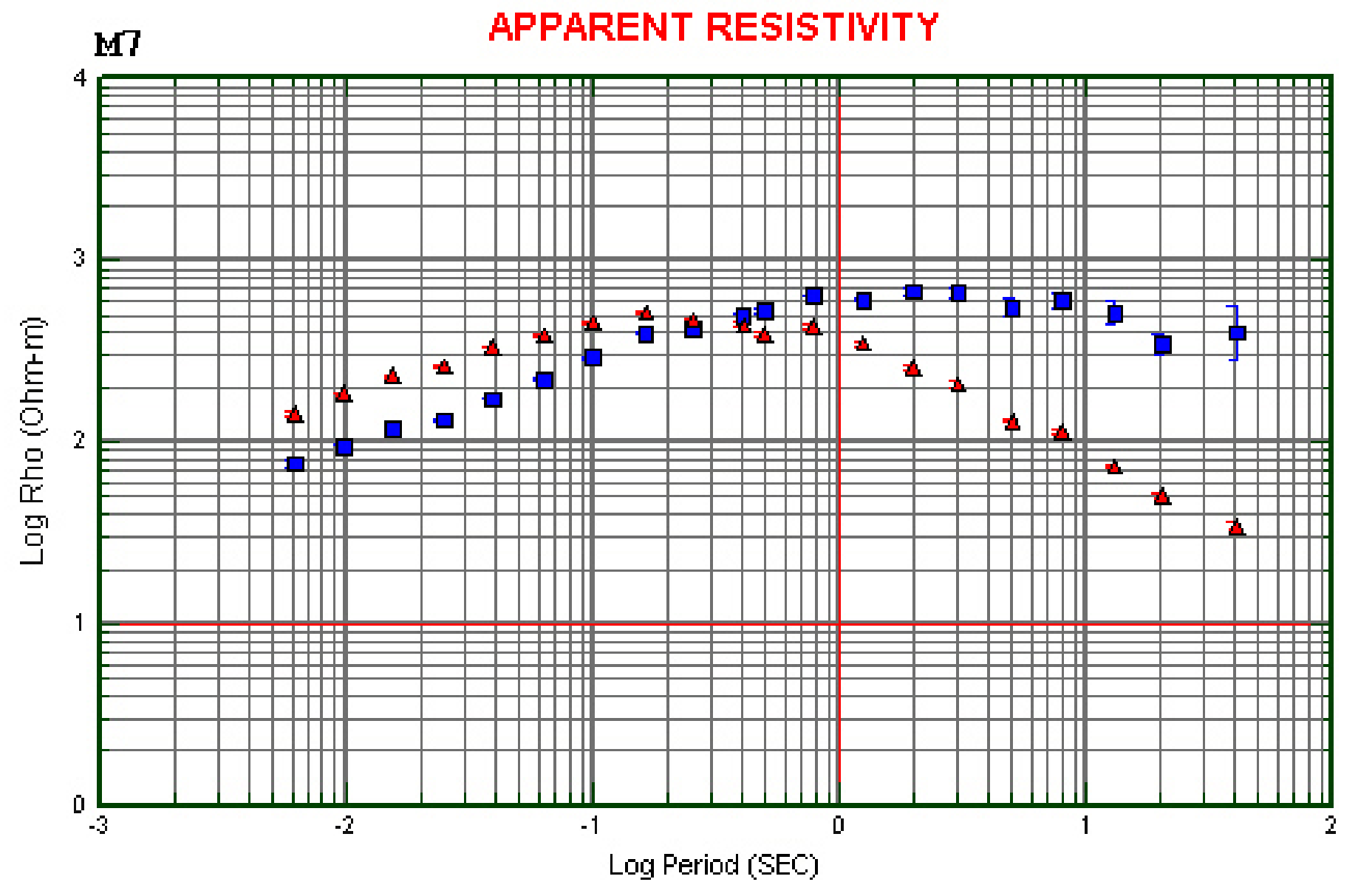

- Rho $X Y$

$\Delta$ Rho $Y x$ 
్ㅕㅇ

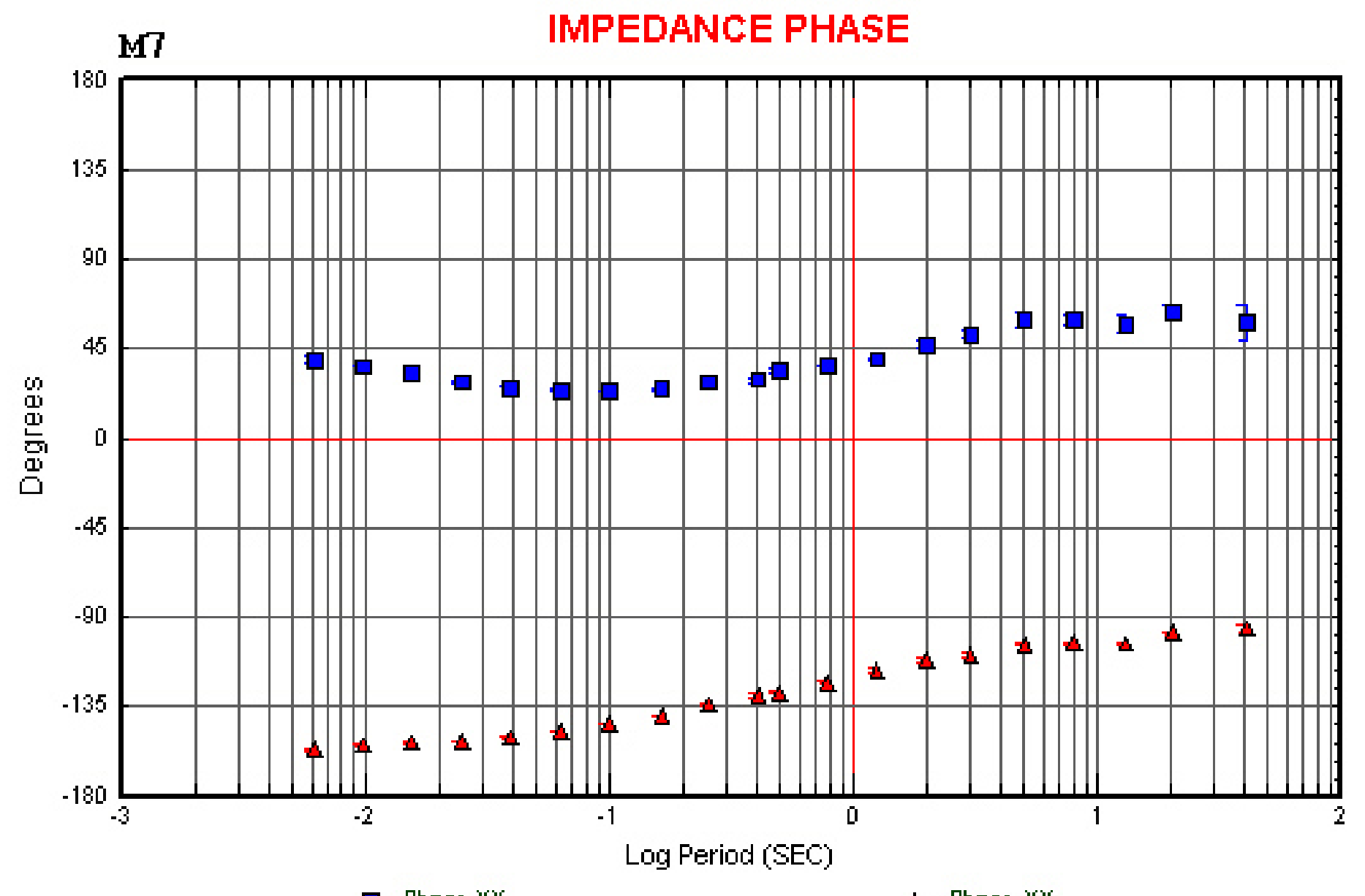

i Phase $Y X$ 


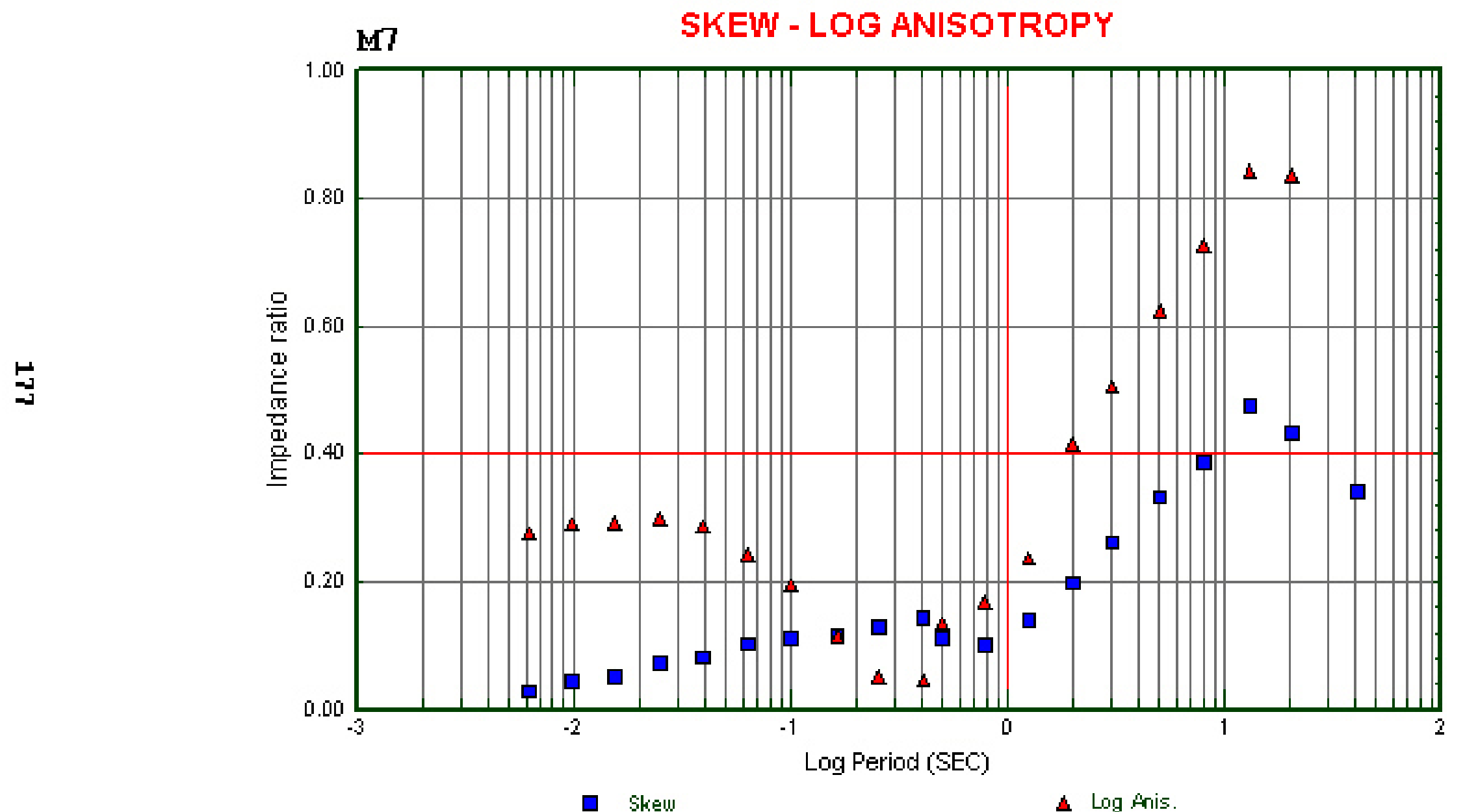




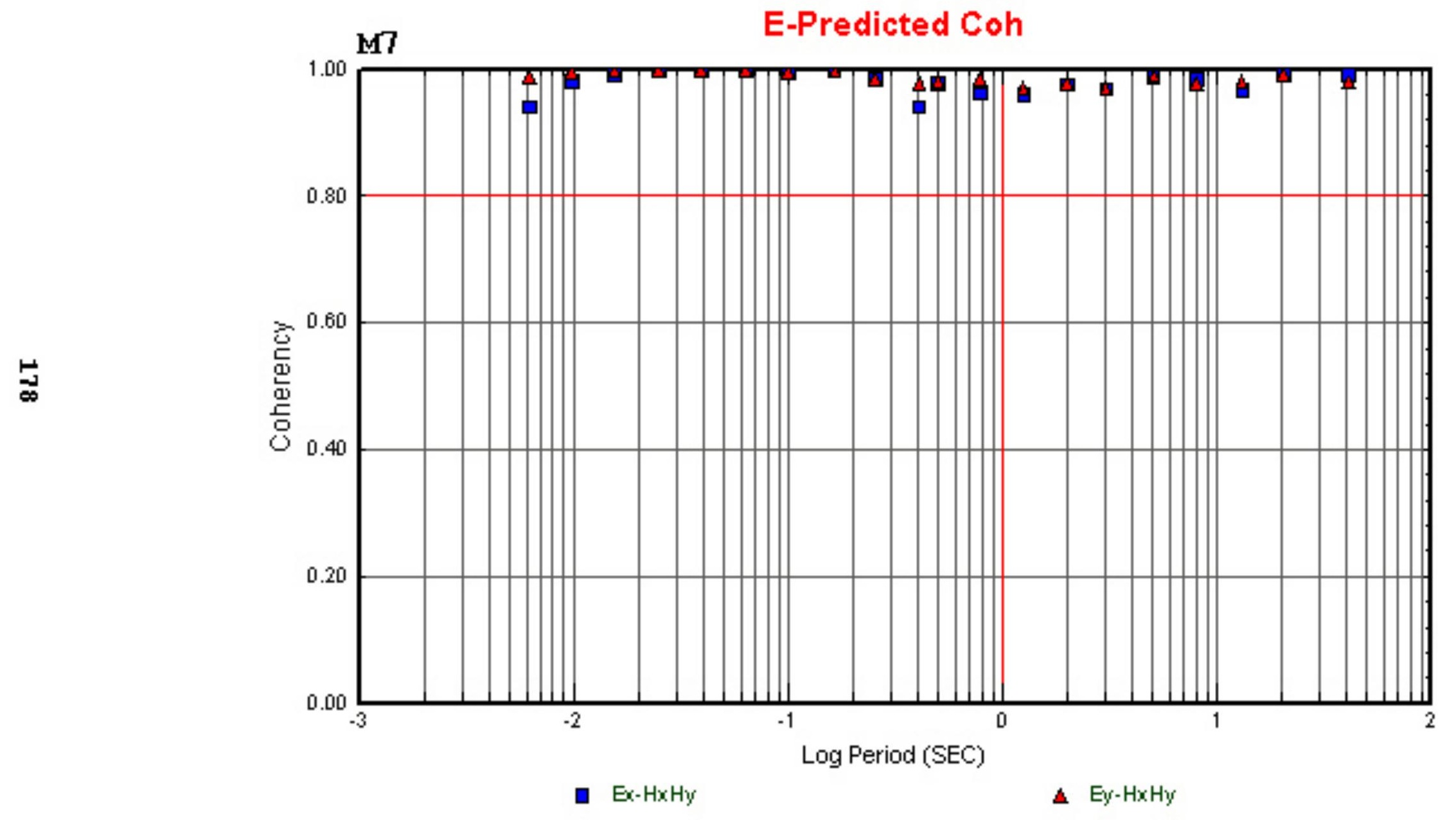




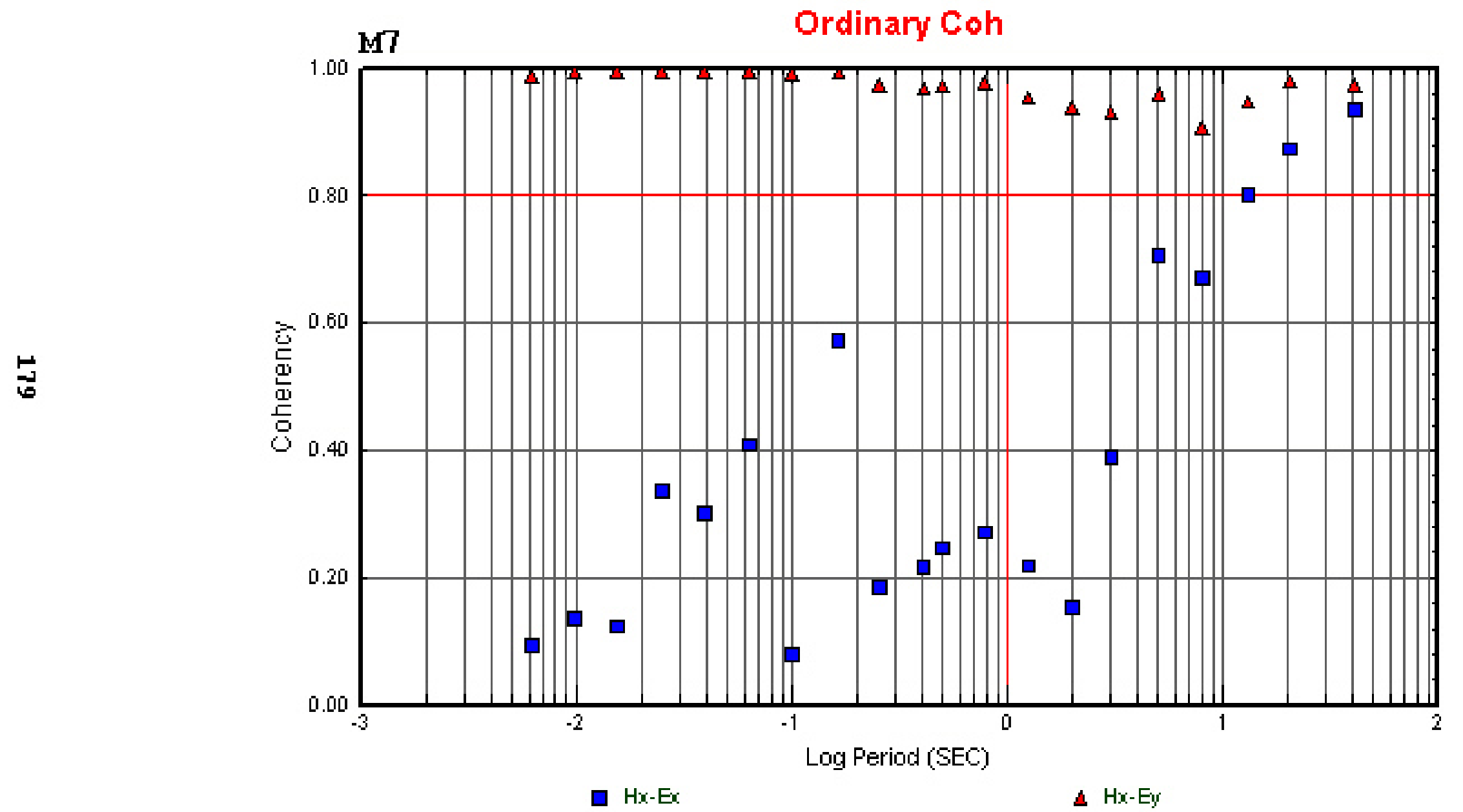




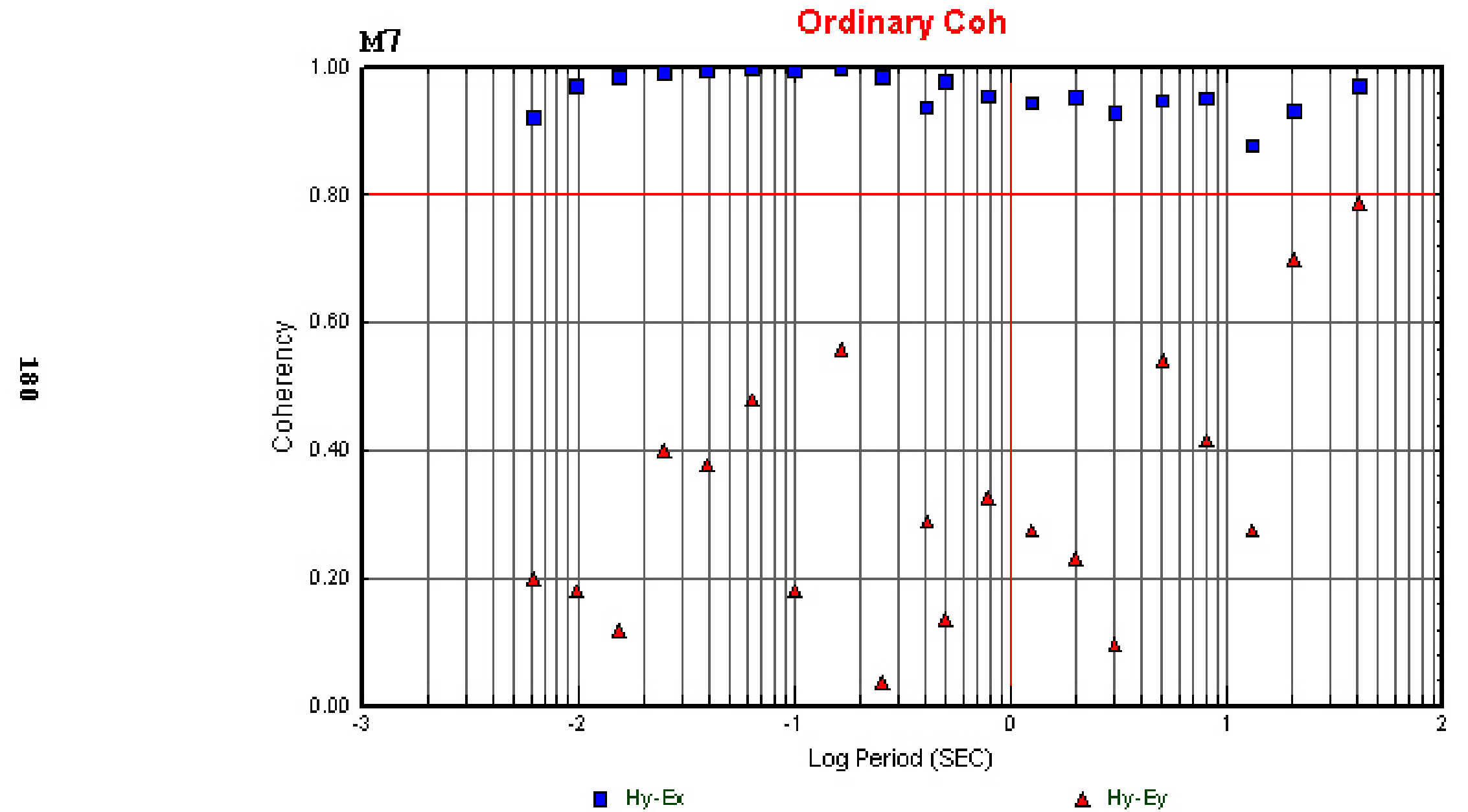




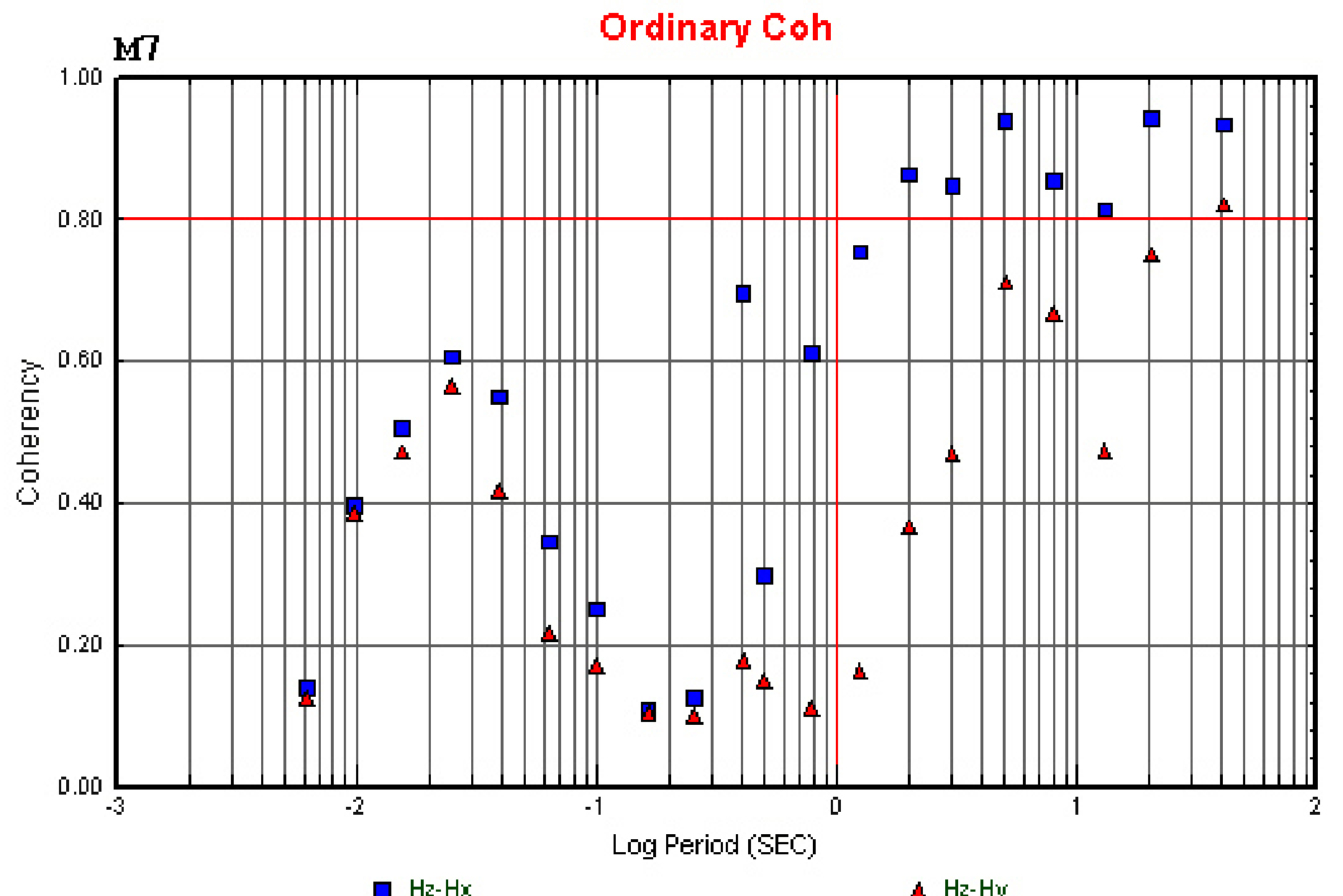




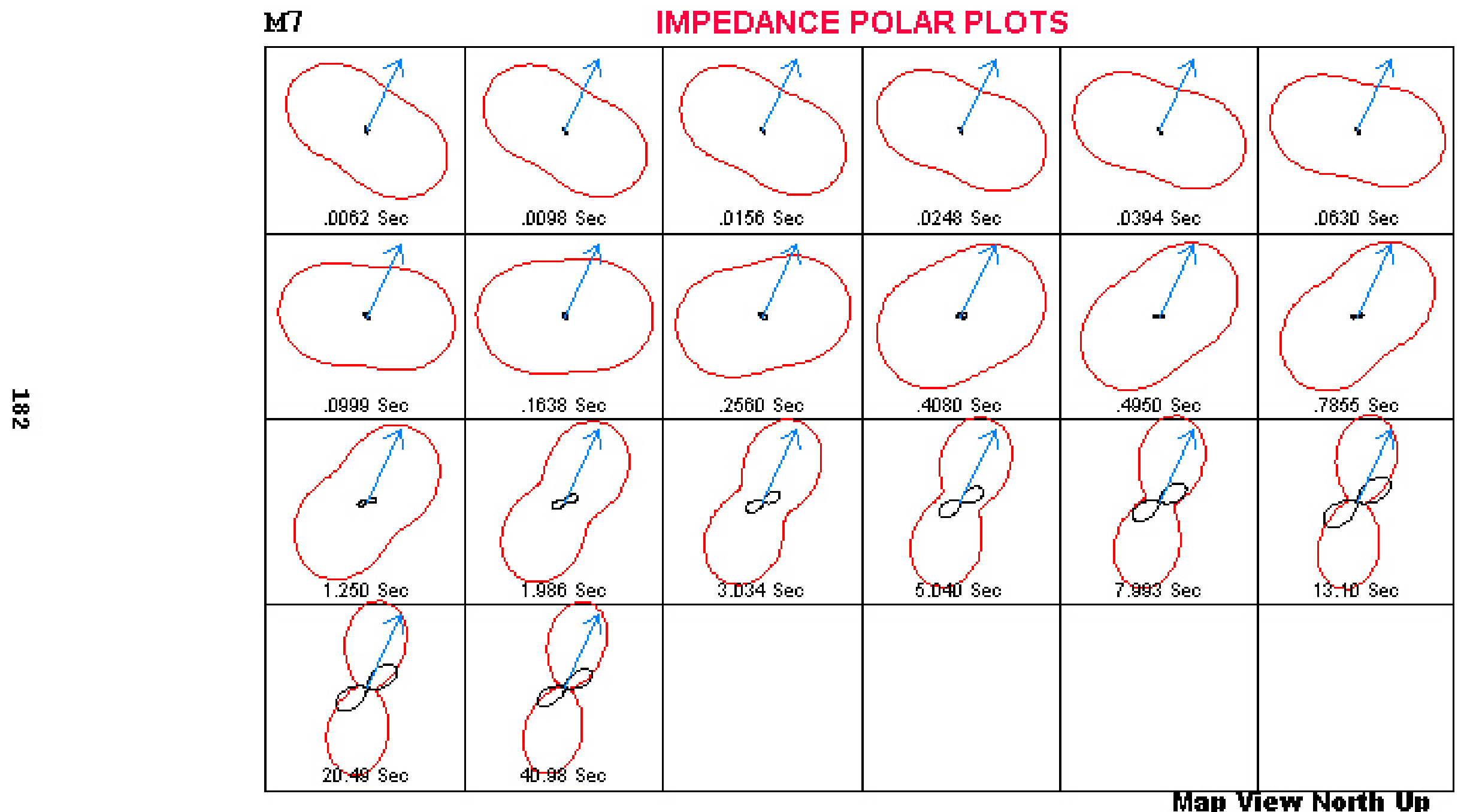




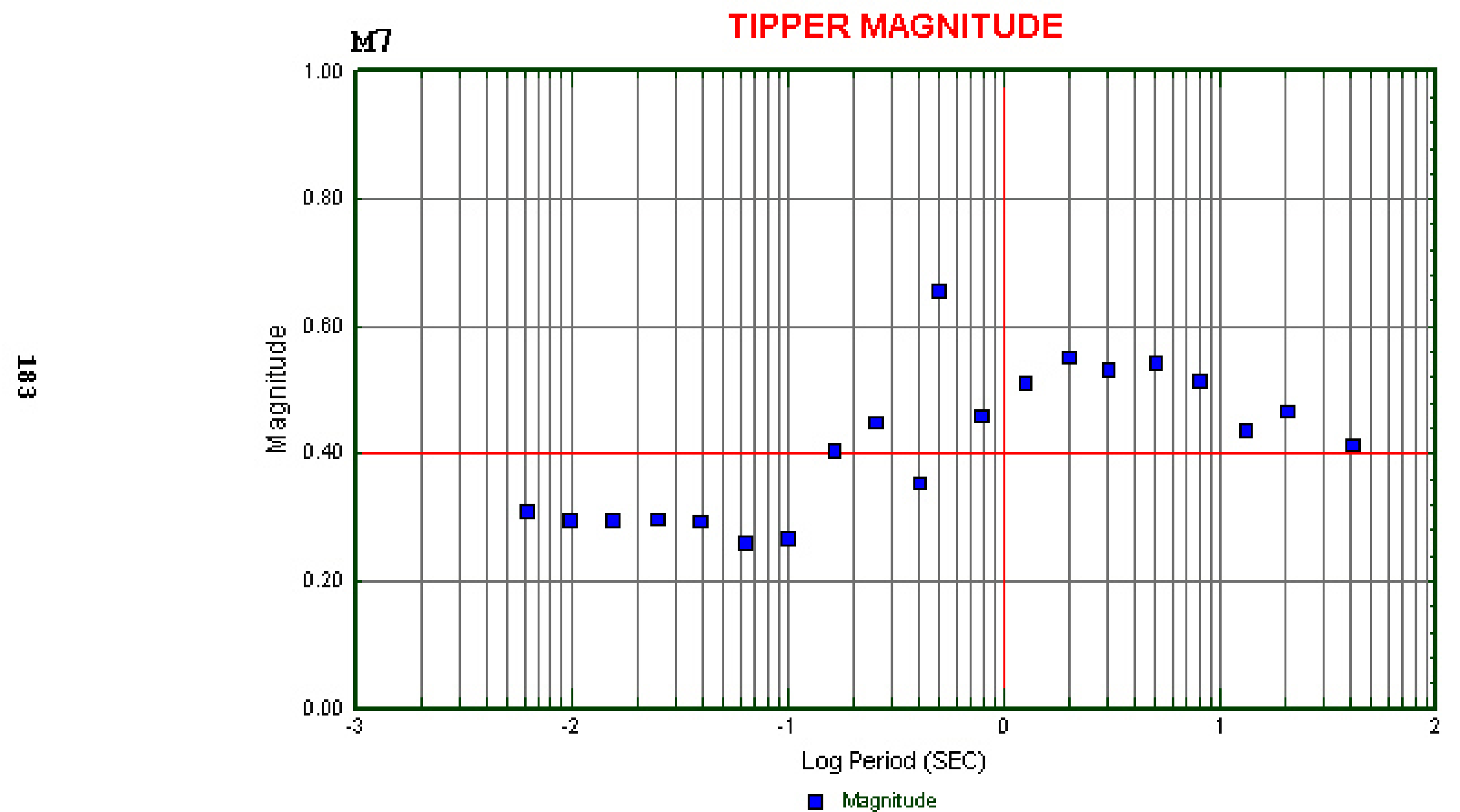




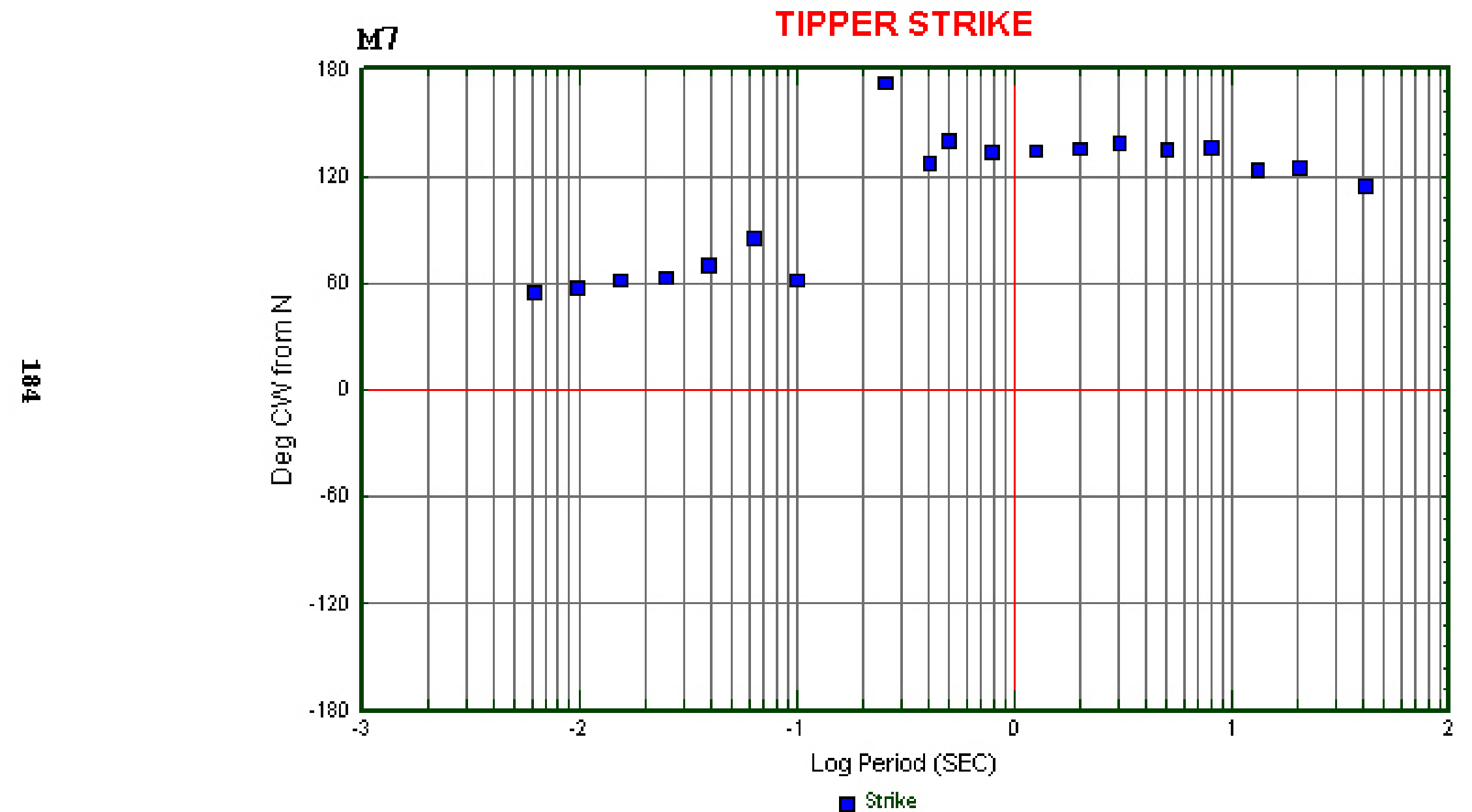

